\title{
PYROLYSIS OIL UPGRADING FOR CO-PROCESSING IN STANDARD REFINERY UNITS
}

00014 Ferran de Miguel Mercader 


\section{Pyrolysis oil upgrading for co-processing in standard refinery units}




\section{Promotion committee:}

$\begin{array}{lll}\begin{array}{ll}\text { Chairman/Secretary: } \\ \text { Promoter: }\end{array} & \begin{array}{l}\text { Prof.dr. G. van der Steenhoven } \\ \text { Prof.dr.ir. W.P.M. van Swaaij }\end{array} & \begin{array}{l}\text { University of Twente } \\ \text { University of Twente } \\ \text { University of Twente }\end{array} \\ & \text { Dr.ir. J.A Hogendoorn } & \\ \text { Members: } & \text { Prof.dr.ir. G. Brem } & \text { University of Twente } \\ & \text { Prof.dr.ir. H.J. Heeres } & \text { University of Groningen } \\ & \text { Dr. S.R.A. Kersten } & \text { University of Twente } \\ & \text { Dr. C. Mirodatos } & \text { CNRS } \\ & \text { Dr. C.J. Schaverien } & \text { Shell } \\ & \text { Dr.ir. R.H. Venderbosch } & \text { BTG }\end{array}$

The research described in this thesis was financially supported by the European Union through the BIOCOUP project within the 6th Framework Program (contract number: 518312) and Senter Novem through the CORAF project (project number EOSLT04018).

Ph.D. Thesis, University of Twente

F. de Miguel Mercader, Enschede, The Netherlands, 2010.

Printed by Ipskamp Drukkers B.V., Enschede, The Netherlands.

Cover and interior design by Imma Franch (www.immafranch.com) 


\title{
PYROLYSIS OIL UPGRADING FOR CO-PROCESSING IN STANDARD REFINERY UNITS
}

\author{
PROEFSCHRIFT
}

ter verkrijging van

de graad van doctor aan de Universiteit Twente, op gezag van de rector magnificus, prof.dr.H. Brinksma, volgens besluit van het College voor Promoties

in het openbaar te verdedigen op vrijdag 12 november 2010 om 16.45 uur

door

Ferran de Miguel Mercader

geboren op 12 december 1981

te Balsareny, Spanje 
This dissertation has been approved by the promoter

Prof.dr.ir. W.P.M. van Swaaij

and the assistant promoter

Dr.ir. J.A. Hogendoorn 
To Michael, 



\section{Contents}

Summary and main conclusions

Chapter $1 \quad$ Introduction

Chapter $2 \quad$ Pyrolysis oil upgrading by high

pressure thermal treatment

Chapter 3 Production of advanced biofuels: Co-processing

upgraded pyrolysis oil in standard refinery units

Chapter $4 \quad$ Hydrodeoxygenation of pyrolysis oil fractions.

Process understanding and quality assessment

through co-processing in standard refinery units

Chapter $5 \quad$ Polymerisation during pyrolysis oil upgrading

Chapter $6 \quad$ Competition between hydrotreating and polymerisation reactions during pyrolysis oil hydrodeoxygenation.

Indications on mass transfer limitations

Abstract

Samenvatting

167

Resum

169

Publications list

Acknowledgements

173 



\section{Summary and main conclusions}

To meet the growing demand of energy, biomass can be used as a renewable and $\mathrm{CO}_{2}$-neutral source. Moreover, biomass is the only source of renewable liquid transportation fuels and chemicals. Pyrolysis can be used as pre-treatment step to convert dry solid biomass into a liquid (pyrolysis oil) which has a higher energy density and is easier to handle than bulk biomass. However, pyrolysis oil (also known as bio-oil) has limited end-user applications due to its low energy content (compared to fossil fuels) and instability.

This thesis considers the upgrading of pyrolysis oil to produce an oil that can be further co-processed in standard refinery units. In the underlying concept, pyrolysis oil is produced where biomass is available and then transported to a central upgrading unit. This unit is located next or inside a standard petroleum refinery, enabling the use of existing facilities. Then, the upgraded oil is co-processed with fossil feed to obtain a product that can be readily incorporated in the refinery process chain. The ultimate product (mixture of fossil and biomass-derived organics) can be used as chemicals and fuels source, taking advantage of existing distribution networks.

This thesis focuses on the study of different pyrolysis oil upgrading techniques. At the beginning of the project, the reduction of the high oxygen content ( $40 \mathrm{wt} \%$ on dry basis) of pyrolysis oil was considered the key objective of upgrading. Reducing this oxygen content was assumed to improve miscibility with fossil fuels (to allow coprocessing), reduce the reactivity of the oxygenated functional groups (that lead to thermal instability) and to increase the energy content. Two upgrading processes, which were expected to achieve this, were considered: high pressure thermal treatment (HPTT) and hydrodeoxygenation (HDO).

HPTT of pyrolysis oil was studied in a newly designed continuous tubular reactor. It allowed full control of the temperature profile inside the reactor and high mass balance closures. HPTT was studied at different temperatures $\left(200-350{ }^{\circ} \mathrm{C}\right)$, residence times $(1-4$ min) and dilution ratios (1:1 oil:water in vol.). Pressure inside the reactor was kept at 200-240 bar to keep the water in liquid state and avoid extensive charring. After HPTT, pyrolysis oil underwent phase separation, producing an oil, an aqueous phase and gas (mainly $\mathrm{CO}_{2}$ ). By increasing the HPTT temperature, the energy recovered in the oil phase product increased (from $\sim 70$ to $\sim 90 \%$ ) due to the transfer of organics from the aqueous phase to the oil phase. The energy density of the oil product also increased by the reduction of the oxygen (from 40 to $31-20 \mathrm{wt} . \%$ on dry basis) and water content. Solvent fractionation analysis revealed that the amount of sugar constituents present in the aqueous phase by-product decreased with temperature. This, combined with the increase in molecular weight observed in oil, suggested that polymerisation of, among 
others, the sugar constituents occurred. Experiments using water to dilute pyrolysis oil at the entrance of the reactor produced a lower molecular weight oil, indicating a dependence between the extent of polymerisation and the feed concentration.

HDO of pyrolysis oil was studied in a 5 I autoclave. With this autoclave, larger quantities of upgraded oil could be produced, so that the resulting oils could be co-processed in lab-scale refinery units. In this study, pyrolysis oil was treated at high $\mathrm{H}_{2}$ pressures ( 300 bar total) in the presence of an active catalyst (Ruthenium on carbon, $\mathrm{Ru} / \mathrm{C}$ ) using different end temperatures $\left(230-340{ }^{\circ} \mathrm{C}\right.$ ). In this case, a reaction time of $4 \mathrm{~h}$ (plus 1.5-2 $\mathrm{h}$ heating time) was used, being much longer than the reaction time typically used in the HPTT process. The hydrogen consumption increased with temperature from $\sim 230$ to $330 \mathrm{NI} / \mathrm{kg}$ feed oil. The oxygen content of the product oil decreased with temperature to similar values (28-15 wt.\% on dry basis) as obtained by HPTT. Also similar to HPTT, transfer of organics from the aqueous phase to the oil phase was observed, increasing the carbon/energy recovery in the upgraded oil phase. This transfer was not accompanied by an increase of molecular weight as in HPTT; the molecular weight of the oil obtained at the highest temperature was even lower than that of the feed. This showed that not only by dehydration/polymerisation (as in HPTT), but also by hydrodeoxygenation, organics can be transferred to the oil phase product. Based on these results, a competition between hydrodeoxygenation and polymerisation during HDO was postulated.

HDO oils were further co-processed in a lab-scale FCC unit (catalytic cracking) with Long Residue fossil feed (20 wt.\% HDO oil). Surprisingly, all the HDO oils (with very different and still substantial oxygen content, 28-15 wt.\% on dry basis) could be successfully co-processed without operational problems, obtaining near oxygen free biohydrocarbons. Furthermore, the products and yields obtained by co-processing were similar to those obtained using fossil feed only. On the other hand, HPTT oil (with similar oxygen content) could not be co-processed because of its high coking tendency (measured by MCRT, a type of Conradson carbon). Upon catalytic cracking of pure HDO oils (having a low MCRT and oxygen content), the yield to undesired products (coke and dry gas) increased significantly at the expense of, mainly, gasoline. This showed the importance of hydrogen donation from the fossil feed during co-processing.

To further understand the HDO process, pyrolysis oil fractions were used as feedstock. These fractions were prepared by adding water, thus inducing a phase separation. Two fractions were obtained: oil fraction water addition (OFWA) and aqueous fraction water addition (AFWA). OFWA mainly contains lignin derivates, extractives and polymerisation products. AFWA comprises most of the water soluble components such as sugar constituents, acids, ketones, aldehydes, etc. HDO experiments of these fractions were conducted in a $0.6 \mathrm{I}$ autoclave using different reaction end temperatures $\left(220-310{ }^{\circ} \mathrm{C}\right)$ under hydrogen atmosphere (200 bar total pressure) and Ru/C as catalyst. The reaction time was $4 \mathrm{~h}$, excluding $1-1.5 \mathrm{~h}$ heating time. Similar to the experiments using the $5 \mathrm{I}$ 
autoclave, the long heating period allowed stabilisation reactions to occur. After HDO of AFWA, an oil fraction was obtained, its yield increasing up to $29 \mathrm{wt} . \%$ (on dry basis) with temperature. This oil production from water soluble components explained the increase in carbon recovery observed during HDO of whole pyrolysis oil. From the OFWA, an oil phase was obtained with lower oxygen content than the feed. Analysis of the products showed that with increasing molecular weight, the MCRT increased and the $H / C$ decreased. In general, the MCRT of the resulting HDO oils depended on the feedstock used, and increased in the order AFWA, whole pyrolysis oil, OFWA. Oil products from the fractions were co-processed in lab-scale catalytic cracking and hydrodesulphurisation (HDS) units. Even though the HDO oils had very different properties, coprocessing (20 wt.\%) with Long Residue in a catalytic cracking unit gave very similar results. Again, the results were very similar to those obtained using pure Long Residue as feed. Exploratory experiments on co-processing HDO oils with Straight Run Gas Oil (SRGO) in a HDS unit showed an increase of the sulphur content of the product, indicating a competition between HDO and HDS. Permanent catalyst deactivation was not observed. Further research on the co-processing processes and products is necessary to determine optimal process conditions and to determine whether the significant differences in feed are indeed eliminated upon co-processing.

Polymerisation during pyrolysis oil upgrading (as specifically observed during HPTT experiments) leads to undesired product properties. Sugars are present in pyrolysis oil and known to quickly polymerise at high temperatures. Therefore, aqueous solutions of glucose were used as model system to evaluate the polymerisation behaviour of pyrolysis oil. The experiments showed that by increasing the reaction temperature (200 to $350{ }^{\circ} \mathrm{C}$ ), reaction time (5 to $60 \mathrm{~min}$ ) and especially the initial glucose concentration (5$30 \mathrm{wt} \%$ ), the amount of polymerisation products (water-acetone insoluble organics) increased considerably. The reduction in the extent of polymerisation at low concentrations was in accordance with the results of the HPTT study in which diluted pyrolysis oil was used as feed. When HPTT experiments were conducted using sorbitol as feedstock (typically produced by low temperature hydrogenation of glucose), no polymerisation was observed. This suggested that during low temperature HDO ("stabilisation"), sugars are hydrogenated towards more stable products, less susceptible towards fast polymerisation at high temperatures. Addition of ethanol was studied in HPTT experiments using different feedstocks: glucose; a sugar fraction derived from pyrolysis oil; and whole pyrolysis oil. In all cases, the extent of polymerisation was reduced.

Finally, to study in more detail the competition between the polymerisation and the hydrotreating reactions during HDO of pyrolysis oil, HDO experiments were carried out in various small scale autoclaves $(9-45 \mathrm{ml})$. These autoclaves exhibited very fast, but varying, heating rates. For these reactors, the heating time to reach the desired temperature $\left( \pm 10^{\circ} \mathrm{C}\right)$ was between 1 and $15 \mathrm{~min}$, which was very short compared to those in the 0.6 and $5 \mathrm{I}$ autoclaves. Using the $9 \mathrm{ml}$ autoclave, HDO experiments were 
performed with a total reaction time of 10 to $60 \mathrm{~min}$, using $\mathrm{Ru} / \mathrm{C}$ as catalyst. Results showed that there was hydrogen consumption already at $80^{\circ} \mathrm{C}$, increasing with the temperature and reaction time. However, when the end temperature was above $200{ }^{\circ} \mathrm{C}$, polymerisation created products refractive towards hydrotreating and hydrogen uptake reached a plateau. By using the larger $40 \mathrm{ml}$ reactor, having a slower heating rate than the $9 \mathrm{ml}$ autoclave, and the same HDO conditions, the extent of polymerisation decreased (observed by a reduction of the molecular weight of the product) and hydrogen uptake increased. These experiments indicated once more that when opportunity is given to hydrotreating reactions at low temperature ("stabilisation"), overall polymerisation in HDO can be reduced. The effect of the gas-liquid mass transfer was evaluated by changing the stirring speed in the $45 \mathrm{ml}$ autoclave, in experiments at 300 ${ }^{\circ} \mathrm{C}$ and 30 min reaction time. The results showed that with stirring intensity, the extent of hydrotreating increased and polymerisation decreased. These results point at the role of hydrogen mass transfer in the HDO process, which proved to be especially important in the initial stage. Calculations of the hydrogen consumption rates indicated that, in the very initial stages (under $5 \mathrm{~min}$ ), gas-liquid mass transfer was the rate controlling step, while the kinetics (with possibly intraparticle mass transfer resistances) gained importance afterwards (5-30 minutes). This was confirmed in experiments using different catalyst hold-ups. The degree of utilisation for catalyst particle sizes as typically used in industrial fixed bed hydrotreating reactors was estimated and shown to be below unity.

In conclusion, this study has shown that during HDO of pyrolysis oil, a competition between polymerisation and hydrotreating reactions occurs, with the sugars constituents playing an important role. Once components are polymerised, it seems that the resulting product is less sensitive towards hydrotreating, and vice versa. Both reaction pathways increase the oil product yield and reduce the oxygen content, but otherwise create an oil with very different properties. While the coking tendency of HPTT oil is much higher than that of the feed, it is lower for HDO oil. The rate of polymerisation is affected by the temperature level and concentration, but is very fast above $200{ }^{\circ} \mathrm{C}$ in all cases. To favour the balance towards hydrotreatment and not polymerisation, low heating rates, good hydrogen mass transfer, high hydrogen availability inside the catalyst and, of course, an active catalyst are crucial. Co-processing of HDO oil (with low coking tendency), blended 20 wt.\% with Long Residue in a lab-scale catalytic cracking unit is successful, yielding similar results to those obtained using Long Residue only. On the other hand, extensively polymerised HPTT oils, with similar oxygen content, can not be co-processed due to their high coking tendency. Upon co-processing, hydrogen transfer from the fossil feed to the HDO oil occurs. This phenomenon is essential to obtain a good product distribution. Near oxygen free, valuable products can be produced by coprocessing a wide range of HDO oils. As long as the HDO oils are co-processed with sufficient and suitable fossil co-feed and the feed blend is thermally stable (low coking tendency), catalytic cracking product yields are independent of feedstock and oxygen content. 


\section{Introduction}

In this thesis, research about upgrading of pyrolysis oil to obtain a product that can be coprocessed in standard refinery units is presented. Chapter 1 gives a general introduction, describing the larger project in which this work was carried out and why the chosen route is of interest. Thereafter, the different technologies and materials used are briefly described. Finally, an overview of the remainder of the chapters in this thesis is given. 



\section{Energy and oil}

The global economy is expected to increase a four-fold between 2005 and 2050. Fast developing countries such as India and China will even increase their economies up to ten-fold [1]. Following the journey through the energy ladder, this increase in economy will inevitably be accompanied by an increase in energy demand [2].

Although several scenarios predict a gradual shift to an all-electric society [3] in which the electrons are produced from renewable sources (such as wind and solar), there are situations for which the use of oil will remain to be preferred or is the only option. Groeneveld [4] indicated situations in which oil is still the better option:

- Oil can store energy $\left(\mathrm{MJ} / \mathrm{kg}\right.$ and $\left.\mathrm{MJ} / \mathrm{m}^{3}\right)$, and can also be transported very efficiently: oil effectively loses approximately $1 \%$ of its energy content when transported over a distance of $5000 \mathrm{~km}$. Electricity losses with current technologies are $21 \%$ over the same distance. Storage of electricity at GW scale is virtually impossible.

- Oil can be used in off-grid (agricultural or civil) applications, which is especially important in developing countries without reliable infrastructure.

- Oil can not be easily replaced in several areas in transportation. While short distances could be covered with electric transport (if/when the adequate infrastructure is available), long distance transportation needs high energy density liquids to travel for long time without refuelling. This long distance transportation is related to the use of terrestrial trucks and busses, but also ships and planes.

- Oil is still the pillar of petrochemical industry, used for the production carbon-based chemicals.

These benefits of oil and the slow development of alternatives will most probably imply that there will be a continuing demand and need for oil in the coming decades. However, the intensive use of fossil fuels has serious consequences on the emission of greenhouse gasses. The "business-as-usual" baseline scenario as presented by the Intergovernmental Panel on Climate Change (IPCC) in 2008, predicted a $130 \%$ rise in $\mathrm{CO}_{2}$ emissions from 2005 to 2050 [1]. Furthermore, the availability (and related price) of fossil fuels can be substantially influenced by political and economical disturbances. For a more sustainable future, the development of new, reliable and sustainable technology that can guarantee the supply of energy but also the availability of a product that can be used together (or even instead) of fossil fuel products is needed. 


\section{Biomass and liquid biofuels}

The utilisation of biomass can contribute to diversify and secure the energy supply. Moreover, the $\mathrm{CO}_{2}$ that is produced during the utilisation of biomass (or its products) can be reabsorbed by the new growing generation, closing in this way the $\mathrm{CO}_{2}$ cycle. Of course, this is only true if the utilisation and growing rates are balanced. Moreover, the usage of fossil fuel to produce biofuels (for processing, fertiliser production,...) should be lower than the energy content of the final product. Biodiversity, water and land use, soil depletion, etc. are aspects that should also be taken into account when considering and evaluating the biomass to biofuel route.

There are several process options to turn solid biomass into a liquid fuel. Currently, the utilisation of first generation biofuels can already be encountered in many countries. The main representatives of this first generation biofuels are bio-ethanol (from biomass with high sugar content such as sugar cane and corn) and bio-diesel (from biomass with high lipid content such as rape and sunflower seeds). These types of biofuels have opened the door to the usage of biomass in the transportation sector, creating new legislation, distribution networks, product awareness, etc. However, the net energy output (compared to the fossil energy needed to produce them) of some of them, and thus, the net reduction in $\mathrm{CO}_{2}$ emission has been questioned [5]. Furthermore, the feedstock used for their production can also be used for food or feed, raising ethical questions.

Advanced biofuels (including the second and further generation biofuels) can be produced from a much wider range of biomass and for their production the whole biomass (cellulose, hemi-cellulose and lignin components) can be used. This also allows the use of agricultural and forestry wastes. The typically proposed thermo-chemical conversion routes for the production of advanced biofuels are hydrothermal conversion, pyrolysis, sugar extraction (fractionation) followed by sugar conversion and gasification to synthesis gas followed by a Gas to Liquid process (GTL) like Fischer-Tropsch. Each of these technologies has its advantages and disadvantages and they are in different stages of development.

Hydrothermal conversion of wet biomass in sub-critical water uses high pressure and moderate temperature $\left(300-370^{\circ} \mathrm{C}\right)$ to create an oil with higher energy density than its starting material. This oil can be used directly for heat and power applications, or further upgraded/refined to obtain transportation fuels and chemicals [6, 7]. If higher temperatures (up to $700{ }^{\circ} \mathrm{C}$ ) and/or catalysts are applied, the production of gases is achieved $[8,9]$. In this last case, the gas can also be recombined to a liquid via a GTL process. Several pilot/demonstration plants are (being) built around the world, involving processes such us the Slurrycarb (EnerTech Evironmental Inc., USA) [6]. 
Similar to processes used in the pulp and paper industry [10], biomass fractionation into its different constituents (lignin, hemi-cellulose and cellulose) can be achieved. Thereafter, the fractions obtained can be further processed through the traditional enzymatic routes or chemically $[11,12]$ to obtain fuels.

Gasification of dry biomass can be achieved in one step using fixed and fluidised beds, entrained flow reactors, etc. The process temperature varies from approximately 800 to $1300{ }^{\circ} \mathrm{C}$, depending on reactor choice and catalyst [8, 13]. From this process, synthesis gas can be obtained. It can be used directly or, as mentioned above, can be further converted to liquid fuels. For example, Choren (Germany) has a Biomass to Liquid process with a capacity of approximately 7.5 ton/h [14].

During pyrolysis, dry biomass is subjected to temperature between 400 and $600{ }^{\circ} \mathrm{C}$, in the absence of oxygen for very short residence times (under $2 \mathrm{~s}$ ) [15, 16]. Depending on process conditions (especially temperature), typical products yields are: $\sim 5-15 \mathrm{wt} . \%$ for char, $\sim 10-30$ wt. $\%$ for gas and $\sim 60-75$ wt. $\%$ for oil $[15,17]$. Several plants are in operation including a $1 \mathrm{ton} / \mathrm{h}$ from Ensyn (USA and Canada) for the production of food flavours, and 2 to 4 ton/h plants from Dynamotive (Canada) and BTG (The Netherlands) for energy production [18]. Pyrolysis oil can be used directly in burners/boilers and some modified engines and can also be used as source of chemicals [19]. It can also be further processed in, for example, gasification units [20] or upgraded so that it can be coprocessed in standard petroleum refiners. This last option is the one explored in the present thesis.

\section{From biomass to transportation fuels and chemicals, the co-processing concept}

The work reported in this thesis has been carried out in the framework of a large EU project (BIOCOUP) that evaluates and studies the chain from biomass to conventional refinery products (fuels and chemicals). More specifically, the route consists of the use of decentralised pyrolysis units (located where biomass is available) and transportation of the resulting pyrolysis oil to a central upgrading plant. This plant can be located close to a standard refinery (see Figure 1). The main advantages of this route are:

- During pyrolysis, biomass is converted into a higher volumetric energy density liquid. This liquid is cheaper to transport and easier to handle than bulk solid biomass. Minerals are largely separated and can be used at the biomass production location. 
- The upgrading (deoxygenation) plant can be located next or inside the (existing) refinery. In this way, the required process utilities and product distribution network are already available, creating a product compatible with existing end user requirements.

- Using this concept, it is neither necessary to build a whole new bio-refinery nor to invest in new re-fuelling stations or car engines.

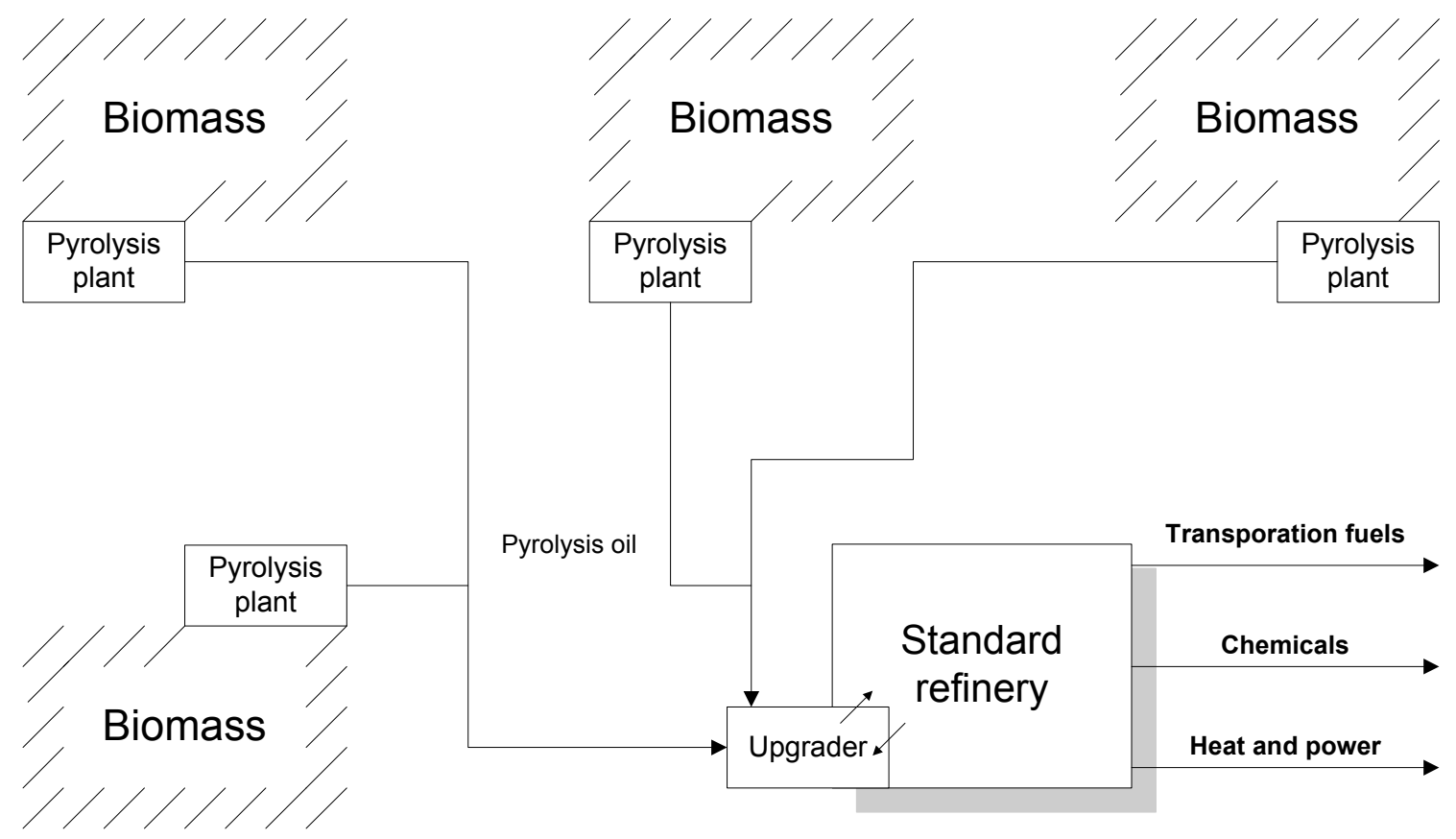

Figure 1. Schematic representation of the biomass-pyrolysis-upgrading-refinery concept.

To better understand the project in which the work as reported in this thesis was enclosed, a short description is given. Figure 2 shows a schematic representation of the division of BIOCOUP [21] in different subprojects (SP). A brief description of the SP's would be as follows:

- SP1: Pyrolysis. In this SP, the study of the pyrolysis process, including possible process modifications (such us in-situ filtration [22]) to improve product properties was conducted.

- SP2: Pyrolysis oil deoxygenation. The work reported in this thesis was part of the work in this SP. Different processes, catalysts, reactor configurations, etc. were studied to develop a process concept, in which upgraded pyrolysis oil could be used as refinery feedstock. It should be noted that the original aim of the work in this SP was to remove oxygen from pyrolysis oil, because in literature a low oxygen content was typically targeted for petroleum-like products and for further co-processing [23, 24]. As the title of the thesis does not contain the word "deoxygenation" but 
"upgrading", this already suggests that deep deoxygenation is not the key parameter for co-processing. Proof of this will be given in this thesis.

- SP3: Co-processing in petroleum refineries. In this SP the technical feasibility of coprocessing the product from SP2 in different refinery units was studied. Product yields and properties after co-processing were determined.

- SP4: Chemicals recovery: Value added chemicals are present in pyrolysis oil but also in different by-product streams from SP2. The recovery of these chemicals can improve overall process economics, and moreover, can lead to a 'zero waste' concept. In particular, recovery concepts were developed for (acetic) acids, phenolics and aldehydes.

- SP5: Scenario analysis. With the data obtained from the different SP's, economic evaluations and life-cycle analysis were performed.

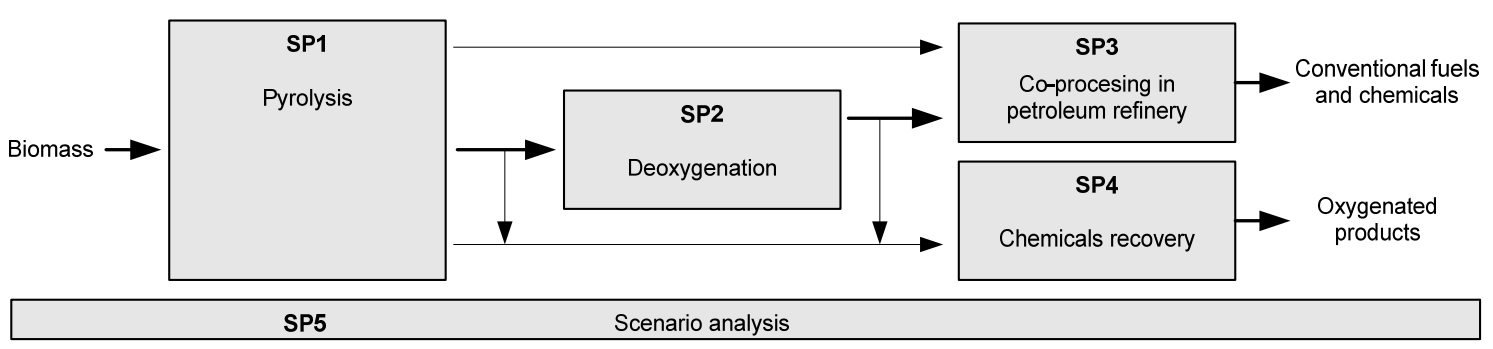

Figure 2. Different subprojects (SP) that BIOCOUP comprises

\section{Pyrolysis oil upgrading for co-processing in standard refinery units}

In the previous sections, the context of the research was presented. This section will give a brief description of the materials and technologies used for the present work.

\section{Pyrolysis oil}

Pyrolysis oil, also referred to as bio-oil, is a dark brown viscous liquid product obtained after fast condensation of the vapours generated during biomass pyrolysis. Its composition depends on the feedstock and the pyrolysis process conditions at which it is produced. Typically, it contains 15-30 wt.\% of water (from the moisture in the biomass feed and produced during pyrolysis) [25]. It has a high oxygen content (20-40 wt.\% on dry basis) originating from the more than 200 different components present in the oil, 
yielding almost all types of oxygenated functional groups [26]. This high oxygen and water content causes a low heating value $(\sim 14-18 \mathrm{MJ} / \mathrm{kg})$ which is less than half of that of hydrocarbon fuels [25]. Moreover, pyrolysis oil is not miscible with fossil fuels.

Pyrolysis oil can be separated into different families using solvent fractionation. According to the fractionation technique developed by VTT (Finland) and averaging for different types of biomass, pyrolysis oil can be split in [27]:

- Water

- Ether soluble organics (aldehydes, ketones lignin monomers)

- Volatile acids (mainly acetic)

- Ether insoluble organics (anhydrosugars, anhydrooligomers, hydroxyacids C > 10)

- Lignin derivates, polymerisation products and solids

- Extractives (n-hexane soluble organics)
27 wt. \%

21 wt. $\%$

$5 \mathrm{wt} . \%$

28 wt. $\%$

15 wt. $\%$

$4 \mathrm{wt} . \%$

Pyrolysis oil has a $\mathrm{pH}$ of 2-3 due to the presence of considerable amount of organic acids, which makes it corrosive. Pyrolysis oil can be unstable, even at room temperature [25]. Components react with themselves producing heavier molecules accompanied by an increase in water content and viscosity of the oil. These reactions are referred to as "aging". Eventually, this degradation can even lead to phase separation, creating an aqueous phase and a heavier organic phase. This process is accelerated by temperature.

\section{Pyrolysis oil upgrading}

At the beginning of BIOCOUP, deoxygenation was the aim of pyrolysis oil upgrading. For this purpose, two processes were thought to be applicable: high pressure thermal treatment and hydrodeoxygenation.

High pressure thermal treatment (HPTT) was originally developed by BTG (Biomass technology group, The Netherlands) and the University of Twente [28]. In this process, pyrolysis oil is subjected to a thermal treatment at temperatures between 300 and $340{ }^{\circ} \mathrm{C}$ at high pressures (140 bar) for short residence time (minutes). This high pressure was needed to keep the water in liquid state and avoid charring of the oil. After HPTT, pyrolysis oil underwent phase separation, creating an aqueous phase, an oil phase and a gas phase. Most of the gas produced was $\mathrm{CO}_{2}$, indicating that upon HPTT decarboxylation occurred. The resulting oil phase contained $\sim 80 \%$ of the energy from the starting pyrolysis oil. By HPTT, the (dry) oxygen content of the oil was nearly halved. Because of this reduction in oxygen content, the simplicity of the process (compared to hydrodeoxygenation, no hydrogen or catalyst is required) and short residence times, this process was chosen for further study in this thesis. 
During Hydrodeoxygenation (HDO), pyrolysis oil is processed under high hydrogen pressures in the presence of an active catalyst at elevated temperatures. After HDO of pyrolysis oil, an oil with lower oxygen content is produced. Because of this reduction in oxygen content, HDO was also selected for study in the present work. Similar to HPTT, an aqueous phase and a gas phase are also produced. The recovery of organics in each phase depends largely on the process conditions. Elliott (2007) [23] and Wildschut (2009) [29] wrote extensive reviews on pyrolysis oil HDO to which the reader may refer to for further historical developments on this topic. In this introduction, only a brief description of HDO will be given.

PNL/PNNL (USA) started HDO of pyrolysis oil in the mid 1980's. They based their initial experiments on the hydrodesulphurisation process carried out in the petroleum industry. They quickly found that pyrolysis oil could not be processed in the same way because of its high coking tendency when exposed to high temperatures $\left(>350^{\circ} \mathrm{C}\right)$ [30]. Therefore, they tested a low temperature $\left(\sim 250-300{ }^{\circ} \mathrm{C}\right) \mathrm{HDO}$ step to reduce the reactivity of several functional groups and stabilise the oil. This stabilisation step needed an active catalyst, otherwise coking also occurred [23]. Laurent et al. [31] developed a reactivity scale showing at which temperatures different functional groups could be hydrotreated. They showed that below $250{ }^{\circ} \mathrm{C}$, olefins, aldehydes, ketones and ethers are already reactive. In a non-isothermal fix-bed reactor, unifying stabilisation $\left(\sim 250{ }^{\circ} \mathrm{C}\right)$ and deep deoxygenation $\left(\sim 390{ }^{\circ} \mathrm{C}\right)$, Baker and Elliott [32] produced an oil with a yield around 40 vol. \% and with an oxygen content of 1-2 wt.\%. Hydrogen consumption was between 500 and $700 \mathrm{I} \mathrm{H}_{2} / \mathrm{l}$ feed, which was too high to allow commercialisation. Due to recent interest in $\mathrm{CO}_{2}$ neutral fuels, research on $\mathrm{HDO}$ of pyrolysis oil has attracted new attention. Various papers have been published on different aspects of HDO such as catalyst development [33-35], the use of model compounds for the different fractions of pyrolysis oil $[36,37]$ and mild HDO [38-40]. These new publications aim for the reduction of the hydrogen consumption, improvement of the catalyst and a better understanding of the process. Baldauf et al. [24] proposed the use of upgraded pyrolysis oil in refineries. UOP LLC even patented a process for the hydrotreatment of the pyrolysis oil lignin fraction and the subsequent hydrocracking of the organic phase product [41].

Some of the publications mentioned in this section are also comprised within the BIOCOUP project. Together with these publications, this thesis will give new information on the pyrolysis oil upgrading routes, the relationship between upgrading process (and process condition) and product properties and how these properties influence the coprocessing performance. 


\section{This thesis}

In Chapter 2, a study about HPTT is reported. Pyrolysis oil was processed in a continuous set-up at different temperatures $\left(200-350{ }^{\circ} \mathrm{C}\right)$ and residence times (1-4 min) to evaluate its deoxygenation. The set-up ensured comprehensive control over the temperature profile in the reactor as well as good mass balance closure. Along with the traditional study of yields and elemental composition, analysis on the molecular weight distribution and the composition (by chemical families) was performed. Based on the results, the suitability of HPTT as pyrolysis upgrading step prior to co-processing is discussed.

In Chapter 3, the hydrodeoxygenation (HDO) of pyrolysis oil is described. Experiments were carried out at similar temperatures as used in the HPTT study $\left(230-340{ }^{\circ} \mathrm{C}\right)$ but for longer reaction time $(>4 \mathrm{~h})$ and in the presence of hydrogen and catalyst. The set-up used was a large $(5 \mathrm{I})$ batch autoclave, in which up to $\sim 500 \mathrm{~g}$ of HDO oil could be produced. These oils were subsequently co-processed with fossil feed in a lab scale catalytic cracking unit (MAT). In this way the relationship between HDO process conditions, resulting HDO oil properties and the performance of these oils in refinery units could be studied.

In a typical refinery, crude oil is fractionated in a first step (atmospheric distillation). This concept might also be used in case of pyrolysis oil, trying to maximise the end value of the products. However, because of the high reactivity of pyrolysis oil at higher temperatures this fractionation cannot be achieved by atmospheric distillation. Pyrolysis oil fractions were therefore prepared by water addition, resulting in an 'aqueous fraction' and 'organic fraction'. These fractions were independently processed under HDO conditions. This is reported in Chapter 4. Experiments were conducted batch-wise in a 0.6 I autoclave at temperatures between $220-310{ }^{\circ} \mathrm{C}$. Results are presented in terms of yields and product analysis. To study possible differences in quality, the resulting HDO oils were co-processed in two different lab scale refinery units (hydrodesulphurisation and catalytic cracking). The co-processing results are also discussed in Chapter 4.

Sugars, as present in pyrolysis oil, appear to be key components during pyrolysis oil upgrading because they can easily polymerise and reduce product quality. In Chapter 5 , the polymerisation of glucose (as model compound for sugars in pyrolysis oil) as a function of process conditions is reported. A sugar fraction obtained from pyrolysis oil was also used to reaffirm results. Suggestions on polymerisation prevention are presented.

The combined results of Chapter 2-5 of this thesis indicate that, during HDO, competition between polymerisation and hydrotreating reactions occurs, and can influence final 
product properties. Improving product quality in HDO thus might not only be achieved by minimising the extent of polymerisation, but also by maximising the extent of hydrotreating. This hypothesis was studied and the results are reported in Chapter 6. Results are thought to be valuable for the design of demo units and industrial reactors. 


\section{References}

[1] International Energy Agency, Energy Technology Perspectives 2008. IEA Publications, Paris, 2008.

Available at: http://www.iea.org/w/bookshop/add.aspx?id=330

[2] Shell energy scenarios to 2050. Shell international BV, 2008. Available at: http://www.shell.com/home/content/aboutshell/our_strategy/shell_global_scenarios/

[3] Friedman TL, Hot, flat, and crowded. Farrar, Straus and Giroux, New York, 2008.

[4] Groeneveld MJ, The change from fossil to solar and biofuels needs our energy. Inaugural Lecture. University of Twente, Enchede, 2008. Available at: http://doc.utwente.nl/67339/

[5] Pimentel D, Patzek TW. Ethanol Production Using Corn, Switchgrass, and Wood; Biodiesel Production Using Soybean and Sunflower. Nat. Res. Res. 2005;14:65-76.

[6] Knežević D, Hydrothermal conversion of biomass. PhD Thesis. Univeristy of Twente, Enschede, 2009. Available at: http://doc.utwente.nl/67359/

[7] Goudriaan F, Peferoen DGR. Liquid fuels from biomass via a hydrothermal process. Chem. Eng. Sci. 1990;45:2729-2734.

[8] Van Rossum G, Potic B, Kersten SRA, van Swaaij WPM. Catalytic gasification of dry and wet biomass. Catal. Today. 2009;145:10-18.

[9] Elliott DC, Neuenschwander GG, Hart TR, Butner RS, Zacher AH, Engelhard MH, Young JS, McCready DE. Chemical Processing in High-Pressure Aqueous Environments. 7. Process Development for Catalytic Gasification of Wet Biomass Feedstocks. Ind. Eng. Chem. Res. 2004;43:1999-2004.

[10] Patt R, Kordsachia $O$, Süttinger R, Ohtani $Y$, Hoesch JF, Ehrler $P$, Eichinger $R$, Holik H, Hamm U, Rohmann ME, Mummenhoff P, Petermann E, Miller RF, Frank D, Wilken R, Baumgarten HL, Rentrop GH, Paper and Pulp, Ullmann's Encyclopedia of Industrial Chemistry.

[11] West RM, Liu ZY, Peter M, Gärtner CA, Dumesic JA. Carbon-carbon bond formation for biomass-derived furfurals and ketones by aldol condensation in a biphasic system. J. Mol. Catal. A-Chem. 2008;296:18-27.

[12] Serrano-Ruiz JC, Braden DJ, West RM, Dumesic JA. Conversion of cellulose to hydrocarbon fuels by progressive removal of oxygen. Appl. Catal. B Environ. In press (doi:10.1016/j.apcatb.2010.07.029).

[13] Kersten SRA, Biomass Gasification in circulating fluidized bed. PhD Thesis. University of Twente, Enschede, 2002. 
[14] Choren website. Last visited on 06-08-2010; Available at: http://www.choren.com/en/.

[15] Bridgwater AV, Peacocke GVC. Fast pyrolysis processes for biomass. Renewable Sustainable Energy Rev. 2000;4:1-73.

[16] Kersten SRA, Wang X, Prins W, van Swaaij WPM. Biomass Pyrolysis in a Fluidized Bed Reactor. Part 1: Literature Review and Model Simulations. Ind. Eng. Chem. Res. 2005;44:8773-8785.

[17] Scott DS, Piskorz J, Radlein D. Liquid products from the continuous flash pyrolysis of biomass. Ind. Eng. Chem. Process Design Dev. 1985;24:581-588.

[18] Venderbosch R, Prins W. Fast pyrolysis technology development. Biofuels, Bioproducts and Biorefining. 2010;4:178-208.

[19] Czernik S, Bridgwater AV. Overview of applications of biomass fast pyrolysis oil. Energy Fuels. 2004;18:590-598.

[20] Van Rossum G, Steam reforming and gasification of pyrolysis oil. 2009, Univeristy of Twente: Enschede.

[21] Biocoup website. Last visited on 06-08-2010; Available at: www.biocoup.eu.

[22] Hoekstra E, Hogendoorn KJA, Wang X, Westerhof RJM, Kersten SRA, van Swaaij WPM, Groeneveld MJ. Fast Pyrolysis of Biomass in a Fluidized Bed Reactor: In Situ Filtering of the Vapors. Ind. Eng. Chem. Res. 2009;48:4744-4756.

[23] Elliott DC. Historical developments in hydroprocessing bio-oils. Energy Fuels. 2007;21:1792-1815.

[24] Baldauf W, Balfanz U, Rupp M. Upgrading of flash pyrolysis oil and utilization in refineries. Biomass and Bioenergy 1994;7:237-244.

[25] Oasmaa A, Czernik S. Fuel oil quality of biomass pyrolysis oils-State of the art for the end users. Energy Fuels. 1999;13:914-921.

[26] Branca C, Blasi CD, Elefante R. Devolatilization and Heterogeneous Combustion of Wood Fast Pyrolysis Oils. Ind. Eng. Chem. Res. 2005;44:799-810.

[27] Oasmaa A, Solantausta Y, Arpiainen V, Kuoppala E, Sipila K. Fast Pyrolysis BioOils from Wood and Agricultural Residues. Energy Fuels. 2009;24:1380-1388.

[28] Rep M, Venderbosch RH, Assink D, Tromp W, Kersten SRA, Prins W, Van Swaaij WPM. De-oxygenation of bio-oils. In: A.V. Bridgwater and D.G.B. Boocock editors. Science in thermal and chemical biomass conversion, Chippenham: CLP Press. 2006; p. 1526-1535.

[29] Wildschut J, Pyrolysis oil upgrading to transportation fuels by catalytic hydrotreatment. PhD Thesis, University of Gronignen, Gronignen, 2009. Available at: http://irs.ub.rug.nl/ppn/322501776 
[30] Elliott DC, Baker EG, Process for upgrading biomass pyrolyzates, US Patent number: 4795841,1989.

[31] Laurent E, Pierret C, Grange P, Delmon B. Control of the deoxygenation of pyrolytic oils by hydrotreatment. In: Proc. of 6th conference on Biomass for energy, industry and environment, Athens, Greece. 1991; p. 665-671.

[32] Baker EG, Elliott DC. Catalytic upgrading of biomass pyrolysis oils. In: A.V. Bridgwater and J.L. Kuester editors. Research in thermochemical biomass conversion, London: Elsevier science publishers LTD. 1988.

[33] Gutierrez A, Kaila RK, Honkela ML, Slioor R, Krause AOI. Hydrodeoxygenation of guaiacol on noble metal catalysts. Catal. Today. 2009;147:239-246.

[34] Yakovlev VA, Khromova SA, Sherstyuk OV, Dundich VO, Ermakov DY, Novopashina VM, Lebedev MY, Bulavchenko O, Parmon VN. Development of new catalytic systems for upgraded bio-fuels production from bio-crude-oil and biodiesel. Catal. Today. 2009;144:362-366.

[35] Wildschut J, Mahfud FH, Venderbosch RH, Heeres HJ. Hydrotreatment of Fast Pyrolysis Oil Using Heterogeneous Noble-Metal Catalysts. Ind. Eng. Chem. Res. 2009;48:10324-10334.

[36] Wildschut J, Arentz J, Rasrendra CB, Venderbosch RH, Heeres HJ. Catalytic hydrotreatment of fast pyrolysis oil: Model studies on reaction pathways for the carbohydrate fraction. Environ. Prog. Sustain. Energy. 2009;28:450-460.

[37] Elliott DC, Hart TR. Catalytic Hydroprocessing of Chemical Models for Bio-oil. Energy Fuels 2008;23:631-637.

[38] Elliott DC, Hart TR, Neuenschwander GG, Rotness LJ, Zacher AH. Catalytic hydroprocessing of biomass fast pyrolysis bio-oil to produce hydrocarbon products. Environ. Prog. Sustain. Energy. 2009;28:441-449.

[39] French RJ, Hrdlicka J, Baldwin R. Mild hydrotreating of biomass pyrolysis oils to produce a suitable refinery feedstock. Environ. Prog. Sustain. Energy. 2010;29:142150.

[40] Venderbosch RH, Ardiyanti AR, Wildschut J, Oasmaa A, Heeres HJ. Stabilization of biomass-derived pyrolysis oils. J. Chem. Technol. Biot. 2010;85:674-686.

[41] Marker TL, Petri JA, Gasoline and diesel production from pyrolytic lignin produced from pyrolysis of cellulosic waste, Patent number WO 2008/027699, 2008. 


\section{Pyrolysis oil upgrading by high pressure thermal treatment}

High pressure thermal treatment (HPTT) is a new process developed by BTG and University of Twente with the potential to economically reduce the oxygen and water content of oil obtained by fast pyrolysis (pyrolysis oil), properties that currently complicate its co-processing in standard refineries. During the HPTT process, pyrolysis oil undergoes a phase separation yielding a gas phase, an aqueous phase and an oil phase. In this study, HPTT experiments were carried out at different operating conditions in a continuous tubular reactor. Experimental results showed that, with increasing temperature and residence time, the release of gases (mainly $\left.\mathrm{CO}_{2}\right)$ and the production of water increased, reducing the oxygen content of the oil phase and hence increasing the energy content (from 14.1 to $28.4 \mathrm{MJ} / \mathrm{kg}$ ) having the temperature a larger effect when compared to the residence time. Using gel permeation chromatography (GPC), an increase of the molecular weight of the oil phase, probably due to polymerisation of the sugars present in pyrolysis oil, was observed. When water was added as solvent to dilute the feed oil, a decrease of the molecular weight of the resulting oil phase was observed. This indicated that the concentration of organic components had a direct effect on the formation of high molecular weight components. In conclusion, during HPTT an oil with lower oxygen and water content with higher energy value was produced, but adverse formation of high molecular weight components was also detected. 



\section{Introduction}

Biomass is one of the renewable energy carriers and currently the only renewable source of chemicals. Its use can contribute to the reduction of the green-house-gas emissions because the $\mathrm{CO}_{2}$ that is produced during the utilisation of biomass can be reabsorbed by new growing biomass, thereby closing the $\mathrm{CO}_{2}$ cycle. Due to its wide availability, biomass can contribute to securing the energy supply and, when organised in an efficient way, it can stimulate employment especially in developing countries.

Fast (or flash) pyrolysis is a process to thermo-chemically convert solid biomass into a liquid oil. In this process, dry biomass is rapidly heated (residence times of a few seconds) to temperatures around $450-500{ }^{\circ} \mathrm{C}$ in the absence of oxygen and at atmospheric pressure. In the past, many studies have been carried out to find the operation conditions for which the oil yield can be maximized [1]. In the temperature range mentioned and using residence times of up to $2 \mathrm{~s}$, oil yields of up to $70-80 \mathrm{wt} . \%$ were obtained [2]. Besides pyrolysis oil - present as condensable vapours at reactions conditions-, also char ( $\sim-10 \mathrm{wt} . \%)$ and gases ( 20-30 wt.\%) are produced. After the reactor, the vapours are rapidly quenched creating a dark brown oil named pyrolysis oil (also know as bio-oil or bio-crude).

Pyrolysis oil is a mixture of hundreds of different components that are formed during the decomposition of the holocellulose and the lignin present in the feedstock. It has a high water content (15-30 wt.\%) and contains a large amount of oxygenated compounds, including acids, aldehydes, alcohols and others (total oxygen content excluding water is 20-40 wt.\%) [2]. Due to this high water and oxygen content, the heating value of the oil (HHV 17 MJ/kg) is low as compared to fossil fuels (HHV $45 \mathrm{MJ} / \mathrm{kg}$ ). Moreover, because of its high oxygen content and acidity, pyrolysis oil is not miscible with fossil fuels and is corrosive to engines and archetype refinery units, respectively. Another of the problems related to pyrolysis oil is its instability, especially during storage (referred to as "aging" [2]). This aging leads to an increase of viscosity and a possibly unwanted change in chemical composition of pyrolysis oil.

For some applications such as combustion in boilers, the quality of the product obtained via pyrolysis might be sufficient for direct use [3]. However, its direct usage in a diesel engine is difficult due to reasons mentioned in the previous section and, above that, the tendency of char formation of pyrolysis oil, which can, for example, cause blockage of nozzles in the engines [3]. An option to introduce pyrolysis oil in the transportation fuel market is to co-process it in existing petroleum refineries. Several studies have been carried out towards the direct processing of pyrolysis oil in (lab-scale) FCC units but the results show an excessive char formation resulting in unacceptably low overall gasoline yields [4]. Because of this, an intermediate step, in which pyrolysis oil is upgraded prior to its co-processing, is necessary [5]. 
One of the possible upgrading processes that has been studied is hydrodeoxygenation (HDO) of pyrolysis oil. This process, in which pyrolysis oil reacts with $\mathrm{H}_{2}$ in the presence of a catalyst, led to a product with low oxygen content ( $<5 \mathrm{wt} . \%)$ but it has the drawback of high $\mathrm{H}_{2}$ consumption (up to $900 \mathrm{Nl} / \mathrm{kg}$ pyrolysis oil [6]) and thus costs.

Biomass Technology Group-BTG, The Netherlands, and in a later stage in collaboration with the University of Twente, developed a process in which pyrolysis oil was thermally treated at high pressures (High Pressure Thermal Treatment, HPTT, Rep et al. [7]). The oil was processed at temperatures of $300-340{ }^{\circ} \mathrm{C}$ with a residence time of several minutes at 140 bar. The products obtained after this treatment were an oil phase (which contained $\sim 79 \%$ of the initial pyrolysis oil energy) and an aqueous phase (with some organic components containing $\sim 18 \%$ of the initial energy). About $5 \mathrm{wt} \%$ of the oil was converted to gas (mainly $\mathrm{CO}_{2}$ ) and a small amount of char was produced. The pressure needed to be high to keep the water in liquid state, because evaporation of water led to extensive charring of the oil. After the HPTT process, the oxygen content of the oil phase was reduced from $40 \mathrm{wt} \%$ to $23 \mathrm{wt} \%$ (on dry basis) due to the formation of gaseous $\mathrm{CO}_{2}$ and water and because several oxygenated compounds were transferred the aqueous phase. Basically, HPTT was shown to be a cheap de-oxygenation process (no need of catalyst or hydrogen) in which the energy of pyrolysis oil was concentrated due to the reduction of the oxygen and water content.

In this chapter, new results of the HPTT of pyrolysis oil in a continuous reactor operated at different conditions (temperature, residence time and water dilution ratio) are presented. The aim was to find an operating regime in which an upgraded oil can be obtained that has a higher energy content and lower oxygen content. Ultimately, the goal of this research is to obtain an upgraded oil that can be co-fed (directly or after further upgrading by hydrodeoxygenation) to a standard refinery.

\section{Experimental section}

\subsection{Pyrolysis oil}

The pyrolysis oil used for this research was produced by VTT, Finland, using pine wood as feedstock. More details about the properties of the wood can be found elsewhere [8]. The oil received was analysed and stored in bottles of the size needed for one run (250 $\mathrm{ml})$. These bottles were frozen $\left(-16^{\circ} \mathrm{C}\right)$ to avoid "aging" of pyrolysis oil. The day before an experiment, a bottle was unfrozen and when the oil was at room temperature, it was filtered (paper filter $6 \mu \mathrm{m}$ ) to remove possible remaining solids (char, ash, sand...). A summary of the pyrolysis oil properties is shown in Table 1 (analyses performed by VTT). 
Table 1. Pine wood pyrolysis oil properties (supplied by VTT).

\begin{tabular}{|c|c|}
\hline Property & Pine wood pyrolysis oil \\
\hline Water [wt.\%] & 23.9 \\
\hline Solids [wt.\%] & 0.011 \\
\hline Ash [wt.\%] & 0.03 \\
\hline Carbon [wt.\%] & 40.6 \\
\hline Hydrogen [wt.\%] & 7.6 \\
\hline Nitrogen [wt.\%] & $<0.1$ \\
\hline Sulphur [wt.\%] & 0.01 \\
\hline Chlorine [ppm] & 64 \\
\hline Sodium [ppm] & $<5$ \\
\hline Potassium [ppm] & 34 \\
\hline Oxygen (as difference) [wt.\%] & 51.7 \\
\hline $\mathrm{pH}$ & 2.7 \\
\hline Density $15^{\circ} \mathrm{C}[\mathrm{kg} / \mathrm{l}]$ & 1.206 \\
\hline Viscosity $20^{\circ} \mathrm{C}$ [cSt] & 58 \\
\hline Viscosity $40^{\circ} \mathrm{C}$ [cSt] & 17 \\
\hline Viscosity $80^{\circ} \mathrm{C}$ [cSt] & 4 \\
\hline Flash point $\left[{ }^{\circ} \mathrm{C}\right]$ & 53 \\
\hline Pour point $\left[{ }^{\circ} \mathrm{C}\right]$ & -36 \\
\hline
\end{tabular}

\subsection{Experimental set-up and procedure}

A tubular reactor was built with the aim of studying the HPTT of pyrolysis oil with a fully controllable temperature profile along the reactor and to obtain good mass balance closure. Figure 1 shows a flow diagram of the set-up.

The feeding system consisted of a HPLC pump that supplied pyrolysis oil (or 2-propanol for cleaning purposes) with flows between 1 and $10 \mathrm{ml} / \mathrm{min}$. A pre-heater was placed before the reactor. It consisted of a cartridge heater with a steel capillary (length: 350 $\mathrm{mm}$, internal diameter: $2 \mathrm{~mm}$ ) coiled around it which ensured that the oil was entering the reactor at reaction temperature. The heating time in the pre-heater was typically $\sim 10 \%$ of the residence time in the reactor. Preliminary experiments without the pre-heater showed that half of the length of the reactor was needed to reach the desired operation temperature. The reactor itself consisted of a $82 \mathrm{~cm}$ long steel tube with an internal diameter of $4 \mathrm{~mm}$. It was heated using an oven with three independent zones that were controlled using the signals of the thermocouples placed inside the reactor at different positions. Along the reactor, 7 temperature indicators where placed to log the temperature profile. In a typical experiment, the temperatures registered by the 
thermocouples were equal to the desired reaction temperature $\pm 5{ }^{\circ} \mathrm{C}$. When the oil exited the reactor, it was cooled but kept at $100{ }^{\circ} \mathrm{C}$ to keep the viscosity low. At that point, a back-pressure valve was present to be able to regulate the pressure of the system (typically 200 bar). After the valve, the products could be directed to 3 product collection vessels. The first one was used to collect the products during heating and cooling, and the second and third ones, to collect the product during steady-state. The collection vessels consisted of $1.2 \mathrm{I}$ steel vessels that were kept at $100{ }^{\circ} \mathrm{C}$ with the use of an oven (to keep the viscosity low and help with the desorption of produced gases from the oil phase). Inside these vessels, 1 I glass jars actually collected the liquid products and could be easily removed after an experiment to facilitate the reliable quantification of the yields. In these vessels the gases produced during the process were separated from the liquid. The gases produced during heating and cooling were vented and gases produced during steady-state were collected in a gas collection bottle for analysis. Between the liquid collection vessels and the gas collection bottle, a back pressure valve kept the pressure at 5 bar to keep the water in the collection vessels in the liquid state. At the end of each experiment, after cooling, the pressures of the gas collection bottle and the liquid collection vessel (the one with the steady-state product) were noted and samples of these gases were taken for GC analysis. Next, the set-up was opened to obtain the liquid products. Typically the liquid product consisted of an aqueous phase on top and viscous oil phase at the bottom. The two phases were separated, weighted and analysed.

At a later stage during the research, a second HPLC pump was added to be able to supply a solvent to dilute the pyrolysis oil feed. The solvent used was water. To avoid phase splitting due to cold water addition, a second pre-heater and a static mixer were installed as shown in Figure 2.

\subsection{Analytical equipment and procedures}

\subsubsection{Gas phase}

The gas samples were analysed in a gas chromatograph (Varian Micro GC CP-4900 with two analytical columns, $10 \mathrm{~m}$ Molsieve 5A and $10 \mathrm{~m} \mathrm{PPQ}$, using Helium are carrier gas). The exact volume of the gas collection bottle was known. The gas volume of the liquid collection vessel was calculated from the total volume minus the volume of the liquid product measured after each experiment. With these measurements and the monitored pressure read-outs, the amount and composition of the gas could be calculated. 


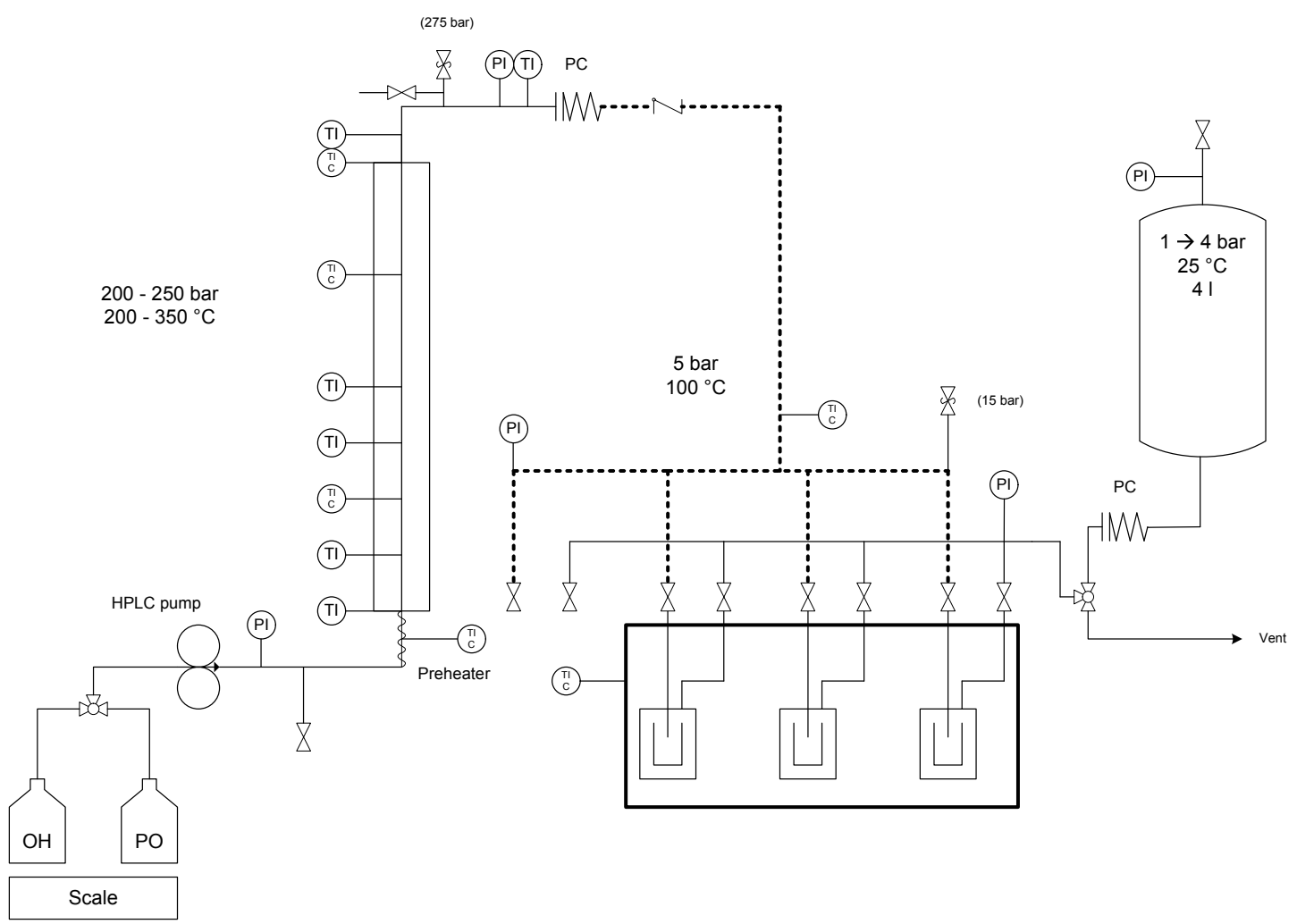

Figure 1. Flow diagram of HPTT set-up.

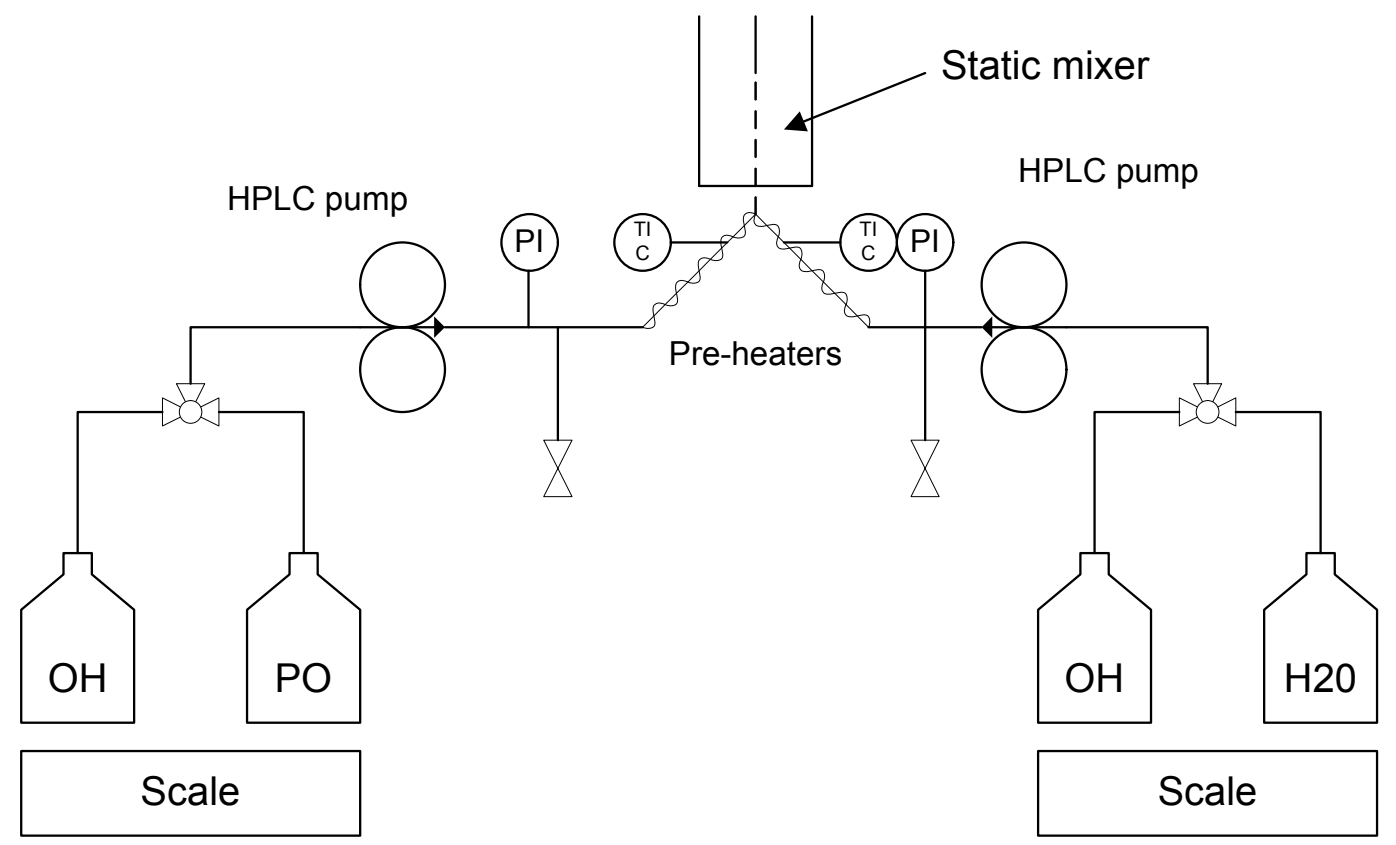

Figure 2. Modification of the set-up to enable solvent addition to the feed. 


\subsubsection{Liquid phase}

To determine the elemental composition of all the liquid phases, a Fisions Instruments 1108 EA CHN-S was used. Each sample was analysed at least twice. If the reproducibility was within $\pm 1 \%$, the results were considered good and the average values were taken.

A HPLC system with gel permeation chromatography (GPC) columns was used to determine the molecular weight distribution of the liquid products. This type of analysis was initially performed by the Johann Heinrich von Thünen Institute (VTI), Germany, but in a later stage of this study these analysis could be carried out in-house. The analyses performed by VTI were carried out using an Agilent 1100 HPLC system, using 3 GPC PLgel3micrometer MIXED-E columns connected in series. The column temperature was $40{ }^{\circ} \mathrm{C}$ and the solvent used was THF. Calibration was performed using solutions of polystyrene with molecular weight ranging from 162 to $29510 \mathrm{~g} / \mathrm{mol}$. The HPLC equipment at the University of Twente (Agilent 1200 HPLC) was a similar but updated version of the equipment of VTI. The columns, solvent and temperatures used by the UT were the same. These differences in equipment caused small differences in results, especially in the analysis of the feed oil. Because of this, only analyses from the same equipment were compared with each other. The HPLC equipment from VTI was used for the analysis of the products of the HPTT experiments carried out at different temperatures and residence times. The HPLC from the UT was used for the analysis of the products of the HPTT experiments with solvent addition.

A $787 \mathrm{KF}$ Titrino was used to quantify the water content of the original pyrolysis oil and the produced liquid phases (aqueous and oil). The solvent used was a solution of methanol (Aldrich) and dichloromethane (Aldrich) (volumetric ratio 3:1). The titrant used was Hydranal Composite 5 (Riedel-deHaën).

The solvent fractionation technique developed by VTT was used to separate the whole pyrolysis oil and the products of HPTT in major fractions. The fractions obtained by this technique are shown in Figure 3. More details about this fractionation can be found in the article of Oasmaa et al. [9].

\subsection{Definitions}

In the results presented, the yields of the products $\left(\eta_{i}(w e t)\right.$, in wt.\%) have been defined as:

$\eta_{i}($ wet $)=\frac{M_{i}}{M_{\text {feed }}} \cdot 100$ 
being $i$ : aqueous, oil or gas phase products and $M_{i}$ and $M_{\text {feed: }}$ the total mass of product phases and feed, respectively.

Knowing the water content of the samples, the dry yields ( $\eta_{i}(d r y)$, in wt.\%) could also be calculated. These dry yields of the aqueous and oil phase refer to the yields of organics in these respective phases with respect to the organics in the feed (dry feed):

$\eta_{i}($ dry $)=\frac{\eta_{i}(\text { wet }) \cdot\left(1-\left(\mathrm{H}_{2} \mathrm{O}_{i} / 100\right)\right)}{1-\left(\mathrm{H}_{2} \mathrm{O}_{\text {feed oil }} / 100\right)}$

with $\mathrm{H}_{2} \mathrm{O}_{i}$ and $\mathrm{H}_{2} \mathrm{O}_{\text {feed oil }}$ being the water content (in wt.\%) of the product phases and feed, respectively.

To complete the specification of the products on a dry basis, the yield of water produced ( $\eta_{\text {water produced, }}$ in wt.\%) per 100 grams of dry feed oil has to be incorporated:

$\eta_{\text {water produced }}=\left(\frac{\sum_{j}\left(\eta_{i}(\text { wet }) \cdot H_{2} \mathrm{O}_{i}\right)-\mathrm{H}_{2} \mathrm{O}_{\text {feed oil }}}{1-\left(\mathrm{H}_{2} \mathrm{O}_{\text {feed oil }} / 100\right)}\right)$

being $j$ : aqueous or oil phase products

From the elemental analysis (wet), the dry elemental composition could be calculated by subtracting the contribution of $\mathrm{H}$ and $\mathrm{O}$ originating from the water:

$C_{d r y, i}=\frac{C_{w e t, i}}{1-\left(H_{2} O_{i} / 100\right)}$

$H_{d r y, i}=\frac{H_{w e t, i}-\left(H_{2} \mathrm{O}_{i} \cdot\left(2 \cdot M W_{H} /\left(2 \cdot M W_{H}+M W_{O}\right)\right)\right)}{1-\left(H_{2} \mathrm{O}_{i} / 100\right)}$

$O_{d r y, i}=\frac{O_{w e t, i}-\left(H_{2} O_{i} \cdot\left(M W_{O} /\left(2 \cdot M W_{H}+M W_{O}\right)\right)\right)}{1-\left(H_{2} \mathrm{O}_{i} / 100\right)}$

with $C_{d r y}$ in wt.\% and being $M W_{H}, M W_{O}$ and $M W_{C}$ the molecular weight of atomic hydrogen, atomic oxygen and atomic carbon, respectively.

From these dry elemental values, the molar $\mathrm{H} / \mathrm{C}$ and $\mathrm{O} / \mathrm{C}$ ratios of the organics in the liquid product phases were calculated: 
$H / C=\frac{H_{d r y, i}}{C_{d r y, i}} \cdot \frac{M W_{C}}{M W_{H}} \quad O / C=\frac{O_{d r y, i}}{C_{d r y, i}} \cdot \frac{M W_{C}}{M W_{O}} \quad$ (Eq. 7) $\quad$ (Eq. 8)

From the dry elemental composition and the water content, the higher heating value (HHV) was calculated using the Reed's formula [10]:

$$
H H V_{R e e d, i}(w e t)=\left(1-H_{2} O_{i} / 100\right) \cdot\left(0.341 \cdot C_{d r y, i}+1.322 \cdot H_{d r y, i}-0.12 \cdot O_{d r y, i}\right)
$$

In the original formula, factors concerning the amount of nitrogen, sulphur and ash are also present. However, since pyrolysis oil contains very little of them $(<0.1 \mathrm{wt} . \%)$, they were not taken into account.

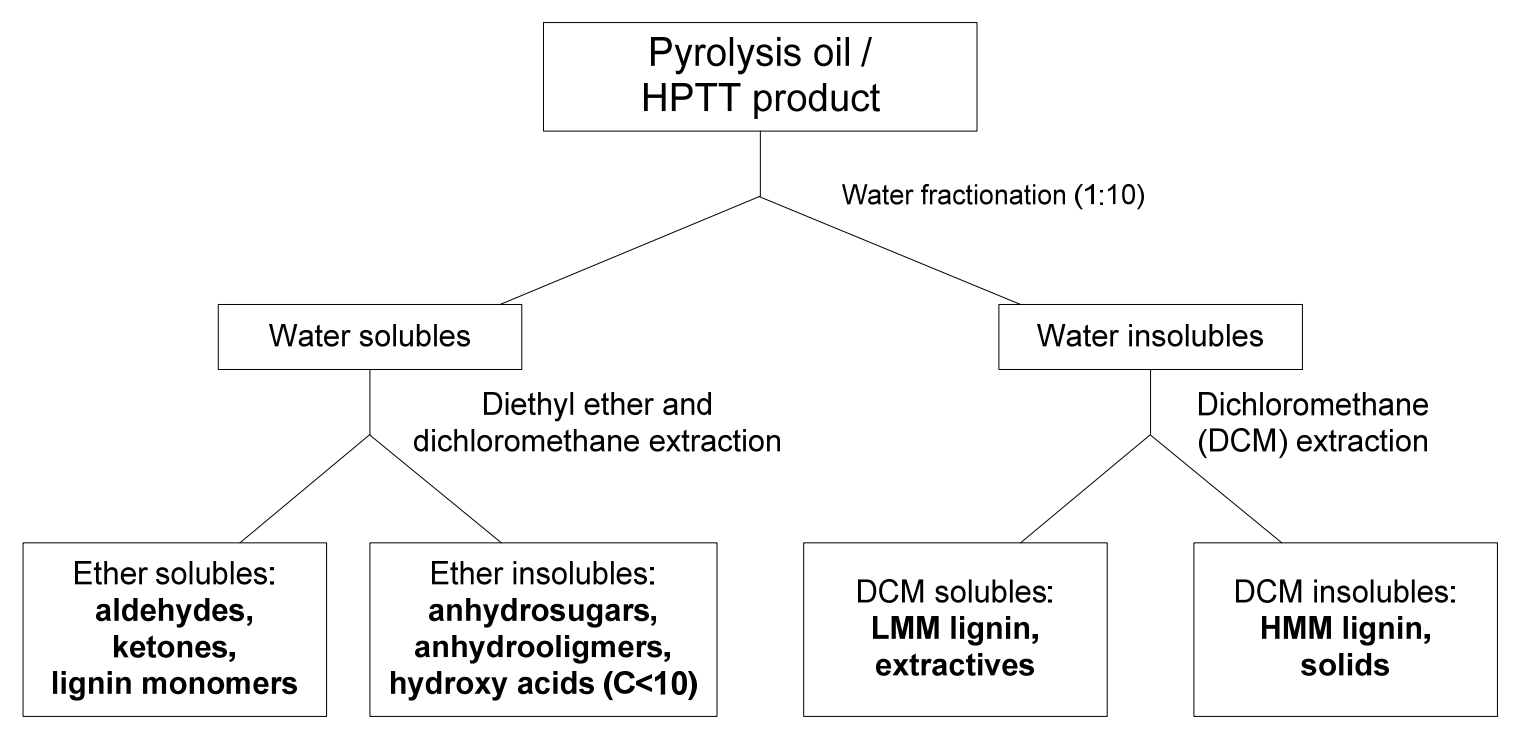

Figure 3. VTT's solvent fractionation technique applied to pyrolysis oil or an HPTT product. LMM lignin and HMM lignin stand for Low and High Molecular Mass lignin, respectively [9].

\section{Experimental results and discussion}

Experiments carried out under different operating conditions were performed to determine their influence on product quality and phase yields. The parameters studied were temperature $\left(200-350{ }^{\circ} \mathrm{C}\right)$, residence time (1.5-3.5 $\mathrm{min}$ ) and the addition of a solvent (water:pyrolysis oil, vol. 1:1). 
It is known that pyrolysis oil remains one liquid phase under HPTT conditions [11] and the liquid phase separation occurs during cooling (approximately around $200{ }^{\circ} \mathrm{C}$ ). After the process, the aqueous phase product was typically black for experiments at relatively low temperature $\left(\sim 200-260{ }^{\circ} \mathrm{C}\right)$ and light brown (becoming translucent) at higher temperatures $\left(>300{ }^{\circ} \mathrm{C}\right)$. The oil phase was always black and its visual viscosity increased with reaction temperature.

After the experiments, char was observed at the walls of the reactor $(<1 \mathrm{wt} . \%)$. The extent of char formation increased with temperature, at higher temperature $\left(>300{ }^{\circ} \mathrm{C}\right)$ even clogging the pre-heater line (internal diameter of $2 \mathrm{~mm}$ ) and sometimes forcing the end of the experiment.

Comparing the known amount of pyrolysis oil fed to the system during steady-state (values obtained from the weighing scale under the feeding bottle) and the sum of the mass of aqueous and oil phases and the mass of the gases produced, the mass balance could be determined. For all the experiments described in this paper, the mass balance closure was between 96 and $101 \%$ (being between 94 and $102 \%$ when the dry yields and water production are used). The wet elemental balances were 100-107 wt.\% (carbon), 93-103 wt.\% (hydrogen) and 91-99 wt.\% (oxygen).

\subsection{Effect of temperature}

The minimum temperature during the experiments was $200^{\circ} \mathrm{C}$ as below this temperature HPTT reactions could not be observed. A maximum temperature of $350{ }^{\circ} \mathrm{C}$ was used to avoid water in the super critical state $\left(374{ }^{\circ} \mathrm{C}\right)$ and prevent excessive char formation/product deterioration. During these experiments the other operating conditions such as residence time and pressure were kept (approximately) constant with the following values:

- Residence time: 3.3 - 3.5 minutes (less than 10\% of this residence time was used to heat the oil in the pre-heater).

- Pressure: 200 bar.

The results shown for the experiment at $350{ }^{\circ} \mathrm{C}$ correspond to an experiment carried out at 240 bar. This was done because at a pressure of 200 bars and $350{ }^{\circ} \mathrm{C}$, the lines clogged by char.

The properties (elemental composition and water content) of the liquid products are shown in Table 2. It can be seen that, for the oil phase, the water content was reduced as compared to the original pyrolysis oil. The oxygen content also decreased considerably with the temperature. 
Table 2. Liquid product properties after HPTT at different temperature (residence time of $3.4 \pm 0.1$ min; pressure of 200 bar, except experiment at $350{ }^{\circ} \mathrm{C}$ for which the pressure was 240 bar). Elemental composition on dry basis. Oxygen content determined by difference.

\begin{tabular}{ccccccccc}
\hline \multirow{2}{*}[{}^{\circ}\mathrm{C}]{} & \multicolumn{2}{c}{200} & \multicolumn{2}{c}{260} & \multicolumn{2}{c}{300} & \multicolumn{2}{c}{350} \\
\cline { 2 - 9 } & $\begin{array}{c}\text { Oil } \\
\text { phase }\end{array}$ & $\begin{array}{c}\text { Aq. } \\
\text { phase }\end{array}$ & $\begin{array}{c}\text { Oil } \\
\text { phase }\end{array}$ & $\begin{array}{c}\text { Aq. } \\
\text { phase }\end{array}$ & $\begin{array}{c}\text { Oil } \\
\text { phase }\end{array}$ & $\begin{array}{c}\text { Aq. } \\
\text { phase }\end{array}$ & $\begin{array}{c}\text { Oil } \\
\text { phase }\end{array}$ & $\begin{array}{c}\text { Aq. } \\
\text { phase }\end{array}$ \\
\hline $\mathrm{C}[w t . \%]$ & 62.7 & 52.4 & 68.4 & 51.3 & 71.5 & 48.6 & 73.5 & 47.6 \\
$\mathrm{H}[\mathrm{wt} . \%]$ & 6.2 & 7.1 & 6.1 & 8.3 & 6.3 & 7.3 & 6.5 & 7.7 \\
$\mathrm{O}[\mathrm{wt} . \%]$ & 31.1 & 40.5 & 25.5 & 40.3 & 22.2 & 42.9 & 20 & 43.3 \\
$\mathrm{H} 2 \mathrm{O}[\mathrm{wt} . \%]$ & 15.7 & 36.6 & 14.9 & 62.8 & 9.9 & 68.3 & 9.1 & 70.6 \\
\hline
\end{tabular}

The dry yields of the phases obtained, $\eta_{i}(d r y)$, and the water produced, $\eta_{\text {water produced, }}$ after HPTT of pyrolysis oil are shown in Figure 4 as a function of temperature. Although yields are traditionally expressed using wet yields, the graph of the dry yield (as defined in Eq.2) gives more insight in the phenomena occurring during the HPTT process. The $\eta_{\text {oil }}(d r y)$ went through a maximum at approximately $260{ }^{\circ} \mathrm{C}$. At the same time, the dry yield of organics present in the aqueous phase, $\eta_{\text {aqueous }}(d r y)$, decreased with temperature between 200 and $260{ }^{\circ} \mathrm{C}$ but became stable between $260-300{ }^{\circ} \mathrm{C}$. This indicates that, at a temperature between 200 and $260{ }^{\circ} \mathrm{C}$ there was net transfer of organics from the aqueous phase to the oil phase accompanied by the formation of some water and gas. At further increasing temperature $\left(260-350{ }^{\circ} \mathrm{C}\right)$, the production of gas steadily increased probably at the expense of the oil yield, as the $\eta_{\text {aqueous }}(d r y)$ was approximately constant. The gases produced were mainly $\mathrm{CO}_{2}$ with some small amounts of $\mathrm{CO}$ and other gases; the ratio depending on the temperature (Table 3 ). The $\eta_{\text {water }}$ produced follows the same trend as the gas yield, although at a somewhat higher absolute level suggesting that deoxygenation by dehydration can start at milder conditions than deoxygenation by decarboxylation.

Table 3. Gas composition of HPTT experiments at different temperatures.

\begin{tabular}{cccccc}
\hline \multirow{2}{*}[{}^{\circ}\mathrm{C}]{} & \multicolumn{5}{c}{ Gas composition [mol\%] } \\
\cline { 2 - 6 } & $\mathrm{H}_{2}$ & $\mathrm{CH}_{4}$ & $\mathrm{CO}$ & $\mathrm{CO}_{2}$ & $\mathrm{C} 2-\mathrm{C} 3$ \\
\hline 200 & 0 & 0 & 4.4 & 95.1 & 0.5 \\
260 & 0.8 & 0.1 & 5.2 & 90.3 & 3.6 \\
300 & 1.3 & 0.2 & 7.7 & 87.0 & 3.7 \\
350 & 1.1 & 1.2 & 13.1 & 79.3 & 5.3 \\
\hline
\end{tabular}

Figure 5 shows the results of VTT's solvent fractionation technique applied to the aqueous phase products. In this figure, a remarkable decrease of the sugar constituents with increase in temperature can be seen. Knežević et al. [12] showed that during the treatment of aqueous solutions of glucose under similar HPTT conditions, among others, water and a polymerised product were obtained. Combining this information with the 
current observations that water was produced and the oil yield increased, it is likely that the sugar constituents present in the aqueous phase underwent dehydration and probably polymerisation, and the resulting product was transferred to the oil phase. To prove that this polymerisation occurred, GPC analyses were performed to the original feed, the oil phase and the aqueous phase (Figure 6). A considerable increase in the molecular weight of the oil phase as compared to the untreated oil was observed, confirming that polymerisation had occurred during HPTT of pyrolysis oil. Because a part of the organics from the aqueous phase was transferred to the oil phase (extractives, LMM lignin, HMM lignin and most likely also the HPTT products of the sugars), it can be concluded that for various components in the aqueous phase a change in polarity took place upon HPTT. Besides that, it is likely that also the overall polarity of the organic phase decreased, which can be derived from the lower water content in the oil phase (Table 2).

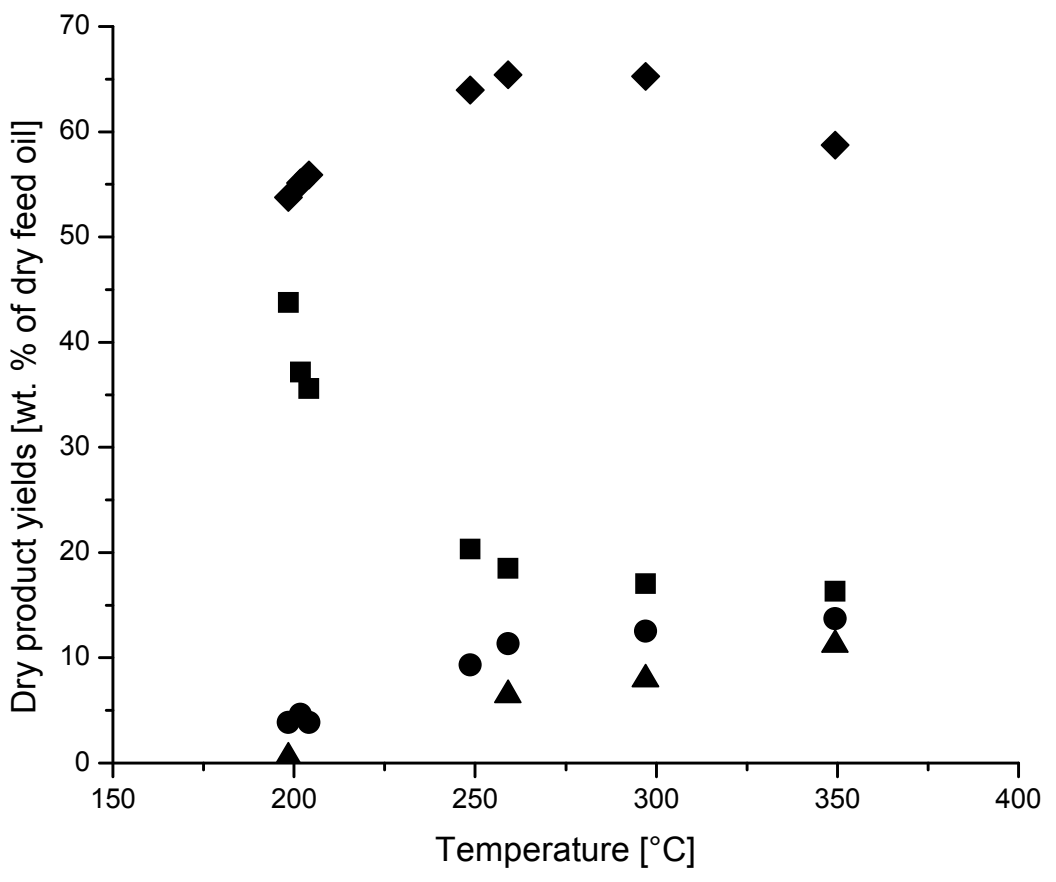

Figure 4. HPTT product dry phase yields at different temperatures including water production. Oil phase yield $(\bullet)$, aqueous phase yield $(\boldsymbol{\square})$, water produced yield $(\bullet)$ and gas phase yield $(\boldsymbol{\Delta})$.

After HPTT at different temperatures, there were clear differences in physical appearance of the resulting oil phases: at $200{ }^{\circ} \mathrm{C}$ it was a viscous liquid and at $350{ }^{\circ} \mathrm{C}$ a rubber-like material. However, the comparison of the GPC diagrams of these oil phases did not show any appreciable differences (results not shown). This apparent controversy might be caused by the poor solubility of the very heavy compounds in the solvent used 
for GPC analysis (THF), keeping these compounds in the filter during sample preparation.

To be able to properly compare the HPTT oil phase and the 'oil phase' of the original feed, water was added to pyrolysis oil at room temperature, forcing a phase split [13]. For this, $25.5 \mathrm{~g}$ of water was added to $50.4 \mathrm{~g}$ of pyrolysis oil under stirring. The mixture was allowed to settle and two liquid fractions were obtained: an aqueous fraction $(60.2 \mathrm{~g})$ and an organic viscous oil fraction (15.6 g). This ratio was chosen because enough water was used to clearly produce two liquid fractions and to avoid producing powder pyrolytic lignin [14]. The oil fraction obtained after water addition (OFWA) was separated from the aqueous fraction and used for comparison with the oil phases obtained after HPTT.

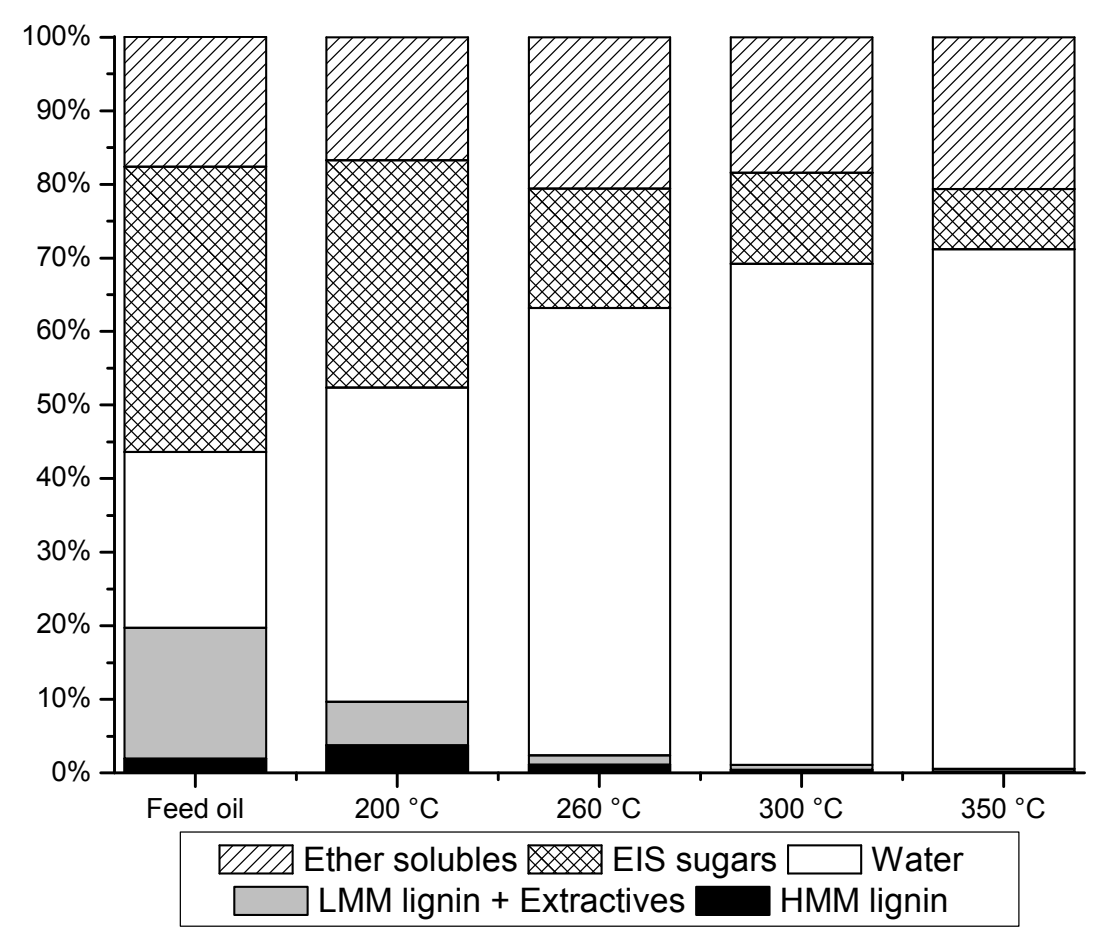

Figure 5. Results of VTT's solvent fractionation technique applied to the aqueous phase product obtained at various HPTT temperatures. 


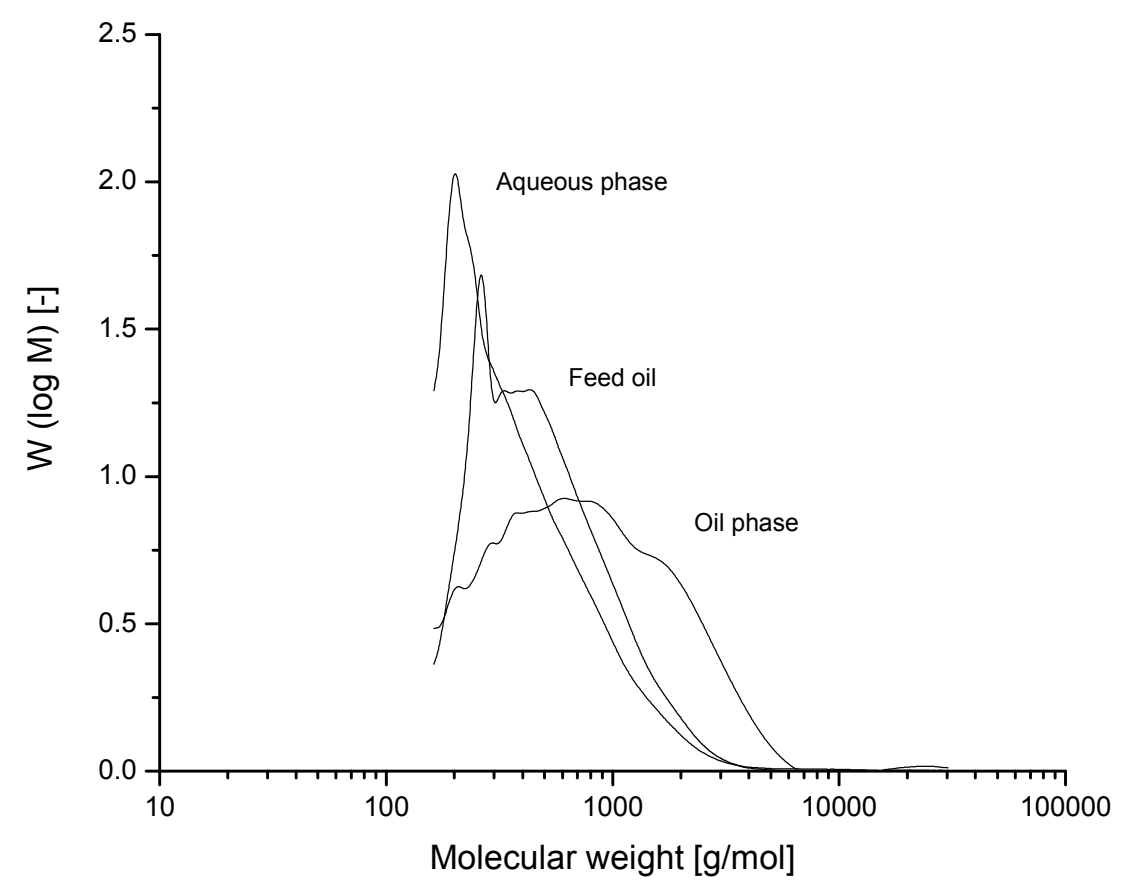

Figure 6. Molecular weight distribution obtained by GPC analysis of the original pyrolysis oil (feed oil) and the products obtained by HPTT at $200^{\circ} \mathrm{C}, 3.4 \mathrm{~min}, 198$ bar. Analysis performed by vTI.

From the elemental analysis and the water content of the oil phase products, dry $\mathrm{H} / \mathrm{C}$ and $O / C$ molar ratios could be determined (Eq. 7 and 8). This ratio was also calculated for the original oil and for the OFWA. Figure 7 shows that after a major reduction of the $\mathrm{O} / \mathrm{C}$ ratio when pyrolysis oil was processed at $200{ }^{\circ} \mathrm{C}$, higher temperatures did not significantly reduce it. This major reduction of the $\mathrm{O} / \mathrm{C}$ ratio was most likely caused by phase splitting that occurred during HPTT, as the same decrease in $O / C$ ratio was observed for OFWA (open symbols in Figure 7). The subsequent reduction of the $O / C$ ratio was due to the production of gases (especially $\mathrm{CO}_{2}$ ) and the formation of water by dehydration. The $H / C$ ratio did not vary significantly for the oil phase indicating that the water produced came from the organics present in the aqueous phase.

The reduction of oxygen and water content (see Table 2) in the oil phase had a direct effect on its energy content. Figure 8a shows the increase of the HHV of the oil phase, calculated using the Reed's formula (Eq. 9), with temperature. The HHV of the oil phase was, in all cases, higher than the original oil (value also calculated from Eq. 9). The yield of the OFWA was very low (31 wt.\%) compared to the yield of the oil phase obtained during HPTT (between 50 and 60 wt.\%). Figure $8 \mathrm{~b}$ shows the HHV corrected by the oil phase yields. It can be seen that while the OFWA just took part of the energy of the feed oil, HPTT concentrated the energy in the oil phase. This is likely to be caused by the transfer of sugar constituents from the aqueous phase to the oil phase, as demonstrated in Figure 5. 


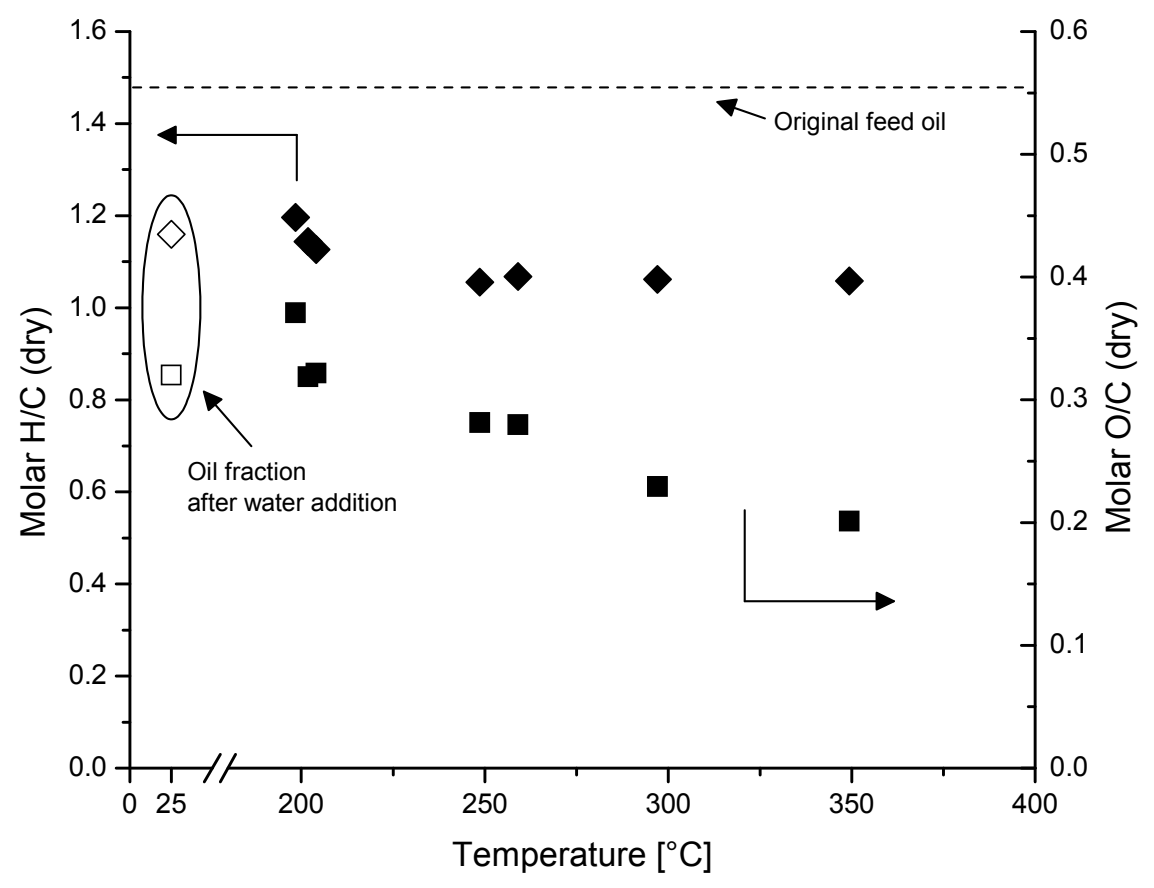

Figure 7. Molar $H / C$ ( $\bullet$; left axis) and $O / C$ ( $\mathbf{\square}$; right axis) ratios of dry oil phase at different temperatures. Empty marks correspond to the values of molar $H / C(\diamond)$ and $O / C(\square)$ for the unprocessed oil fraction obtained by adding water (OFWA) to crude pyrolysis oil and forcing phase separation (on dry basis).

\subsection{Effect of residence time}

Two series of experiments were carried out at different residence times keeping the temperature constant (first series at $260{ }^{\circ} \mathrm{C}$ and a second series was carried out at 300 ${ }^{\circ} \mathrm{C}$ ). The residence times applied (including heating up time) were:

$-260{ }^{\circ} \mathrm{C}: 1.5,2$ and $3.5 \mathrm{~min}$.

$-300^{\circ} \mathrm{C}: 1.5,2.2$ and $3.5 \mathrm{~min}$.

The $\eta_{i}$ (dry) of the two series of experiments are shown in Figure 9. It can be seen that, in the experiments conducted at $260{ }^{\circ} \mathrm{C}$, the $\eta_{\text {water produced }}$ and $\eta_{\text {gas }}(d r y)$ increased with the residence time. On the other hand, at $300{ }^{\circ} \mathrm{C}$, the residence time had almost no influence on the yields. This shows that using longer residence times has the same influence, though to lesser extent, as increasing the temperature.

Elemental analysis of the oil phase products did not reveal a significant dependence on the residence time: $H / C$ ratios of the dry oil phase remained approximately constant and similar in both temperature series (from 1.02 to 1.06 for both series). $O / C$ ratios of the dry oil phase slightly decreased with increasing residence time; this reduction was at 260 ${ }^{\circ} \mathrm{C}$ from 0.33 to 0.28 and at $300{ }^{\circ} \mathrm{C}$ from 0.27 to 0.23 . 

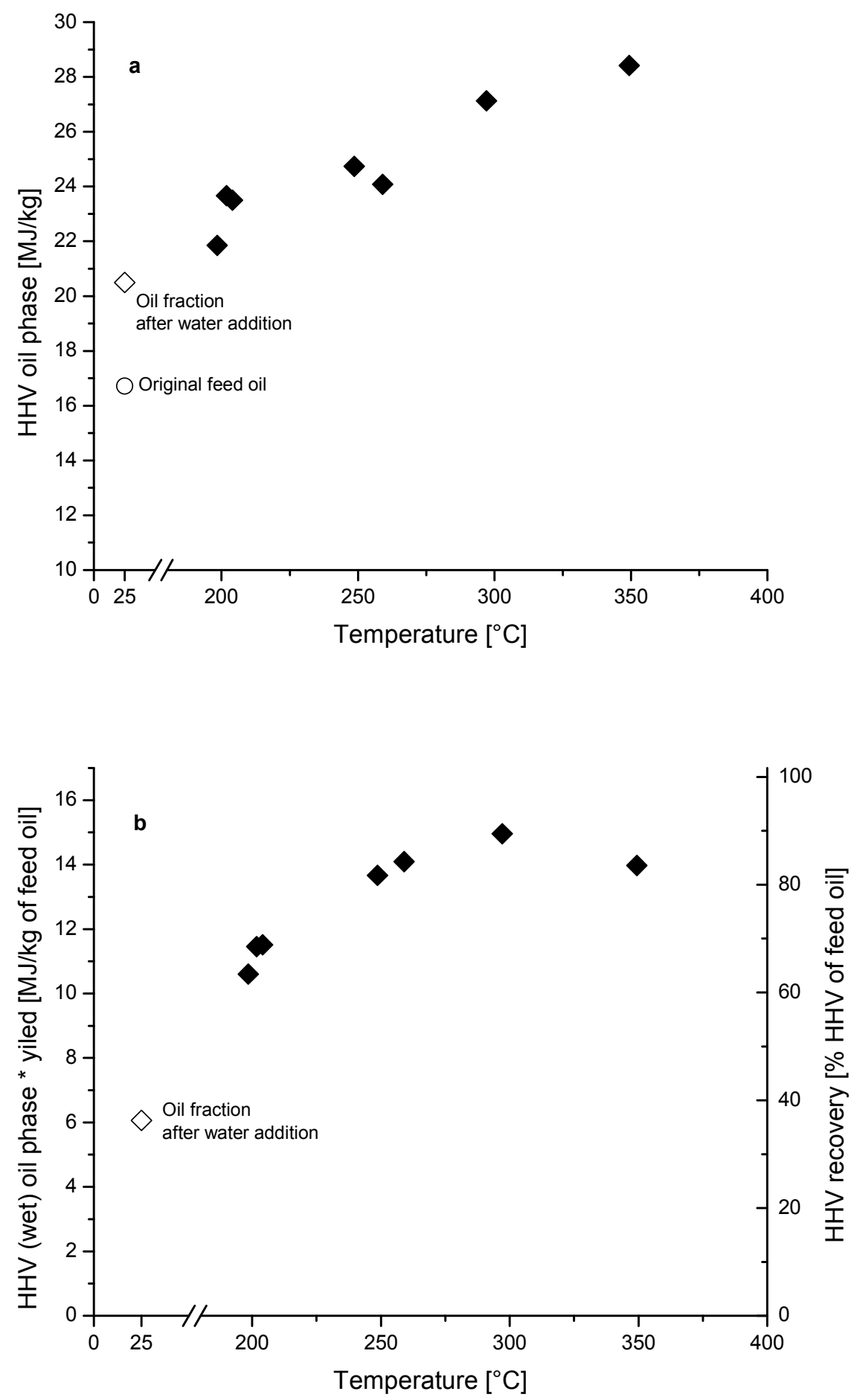

Figure 8. a) HHV of the oil phase obtained via HPTT $(\diamond)$, HHV of unprocessed oil fraction obtained by adding water to crude pyrolysis oil $(\diamond)$ and $\mathrm{HHV}$ of original feed oil $(\bigcirc)$. b) HHV oil phases corrected by their yield and HHV recovery of HPTT $(\diamond)$ and unprocessed oil fraction obtained by adding water to crude pyrolysis oil $(\diamond)$. 


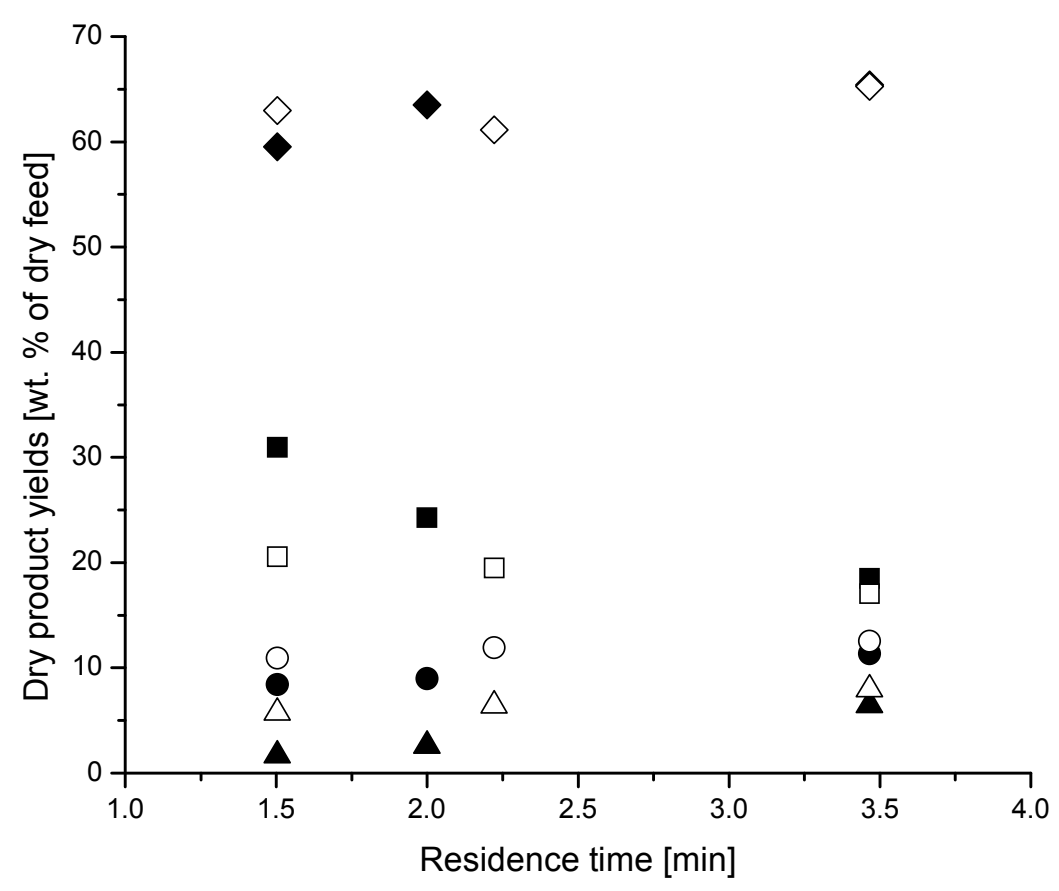

Figure 9. HPTT product dry phase yields at different residence times including water production. Experiment at $260{ }^{\circ} \mathrm{C}$ closed symbols, experiments at $300{ }^{\circ} \mathrm{C}$ open symbols. Oil phase yield $(\diamond, \diamond)$, aqueous phase yield $(\boldsymbol{\square}, \square)$, water produced yield $(\bullet, \bigcirc)$ and gas phase yield $(\boldsymbol{\Lambda}, \triangle)$.

\subsection{Effect of solvent addition (water dilution)}

Boocock and Sherman [15] studied the influence of the water/wood ratio during the liquefaction of poplar wood in aqueous media at temperatures of $370{ }^{\circ} \mathrm{C}$. Recently, Knežević et al. [12] studied the hydrothermal liquefaction of glucose at similar conditions as used in this study. In their studies, a significant effect of water/wood ratio and glucose concentration, respectively, was observed. These results from literature indicate that the HPTT product composition can be influenced by dilution of the pyrolysis oil with water.

Assuming that the undesired increase of molecular weight of pyrolysis oil during HPTT (as shown in Figure 6) was (partly) caused by the polymerisation of sugars, water was added to the feed to decrease the effective sugar concentration in pyrolysis oil and therewith suppress the extent of polymerisation as observed for glucose by Knežević et al. [12]. Details of the experimental set-up are given in Figure 2.

In this section, results of two experiments with water dilution are shown. Both experiments were carried out at $300{ }^{\circ} \mathrm{C}$ and with a volumetric dilution ratio of $1: 1$ (pyrolysis oil:water). The residence times were 1.7 and $3.8 \mathrm{~min}$, respectively. In Figure 10 , the molecular weight distribution of the product oil is compared to the molecular weight distribution of the oil obtained in two experiments at similar experimental 
conditions without solvent addition. It can be seen that, in the experiments without water addition, the molecular weight distribution was practically the same and independent of the residence time. On the other hand, when water was added to the system, the molecular weight of the products was reduced for both experiments and the effect of residence time appeared to be more significant. At short residence time, less heavy compounds seemed to be formed. These results indicate that dilution has an influence on the overall polymerisation kinetics.

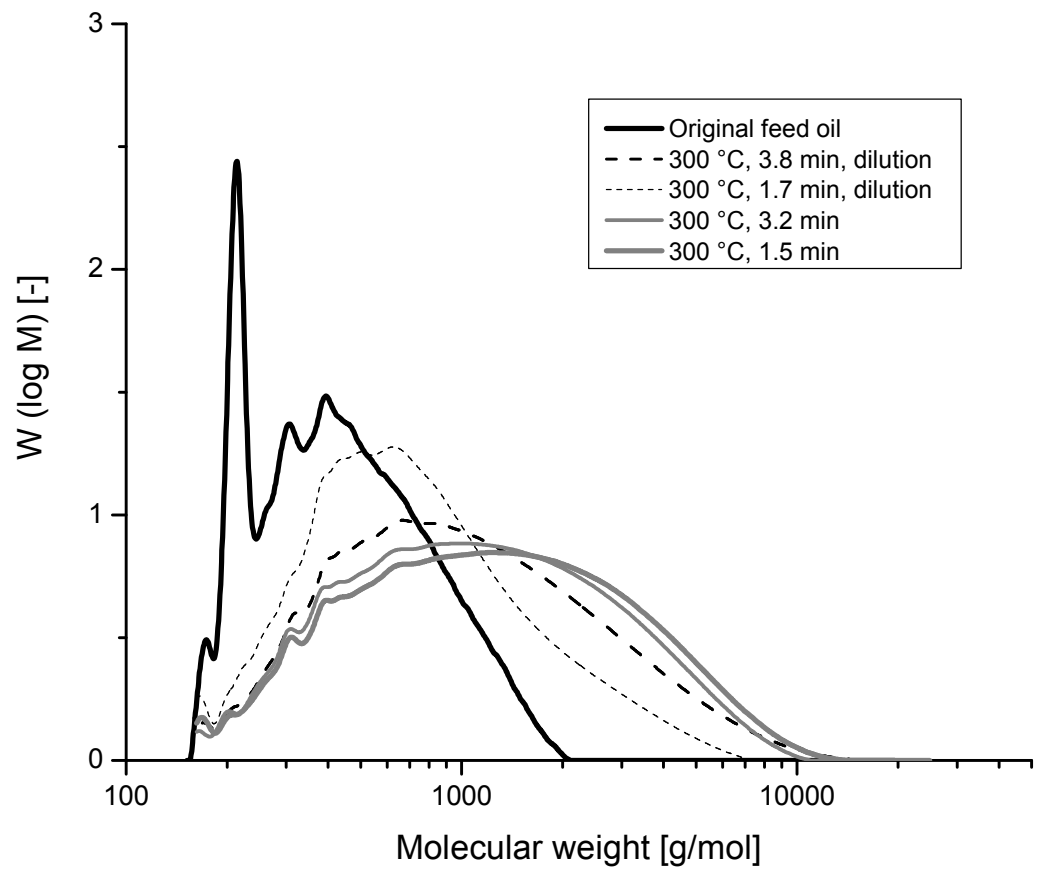

Figure 10. Molecular weight distribution obtained by GPC analysis of original pyrolysis oil (feed oil) and the oil phase products of HPTT experiments at $300{ }^{\circ} \mathrm{C}$ and 200 bar at different residence times. The solid lines correspond to experiments without dilution and the dashed lines correspond to experiments in which pyrolysis oil was diluted 1:1 in volume with water. Analysis performed by University of Twente.

Table 4 shows the production of $\mathrm{CO}_{2}$ (wt.\% of feed) for the same experiments described in the previous paragraph. It shows the production of $\mathrm{CO}_{2}$ (that would reduce the oxygen content in the oil product) also decreased when water was added to the system. This is an undesired effect because the addition of solvent was meant to reduce the rate of formation of heavy compounds, while maintaining the same level of decarboxylation. However, these results suggest that the increase of molecular weight and the production of $\mathrm{CO}_{2}$ are related. Based on the current results, it is not possible to state whether decarboxylation and polymerisation are indeed the consequence of one (type of) reaction, or the independent result of various decoupled reactions. Only in the last case, 
it would be possible to achieve high levels of desired decarboxylation while preventing undesired polymerisation.

Table 4. Decarboxylation $\left(\mathrm{CO}_{2}\right.$ produced for $100 \mathrm{~g}$ of feed) of HPTT process at $300{ }^{\circ} \mathrm{C}$ and 200 bar at different residence times with and without water addition.

\begin{tabular}{lcc}
\hline & Residence time $(\mathrm{min})$ & $\begin{array}{c}\text { Decarboxylation } \\
\left(\mathrm{wt} . \% \mathrm{CO}_{2}\right)\end{array}$ \\
\hline Without water addition & 1.5 & 3.7 \\
& 3.2 & 4.7 \\
With water addition (1:1) & 1.7 & 1.8 \\
& 3.8 & 4.6 \\
\hline
\end{tabular}

\section{Discussion}

The process temperature has a direct and significant effect on product yields and composition. The yield of the dry oil phase, $\eta_{\text {oil }}(d r y)$ went through a maximum between 260 and $300{ }^{\circ} \mathrm{C}$. The increase of $\eta_{\text {oil }}(d r y)$ in this temperature range was most likely caused by the polymerisation of the sugar constituents of pyrolysis oil, which otherwise would have remained in the aqueous phase. At temperatures above $300{ }^{\circ} \mathrm{C}$, organics were being converted and transferred to the gas phase, thereby reducing the $\eta_{\text {oil }}(d r y)$ again. A significant reduction of the oxygen and water content already occurs due to the (non-reactive) phase separation of the aqueous and organic phase. However, at increasing temperatures, the oxygen content further reduces, but in a less significant manner than already caused by the phase separation. This further reduction in oxygen content was caused by the production of $\mathrm{CO}_{2}$ and water. The phase separation on one hand and the decarboxylation/dehydration on the other resulted in an increase of the energy value of the oil. The oil obtained after HPTT had a higher energy density (wet $\mathrm{HHV}$ ranging from 21.8 to $28.4 \mathrm{MJ} / \mathrm{kg}$, depending on the temperature of the process, see Figure 8a) compared to the original pyrolysis oil (wet HHV $16.7 \mathrm{MJ} / \mathrm{kg}$ ). Taking into account the yields of HPTT oil obtained, the recovery of energy from the starting oil in the HPTT product oil was $63 \%$ at $200{ }^{\circ} \mathrm{C}, 82 \%$ at $260{ }^{\circ} \mathrm{C}, 89 \%$ at $300{ }^{\circ} \mathrm{C}$ and $84 \%$ at $350{ }^{\circ} \mathrm{C}$. As reference, the energy of the oil fraction obtained by adding water to pyrolysis oil (OFWA) was just $36 \%$ of the starting oil. These results, together with the analyses of the aqueous phase products (Figure 5), indicate that, from $200^{\circ} \mathrm{C}$ to $300{ }^{\circ} \mathrm{C}$, there was a transfer of energy from the aqueous phase to the oil phase. At $350{ }^{\circ} \mathrm{C}$, some of the energy was transferred from the liquid phase to the gas phase, possibly induced by high temperature cracking. Therefore, this study indicates that HPTT concentrates the energy of pyrolysis oil substantially making it useful as energy carrier, further reducing the transportation costs as compared to untreated pyrolysis oil. From the organics that remain in the aqueous phase, value added chemicals may be recovered or the whole 
fraction can be gasified via steam reforming $[16,17]$ or supercritical water gasification $[18,19]$ to obtain hydrogen or synthesis gas.

Dilution of pyrolysis oil with water caused the decrease of the rate of formation of heavy compounds. However, the rate at which $\mathrm{CO}_{2}$ was formed was also reduced. Therefore, the addition of water had positive and negative effects. At this stage it is not known whether decarboxylation and polymerisation are part of the same type of reaction or can be decoupled.

Although the oxygen and water content of the HPTT oil phase was considerably lowered with respect to untreated pyrolysis oil, miscibility tests showed that it was still completely immiscible with a conventional heavy refinery stream, Long Residue (properties of this oil can be found in Chapter 3). This shows that oxygen and water content are not the only parameters that determine the quality of the upgraded product with respect to co-refining possibilities but other aspects (one of them most likely being the molecular weight distribution) are probably also of importance. Further upgrading of the HPTT oil by HDO is an option that can be explored, as one of the obstacles of HDO of untreated pyrolysis oil is its high hydrogen consumption [6]. Since the HPTT oil phase has a much lower oxygen (between 20 and 27 wt.\% on dry basis) than the original oil (40 wt.\% on dry basis), the stoichiometric amount of hydrogen needed to convert oxygen into water is considerably reduced when using HPPT oil in HDO. Besides that, there are two other possible influences of the pre-treatment of pyrolysis oil via HPTT which might benefit the HDO process:

1. The lower content of light components and water in the oil phase might enable a higher hydrogen partial pressure at the same total reactor pressure thereby possibly reducing the required reaction times.

2. Components that remain in the water phase after HPTT are to a large extent acids and other small molecules (see Figure 5), which are not likely to yield transportation fuel type components. Hydrogen consumption of these components during HDO is prevented as the aqueous fraction would be excluded from HDO.

One possible problem that has to be investigated is if the higher molecular weight components formed during HPTT are refractive towards further processing by HDO. Especially then, ways to prevent polymerisation during HPTT, like water dilution, are of crucial importance. 


\section{Conclusions}

The current work has shown that the high pressure thermal treatment (HPTT) is an effective way to reduce the oxygen and water content of pyrolysis oil, thereby also substantially increasing the energy density.

The main phenomenon observed during HPTT of pyrolysis oil is a phase separation that is provoked by the change of polarity of various compounds. This is likely to be caused by dehydration, decarboxylation and probably polymerisation reactions. All these reactions are fast: the residence time did not have significant influences between 1.5 and $3.7 \mathrm{~min}$. The process temperature (varied between 200 and $350{ }^{\circ} \mathrm{C}$ ) had a much larger influence on product yields and properties. Dilution of the organic components changes the speed of some of these reactions. However, it is not yet clear if the desired decarboxylation and the undesired increase of molecular weight are part of the same or different reaction paths.

Despite the reduction of oxygen and water content, the HPTT oil proved to be immiscible with a conventional heavy refinery stream (Long Residue). Further processing of HPTT oil via $\mathrm{HDO}$, might be an option that could reduce the $\mathrm{H}_{2}$ consumption during $\mathrm{HDO}$ as compared to direct HDO of pyrolysis oil. 


\section{Nomenclature}

$\begin{array}{ll}\eta_{i}(\text { wet }) & \text { Wet yield of phase } i[\mathrm{wt} . \%] \\ \eta_{i}(d r y) & \text { Dry yield of phase } i[\mathrm{wt} . \%] \\ \eta_{\text {water produced }} & \text { Water produced yield [wt.\%] } \\ M_{i} & \text { Mass phase } i[\mathrm{~kg}] \\ \mathrm{H}_{2} \mathrm{O}_{i} & \text { Water content phase } \mathrm{i}[\mathrm{wt} . \%] \\ C_{d r y, i} & \mathrm{C} \text { content phase } i \text {, dry basis [wt.\%] } \\ H_{d r y, i} & \mathrm{H} \text { content phase } i \text {, dry basis [wt.\%] } \\ \mathrm{O}_{d r y, i} & \text { O content phase } i \text {, dry basis [wt.\%] } \\ M W_{j} & \text { Molecular weight element } j[\mathrm{~g} / \mathrm{mol}] \\ \mathrm{H} / \mathrm{C} & \text { Dry molar } \mathrm{H} / \mathrm{C} \text { ratio } \\ \text { O/C } & \text { Dry molar O/C ratio } \\ \mathrm{HHV} & \text { Higher heating value [MJ/kg] } \\ \mathrm{HPTT} & \text { High pressure thermal treatment } \\ \text { FCC } & \text { Fluid catalytic cracking } \\ \text { HDO } & \text { Hydrodeoxygenation } \\ \text { GPC } & \text { Gel permeation chromatography } \\ \text { THF } & \text { Tetrahydrofuran } \\ \text { OFWA } & \text { Oil fraction obtained by water addition }\end{array}$




\section{References}

[1] Bridgwater AV, Peacocke GVC. Fast pyrolysis processes for biomass. Renew. Sust. Energ. Rev. 2000;4:1-73.

[2] Oasmaa A, Czernik S. Fuel oil quality of biomass pyrolysis oils-State of the art for the end users. Energy Fuels. 1999;13:914-921.

[3] Czernik S, Bridgwater AV. Overview of applications of biomass fast pyrolysis oil. Energy Fuels. 2004;18:590-598.

[4] Samolada MC, Vasalos IA. Catalytic cracking of biomass flash pyrolysis liquids. In: A.V. Bridgwater and D.G.B. Boocock editors. Developments in Thermochemical Biomass Conversion, London: Blackie Academic \& Professional. 1997; p. 657-671.

[5] Lappas AA, Bezergianni S, Vasalos IA. Production of biofuels via co-processing in conventional refining processes. Catal. Today. 2008;145:55-62.

[6] Elliott DC. Historical developments in hydroprocessing bio-oils. Energy Fuels. 2007;21:1792-1815.

[7] Rep M, Venderbosch RH, Assink D, Tromp W, Kersten SRA, Prins W, Van Swaaij WPM. De-oxygenation of bio-oils. In: A.V. Bridgwater and D.G.B. Boocock editors. Science in thermal and chemical biomass conversion, Chippenham: CLP Press. 2006; p. 1526-1535.

[8] Oasmaa A, Solantausta Y, Arpiainen V, Kuoppala E, Sipila K. Fast pyrolysis bio-oils from wood and agricultural residues. Energy Fuels. 2009; 2009;24:1380-1388.

[9] Oasmaa A, Kuoppala E, Solantausta Y. Fast pyrolysis of forestry residue. 2. Physicochemical composition of product liquid. Energy Fuels. 2003;17:433-443.

[10] Domalski ES, Jobe (Jr.) TL, Milne TA, Thermodynamic data for biomass materials and waste components. The American Society of Mechanical Engineers, New York, 1987.

[11] Knežević D, Van Swaaij WPM, Kersten SRA. Hydrothermal conversion of biomass: II, Conversion of wood, pyrolysis oil, and glucose in hot compressed water. Ind. Eng. Chem. Res. 2010;49:104-112. 
[12] Knežević D, Van Swaaij WPM, Kersten SRA. Hydrothermal conversion of biomass: I, Glucose conversion in hot compressed water. Ind. Eng. Chem. Res. 2009;48:4731-4743.

[13] Radlein D. The production of chemicals from fast pyrolysis bio-oils. In: A.V. Bridgwater editor. Fast pyrolysis of biomass. A handbook, Newbury, Berkshire: CLP Press; 1999, p. 164-185.

[14] Scholze B, Meier D. Characterization of the water-insoluble fraction from pyrolysis oil (pyrolytic lignin). Part I. PY-GC/MS, FTIR, and functional groups. J. Anal. Appl. Pyrol. 2001;60:41-54.

[15] Boocock DGB, Sherman KM. Further aspects of powdered poplar wood liquefaction by aqueous pyrolysis. Can. J. Chem. Eng. 1985;63:627-633.

[16] Czernik S, French R, Feik C, Chornet E. Hydrogen by catalytic steam reforming of liquid byproducts from biomass thermoconversion processes. Ind. Eng. Chem. Res. 2002;41:4209-4215.

[17] Van Rossum G, Kersten SRA, van Swaaij WPM. Staged catalytic gasification/steam reforming of pyrolysis oil. Ind. Eng. Chem. Res. 2009;48:5857-5866.

[18] Kersten SRA, Potic B, Prins W, Van Swaaij WPM. Gasification of model compounds and wood in hot compressed water. Ind. Eng. Chem. Res. 2006;45:4169-4177.

[19] Van Rossum G, Potic B, Kersten SRA, van Swaaij WPM. Catalytic gasification of dry and wet biomass. Catal. Today. 2009;145:10-18. 


\section{Production of advanced}

biofuels: Co-processing of upgraded pyrolysis oil in standard refinery units

One of the possible process options for the production of advanced biofuels is the coprocessing of upgraded pyrolysis oil in standard refineries. The applicability of hydrodeoxygenation (HDO) was studied as a pyrolysis oil upgrading step to allow FCC co-processing. Different HDO reaction end temperatures $\left(230-340{ }^{\circ} \mathrm{C}\right)$ were evaluated in a 5 I autoclave, keeping the other process conditions constant (total 290 bar, 5 wt.\% Ru/C catalyst), in order to find the required oil product properties necessary for successful FCC co-processing (miscibility with FCC feed and good yield structure: little gas/coke make and good boiling range liquid products). After HDO, the upgraded pyrolysis oil underwent phase separation resulting in an aqueous phase, some gases (mainly $\mathrm{CO}_{2}$ and $\mathrm{CH}_{4}$ ), and an oil phase that was further processed in a Micro-Activity Test (MAT) reactor (simulated FCC reactor). Although the oil yield remained approximately constant when the HDO reaction temperature was increased, a net transfer of organic components (probably hydrodeoxygenated sugars) from the aqueous phase to the oil phase was observed, increasing the carbon recovery in the oil product (up to 70 wt.\% of the carbon in pyrolysis oil).

The upgraded oils were subsequently tested in a lab-scale catalytic cracking unit (MAT reactor), assessing the suitability of HDO oils to be used as FCC feed. In spite of the relatively high oxygen content (from $17 \mathrm{wt} \%$ to $28 \mathrm{wt} . \%$, on dry basis) and the different properties of the HDO oils, they all could be successfully dissolved in and co-processed (20 wt.\%) with a Long Residue, yielding near normal FCC gasoline (44-46 wt.\%) and Light Cycle Oil (23-25 wt.\%) products without an excessive increase of undesired coke and dry gas, as compared to the base feed only. Near oxygenate-free bio-hydrocarbons were obtained, probably via hydrogen transfer from the Long Residue. In this way, we have demonstrated on a laboratory scale that it is possible to produce hydrocarbons from ligno-cellulosic biomass via a pyrolysis oil upgrading route. The much higher coke yields obtained from the catalytic cracking of undiluted HDO oil showed the importance of co-processing using a refinery feed as a diluent and hydrogen transfer source. 



\section{Introduction}

First generation biofuels (bioethanol and biodiesel) are currently being used in many countries. Their utilisation can contribute to secure the supply of fuels and to the reduction of green-house-gas emissions, although the net energy value of some of them has been strongly questioned [1]. Advanced biofuels not only have the same advantages as the previously mentioned fuels, but also they do not compete with the food chain and they can be produced from a wider range of ligno-cellulosic biomass, including agricultural waste, wood, forest residues, etc. Several options are under development to produce advanced biofuels. Biomass can be gasified to produce synthesis gas followed by e.g. a Fischer Tropsch process. The process proposed in this work consists of coprocessing upgraded pyrolysis oil from ligno-cellulosic biomass in standard refinery units. The advantages of this process are:

- The use of decentralised pyrolysis plants that can be near the biomass production site. This means that only the oil is transported, reducing transportation costs due to the increase of the volumetric energy of the oil compared to the original biomass.

- After pyrolysis, large part of the minerals from biomass is not transferred to the oil but remain as ash. Thus, pyrolysis oil contains less inorganic material that could poison subsequent catalytic processes. Moreover, the ash can be returned to the soil as fertiliser.

- As the upgrading plant would be next to (or inside) the refinery, all the necessary utilities would be already available and the product obtained after co-processing could use the existing distribution network.

During fast (or flash) pyrolysis, dry solid biomass is rapidly heated to temperatures around $400-500{ }^{\circ} \mathrm{C}$ in the absence of oxygen, converting it into a liquid oil with yields up to $70-80$ wt.\% [2]. Char ( 5-10 wt.\%) and gas ( 20-30 wt.\%) are also produced. Pyrolysis oil (or bio-oil) is a mixture of oxygenated compounds formed during the decomposition of lignin and (hemi-)cellulose and water (generated during the process and from the initial moisture content of the biomass). The oxygen content is typically 45$50 \mathrm{wt} . \%$ and the water content 15-30 wt.\% [2]. Because of this, the heating value of pyrolysis oil (HHV $\sim 17 \mathrm{MJ} / \mathrm{kg}$ [2]) is low compared to fossil fuels (HHV $45 \mathrm{MJ} / \mathrm{kg}$ ). All these properties make the direct co-processing of pyrolysis oil itself in standard refinery units problematic. Several pyrolysis process modifications are currently being studied (hot-gas vapour filtration [3], catalysis [4]) to obtain an oil with better properties. In this study, pyrolysis oil from standard flash pyrolysis has been used as feed for upgrading.

Various upgrading routes have been studied until now: hydrodeoxygenation (HDO) to remove the oxygen as water under high pressures of hydrogen and in the presence of a catalyst [5]; catalytic cracking using zeolites [6]; and high pressure thermal treatment (HPTT, as introduced in Chapter 2), in which pyrolysis oil is thermally treated to obtain an oil with a higher energy density. Previous research on HDO suggested that a two- 
stage process is preferred to prevent excessive coke formation during HDO [7]. In the first step at relatively low temperature $\left(\sim 150-175^{\circ} \mathrm{C}\right)$, pyrolysis oil is stabilised and in a second step at higher temperature $\left(\sim 350-380^{\circ} \mathrm{C}\right)$ deep deoxygenation $(>95 \%)$ could be achieved [8]. The main concern about this process is the high hydrogen consumption (> $800 \mathrm{NI} / \mathrm{kg}$ feed). After catalytic cracking of crude pyrolysis oil, gasoline range products were obtained [9]. However, at low temperatures $\left(370{ }^{\circ} \mathrm{C}\right)$ the amount of oxygenated compounds was high and at higher temperatures $\left(410^{\circ} \mathrm{C}\right)$, the production of coke and gas increased at the expense of the gasoline yield [10]. As already shown in Chapter 2, during HPTT of pyrolysis oil, phase separation occurs producing an aqueous phase (15$35 \mathrm{wt.} \%$ dry basis), an oil phase (55-65 wt.\% dry basis), gas (0-10 wt.\% dry basis) and water (5-15 wt.\% dry basis). Experimental results showed that, with increasing temperatures, the release of gases (mainly $\mathrm{CO}_{2}$ ) and the production of water increased, reducing the oxygen content (from $40.1 \mathrm{wt}$ \% to $20.0 \mathrm{wt} \%$, on dry basis) of the oil phase and hence increasing the energy content (from 14.1 to $28.4 \mathrm{MJ} / \mathrm{kg}$ ). This increase of energy density was due to the transfer of organic components from the aqueous phase to the oil phase. However, an increase of the average molecular weight of the oil, probably caused by the polymerisation of the sugar constituents of the oil, was also detected.

Baldauf et al. [11] proposed the use of hydrotreated pyrolysis oil in standard refineries. From the properties of the hydrotreated pyrolysis oil, they concluded that it should be sent to the distillation tower where the fractions could be diluted in different refinery cuts and be sent for further processing. Co-processing of upgraded pyrolysis oil was studied by Samolada et al. [12]. In their research, a heavy and a light fraction were obtained by thermal hydrotreatment of flash pyrolysis oil (Union Fenosa, Spain). The heavy fraction, with and oxygen content of $4.9 \mathrm{wt} \%$ (wet basis), was catalytically cracked in a MAT reactor, with a dilution ratio of 15 / 85 heavy fraction / LCO (in weight basis). They obtained gasoline yields between $20-25 \mathrm{wt}$. \% and coke yields between 0.8 and $1.4 \mathrm{wt} . \%$. Lappas et al. [13] co-processed the same heavy fraction as Samolada et al. but diluting it in LCO and VGO. The product yields of co-processing were approximately $1 \mathrm{wt} . \%$ higher for gasoline and LCO and $0.5 \mathrm{wt} . \%$ higher for coke, compared to the yields obtained after catalytic cracking of pure VGO. UOP LLC [14] patented a process for the hydrotreatment of the pyrolysis oil lignin fraction and the subsequent hydrocracking of the organic phase product (oxygen content of $5.9 \mathrm{wt} . \%$ ), obtaining a gasoline yield of 30 wt. \% (from the original lignin fraction).

In this chapter, the results of the batch wise hydrodeoxygenation of pyrolysis oil (experiments by University of Twente) and the subsequent co-processing in a lab-scale FCC fluidised bed reactor (experiments by Shell Global Solutions) are presented and discussed. ${ }^{1}$ In the first part, the effect of different experimental HDO conditions on the

\footnotetext{
${ }^{1}$ The work described in this paper has been carried out within the framework of BIOCOUP EU research project [15]. Within the same project, the Biomass Technology Group (BTG) has prepared HDO oils using a packed bed reactor with similar subsequent co-processing of their oils by Shell Global Solutions.
} 
product yield and properties are shown. In the second part, the co-processing of the HDO oils with Long Residue oil in a lab-scale catalytic cracking reactor is evaluated. In this manner, a link between the HDO step (process conditions and oil product properties) and the catalytic cracking product yields can be established.

\section{Experimental section}

\subsection{Materials}

The pyrolysis oil used in the present work was produced in a $20 \mathrm{~kg} / \mathrm{h}$ process development unit from VTT, Finland [16]. The feedstock used to produce it was forest residue. More details about this feedstock can be found elsewhere [17]. i-Propanol (2 wt.\%) was added to the freshly prepared oil to increase homogeneity. A top phase (10.6 wt.\%) including most of the extractives was separated. A specification of the remaining phase, as used in the HDO upgrading experiments, is given in Table 1.

Table 1. Forest residue pyrolysis oil (bottom phase) properties (supplied by VTT).

\begin{tabular}{lc}
\hline Property & $\begin{array}{c}\text { Forest residue pyrolysis oil } \\
\text { (bottom phase) }\end{array}$ \\
\cline { 2 - 2 } Water $(\mathrm{wt} . \%)^{\mathrm{a}}$ & 25.0 \\
Solids $(\mathrm{wt} . \%)$ & 0.04 \\
Nitrogen (wt.\%) & 0.2 \\
Sulphur (wt.\%) & 0.01 \\
Carbon $(\mathrm{wt} . \%)^{\mathrm{a}}$ & 40.7 \\
Hydrogen $(\mathrm{wt} . \%)^{\mathrm{a}}$ & 8.04 \\
Viscosity, $40^{\circ} \mathrm{C}(\mathrm{cSt})$ & 16 \\
Density, $15^{\circ} \mathrm{C}(\mathrm{kg} / \mathrm{l})$ & 1.196 \\
$\mathrm{HHV}(\mathrm{MJ} / \mathrm{kg})$ & 16.8 \\
$\mathrm{LHV}(\mathrm{MJ} / \mathrm{kg})$ & 15.5 \\
pH & 2.6 \\
\hline $\mathrm{a}$ Analyses performed at University of Twente
\end{tabular}

The catalyst used in HDO experiments was ruthenium supported on carbon powder, as this has found to be a good and stable deoxygenation catalyst [18]. It was supplied by Sigma-Aldrich (product number 206180) with a metal loading of $5 \mathrm{wt} . \%$ and a particle size of around $14 \mu \mathrm{m}$. The catalyst has a BET surface area of $810 \pm 11 \mathrm{~m}^{2} / \mathrm{g}$ (total; micro pores only $=579 \mathrm{~m}^{2} / \mathrm{g}$ ). It was used without any further pre-treatment. Within the project this research takes part [15], studies on other catalysts are ongoing [19, 20]. 
For the co-processing experiments, a Long Residue from one of Shell's refineries was used. Detailed information about the Long Residue oil can be found in Appendix A. The catalyst used in these experiments was a typical equilibrium catalyst from one of Shell's FCC units.

\subsection{Experimental set-ups and procedure}

Pyrolysis oil upgrading experiments were carried out in a stirred autoclave (Andreas Hofer, Germany) with a total volume of $5 \mathrm{I}$, which was placed inside a high pressure box for safety reasons. The maximum operating temperature and pressure were $350{ }^{\circ} \mathrm{C}$ and 340 bar, respectively. Figure 1 shows the flow diagram of the set-up.

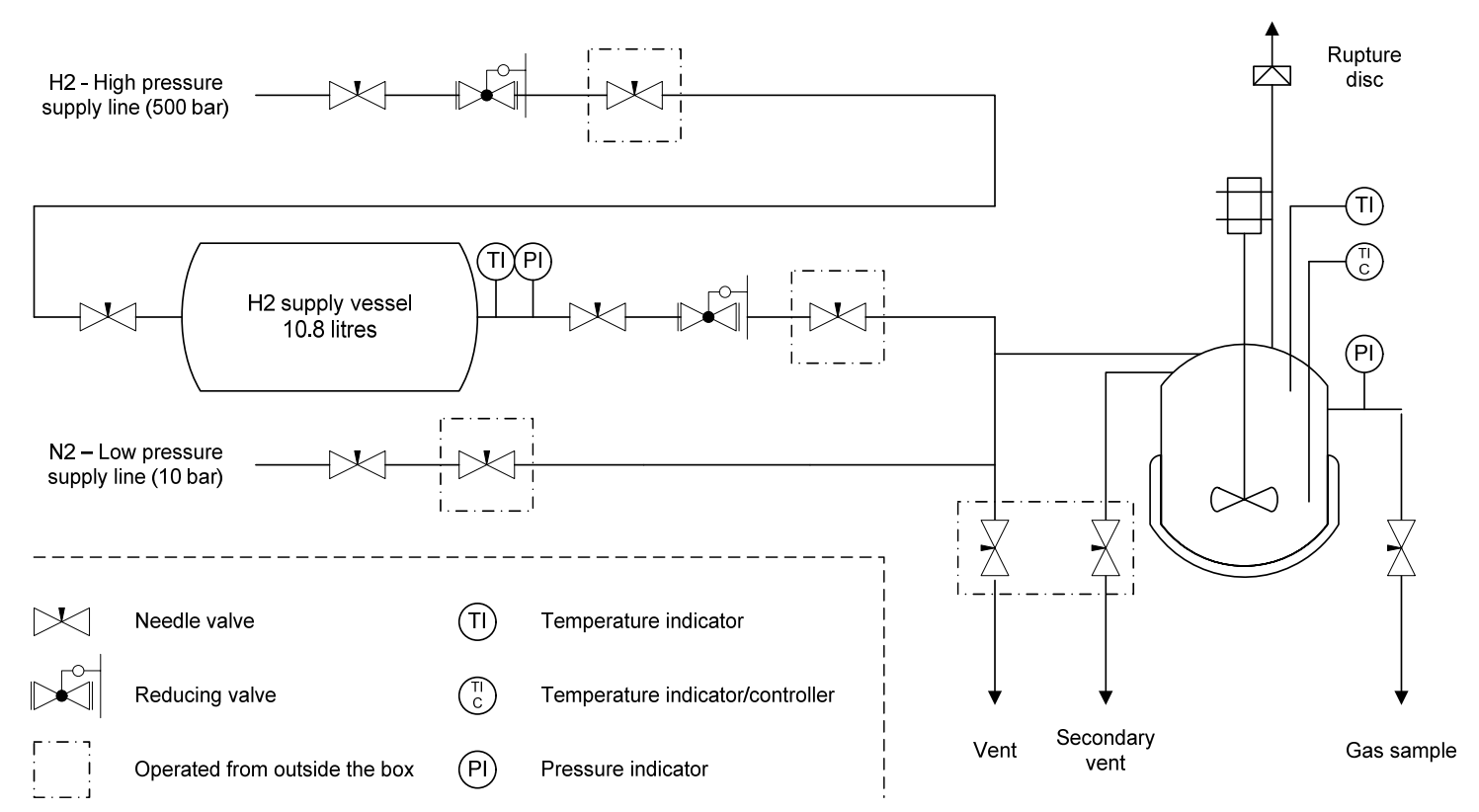

Figure 1. Flow diagram of the HDO set-up.

In a typical experiment, pyrolysis oil (2.5 kg approximately) was loaded into the reactor followed by 5 wt. \% of fresh (unused) catalyst. The autoclave was closed and flushed with nitrogen to remove air and a first leak test was performed. If no leakage was detected, the nitrogen was vented and a second leak test using $\mathrm{H}_{2}$ was performed at the same pressure as the reaction would take place. When the test was successful, the hydrogen was vented. A hydrogen supply vessel was used to feed the autoclave so quantification of the hydrogen consumption (rate) during the experiment was possible. This $\mathrm{H}_{2}$ supply vessel had a volume of $10.8 \mathrm{I}$ and it was typically loaded with an initial pressure of 400 bar. The autoclave was filled with $\mathrm{H}_{2}$ until the desired starting pressure (typically 200 bar) and the valve between the reactor and the supply vessel was closed. Then, the electrical 
heating jacket and the high intensity hollow shaft stirrer (2000 rpm) were started. The typical heating rate was approximately $5.5{ }^{\circ} \mathrm{C} / \mathrm{min}$ until $270{ }^{\circ} \mathrm{C}$, being slower after that $\left(\sim 4{ }^{\circ} \mathrm{C} / \mathrm{min}\right)$. This meant that it took from 1 to 2 hours to reach the desired reaction temperature. Because of the increase in temperature during heating, the total pressure initially increased until the hydrogen started to dissolve/react faster than the pressure increase caused by temperature. At this moment, more hydrogen was added to the reactor until the desired reaction pressure was reached (typically 290 bar). This pressure was regulated by a reducing valve. Strong hydrogen consumption was always observed at temperatures between 150 and $200{ }^{\circ} \mathrm{C}$, the temperature at which the stabilisation is claimed to occur [8]. Therefore, the 'stabilisation step' at lower temperature as reported in literature is thus an integrated, though not controlled, part of the experiment. A typical temperature profile as a function of time and the accompanying hydrogen consumption (estimated taking into account reactor and hydrogen supply vessel pressures corrected by the calculated water vapour pressure inside the reactor) is given in Figure 2 . The total reaction time at the desired end temperature (referred to as reaction temperature) was set for all the experiments at $4 \mathrm{~h}$ (excluding heating time). This reaction time was selected following the findings of Wildschut et al. [18], which showed that at $350{ }^{\circ} \mathrm{C}$ and 200 bar the oil yield was maximised. After 4 hours, the heating and the $\mathrm{H}_{2}$ supply were stopped and the stirrer was left on for $30 \mathrm{~min}$ more. The whole system was left to cool overnight. The final pressure and temperature of the reactor and the supply vessel were recorded, a gas sample was taken for analysis purposes and the system depressurised. After HDO, the liquid product consisted of either two or three phases (depending on the exact process conditions). If a three phase product was obtained, the top layer contained light organic components (top oil), the middle layer consisted mainly of water with some dissolved organics (aqueous phase) and the bottom layer was again organic and contained most of the catalyst (bottom oil). The product phases were separated, quantified and analysed.

Hydrogen consumption was calculated from the difference in pressure of the supply vessel between the beginning and the end of the experiment minus the hydrogen that remained un-reacted inside the autoclave before it was opened. To calculate the amount of hydrogen consumed, the density of hydrogen in the conditions of the supply vessel and reactor was needed. The Soave-Redlich-Kwong equation of state was used [21] to determine this value. This equation gave the smallest error $(\sim 0.5 \mathrm{~mol} \%)$ at the conditions of the supply vessel when compared to values determined experimentally [22]. Other equations like Peng-Robinson, Van der Waals and ideal gas gave errors up to 5, 7 and $25 \mathrm{~mol} \%$, respectively.

The HDO oils were filtered ( $5 \mu \mathrm{m}$ steel wire mesh filter) to remove the Ru/C catalyst.

For the co-processing experiments (performed by Shell Global Solutions), a fluidised bed MAT-5000 reactor was used. A MAT-5000 reactor is designed for unattended, automated operation and on-line GC product analysis for seven cat/oil ratios $(3,4,5,6$, 
6.5, 7 and 8) with in situ catalyst regeneration. $10 \mathrm{~g}$ of a FCC equilibrium catalyst was constantly fluidised with nitrogen. The feed (Long Residue, HDO oil or mixtures thereof) intake was varied to obtain results at different cat/oil ratios. The feed was introduced during $1 \mathrm{~min}$. After cracking, liquid products were collected in glass vessels at $-15^{\circ} \mathrm{C}$. The gas fraction was analysed by on-line GC. After stripping, the catalyst was regenerated, converting the coke to $\mathrm{CO}_{2}$, which was quantified by on-line infrared measurements. Experiments were only deemed valid for mass balances $98 \pm 4$ wt. $\%$. Based on boiling range, the products were classified as follows: gasoline as C5 - 221 ${ }^{\circ} \mathrm{C}$, Light Cycle Oil as $221-370{ }^{\circ} \mathrm{C}$, Heavy Cycle Oil as $370-425^{\circ} \mathrm{C}$ and slurry oil as $>425^{\circ} \mathrm{C}$.

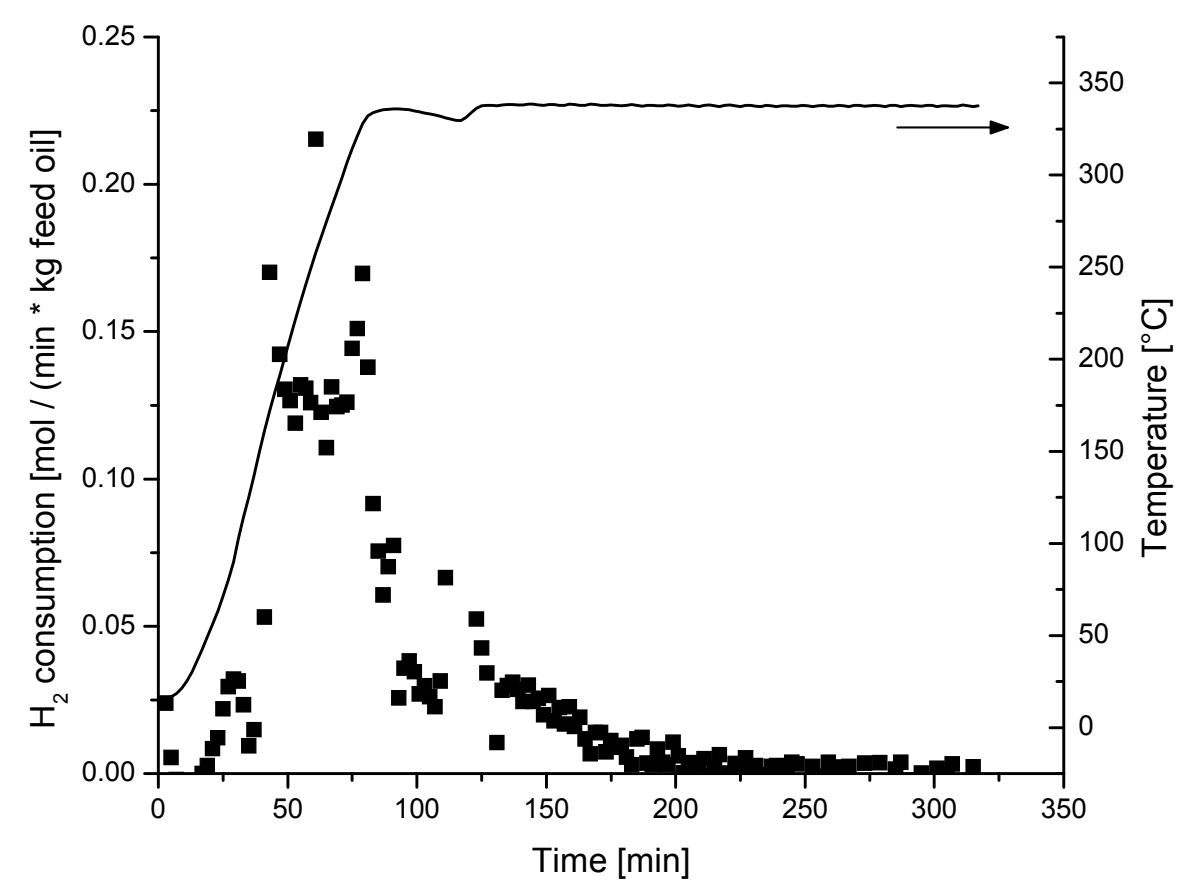

Figure 2. Typical hydrogen consumption rate and temperature profile of an HDO experiment.

\subsection{Analyses}

The gas sample obtained at the end of an HDO experiment was analysed using a Varian Micro GC CP-4900 with three analytical columns: $10 \mathrm{~m}$ Molsieve 5A and 10m PPQ using helium as carrier gas and $10 \mathrm{~m}$ Molsieve $5 \mathrm{~A}$ using argon as carrier gas for better hydrogen quantification.

For the HDO liquid products, the elemental composition (Fisions Instruments $1108 \mathrm{EA}$ $\mathrm{CHN}-\mathrm{S}$ ), the water content (787 KF Titrino), the molecular weight distribution (Agilent 
HPLC 1200, with GPC columns) and the viscosity (Brookfield DV-E viscometer) were determined. More details about the equipment and reactants can be found in Chapter 2 .

A simplified version of VTT's solvent fractionation technique explained in Chapter 2 was used to fractionate the HDO aqueous phase product (analysis performed by VTT, Finland). The main components found in each fraction are:

- Water insoluble fraction: solids, extractives, lignin and polymerisation products.

- Ether insoluble fraction: mainly sugars.

- Ether soluble fraction: aldehydes, ketones and lignin monomers.

Although this technique does not give individual component information, it is of good utility to identify changes in the major fractions of pyrolysis oil and upgraded products. More details about this fractionation technique can be found in the article of Oasmaa et al. [23].

Micro-carbon residue tests (MCRT), a kind of Conradson carbon test, were performed by Shell Global Solutions on the HDO oils, the Long Residue and mixtures thereof, following the ASTM D4530 standard.

The product obtained after co-processing was analysed (by Shell Global Solutions) using true boiling point (TBP) following the ASTM D2887 standard. From this simulated distillation, the different oil fractions yields could be quantified.

\section{Experimental results}

\subsection{Hydrodeoxygenation of pyrolysis oil}

A series of experiments with end reaction temperatures between 230 and $340{ }^{\circ} \mathrm{C}$ was carried out. The total pressure was kept constant at around 290 bar. Because of the vapour pressure of the components present, especially water, and the gas production, the hydrogen partial pressure is expected to decrease with experimental temperature and in the course of an experiment.

As already indicated, after HDO, a product with either two or three phases (depending on the exact process conditions) was obtained. For the experiments carried out at temperatures lower than $300{ }^{\circ} \mathrm{C}$, only bottom oil and an aqueous phase were produced. At $300{ }^{\circ} \mathrm{C}$, three clearly distinguishable phases were obtained. At temperatures higher than $300{ }^{\circ} \mathrm{C}$, three phases were produced, but the amount of bottom phase (also containing the catalyst) was low and had a paste-like appearance. When some of this bottom phase was filtered, the product became top oil. This can be explained when assuming that part of the components with a lower density than the aqueous phase adhered to the catalyst forming the paste-like material that sank the oil to the bottom. It seems that at high temperatures only top oil was produced. Therefore, because the 
process was carried out in slurry and it was difficult to know which parts of this organics were belonging to top or bottom layer (except when only two phases were obtained), the product yields for the oil are shown as the sum of the yields for the top and bottom layer. If coke was produced during the process, it could not be distinguished from the catalyst support and it would be accounted as oil phase (coke yield is expected to be lower than 5 wt.\% [18]).

The mass balance closure was typically between 91 and 97 wt.\% (dry basis). Table 2 shows the yields and elemental composition of the oil product and gas composition. By increasing the reaction temperature, the yields of gas and water produced increased due to the increase of the decarboxylation/methanation and hydrodeoxygenation/dehydration reaction rates, respectively. From the gas composition, up to $25 \mathrm{~mol} \%$ methane was present in the gas phase, which is expected from using a ruthenium-based catalyst [24]. The total gas dry yield was, however, relatively low, having a maximum of $9 \mathrm{wt} \%$ at 340 ${ }^{\circ} \mathrm{C}$. The oil yield appeared to be independent of temperature and the decrease of organics in the aqueous phase seems to be mainly due to their transfer to water and gas. However, this is an artefact due to the removal of oxygen from the oil. Figure 3 clearly illustrates that, indeed, carbon was being transferred from the aqueous phase to the oil phase and not only transferred to the gas phase. The carbon recovery in the oil phase increased from $55 \%$ at $230{ }^{\circ} \mathrm{C}$ to $70 \%$ at $340{ }^{\circ} \mathrm{C}$. This can be explained by the hydrodeoxygenation of water soluble organic components that reduced their polarity and increased their oil affinity. Consequently, the hydrogen consumption also increased with the reaction temperature from 232 to $326 \mathrm{NI} \mathrm{H}_{2} / \mathrm{kg}$ of feed oil. If, however, hydrogen use is expressed in $\mathrm{NI} / \mathrm{HHV}_{\text {product oil }}$ then hydrogen consumption remains approximately constant and almost independent of temperature at $\sim 22 \mathrm{NI} / \mathrm{MJ}$ (see Table 2 for exact hydrogen use). This way of calculating $\mathrm{H}_{2}$ consumption also takes into account the yield of product oil and its properties (HHV is directly related to elemental composition and water content [25]), making this value more significant when evaluating the process requirements.

In Figure 4, the Van Krevelen diagram shows the molar $H / C$ and $O / C$ ratios of the feed oil, the HDO product oils and the oil fraction obtained by mixing water and pyrolysis oil [26] in a water:oil weight ratio of 0.35 (this oil fraction will be referred as Oil Fraction Water Addition, OFWA). It shows that even at the lowest temperature the $\mathrm{O} / \mathrm{C}$ was substantially reduced as compared to original pyrolysis oil (at $230{ }^{\circ} \mathrm{C}$ : $\mathrm{O} / \mathrm{C} \sim 0.33$; original pyrolysis oil $\mathrm{O} / \mathrm{C} \sim 0.53$ ) and this ratio decreased further with temperature (at $340^{\circ} \mathrm{C}: \mathrm{O} / \mathrm{C} \sim 0.17$ ). The deoxygenation at low temperature seems to be mainly caused by an aqueous/organic phase split (with a large fraction of the oxygenated components being transferred to the aqueous phase), as water addition to pyrolysis oil did also yield an oil with similar $\mathrm{O} / \mathrm{C}$ as the $\mathrm{HDO}$ oil obtained at $230^{\circ} \mathrm{C}$. Nevertheless, the $H / C$ of the HDO oils always was substantially higher than that of the OFWA. Generally, the further increase in HDO temperature did not lead to an increase, but a small decrease in the 
Table 2. Dry product yields and oil properties after HDO at different temperatures (residence time: 4 h, total pressure 290 bar).

\begin{tabular}{|c|c|c|c|c|c|}
\hline \multicolumn{6}{|l|}{$\begin{array}{l}\text { Dry yields }{ }^{\text {a }} \\
\text { [wt. } \% \text { of dry feed] }\end{array}$} \\
\hline Top oil + bottom oil & 47 & 49 & 50 & 48 & 50 \\
\hline Aqueous phase & 39 & 33 & 26 & 16 & 14 \\
\hline Gas & 3 & 4 & 4 & 3 & 9 \\
\hline Water produced & 9 & 10 & 13 & 19 & 18 \\
\hline Mass balance closure & 97 & 96 & 92 & 86 & 91 \\
\hline \multicolumn{6}{|l|}{$\mathrm{H}_{2}$ consumption } \\
\hline $\mathrm{NL} \mathrm{H}_{2} / \mathrm{kg}$ feed oil & 232 & 237 & 290 & 297 & 326 \\
\hline $\mathrm{NL} \mathrm{H}_{2} / \mathrm{kg} \mathrm{C}$ in product & 1031 & 1059 & 1098 & 1089 & 1153 \\
\hline $\mathrm{NL} \mathrm{H}_{2} / \mathrm{MJ}$ of product & 21.6 & 22.0 & 22.3 & 21.8 & 23.6 \\
\hline \multicolumn{6}{|l|}{ Product properties } \\
\hline Oil phase & $\begin{array}{l}\text { Bottom } \\
\text { oil }\end{array}$ & $\begin{array}{c}\text { Bottom } \\
\text { oil }\end{array}$ & Top oil & Top oil & Top oil \\
\hline C dry [wt.\%] & 63.0 & 66.3 & 67.7 & 74.2 & 73.3 \\
\hline H dry [wt.\%] & 9.0 & 9.3 & 9.7 & 10.3 & 9.8 \\
\hline O dry ${ }^{b}$ [wt.\%] & 28.0 & 24.4 & 22.6 & 15.5 & 16.9 \\
\hline $\mathrm{H}_{2} \mathrm{O}[\mathrm{wt} . \%]$ & 15.9 & 10.0 & 5.7 & 3.2 & 2.1 \\
\hline $\mathrm{HHV}_{\text {wet }}^{\mathrm{c}}[\mathrm{MJ} / \mathrm{kg}]$ & 25.2 & 28.7 & 31.3 & 35.8 & 35.1 \\
\hline MCRT [wt.\%] & 11.7 & 9.1 & 4.7 & 1.8 & 2.2 \\
\hline $\begin{array}{l}\text { MCRT of } 20 \text { wt. } \% \text { blend in } \\
\text { Long Residue }^{d}[w t . \%]\end{array}$ & 3.2 & 2.9 & 2.2 & 1.9 & 2.0 \\
\hline \multicolumn{6}{|l|}{ Gas composition } \\
\hline $\mathrm{CO}_{2}[\mathrm{~mol} \%]$ & 81.8 & 48.4 & 53.1 & 58.7 & 61.0 \\
\hline $\mathrm{CO}[\mathrm{mol} \%]$ & 0.8 & 4.6 & 2.0 & 1.4 & 1.2 \\
\hline $\mathrm{CH}_{4}[\mathrm{~mol} \%]$ & 14.1 & 24.7 & 22.5 & 21.4 & 22.1 \\
\hline $\mathrm{C}_{2} \mathrm{H}_{6}-\mathrm{C}_{3} \mathrm{H}_{8}[\mathrm{~mol} \%]$ & 3.3 & 21.7 & 22.2 & 18.5 & 15.7 \\
\hline
\end{tabular}

$\mathrm{H} / \mathrm{C}$ ratio. Possibly, the hydrogenation reactions (for example saturation of double bonds or formation of alcohols from aldehyde/ketone functionality [27]) might be favoured at lower temperature and therefore, these reactions could take place during the heating period $\left(100-200^{\circ} \mathrm{C}\right)$ and afterwards hydrodeoxygenation/dehydration could be dominant. This phenomenon has also been observed for guaiacol [19] and phenol [28]. The 
occurrence of low temperature hydrogenation is further supported when the $O / C$ of the oil produced at $230{ }^{\circ} \mathrm{C}$ is compared to the OFWA; the $H / C$ is significantly increased by the HDO process while the $\mathrm{O} / \mathrm{C}$ remains the same. Moreover, there could be a lack of hydrogen availability during reaction at high temperature. The total pressure in the reactor consisted of water (the vapour pressure increases from 28 bar at $230{ }^{\circ} \mathrm{C}$ to 146 bar at $340{ }^{\circ} \mathrm{C}$ ), hydrogen and gases/vapours formed during the HDO process. When the total pressure dropped below the set-point, hydrogen was added again to reach the pressure set-point. However, due to a gradual increase in partial pressure of the gaseous, volatile reaction products and water vapour pressure, the partial hydrogen pressure decreased during the course of an experiment. Therefore, at higher temperatures and in the course of an experiment, the hydrogen availability decreased for further reactions that could lead to an increase of the $H / C$ ratio. It should be noted that the differences in $H / C$ ratio are relatively small and small errors during the $\mathrm{H}$ determination and water content could have a significant influence on these results.

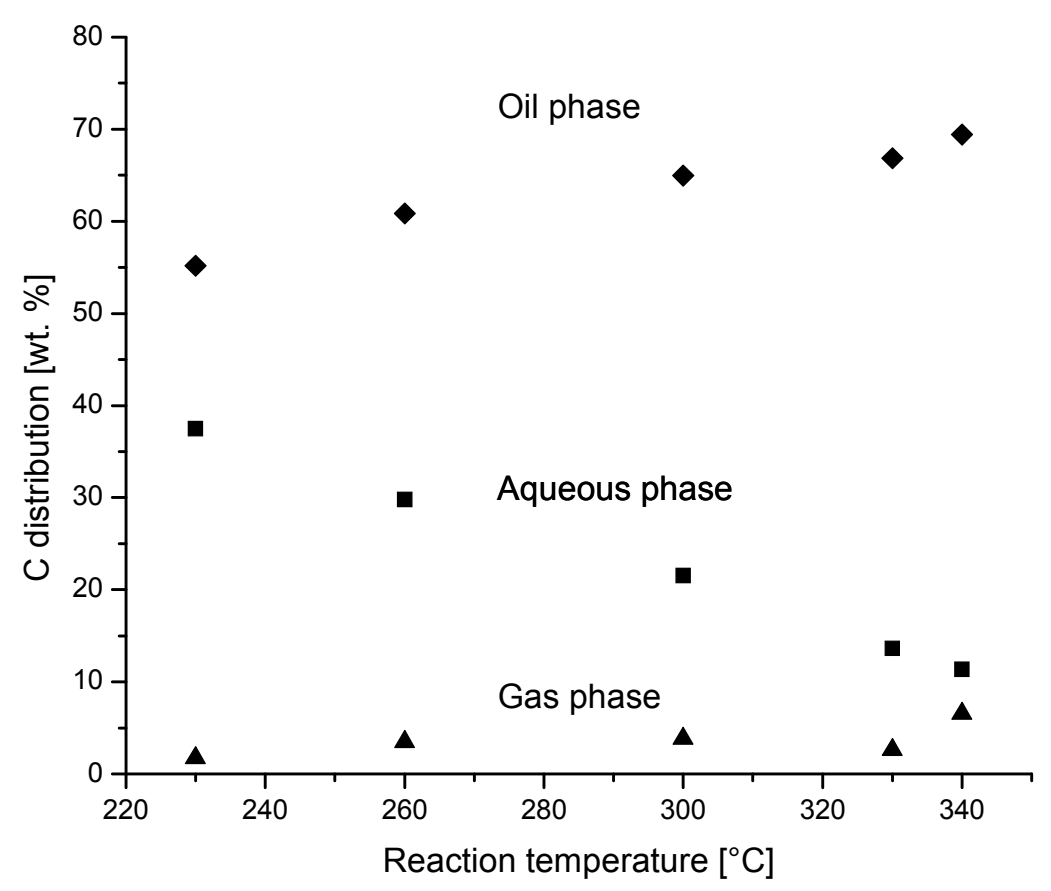

Figure 3. Carbon distribution in the HDO products at different reaction temperature. $(\bullet)$ Oil phase yield, ( $\boldsymbol{\square})$ aqueous phase yield, ( $\boldsymbol{\Delta}$ ) gas phase yield. 100\% represents the total elemental carbon in the feed (pyrolysis oil). 


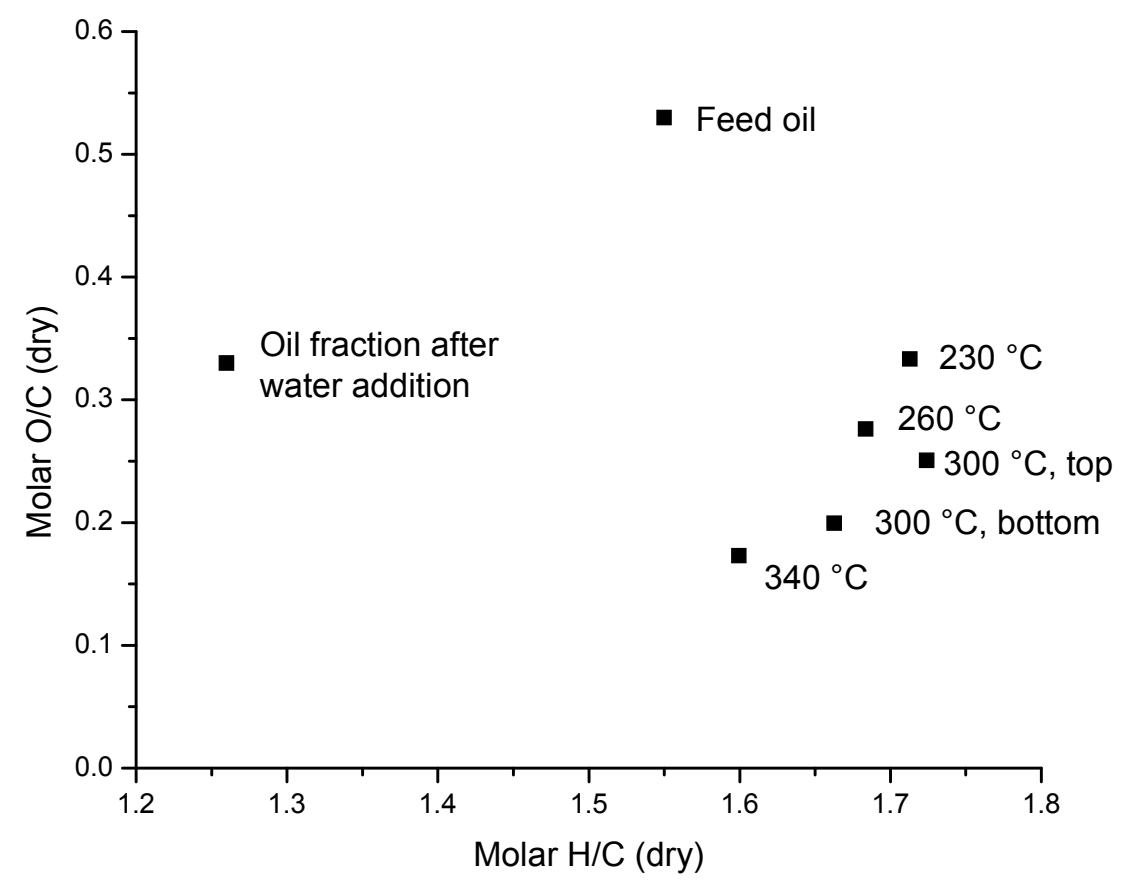

Figure 4. Van Krevelen diagram of the oil product after HDO of pyrolysis oil at different reaction temperature (4h, 290 bar), compared to the feed oil and the oil phase obtained by adding water to crude pyrolysis oil.

To obtain information about the type of components being transferred from the aqueous phase to the oil phase, VTT's solvent fractionation technique was applied to the aqueous phase product. In Figure 5, it can be seen that the ether insoluble fraction (consisting mainly of sugars) decreased with temperature. Therefore, the product of the conversion of sugars could be the cause of the increase of the carbon recovery in the oil phase. This effect of transfer of sugars was already observed during the HPTT of pyrolysis oil (see Chapter 2). However, in that case, the sugars underwent polymerisation creating a very viscous oil with substantially increased molecular weight as compared to the original pyrolysis oil. Molecular weight distribution determined by GPC analyses of the feed oil, the HDO oils and a HPTT oil are shown in Figure 6. It can be seen that when using Ru/C catalyst and hydrogen, the typical polymerisation reactions observed during HPTT seem to be avoided and/or the high molecular weight components (including any possible polymerisation product) underwent hydrocracking reducing their amount or even disappearing. Although GPC separates the components by size and not by weight and HDO reactions could have changed the first, leaving the latter almost untouched, the viscosity of the oils also decreased at higher HDO reaction temperatures, from 471 to 57 $\mathrm{cP}$ (measured at $20^{\circ} \mathrm{C}$, HDO temperature $230^{\circ} \mathrm{C}$ and $340{ }^{\circ} \mathrm{C}$, respectively) supporting the GPC results. 


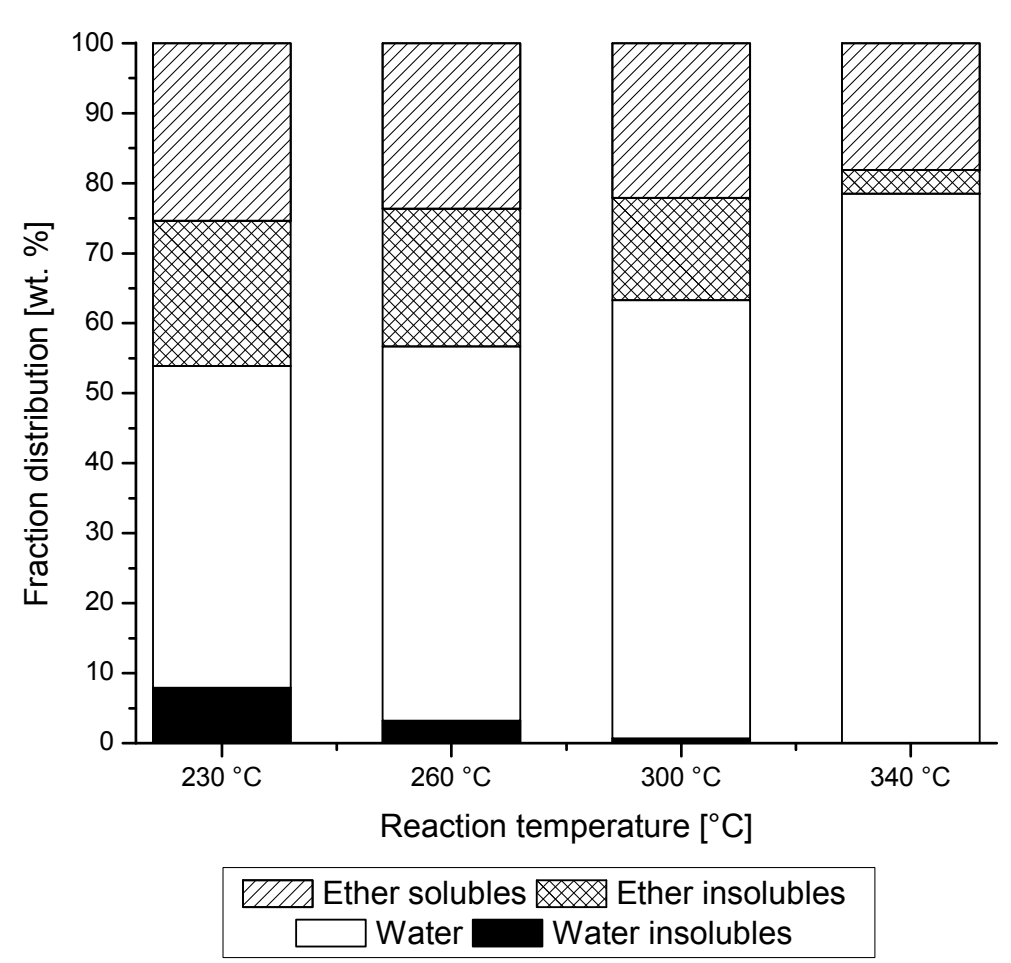

Figure 5. Results of VTT's solvent fractionation technique applied to the aqueous phase product obtained at various HDO reaction temperatures (analysis performed by VTT, Finland)

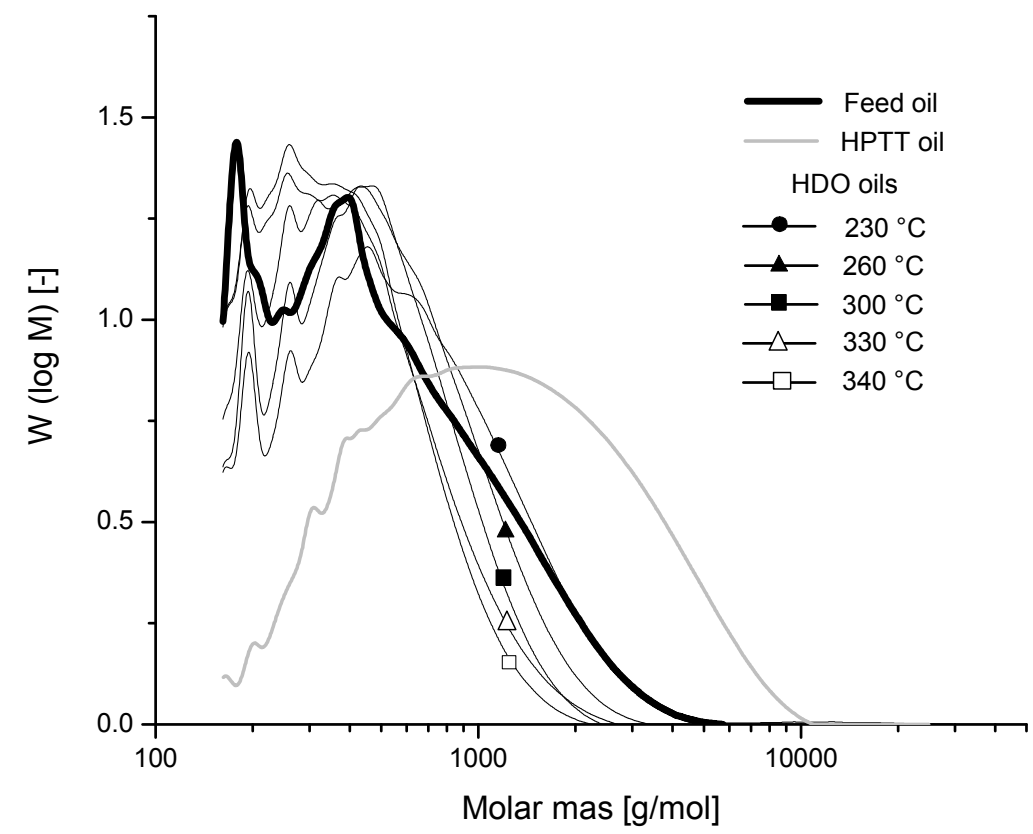

Figure 6. Molecular weight distribution obtained by GPC analysis of the original pyrolysis oil (feed oil), the oil products obtained by HDO at different reaction temperatures $(230,260,300,330$ and $340{ }^{\circ} \mathrm{C}$ ) and $4 \mathrm{~h}, 290 \mathrm{bar}$ and the product of HPTT of pine oil at $300{ }^{\circ} \mathrm{C}, 3.2 \mathrm{~min}$ and $200 \mathrm{bar}$ (see Chapter 2). 


\subsection{Catalytic cracking of upgraded pyrolysis oil}

Prior to co-processing the HDO oils in the MAT reactor, miscibility tests oils of these HDO oils in Long Residue were performed. Although the miscibility at room temperature was limited, especially for the oils obtained at low HDO temperature, after mixing and heating to $75^{\circ} \mathrm{C}$ the $\mathrm{HDO}$ oil was miscible in the Long Residue FCC feed. This was checked by using the same Long Residue/HDO oil mixture in two consecutive experiments and obtaining good product yield reproducibility indicating that separation of the mixture had not occurred in the feed reservoir.

Two different types of tests were performed in the MAT reactor. First, $20 \mathrm{wt} \% \mathrm{HDO}$ oil in Long Residue was evaluated. Afterwards, HDO oils with relatively low oxygen content (oils processed at 300 and $340{ }^{\circ} \mathrm{C}$ ) were processed un-diluted. For all the experiments the mass balance closure was between 94 and 102 wt.\%. For better comparison of the results, FCC product yields are given at a constant $60 \%$ conversion. Conversion is defined as the sum of dry gas, LPG, gasoline range $\left(\mathrm{C} 5-221^{\circ} \mathrm{C}\right)$ and coke.

From the TBP analysis of the liquid product obtained after the MAT reactor, together with the coke make $\left(\mathrm{CO}_{2}\right.$ detector) and the gas composition, yields of different types of products could be determined: $\mathrm{H}_{2}$, dry gas, $\mathrm{CO}, \mathrm{CO}_{2}$, propylene, LPG, gasoline, LCO, HCO, slurry oil, and coke. The desired product is mainly gasoline, but LPG and LCO (as diesel precursor) are also considered to be valuable products. Dry gas and especially coke (in high amounts) are the not desired products. The amounts of $\mathrm{CO}, \mathrm{CO}_{2}, \mathrm{HCO}$ and slurry oil were low (<8 wt.\%) and grouped as "other" in the analysis of the results.

It should be noted that all the co-processing experiments were conducted without any plugging issues and the coke and dry gas yields were similar to those obtained using only the Long Residue feed (see Table 3). The yields are normalised by the amount of water produced, considering that basically all the oxygen present in the HDO oils was converted to water ( $\mathrm{CO}$ and $\mathrm{CO}_{2}$ yields were always lower than 0.5 wt.\%). Between parentheses, the yields taking into account the produced water are also shown. It can be seen that only a slightly higher cat/oil ratio was required when Long Residue/HDO mixtures were processed. Table 3 also shows that at the same conversion level, the yields of the various fractions (values normalised by the amount of produced water) did not differ from each other significantly. This was unexpected taking into account the differences in dry $\mathrm{O}$ content ranging from 16.9 to $28.0 \mathrm{wt} . \%$. This indicates that with respect to achieving the required quality for FCC processing of HDO oils, the HDO step might be less severe than traditionally thought to be required, even suggesting that the HDO step at low temperature (the "stabilisation step") might be enough to enable coprocessing. This would reduce hydrogen consumption during pyrolysis oil upgrading. On the other hand, at lower HDO reaction temperature, less carbon was recovered in the oil 
Table 3. Product yields at $60 \mathrm{wt} . \%$ conversion after catalytic cracking of $20 \mathrm{wt.} \% \mathrm{HDO}$ oil in Long Residue feed at $520{ }^{\circ} \mathrm{C}$. Yields of products (in wt.\%) normalised by amount of produced water. Between parentheses, yields including produced water (data from Shell Global Solutions).

\begin{tabular}{|c|c|c|c|c|c|c|}
\hline & $\begin{array}{c}\text { Long } \\
\text { Residue } \\
\text { reference }\end{array}$ & $\begin{array}{c}20 \% \mathrm{HDO} \\
230^{\circ} \mathrm{C} \\
\text { Bottom oil }\end{array}$ & $\begin{array}{c}20 \% \mathrm{HDO} \\
260^{\circ} \mathrm{C} \\
\text { Bottom oil }\end{array}$ & $\begin{array}{c}20 \% \text { HDO } \\
300^{\circ} \mathrm{C} \\
\text { Top oil }\end{array}$ & $\begin{array}{c}20 \% \text { HDO } \\
330^{\circ} \mathrm{C} \\
\text { Top oil } \\
\end{array}$ & $\begin{array}{c}20 \% \text { HDO } \\
340^{\circ} \mathrm{C} \\
\text { Top oil } \\
\end{array}$ \\
\hline Cat/oil ratio & 3.1 & 4.3 & 3.4 & 3.4 & 3.7 & 3.8 \\
\hline LPG yield & 8.5 & $11.0(10.1)$ & $10.1 \quad(9.4)$ & $10.2(9.6)$ & 9.3 (8.9) & $9.6(9.2)$ \\
\hline Gasoline yield & 44.0 & $43.7 \quad(40.2)$ & $44.7 \quad(41.7)$ & $46.0 \quad(43.4)$ & $45.3 \quad(43.5)$ & $44.7 \quad(43.0)$ \\
\hline LCO yield & 25.2 & 23.1 (21.3) & $23.8 \quad(22.2)$ & 23.9 (22.5) & 24.8 (23.8) & $25.0 \quad(24.0)$ \\
\hline Dry gas yield & 1.5 & $2.5 \quad(2.3)$ & $2.3 \quad(2.1)$ & $1.9(1.8)$ & $2.0 \quad(1.9)$ & $2.1 \quad(2.0)$ \\
\hline Coke yield & 5.9 & $7.8 \quad(7.2)$ & 7.1 (6.6) & $5.5 \quad(5.2)$ & $5.7 \quad(5.5)$ & $6.0(5.8)$ \\
\hline $\begin{array}{c}\text { Other (HCO, } \\
\text { slurry oil, CO } \\
\text { and CO2) }\end{array}$ & 14.8 & $11.7(10.8)$ & $11.8(11.0)$ & $12.3(11.6)$ & $12.7 \quad(12.2)$ & $12.5(12.0)$ \\
\hline Water & - & - (7.9) & - (6.7) & $-(5.7)$ & - (3.9) & - (3.9) \\
\hline
\end{tabular}


phase during the HDO step (Figure 3), reducing the overall carbon efficiency from pyrolysis oil to FCC product. However, the organic components present in the aqueous phase could be used in subsequent processes to generate value added chemicals or for hydrogen production (through steam reforming or supercritical water gasification).

The catalytic cracking of some undiluted HDO oils was shown to be technically feasible for those HDO oils made at more severe upgrading conditions (Table 4). Compared to the product yields from the catalytic cracking of the Long Residue feed alone or blends thereof with HDO oils, the dry gas and coke yield are significantly higher (compare with Table 3). For the undiluted HDO oils, the coke and dry gas yields also decrease with increasing upgrading severity, while the gasoline and LCO yields concomitantly increase. The cat/oil ratio required to obtain a $60 \mathrm{wt}$.\% conversion is also much higher than for coprocessing $20 \mathrm{wt} . \%$ HDO oils. This shows that co-processing is necessary to obtain good product yields.

Table 4. Product yields at constant 60 wt.\% conversion from the catalytic cracking of undiluted HDO oils at $520^{\circ} \mathrm{C}$ normalised by amount of produced water (data from Shell Global Solutions).

\begin{tabular}{lccc}
\hline & $\begin{array}{c}\text { Pure HDO oil } \\
\left(300^{\circ} \mathrm{C} / 295 \mathrm{bar}\right)\end{array}$ & $\begin{array}{c}\text { Pure HDO oil } \\
\left(330^{\circ} \mathrm{C} / 300 \mathrm{bar}\right)\end{array}$ & $\begin{array}{c}\text { Pure HDO oil } \\
\left(340^{\circ} \mathrm{C} / 290 \mathrm{bar}\right)\end{array}$ \\
\hline Cat/oil ratio & 20.2 & 12 & 12.6 \\
LPG yield & 11.7 & 10.5 & 9.7 \\
Gasoline yield & 22.3 & 34.4 & 36.2 \\
LCO yield & 10.9 & 19.3 & 18.4 \\
Dry gas yield & 10.8 & 5.6 & 5.7 \\
Coke yield & 37.5 & 22.4 & 21.9 \\
$\begin{array}{l}\text { Other (HCO, } \\
\text { slurry oil, CO and }\end{array}$ & 6.7 & 7.5 & 7.8 \\
$\left.\mathrm{CO}_{2}\right)$ & & & \\
\hline
\end{tabular}

From the results shown in Table 3, a linear extrapolation via 100 wt.\% Long Residue and at $20 \mathrm{wt} . \% \mathrm{HDO}$ oil/80 wt.\% Long Residue gives the putative product yields from a virtual 100 wt.\% HDO oil. Figure 7 compares this extrapolated yield with that from actual experimental product yields of the catalytic cracking of undiluted HDO oils (obtained at a HDO temperature of 300 and $340{ }^{\circ} \mathrm{C}$ ). As expected, linear extrapolation substantially underestimates the coke and dry gas yields. This is probably due to hydrogen transfer, known to be prevalent during catalytic cracking. Another possible cause could be the reduction of the coke formation rate from HDO oil components due to a decrease in the coke precursor concentration by dilution with Long Residue oil. If these coke formation reactions have a reaction order higher than one (for example bimolecular reaction mechanism), then reducing the concentration of HDO oil components by dilution might cause a reduction in the coke yield. The internal hydrogen transfer has been already observed during coal liquefaction [29], and during HDO of pyrolysis oil using hydrogen 
donor solvents such as tetralin [30]. At this stage, it is impossible to state which of the aforementioned mechanisms actually causes this reduced coke yield.

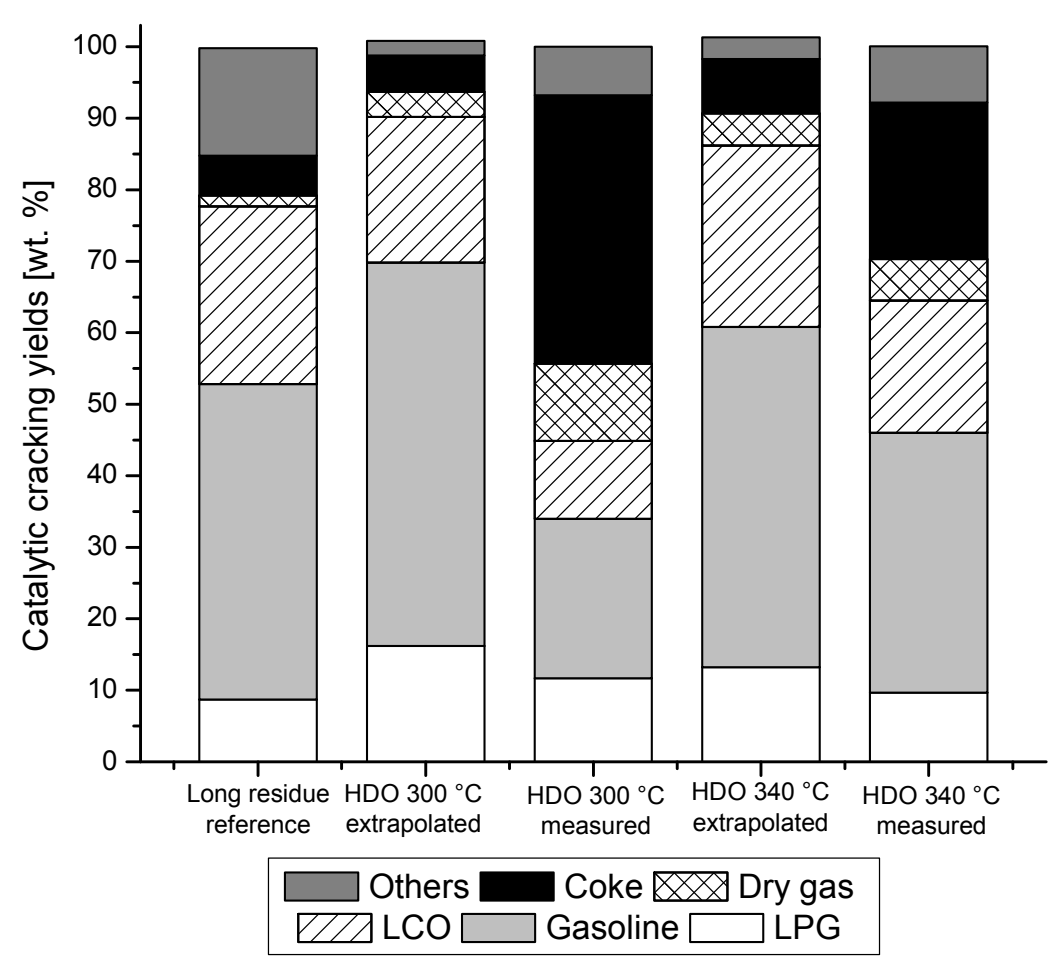

Figure 7. Product yields after catalytic cracking. Results for experiments denoted as "extrapolated" are theoretical yields obtained when extrapolating actual yields at $20 \mathrm{wt} . \% \mathrm{mix} \mathrm{HDO}$ oil in Long Residue to $100 \mathrm{wt} . \% \mathrm{HDO}$ oil (data from Shell Global Solutions).

Surprisingly, bio-hydrocarbon products were obtained with very little oxygen, indicating that hydrogen transfer from the refinery feed eliminates the HDO oil oxygen as water. The residual oxygen containing compounds were identified and quantified by GC $x$ GC $x$ ToF MS (Table 5) and were substituted phenols (mainly dimethyl). However, it is not possible to exclude the possibility that other substituted phenols were hidden under these peaks. Comparing the HDO oil prepared at $300{ }^{\circ} \mathrm{C}$ in both co-processing a 20 wt. $\%$ blend and $100 \mathrm{wt} \%$, the amount of phenols present in the products was much lower (a factor 15 versus expected factor 5).

An indication of the quality of the HDO oil with respect to FCC co-processing can be obtained when the coking tendency of the oil is known. This can be obtained by the micro-carbon residue test (MCRT). For better comparison, the MCRT results shown in Table 2 for the undiluted HDO oils were scaled to account for the amount of water in the feed, which cannot contribute to the coke formation. The carbon residue from the 20 wt.\% diluted samples was extrapolated to a virtual $100 \mathrm{wt} \%$ HDO oil to determine the theoretical contribution to the MCRT of the (dry) HDO oil (the MCRT contribution of the 
Long Residue was corrected assuming proportional contribution of this fraction to the total MCRT). The results (see Figure 8) show that dilution in Long Residue feed generally reduced the theoretical contribution to the MCRT value of the HDO oil, but this effect was much stronger for oils processed at low HDO temperature (especially $230{ }^{\circ} \mathrm{C}$; $260{ }^{\circ} \mathrm{C}$; less at $\left.300{ }^{\circ} \mathrm{C}\right)$ than at high temperature $\left(330^{\circ} \mathrm{C} ; 340{ }^{\circ} \mathrm{C}\right)$ where the difference was hardly noticeable. In a MCRT test the sample is exposed to a thermal treatment, so the MCRT test gives an indication of the intrinsic (non-catalysed) charring or polymerisation. Apparently the intrinsic charring of HDO oils decreases with HDO reaction temperature. At the same time, Figure 8 shows that intrinsic charring of less stable oils (produced at lower temperature) can be decreased (more than based on the dilution ratio) by dilution with a Long Residue. It should be noted that the more than proportional decrease of MCRT was also be observed in the work of Samolada et al. [12]. A similar phenomenon was observed in Chapter 2 during the HPTT of pyrolysis oil , in which dilution also decreased charring/polymerisation. The near equal MCRT values but totally different MAT reactor results for the (20 wt.\% HDO/80 wt.\% Long Residue) mixture and 100 wt.\% HDO oil (Table 3, Table 4 and Figure 7), shows that a low MCRT value of the feed/blend in itself is not enough to achieve a good product spec upon FCC processing. This seems logical as the MCRT does not account for hydrogen transfer initiated by catalytic reactions.

Table 5. Phenols (ppm wt) in the catalytic cracking product measured by GCxGCxTime of Flight Mass Spectrometry (data from Shell Global Solutions).

\begin{tabular}{|c|c|c|c|c|c|c|}
\hline & \multicolumn{3}{|c|}{$\begin{array}{l}\text { From catalytic cracking of } 20 \% \\
\text { blend in Long Residue at } 520{ }^{\circ} \mathrm{C}\end{array}$} & \multicolumn{3}{|c|}{$\begin{array}{l}\text { From catalytic cracking of } 100 \% \\
\text { HDO oil at } 520^{\circ} \mathrm{C}\end{array}$} \\
\hline & $\begin{array}{c}20 \% \mathrm{HDO} \\
230^{\circ} \mathrm{C} \\
\text { Bottom oil }\end{array}$ & $\begin{array}{c}20 \% \mathrm{HDO} \\
260^{\circ} \mathrm{C} \\
\text { Bottom oil }\end{array}$ & $\begin{array}{c}20 \% \text { HDO } \\
300^{\circ} \mathrm{C} \\
\text { Top oil }\end{array}$ & $\begin{array}{c}\text { Pure HDO } \\
300^{\circ} \mathrm{C} \\
\text { Top oil }\end{array}$ & $\begin{array}{c}\text { Pure HDO } \\
330^{\circ} \mathrm{C} \\
\text { Top oil } \\
\end{array}$ & $\begin{array}{c}\text { Pure HDO } \\
340^{\circ} \mathrm{C} \\
\text { Top oil }\end{array}$ \\
\hline Phenol & 2769 & 1686 & 1169 & 12727 & 10120 & 9800 \\
\hline 3/4-MePhenol & 1606 & 944 & 730 & 7179 & 6799 & 6634 \\
\hline 2,5-DiMePhenol & 3223 & 1660 & 1194 & 20227 & 16400 & 16192 \\
\hline 2,4/5-DiMePhenol & 336 & 164 & 135 & 2384 & 2154 & 2061 \\
\hline 2,3-DiMePhenol & 492 & 276 & 125 & 2236 & 2602 & 2542 \\
\hline 2-MePhenol & 1855 & 1506 & 1250 & 11273 & 10500 & 10279 \\
\hline 2-EtPhenol & 1593 & 765 & 652 & 11261 & 10161 & 10131 \\
\hline 3,5-DiMePhenol & 508 & 221 & 193 & 2808 & 2717 & 2652 \\
\hline 3/4-EtPhenol & 382 & 155 & 125 & 2949 & 2586 & 2575 \\
\hline Totals phenols & 12765 & 7377 & 5572 & 73045 & 64039 & 62865 \\
\hline
\end{tabular}




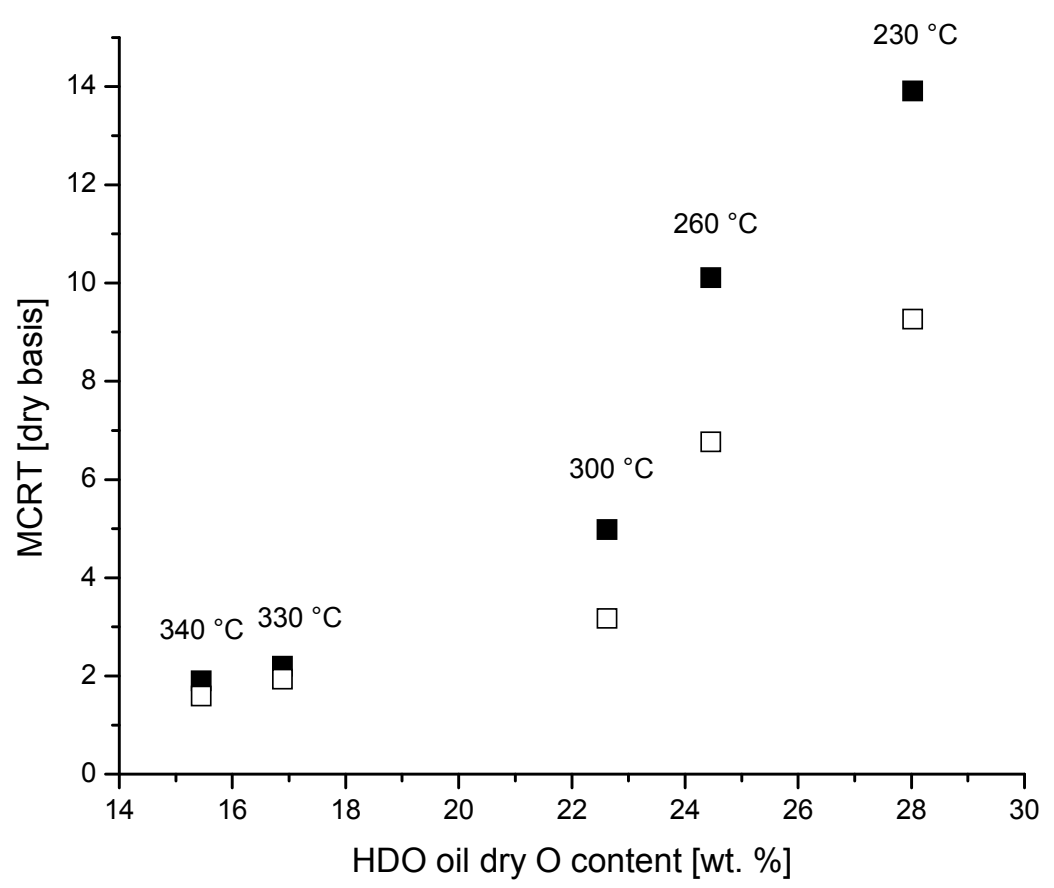

Figure 8. MCRT results (dry basis) of undiluted HDO oil (dry basis, measured, $\mathbf{\square}$ ) and 20 wt. $\%$ HDO oil in Long Residue (dry HDO oil basis, recalculated based on experimental MCRT values for 20 wt.\% HDO blend and assuming proportional contribution of Long Residue, $\square$ ). The values above the data points correspond to the temperature of the HDO treatment (data from Shell Global Solutions)

\section{Discussion}

The decrease of oxygen content of pyrolysis oil can be achieved by HDO. This already known fact [5] was, until now, considered to be the goal of HDO and the remaining level of oxygen the parameter that determines the quality of the HDO oil with respect to further use like FCC. Low oxygen levels $(<10 \mathrm{wt} . \%)$ were targeted in most of the available literature [12, 13, 31]. However, this work has shown that high remaining levels of oxygen can be allowed in upgraded HDO oil (up to $28 \mathrm{wt}$.\%) without deterioration of the yield structure after lab-scale FCC co-processing. In general in FCC, the coking tendency of the feed, which can be expressed by the MCRT, should be low to technically allow FCC processing (for the MAT reactor as used in this study the maximum MCRT is about $5 \%$ ). The MCRT of normal FCC feeds is typically less than $0.5 \mathrm{wt} . \%$ [32]. This study shows that the MCRT of pure HDO oil can be lowered, sometimes more than proportional, using a suitable co-processing feed. A low MCRT blend (low in relation to FCC process it is used in) seems a prerequisite for co-processing, but does not guarantee a good product yield structure. In addition miscibility also seems a requirement, but for the HDO oils as used in this study good miscibility was obtained in all cases. In FCC, the H/C (mole basis) is another parameter used to express the quality 
of the (fossil) feed: an increase in $H / C$ generally results in higher value products like gasoline [32, 33]. For biomass and also $\mathrm{HDO}$ oil, an $H / C$ effective $\left(H / C_{\text {eff }}\right)$ can be used (Chen et al [34], Corma et al. [35]). In the absence of nitrogen and sulphur, this parameter is defined as $H / C_{\text {eff }}=(H-2 \times O) / C$, the correction reflecting the net oxygen removal (dry oil) via water production. The $H / C_{\text {blend }}$ (feedstock MAT reactor) can be determined from the $H / C_{\text {eff }}$ (dry $\mathrm{HDO}$ oil) the $H / C_{\text {fossil fuel }}$ and the weight based mixing ratio (based on dry HDO oil). Although the use of the MCRT blend and the $H / C_{\text {blend }}$ might just be a start in the definition of product quality for HDO oil (blends) in FCC co-processing, this type of approach is needed to come to a proper definition and quantification of HDO oil quality for FCC co-processing.

In relation to this study and comparing the HDO with the HPTT of pyrolysis oil, both processes produce an oil phase and reduce the oxygen content (HPTT yields an oil with a dry oxygen content of $\sim 20$ wt. \%). However, HPTT oil could not be processed in the MAT reactor because of its high coking tendency (MCRT on dry basis of $45.1 \mathrm{wt} . \%$ ). For these HPTT oils the molecular weight distribution strongly increased during HPTT upgrading as compared to the original pyrolysis oil. In contrast, for the HDO oils, as reported in this study, the molecular weight distribution remained similar during upgrading or even decreased, which is an indication of the thermal stability of these HDO oils reflected by a relatively low MCRT (especially for the blends). These results on HDO oils are in line with the ones from Ardiyanti et al. [36], although they report the TGA residue instead of a MCRT. These blended HDO oils also had good co-processing performance although in pure form, even the HDO oil produced at a reaction temperature of $340{ }^{\circ} \mathrm{C}$ (MCRT pure and blend near equal), did not give a good yield structure in the MAT reactor which might be attributed to the low $H / C_{\text {eff }}$ of the pure feed as compared to the $20 \%$ blend $\left(H / C_{\text {eff }}\right.$ at $340{ }^{\circ} \mathrm{C}$ only 1.26$\left.) ; H / C_{\text {blend }}=1.67\right)$.

During the HDO process, hydrogenation of reactive groups (such as olefins, aldehydes and ketones) at relatively low temperatures of $100-200{ }^{\circ} \mathrm{C}$ [27] seems to play a critical role to obtain thermally stable molecules/feed suitable for further processing in a FCC unit (i.e. low MCRT). These reactions appear to be in competition with the polymerisation reactions (as already seen by Gagnon and Kaliaguine [37]). In Figure 9 a schematic impression of the competition between polymerisation and stabilisation is given; a similar view of this competition is reported by Venderbosch et al. [38]. Depending on the operating conditions and parameters, such as heating rate/temperature and hydrogen mass transfer rate, it may be possible to steer the ratio of the heterogeneous HDO reaction to the homogeneous polymerisation reaction and thereby influence product quality. These fast polymerisation reactions (not counteracted by fast enough hydrogenation reactions) seem to be cause of the reactor plugging reported in literature when pyrolysis oil was directly fed to continuous HDO reactors at high temperature [7]. 


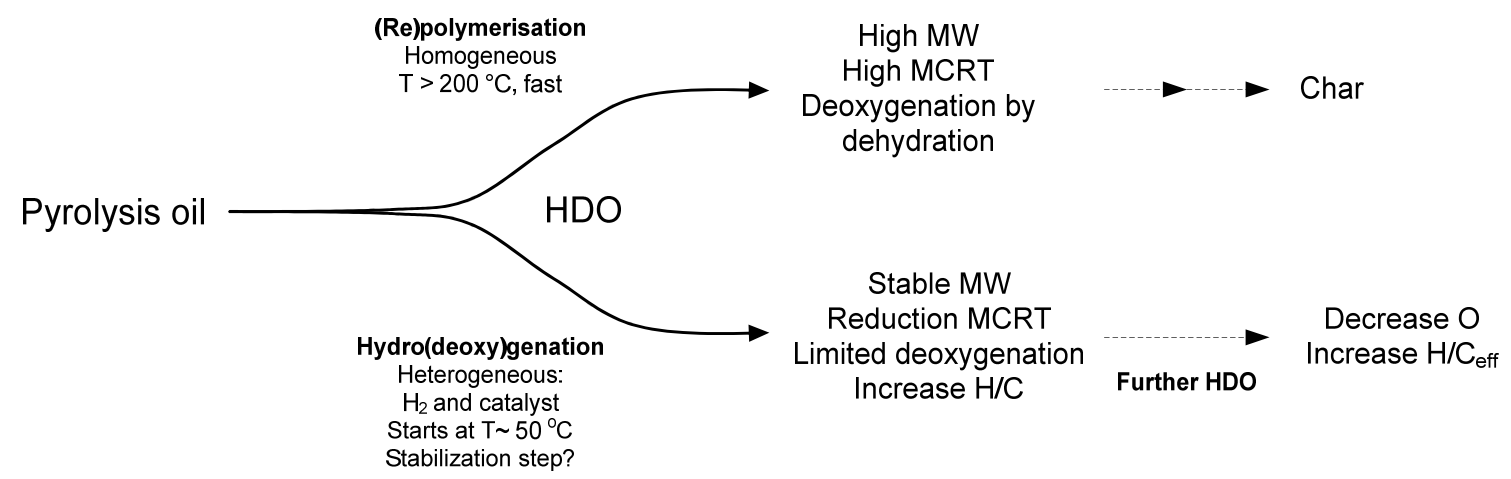

Figure 9. Schematic overview of the competition between polymerisation and hydro(deoxy)genation reaction during HDO process (MCRT, micro carbon residue test; MW, molecular weight). See also [38].

HDO reactions lead to a better product (with respect to FCC co-processing) but at the expense of hydrogen. In contrast, the product of HPTT has a lower quality but it is simpler to produce (neither catalyst nor hydrogen is needed). For a continuous process, a balance between product quality and economics (carbon recovery in oil, $\mathrm{H}_{2}$ consumption, operating conditions, reactor volume, type and amount of catalyst, etc.) should be found which may result in a reactor configuration that integrates both the HDO and HPTT process step. As part of this, it should be noted that the assessment of the (required) quality of upgraded (HDO) oil should always be done in relation to, and in combination with, the mixing ratio and quality of the typical FCC feed. 


\section{Conclusions}

Co-processing hydrodeoxygenated pyrolysis oils having a dry oxygen content up to 28 wt.\% under standard lab-scale FCC conditions gives gasoline and LCO range biohydrocarbons from a ligno-cellulosic feed source with similar product yields as that obtained from the base FCC feed.

After the HDO step, pyrolysis oil underwent phase separation into an aqueous phase and one or two oil phases. An increase in the process temperature led to an oil with lower oxygen content and to the transfer of organic components (sugar-type) from the aqueous phase to the oil phase. In contrast to the thermal treatment of pyrolysis oil, this transfer was not due to polymerisation of the sugars but due to their hydrodeoxygenation. Therefore, the molecular weight of the oil did not increase during the process. At the highest temperatures, the average molecular weight even decreased, probably due to the cracking of heavy components. The increase of the $H / C_{\text {eff }}$ ratio and the reduction in reactivity of some functional groups (likely olefins, aldehydes, ketones...), that avoided further polymerisation, appeared to be a key factor to reduce the coking tendency and improve yield structure during catalytic cracking. It should be noted that higher HDO temperatures were accompanied by higher $\mathrm{H}_{2}$ consumption on a $\mathrm{kg}$ feed basis (increasing from 232 to $326 \mathrm{NI} \mathrm{H} / \mathrm{kg}$ feed), but on a MJ product basis, hydrogen consumption was similar within $8 \%\left(\sim 22 \mathrm{NI} \mathrm{H}_{2} / \mathrm{MJ}\right)$.

Despite the significant differences between the properties of the HDO oils, similar and promising results were obtained from their co-processing with a heavy oil petroleum fraction (Long Residue) which might be attributed to a similar MCRT blend and $H / C_{\text {blend }}$. There are two main observations from these results. Firstly, the possibility to successfully co-process HDO oils with high oxygen content (28.0 wt. $\%$ on dry basis) without a significant increase in coke formation. Secondly, the absence of a co-processing solvent (Long Residue in the present work) caused an increase of the undesired products (coke, dry gas...) yields by reducing the production of valuable products (gasoline, LCO...). This indicates that, as long as the catalytic cracking is done in the presence of a suitable co-feed present in sufficient quantity, the HDO step does not need to aim towards full deoxygenation, but only to the reduction of the highly reactive components/functional groups that lead to coke formation and prevent successful co-processing. 


\section{References}

[1] Pimentel D, Patzek TW. Ethanol Production Using Corn, Switchgrass, and Wood; Biodiesel Production Using Soybean and Sunflower. Nat. Res. Res. 2005;14:65-76.

[2] Oasmaa A, Czernik S. Fuel oil quality of biomass pyrolysis oils-State of the art for the end users. Energy Fuels 1999;13:914-921.

[3] Hoekstra E, Hogendoorn KJA, Wang X, Westerhof RJM, Kersten SRA, van Swaaij WPM, Groeneveld MJ. Fast Pyrolysis of Biomass in a Fluidized Bed Reactor: In Situ Filtering of the Vapors. Ind. Eng. Chem. Res. 2009;48:4744-4756.

[4] Lappas AA, Samolada MC, latridis DK, Voutetakis SS, Vasalos IA. Biomass pyrolysis in a circulating fluid bed reactor for the production of fuels and chemicals. Fuel 2002;81:2087-2095.

[5] Elliott DC. Historical developments in hydroprocessing bio-oils. Energy Fuels 2007;21:1792-1815.

[6] Sharma RK, Bakhshi NN. Catalytic upgrading of pyrolysis oil. Energy Fuels 1993;7:306-314.

[7] Elliott DC, Baker EG. Hydrotreating biomass liquids to produce hydrocarbon fuels. In: D.L. Klass editor. Energy from Biomass and Waste X, Chicago: Institute of Gas Technology. 1987; p. 765-784.

[8] Elliott DC, Neuenschwander GG. Liquid fuels by low-severity hydrotreating of biocrude. In: A.V. Bridgwater and D.G.B. Boocock editors. Developments in Thermochemical Biomass Conversion, London: Blackie Academic \& Professional. 1996; p. 611-621.

[9] Adjaye JD, Bakhshi NN. Production of hydrocarbons by catalytic upgrading of a fast pyrolysis bio-oil. Part I: Conversion over various catalysts. Fuel Process. Technol. 1995;45:161-183.

[10] Sharma RK, Bakhshi NN. Upgrading of wood-derived bio-oil over HZSM-5. Bioresour. Technol. 1991;35:57-66.

[11] Baldauf W, Balfanz U, Rupp M. Upgrading of flash pyrolysis oil and utilization in refineries. Biomass Bioenergy. 1994;7:237-244. 
[12] Samolada MC, Baldauf W, Vasalos IA. Production of a bio-gasoline by upgrading biomass flash pyrolysis liquids via hydrogen processing and catalytic cracking. Fuel. 1998;77:1667-1675.

[13] Lappas AA, Bezergianni S, Vasalos IA. Production of biofuels via co-processing in conventional refining processes. Catal. Today. 2008;145:55-62.

[14] Marker TL, Petri JA, Gasoline and diesel production from pyrolytic lignin produced from pyrolysis of cellulosic waste, Patent number WO 2008/027699, 2008.

[15] Biocoup website. Last visited on 09-09-09; Available from: www.biocoup.eu.

[16] Oasmaa A, Kuoppala E, Gust S, Solantausta Y. Fast pyrolysis of forestry residue. 1. Effect of extractives on phase separation of pyrolysis liquids. Energy Fuels 2003;17:1-12.

[17] Oasmaa A, Solantausta Y, Arpiainen V, Kuoppala E, Sipila K. Fast Pyrolysis BioOils from Wood and Agricultural Residues. Energy Fuels 2009;24:1380-1388.

[18] Wildschut J, Mahfud FH, Venderbosch RH, Heeres HJ. Hydrotreatment of Fast Pyrolysis Oil Using Heterogeneous Noble-Metal Catalysts. Ind. Eng. Chem. Res. 2009;48:10324-10334.

[19] Gutierrez A, Kaila RK, Honkela ML, Slioor R, Krause AOI. Hydrodeoxygenation of guaiacol on noble metal catalysts. Catal. Today. 2009;147:239-246.

[20] Yakovlev VA, Khromova SA, Sherstyuk OV, Dundich VO, Ermakov DY, Novopashina VM, Lebedev MY, Bulavchenko O, Parmon VN. Development of new catalytic systems for upgraded bio-fuels production from bio-crude-oil and biodiesel. Catal. Today. 2009;144:362-366.

[21] B.E. Poling, J.M. Prausnitz, J.P. O'Connell, The Properties of Gases and Liquids, 5th ed., McGraw-Hill, United States, 2001.

[22] Michels A, De Graaff W, Wassenaar T, Levelt JMH, Louwerse P. Compressibility isotherms of hydrogen and deuterium at temperatures between $-175^{\circ} \mathrm{C}$ and $+150^{\circ} \mathrm{C}$ (at densities up to 960 amagat). Physica 1959;25:25-42.

[23] Oasmaa A, Kuoppala E, Solantausta Y. Fast pyrolysis of forestry residue. 2. Physicochemical composition of product liquid. Energy Fuels 2003;17:433-443. 
[24] Elliott DC, Sealock LJ, Baker EG. Chemical processing in high-pressure aqueous environments. 2. Development of catalysts for gasification. Ind. Eng. Chem. Res. 1993;32:1542-1548.

[25] E.S. Domalski, T.L. Jobe (Jr.), T.A. Milne, Thermodynamic Data for Biomass Materials and Waste Components, The American Society of Mechanical Engineers, New York, 1987.

[26] Radlein D. The production of chemicals from fast pyrolysis bio-oils. In: A.V. Bridgwater editor. Fast pyrolysis of biomass. A handbook, Newbury, Berkshire: CLP Press. 1999; p. 164-185.

[27] Laurent E, Pierret C, Grange P, Delmon B. Control of the deoxygenation of pyrolytic oils by hydrotreatment. In. Proc. of 6th conference on Biomass for energy, industry and environment, Athens, Greece. 1991; p. 665-671.

[28] Shin E-J, Keane MA. Gas-Phase Hydrogenation/Hydrogenolysis of Phenol over Supported Nickel Catalysts. Ind. Eng. Chem. Res. 2000;39:883-892.

[29] Neavel RC. Liquefaction of coal in hydrogen-donor and non-donor vehicles. Fuel 1976;55:237-242.

[30] Zhang S, Yan Y, Li T, Ren Z. Upgrading of liquid fuel from the pyrolysis of biomass. Bioresour. Technol. 2005;96:545-550.

[31] S.B. Jones, J.E. Holladay, C. Valkenburg, D.J. Stevens, C.W. Walton, C. Kinchin, D.C. Elliott, S. Czernik, Production of Gasoline and Diesel from Biomass via Fast Pyrolysis, Hydrotreating and Hydrocracking: A Design Case, US Department of Energy, 2009.

[32] R. Sadeghbeigi, Fluid Catalytic Cracking Handbook, Gulf Professional Publishing, Houston, 2000.

[33] Mariaca-Domínguez E, Maya-Yescas R, Rodríguez-Salomón S, González-Ortíz A, Martínez-Tapia GE, Álvarez-Ramirez R, López-Franco C. Reactivity of Fluid Catalytic Cracking Feedstocks as a Function of Reactive Hydrogen Content. Petrol. Sci. Technol. 2004;22:13 - 29.

[34] Chen NY, Degnan Jr. TF, Koening LR. Liquid fuel from carbohydrates. Chemtech 1986;16:506-511. 
[35] Corma A, Huber GW, Sauvanaud L, O'Connor P. Processing biomass-derived oxygenates in the oil refinery: Catalytic cracking (FCC) reaction pathways and role of catalyst. J. Catal. 2007;247:307-327.

[36] A.R. Ardiyanti, R.H. Venderbosch, H.J. Heeres, Process-product studies on pyrolysis oil upgrading by hydrotreatment with Ru/C catalysts, Proceedings of the 2009 AIChE Spring National Meeting, Tampa, FL, US, 2009.

[37] Gagnon J, Kaliaguine S. Catalytic hydrotreatment of vacuum pyrolysis oils from wood. Ind. Eng. Chem. Res. 1988;27:1783-1788.

[38] Venderbosch RH, Ardiyanti AR, Wildschut J, Oasmaa A, Heeres HJ. Stabilization of biomass-derived pyrolysis oils. J. Chem. Technol. Biotechnol. 2010;85:674-686. 


\section{Appendix A}

Table A.1 shows the properties of the Long Residue used in the co-processing experiments. Table A. 2 shows the results of the True boiling point (TBP) analysis.

Table A.1. Long Residue oil properties (data from Shell Global Solutions).

\begin{tabular}{lc}
\hline MCRT (wt. \%) & 2.04 \\
Density D70/4: & 0.872 \\
Mol. Weight (g/mol): & 385 \\
\multicolumn{1}{c}{ Elemental analysis (wt.\%) } \\
\hline Carbon & 86.6 \\
Hydrogen & 12.8 \\
& \\
\multicolumn{1}{c}{ UV-analyses SMS-2783 (wt.\%) } \\
\hline MONO aromatics: & 4.27 \\
DI aromatics: & 3.23 \\
TRI aromatics: & 3.61 \\
TETRA aromatics: & 1.69 \\
TETRA+ aromatics: & 3.35 \\
PENTA+ aromatics: & 1.66 \\
HEXA+ aromatics: & 0.92 \\
HEPTA+ aromatics: & 0.063 \\
PYREN aromatics: & 0 \\
Total aromatics: & 14.46 \\
\hline
\end{tabular}

Table A.2. Results of the True Boiling point analysis of the Long residue $\left[{ }^{\circ} \mathrm{C}\right]$ (data from Shell Global Solutions).

\begin{tabular}{ccccc}
\hline IBP $: 240$ & $22 \%: 382$ & $44 \%: 428$ & $66 \%: 471$ & $88 \%: 548$ \\
$2 \%: 281$ & $24 \%: 387$ & $46 \%: 432$ & $68 \%: 476$ & $90 \%: 563$ \\
$4 \%: 306$ & $26 \%: 392$ & $48 \%: 435$ & $70 \%: 481$ & $92 \%: 585$ \\
$6 \%: 321$ & $28 \%: 397$ & $50 \%: 438$ & $72 \%: 486$ & $94 \%::$ \\
$8 \%: 333$ & $30 \%: 401$ & $52 \%: 442$ & $74 \%: 492$ & $96 \%:$ \\
$10 \%: 342$ & $32 \%: 405$ & $54 \%: 445$ & $76 \%: 498$ & $98 \%:$ \\
$12 \%: 351$ & $34 \%: 410$ & $56 \%: 449$ & $78 \%: 504$ & FBP : \\
$14 \%: 358$ & $36 \%: 414$ & $58 \%: 453$ & $80 \%: 511$ & \\
$16 \%: 365$ & $38 \%: 417$ & $60 \%: 458$ & $82 \%: 519$ & \\
$18 \%: 371$ & $40 \%: 421$ & $62 \%: 462$ & $84 \%: 527$ & \\
$20 \%: 377$ & $42 \%: 425$ & $64 \%: 467$ & $86 \%: 537$ & \\
\hline
\end{tabular}




\section{Hydrodeoxygenation of pyrolysis oil fractions. Process understanding and quality assessment through co-processing in refinery units}

Hydrodeoxygenation (HDO) of pyrolysis oil fractions was studied to better understand the HDO of whole pyrolysis oil and to assess the possibility to use individual upgrading routes for these fractions. By mixing pyrolysis oil and water in a 2:1 weight ratio, two fractions were obtained: oil fraction water addition (OFWA) containing $32 \mathrm{wt} . \%$ of the organics from whole oil and aqueous fraction water addition (AFWA) with the remaining organics. These fractions (and also whole pyrolysis oil as reference) were treated under HDO conditions at different temperatures (220, 270 and $310{ }^{\circ} \mathrm{C}$ ), constant total pressure of 190 bar, and using $5 w t . \%$ Ru/C catalyst. An oil phase product was obtained from all the feedstocks; even from AFWA, 29 wt.\% oil yield was obtained. Quality parameters (such as coking tendency and H/C) for the resulting HDO oils differed considerably, with the quality of the oil from AFWA being the highest. These HDO oils were evaluated by co-processing with an excess of fossil feeds in catalytic cracking and hydrodesulphurisation (HDS) lab-scale units. All co-processing experiments were successfully conducted without operational problems. Despite the quality differences of the (pure) HDO oils, the product yields upon catalytic cracking of their blends with Long Residue were similar. During co-processing of HDO oils and straight run gas oil in a HDS unit, competition between HDS and HDO reactions was observed without permanent catalyst deactivation. The resulting molecular weight distribution of co-processed HDO/fossil oil was similar to when hydrotreating only fossil oil and independent of the origin of the HDO oil. 



\section{Introduction}

Biofuels can help with the reduction of $\mathrm{CO}_{2}$ emissions from fossil fuel usage as well as contribute to the security of energy supply. Unlike first generation biofuels (bio-diesel and bio-ethanol) advanced biofuels can be produced from a wide range of ligno-cellulosic biomass feedstocks, including waste, and their production does not necessarily compete with food or feed production.

One of the options to produce advanced bio-fuels is the co-processing of upgraded pyrolysis oil (also known as bio-oil) in standard refinery units. Using this approach, pyrolysis oil can be obtained where biomass is available and because of the energy densification that the pyrolysis process provides, transportation costs to existing (large scale) refineries could be reduced. The upgrading step would then be integrated in the refinery, using its utilities and product distribution network.

Hydrodeoxygenation (HDO) appears to be a promising upgrading step for pyrolysis oil prior to its co-processing in refinery units (as already seen in Chapter 3 and in literature [1-3]). A review by D.C. Elliot (2007) reviews the achievements regarding HDO of pyrolysis oil over 25 years [4]. Results shown in Chapter 3 indicate that stabilisation of pyrolysis oil by low severity HDO might be sufficient to allow co-processing using refinery processes like FCC. This reduces overall hydrogen consumption during upgrading and is likely to improve overall economics of the production of bio-transportation fuels from pyrolysis oil. The complete removal of oxygen in the upgrading does not seem essential for subsequent co-processing.

Pyrolysis oil can be separated into two fractions by the addition of water, from which a heavy organic rich fraction and an aqueous fraction are obtained [5]. Depending on the amount of water added, the properties of the resulting fractions differ significantly. For example, if an oil:water ratio of at least $1: 10$ is used when pyrolysis oil is added dropwise to intensively stirred ice-cooled water and then filtered, the resulting heavy fraction is a powder, called "pyrolytic lignin" [6]. Typically, the remaining aqueous fraction contains many different components with the "sugar constituents" being a major part (60$70 \mathrm{wt} . \%$ of the organics in this aqueous fraction) [7]. In this paper, the aqueous fraction obtained by water addition will be referred as AFWA. The remaining fraction, when oily in appearance, will be referred as OFWA (oil fraction water addition) and when powder-like, "pyrolytic lignin".

Pyrolytic lignin has a lower oxygen content when compared to whole pyrolysis oil (22-30 wt.\% compared to 33-40 wt.\%, both on dry basis) [6]. For deep deoxygenation [1, 8], this seems advantageous because it reduces the stoichiometric amount of hydrogen required to remove the oxygen as water. Piskorz et al. [9] processed OFWA (in their publication it is called "un-dried pyrolytic lignin") under HDO conditions. A light organic phase was 
obtained with a yield between 60 and $65 \mathrm{wt} \%$ (based on dry feed) with a molar $\mathrm{H} / \mathrm{C}$ ratio of 1.5 and an oxygen content of $\sim 0.5 \mathrm{wt} . \%$. The hydrogen consumption was high with $813 \mathrm{Nl} / \mathrm{kg}$ of product. Oasmaa et al. [10] and Meier et al. [11] conducted hydrotreatment experiments on Kraft and organocell lignins using conventional sulphided NiMo and CoMo catalysts. They found that it is possible to create an oil-like product from lignin and that the presence of catalyst and high hydrogen pressures reduce considerably the formation of coke. De Wild et al. [12] used a Ru/C catalyst for the HDO on the liquid product obtained after pyrolysis of lignin to produce phenols. Using a batch autoclave with an end temperature of $359{ }^{\circ} \mathrm{C}$ and starting with 100 bar of $\mathrm{H}_{2}$, they concluded that $\mathrm{Ru} / \mathrm{C}$ was too active for their process because they mainly produced cycloalkanes, cyclohexanols and alkanes. UOP LCC [4] patented a process in which OFWA (called pyrolytic lignin in the patent) is hydrotreated and thereafter hydrocracked resulting in the production of $30 \mathrm{wt}$ \% gasoline.

Although still relatively little is known about the exact goal and reactions during HDO, the HDO stabilisation step seems to be required to reduce or inhibit rapid self polymerisation of pyrolysis oil that can result in reactor plugging and high coke yields [13]. During high pressure thermal treatment (HPTT) of whole pyrolysis oil (studied in Chapter 2), this fast polymerisation was observed when processing the oil at high pressure (200 bar), temperatures between $200-350{ }^{\circ} \mathrm{C}$ and residence times as short as few minutes. Severe increase in the oil's molecular weight and disappearance of sugar constituents, from the aqueous phase by-product towards the oil phase, indicated that polymerisation of these sugars contributed to the increase in molecular weight. During HDO of whole pyrolysis oil (Chapter 3), with an increasing temperature, also a transfer of water soluble (sugar based) components to the oil phase product was observed, increasing thereby the oil yield. However, in this case, no increase in molecular weight was observed.

This suggests that it should be possible to produce HDO oil from AFWA, and especially from the sugars in it, as long as a proper stabilisation step is applied to prevent excessive polymerisation. Gagnon and Kaliaguine [14] reported that a hydrogenation pre-treatment of vacuum pyrolysis oil at temperatures as low as $80{ }^{\circ} \mathrm{C}$ stabilised the mono- and oligosaccharides (typically present in AFWA) from vacuum pyrolysis oil allowing further HDO without strong polymerisation. During the stabilisation step in HDO functional groups such as aldehydes, ketones and $\mathrm{C}=\mathrm{C}$ double bonds are likely to be hydrogenated towards more stable groups less prone to polymerisation [15]. Based upon pre-fractionation of pyrolysis oil into AFWA and OFWA, HDO of both fractions thus seems a possible process option.

HDO of AFWA can also give more insight into the contribution of the components typically present in this fraction to the yields and qualities of the different product phases (aqueous, oil and gas) upon HDO of whole oil. Wildschut et al. [16] conducted HDO experiments in an autoclave using glucose and cellobiose as model compounds for the sugar fraction of pyrolysis oil. They concluded that, during HDO of these model 
compounds using a ruthenium on carbon $(\mathrm{Ru} / \mathrm{C})$ catalyst, the catalytic hydrotreatment route is preferred over the thermal decomposition that would lead to the formation of tar/solids (humins). The main products observed were polyols and gas products (mostly methane). Elliott and Hart [17] carried out semi-batch HDO experiments using acetic acid and furfural to represent pyrolysis products from hemi-cellulose and cellulose, respectively. From an un-catalysed initial test at $250{ }^{\circ} \mathrm{C}$, a solid polymeric material from furfural was obtained. The conversion of furfural involving two reaction paths: cyclic ketone products (such us cyclopentanone) and cyclic ether products (such us THF). Some of these products reacted to alcohols and even further to $\mathrm{CH}_{4}$ and $\mathrm{CO}_{2}$. These results suggest that in the HDO of AFWA stabilisation is critical to avoid excessive polymerisation, but on the other hand, high temperatures and hydrogen abundance can lead to substantial gas (methane) formation and unnecessarily high hydrogen consumption.

In this chapter, HDO of pyrolysis oil fractions obtained by water addition to pyrolysis oil (AFWA, OFWA) was studied to better understand the HDO of whole pyrolysis oil and to evaluate the suitability of the oils produced from these fractions as feedstock for coprocessing in lab-scale refinery units. In the first part of this chapter, product yields and properties obtained after HDO of the fractions are compared to those obtained after HDO of whole pyrolysis oil (experiments by University of Twente), identifying in this way possible upgrading routes. The results obtained by co-processing the OFWA and AFWA HDO oils in lab-scale refinery units (FCC experiments by Shell Global Solutions and hydrotreating experiments by CNRS) are discussed in the second part of this chapter and are used to assess the quality of the resulting HDO oils.

\section{Experimental section}

\subsection{Materials}

The pyrolysis oil used for this research was produced by VTT (Finland) in a $20 \mathrm{~kg} / \mathrm{h}$ process development unit [18] using forest residue as feedstock. The properties of this oil can be seen in Table 1. 2 wt.\% of i-propanol was added to the fresh oil, facilitating the separation of a top layer (10.6 wt.\%) containing a large number of extractives. The remaining fraction was the one used in this study ('whole pyrolysis oil') and used to prepare the OFWA and AFWA fractions. After receiving the oil from VTT, it was kept at $10^{\circ} \mathrm{C}$ to avoid aging.

In order to know the amount of water needed to induce pyrolysis oil phase separation, different amounts of water (from 10:1 to 1:1 oil:water weight ratio) were added to the pyrolysis oil. They were mixed in an ultrasonic bath for an hour and then centrifuged to facilitate phase separation. The aqueous fraction (AFWA) was on top and had a light 
brown colour and the oil fraction (OFWA) was a dark brown viscous liquid. Each fraction obtained was analysed for water content and elemental composition. The distribution of organics into the two fractions can be seen in Figure 1. It shows that at 10:1 ratio, no phase separation occurred. At 4:1 ratio, most of the organics remained in the AFWA. With increasing amount of water added, a plateau was reached yielding approximately 69 wt. \% and 32 wt.\% of organics in AFWA and OFWA, respectively. From these data, it was decided to use the minimum amount of water needed to reach the plateau, thus, 2:1 oil:water weight ratio was used to prepare the samples for HDO. Figure 2 shows the molecular weight distribution (MWD) of the whole oil and its fractions (AFWA and OFWA). It can be seen that, in general, the light components present in the whole oil were transferred to the AFWA and the heavier ones to the OFWA.

Because of the large quantities of AFWA and OFWA needed for the HDO experiments presented in this work, another less laborious method was used to obtain the fractions. Water was slowly added to pyrolysis oil while stirring with a magnetic stirrer. After adding the desired amount of water, the mixture was stirred for another 30 minutes. Then, the stirrer was stopped to allow the phases to settle. The distribution of organics using this method can also be seen in Figure 1. The MWD of these fractions was the same as obtained using the ultrasonic method (results not shown).

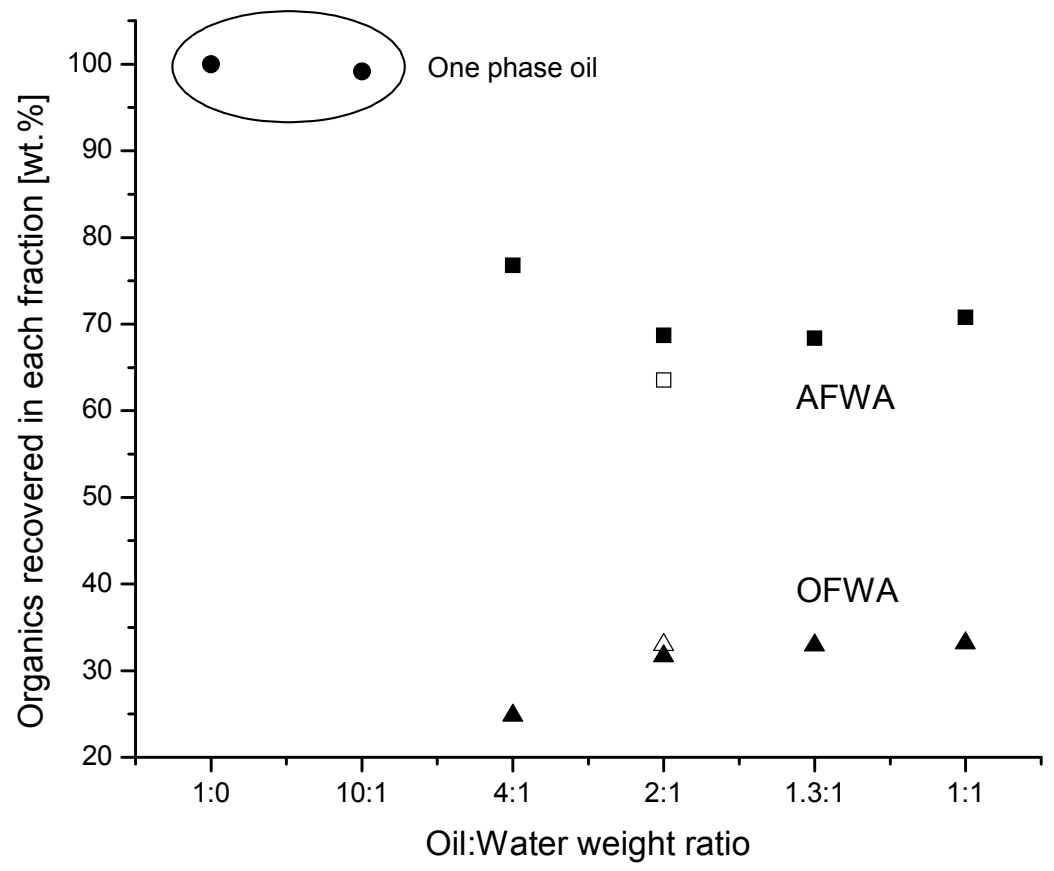

Figure 1. Distribution of organics over AFWA and OFWA as a function of added amount of water to pyrolysis oil. Closed symbols correspond to results obtained using an ultrasonic bath for mixing and a centrifuge for separation. Open symbols correspond to results obtained by using a magnetic stirrer for mixing (30 minutes) followed by gravity separation. 
The catalyst used for the HDO experiments was ruthenium on carbon (Ru/C) with a metal loading of $5 \mathrm{wt} . \%$ and an average particle size of $14 \mu \mathrm{m}$. It was supplied by SigmaAldrich and it was used without any pre-treatment. This catalyst was selected because of its good HDO activity [19] and to allow comparison with results shown in Chapter 3 and literature $[12,16,17]$.

Table 1. Properties of the forest residue pyrolysis oil and the fractions obtained by water addition (2:1 oil:water weight ratio) .

\begin{tabular}{lccc}
\hline & Pyrolysis oil & OFWA & AFWA \\
\cline { 2 - 4 } $\begin{array}{l}\text { Elemental composition and } \\
\text { water content }\end{array}$ & & & \\
C dry [wt.\%] & 54.3 & 62.6 & 53.4 \\
$\mathrm{H}$ dry [wt.\%] & 7.0 & 6.4 & 7.6 \\
O dry [wt.\%] & a & 31.0 & 38.9 \\
Water [wt.\%] & 38.7 & 16.9 & 60.3 \\
& 25.0 & & \\
Carbon residue & & & \\
MCRT [wt.\%] & 19.7 & 29.9 & 8.54 \\
MCRT dry ${ }^{\text {[wt.\%] }}$ & 26.2 & 35.9 & 21.5 \\
\hline${ }^{\text {a by difference }}{ }^{\text {b corrected for water content }}$ & & &
\end{tabular}

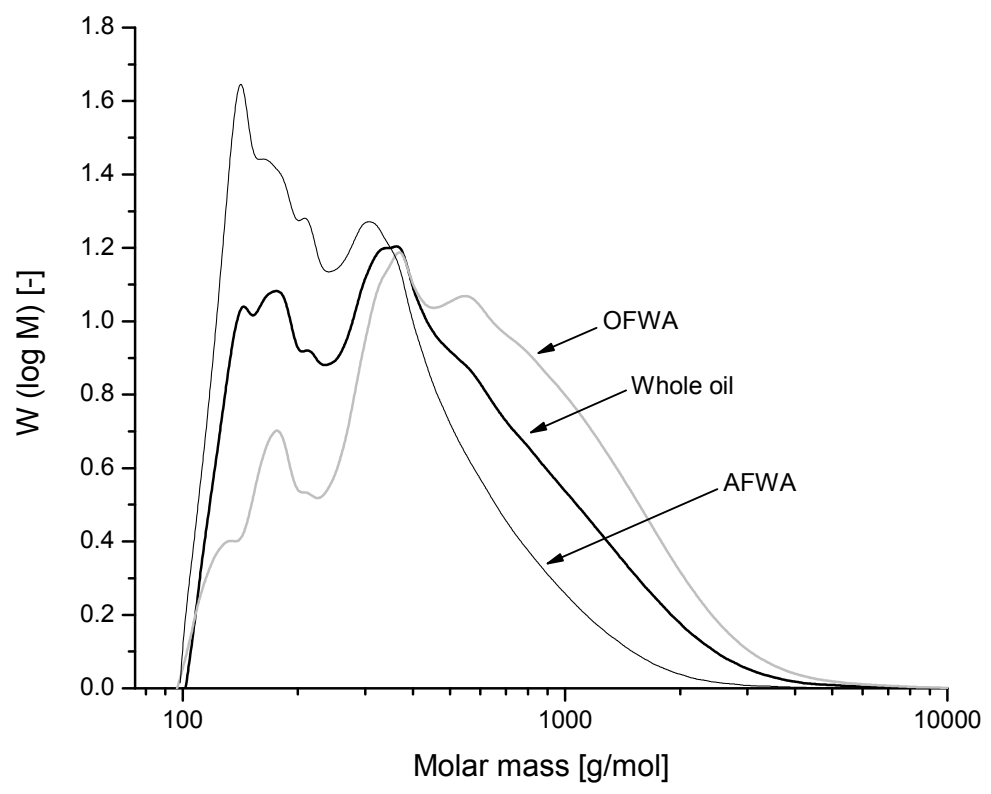

Figure 2. Molecular weight distribution of the whole oil and its fractions (AFWA and OFWA). 


\subsection{Experimental set-up and procedure}

Hydrodeoxygenation experiments were conducted in an intensively stirred autoclave from Autoclave Engineers with an internal volume of $0.6 \mathrm{I}$. The stirrer had a hollow shaft to induce gas-liquid mixing and thereby improve mass transfer. The maximum allowed temperature and pressure were $350{ }^{\circ} \mathrm{C}$ and 210 bar, respectively. For safety reasons, the autoclave was placed inside a high pressure box and it was monitored and controlled from outside. Figure 3 shows a schematic representation of the set-up.

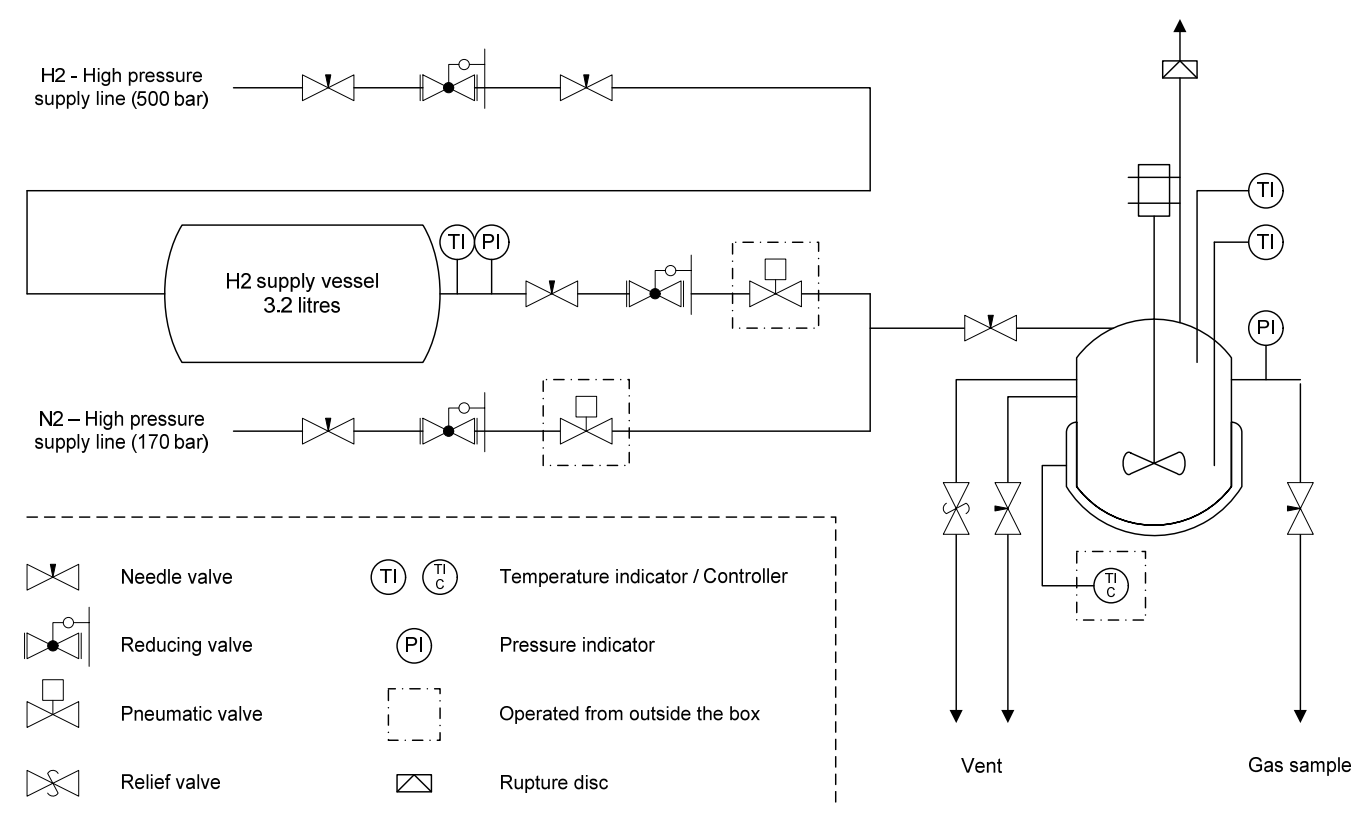

Figure 3. Schematic overview of the HDO set-up.

In a typical experiment, approximately $250 \mathrm{~g}$ of pyrolysis oil or one of its fractions was loaded into the autoclave. Baffles were placed inside the autoclave to improve agitation. Then, $5 \mathrm{wt}$ \% (on wet basis) of fresh catalyst was added. The autoclave was closed and a first leak test was conducted with nitrogen at 170 bar. If the leak test was successful, nitrogen was vented, removing at the same time the remaining air that was inside. Afterwards, a second leak test was carried out using hydrogen at the typical reaction pressure of 190 bar. Then, the hydrogen was vented also removing the remaining nitrogen. A supply vessel with a known volume of 3.21 I was filled with hydrogen to a pressure of 300 bar. The pressure and temperature of this vessel were recorded as a function of time in order to calculate the hydrogen consumption (rate) during the reaction. The reactor was filled with 100 bar of hydrogen and an electric oven (jacket) was placed around it. At this moment, the high pressure box was closed and the monitoring and control of the process was done from outside. The stirrer $(20 \mathrm{~Hz})$ and the heater were started. The heating rate was $7-9{ }^{\circ} \mathrm{C} / \mathrm{min}$ at the beginning and $1.5-2.5{ }^{\circ} \mathrm{C} / \mathrm{min}$ when approaching the temperature set-point. This means that it took from 50 to 80 minutes to 
reach the desired reaction temperature and the low temperature stabilisation reactions were already occurring during this period (hydrogenation of olefins, aldehydes and ketones already occur at temperatures under $200{ }^{\circ} \mathrm{C}$ [15]). This was further confirmed by the high hydrogen consumption (rate) observed during the heating time, especially for the experiments using AFWA as feed (see Figure 4). Up to a temperature of $\sim 150{ }^{\circ} \mathrm{C}$, the pressure inside the reactor increased due to the temperature effects, however after that it started to decrease. Then, more hydrogen was slowly added to the reactor in order to obtain a pressure of 190 bar when the desired reaction temperature was reached. Although reactions had already occurred in the heating period, in this study, this final temperature will be referred to as 'reaction temperature'. When the pressure inside the reactor dropped below the set-point, a reducing valve between the supply vessel and the reactor allowed hydrogen into the reactor, conducting in this way a semi-batch experiment. The reaction time was typically $4 \mathrm{~h}$, excluding heating time. After the desired reaction time, the heating was stopped, and the stirrer was kept on for 30 min more. Subsequently, the system was allowed to cool overnight. When the system was at room temperature, the final pressure and temperature of the reactor and supply vessel were noted and a gas sample from the reactor was taken for analysis. The total hydrogen consumption was calculated taking into account the initial and final number of moles of hydrogen in the supply vessel minus the number of moles of hydrogen that remained unreacted in the reactor. Next, the reactor was depressurised, opened and the liquid product, which normally consisted of different phases (see section 3), collected and weighed.

The resulting HDO oils were co-processed in two different lab-scale refinery processes, viz. hydrodesulphurisation (HDS) and catalytic cracking. HDS experiments were performed by CNRS (Lyon, France), co-processing the upgraded oil with straight run gas oil (SRGO). The catalyst used was a commercial sulphided CoMo catalyst, the reactor temperature was $380{ }^{\circ} \mathrm{C}$ and the LHSV, $2 \mathrm{~h}^{-1}$. Both SRGO and HDO oil (diluted in ipropanol to reduce viscosity) were fed using separate pumps, mixing them at the inlet of the reactor. Further details about this equipment and the SRGO used as co-processing fossil feed can be found elsewhere [20]. Catalytic cracking experiments were conducted by Shell Global Solutions in a MAT-5000 reactor. FCC equilibrium catalyst was used to co-process HDO oil with Long Residue fossil feed. The description of the set-up used and the properties of the Long Residue can be found in Chapter 3.

\subsection{Analysis}

At the end of a HDO experiment, a sample of the remaining gasses was taken and analysed in a Micro GC Varian CP-4900 with three analytical columns: $10 \mathrm{~m}$ Molsieve 5A and $10 \mathrm{~m}$ PPQ using helium as carrier gas and $10 \mathrm{~m}$ Molsieve $5 \mathrm{~A}$ using argon as carrier gas for better hydrogen quantification. 


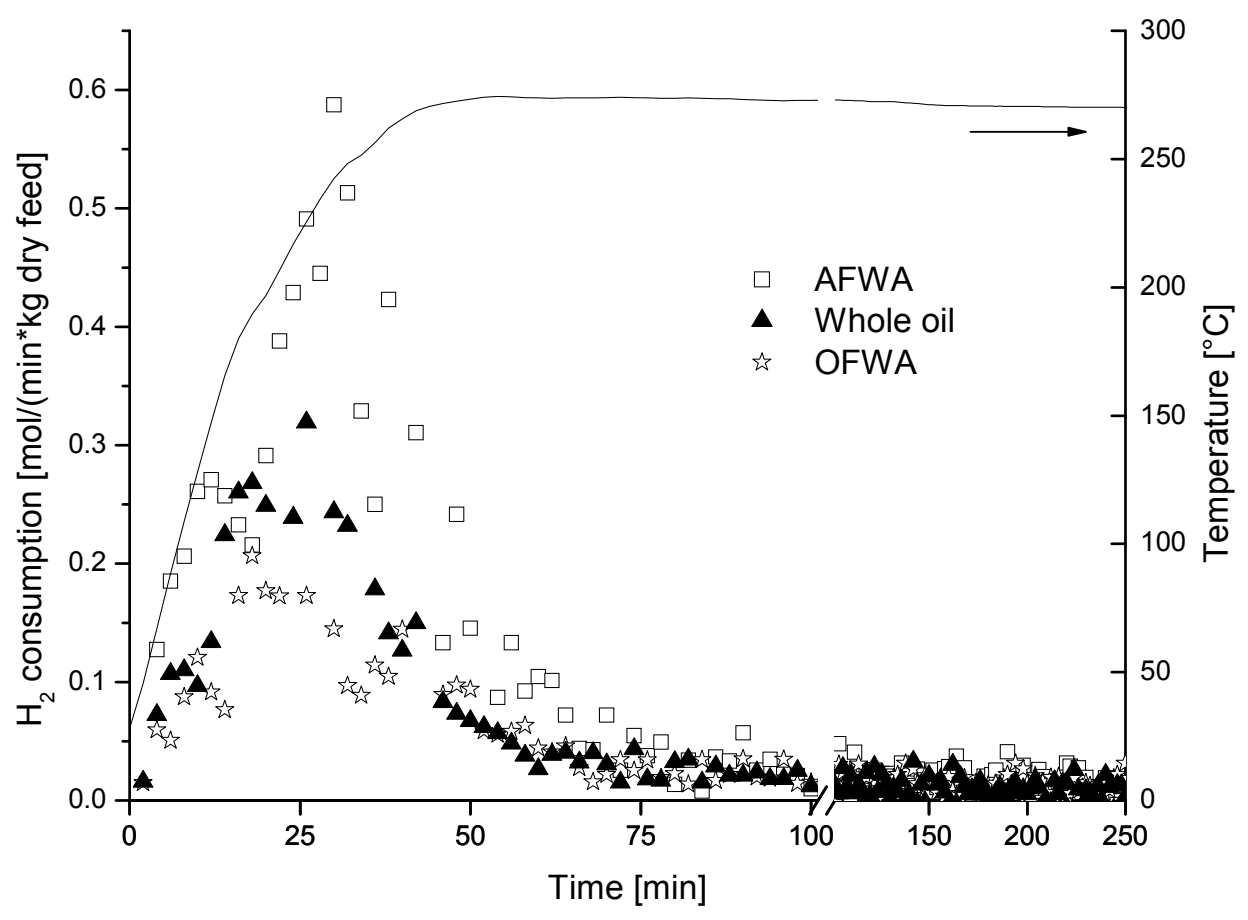

Figure 4. Hydrogen consumption rate and temperature profile for the experiments at $270{ }^{\circ} \mathrm{C}$ using whole oil, AFWA and OFWA. This rate was estimated taking into account reactor and hydrogen supply vessel pressures corrected by the calculated water vapour pressure inside the reactor.

The pyrolysis oil fractions and the HDO products were analysed for elemental composition (Thermo Scientific Flash 2000), water content (787 KF Titrino) and molecular weight distribution (Agilent HPLC 1200, with GPC columns). More details about the equipment and reactants can be found in Chapter 2.

Micro carbon residue tests (MCRT) were performed on all the feeds and oil products following the ASTM D4530 standard.

The SRGO and the co-processed products from the HDS unit were analysed on total sulphur content using an Antek 900 analyser. For these samples also the MWD was measured. In this case, an Agilent HPLC 1200 system with PLGel $5 \mu \mathrm{m} 50 \AA$ and $5 \mu \mathrm{m}$ $500 \AA$ ( $300 \mathrm{~mm} \times 7.5 \mathrm{~mm}$ ) was used (analysis performed by CNRS).

The Long Residue and the products obtained by co-processing in the MAT unit were analysed using true boiling point (TBP) analysis following the ASTM D2887 standard, quantifying the yields of the different oil fractions (analysis by Shell Global Solutions). 


\section{Hydrodeoxygenation of pyrolysis oil and its fractions}

Three series of experiments were conducted using the three different feeds: whole pyrolysis oil, AFWA and OFWA. Each series consisted of three experiments carried out at different temperatures: $220{ }^{\circ} \mathrm{C}, 270{ }^{\circ} \mathrm{C}$ and $310{ }^{\circ} \mathrm{C}$ and a residence time of $4 \mathrm{~h}$ (at reaction temperature, thus excluding heating time). As said in the previous section, all the experiments were carried out at a constant total pressure of 190 bar by allowing hydrogen from the supply vessel to the reactor. However, for the experiment at $310{ }^{\circ} \mathrm{C}$ and using AFWA as feed, only 160 bar of $\mathrm{H}_{2}$ was added when the reaction temperature was reached, stopping the supply of hydrogen from the vessel, to be able to extend the reaction time to the typical $4 \mathrm{~h}$. In spite of this measure, the experiment had to be stopped after $2 \mathrm{~h}$ because the pressure was exceeding 200 bar (safety limit) due to the production of gasses.

The properties and appearance of the liquid product depended on the type of feed used. When AFWA was used as feed, the product not only consisted of an aqueous phase but a new oily organic phase was created. This oil was completely adsorbed in the catalyst, forming a paste-like material. To recover the oil, this catalyst-oil mixture was dissolved in acetone and filtered ( $6 \mu \mathrm{m}$ filter). The acetone was thereafter removed in a rotary evaporator, recovering the solvent-free oil while the catalyst and some char remained on the filter. The resulting oil had a dark brown colour and low viscosity. This oil will be referred to as $\mathrm{AFWA}_{\mathrm{oil}}$ and the aqueous phase by-product $\mathrm{AFWA}_{\mathrm{aq}}$.

When OFWA was processed by HDO, two phases were obtained, viz. an aqueous phase $\left(\right.$ OFWA $\left._{a q}\right)$ floating on top and an oil phase $\left(O F W A_{\text {oil }}\right)$ at the bottom. The OFWA was dark brown and very viscous. These phases were separated and quantified. The amount of OFWA oil $_{\text {il }}$ was determined by correcting for the catalyst intake. Because of the

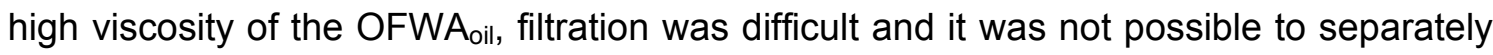
determine the amount of char produced. Some of the OFWA oil $_{\text {was }}$ filtered using a pressurised system ( 8 bar) and a steel wire mesh $(5 \mu \mathrm{m})$ to obtain enough sample for analysis and co-processing.

For whole pyrolysis oil (whole oil), either a two or three phase product was obtained, depending on reaction temperature. If three phases were obtained, an oil phase was on top, an aqueous phase in the middle and another oil phase was at the bottom. Depending on the time the sample was allowed to settle after collecting it from the reactor, the amount of top and bottom phase changed (the sum remaining constant). For that reason, it was decided to separate the aqueous phase (whole-oil ${ }_{a q}$ ) and mix both oil phases into a single oil phase (whole-oil ${ }_{\text {oil }}$ ). This oil phase was filtered with the same filter as used for the OFWA ${ }_{\text {oil. }}$ 
For all the experiments, the mass balance closure in wet basis was between 90 and 98 wt. \%; being between 87 and $98 \mathrm{wt} . \%$ on dry basis. The lower balance closure, mainly for HDO of AFWA (see Table 2), was probably due to the small amount of organics present in the feedstock (water content $60.3 \mathrm{wt} \%$ ), making small losses of organic material (especially during recovery of the oil product) more significant.

Table 2 shows the dry yields of all the experiments (for details on how these yields were calculated see Chapter 2). It can be seen that when AFWA was used as feed, an oil phase $\left(A F W A_{\text {oil }}\right)$ was produced, increasing its yield with the temperature, especially between $220^{\circ} \mathrm{C}$ and $270{ }^{\circ} \mathrm{C}$. Dedicated experiments on HDO of AFWA to determine the amount of sugars in AFWA feed and $\mathrm{AFWA}_{\mathrm{aq}}$ product (using BRIX analysis [21] conducted by VTT, Finland) showed a reduction of the sugars present in AFWA $A_{a q}$ compared to AFWA feed, being this reduction more significant at higher reaction temperature. At $300{ }^{\circ} \mathrm{C}$ and $120 \mathrm{~min}$ reaction time, $80 \mathrm{wt}$ \% of the sugars from the AFWA feed was not present in the AFWA $A_{a q}$ anymore. This indicates that the new oil phase produced from the AFWA contains high amounts of sugars (derivatives). The amount of gas produced also increased considerably with temperature, reaching $18 \mathrm{wt} . \%$ at $310^{\circ} \mathrm{C}$, forcing an early stop of the experiment to prevent an excessive pressure in the reactor. The gas formation was the highest of the three feedstocks. It appears to be logical that the gas formation is much higher for AFWA than for OFWA, since the former contains lighter components than the latter (see Figure 2). Excessive gas production during HDO of acetic acid using a Ru/C as catalyst was already observed by Elliott and Hart [17]. At temperatures higher than $250{ }^{\circ} \mathrm{C}$ they observed a considerable production of $\mathrm{CH}_{4}$ and $\mathrm{CO}_{2}$ while at temperatures lower than $200{ }^{\circ} \mathrm{C}$, most of the acid remained unconverted. Wildschut et al. [16], also found high gas formation (37\% of the carbon was recovered in the gas phase) during HDO of glucose solution, as representative of pyrolysis oil carbohydrate fraction, at $250{ }^{\circ} \mathrm{C}, 4.3 \mathrm{~h}$ reaction time and using $\mathrm{Ru} / \mathrm{C}$ as catalyst. In the present work, the dry gas yield from whole pyrolysis oil at $310{ }^{\circ} \mathrm{C}$ was 6 wt. $\%$. However, when pyrolysis oil is split into the AFWA and OFWA, the overall - weight fraction based - gas yield at the same temperature is $13 \mathrm{~g}$ gas / $100 \mathrm{~g}$ dry whole oil (the contribution from AFWA to this value is $88 \%$ ). This is clearly much higher than the gas yield as obtained for whole oil, which (in this comparison) contains the same quantity of light components as the AFWA. This could be a result of the ratio of catalyst to dry feed; for all the experiments, $5 \mathrm{wt}$ \% of catalyst on wet feed basis was used. This means that for the experiments using AFWA the amount of catalyst per amount of organics (12.4 wt.\%) was much higher than for the experiments with whole oil (6.7 wt.\%) and OFWA (6.0 wt.\%), which might have favoured the overall rate of (irreversible) reactions towards gas formation. The composition of the gas produced from the AFWA is also remarkable (Figure 5): the main gas produced at 220 and $270{ }^{\circ} \mathrm{C}$ was methane. The high methane production is likely to be caused by the use of $\mathrm{Ru}$ based catalyst (known to favour methanation reactions [22]). As indicated, at the highest temperature of $310{ }^{\circ} \mathrm{C}$, the $\mathrm{H}_{2}$ supply had to be stopped earlier because of the pressure increase and associated safety issues, resulting in limited hydrogen availability. At the end of the experiment, after 
Table 2. HDO product yields, hydrogen consumption and oil properties.

\begin{tabular}{|c|c|c|c|c|c|c|c|c|c|}
\hline \multirow{2}{*}{$\begin{array}{l}\text { Feed } \\
\text { Temperature }\left({ }^{\circ} \mathrm{C}\right)\end{array}$} & \multicolumn{3}{|c|}{ AFWA } & \multicolumn{3}{|c|}{ OFWA } & \multicolumn{3}{|c|}{ Whole oil } \\
\hline & 220 & 270 & 310 & 220 & 270 & 310 & 220 & 270 & 310 \\
\hline Residence time $(\mathrm{min})^{\mathrm{a}}$ & 240 & 240 & 120 & 240 & 240 & 240 & 240 & 240 & 240 \\
\hline \multicolumn{10}{|l|}{ Dry yields } \\
\hline Gas phase & 4 & 12 & 18 & 2 & 3 & 5 & 3 & 4 & 6 \\
\hline Water produced & 9 & 11 & 13 & - & 7 & 16 & 10 & 10 & 16 \\
\hline Aqueous phase & 64 & 39 & 25 & 5 & 9 & 5 & 32 & 25 & 17 \\
\hline Oil phase + char & 15 & 30 & 31 & 83 & 74 & 70 & 53 & 58 & 56 \\
\hline Char & 3 & 2 & 2 & N.A. ${ }^{b}$ & N.A. ${ }^{b}$ & N.A. ${ }^{b}$ & N.A. ${ }^{b}$ & N.A. ${ }^{b}$ & N.A. ${ }^{b}$ \\
\hline Mass balance closure & 92 & 92 & 87 & 90 & 93 & 96 & 98 & 97 & 95 \\
\hline \multicolumn{10}{|l|}{$\mathrm{H}_{2}$ consumption } \\
\hline $\mathrm{NL} \mathrm{H}_{2} / \mathrm{kg}$ dry feed & 487 & 674 & 442 & 188 & 253 & 375 & 247 & 299 & 401 \\
\hline $\mathrm{NL}_{2} / \mathrm{MJ}$ oil phase prod. & 114 & 72 & 44 & 7 & 11 & 14 & 15 & 16 & 19 \\
\hline \multicolumn{10}{|l|}{ Product oil properties } \\
\hline C (dry, wt.\%) & 68.5 & 68.2 & 71.6 & 68.4 & 69.4 & 77.8 & 65.2 & 68.5 & 74.4 \\
\hline H (dry, wt.\%) & 9.6 & 9.9 & 9.7 & 7.6 & 8.1 & 8.6 & 8.1 & 8.6 & 10.0 \\
\hline $\mathrm{O}(\mathrm{dry}, \mathrm{wt} . \%)^{\mathrm{c}}$ & 21.9 & 21.9 & 18.7 & 24.0 & 22.5 & 13.6 & 26.7 & 22.9 & 15.6 \\
\hline $\mathrm{H}_{2} \mathrm{O}$ (wt.\%) & 12.1 & 7.7 & 0.8 & 7.5 & 7.6 & 6.7 & 14.7 & 7.6 & 4.4 \\
\hline HHV (wet, MJ/kg) & 29.4 & 31.1 & 34.7 & 28.2 & 29.3 & 33.9 & 25.4 & 29.5 & 35.1 \\
\hline MCRT (wt.\%) & 4.71 & 3.96 & 5.55 & 21.7 & 15.2 & 18.1 & 13.1 & 9.86 & 5.33 \\
\hline MCRT dry ${ }^{\mathrm{e}}$ (wt.\%) & 5.36 & 4.29 & 5.60 & 23.4 & 16.5 & 19.3 & 15.3 & 10.7 & 5.57 \\
\hline$H / C_{\text {eff }}^{f}$ & 1.20 & 1.26 & 1.23 & 0.80 & 0.91 & 1.07 & 0.88 & 1.00 & 1.30 \\
\hline$H / C_{\text {eff }}$ blend $^{g}$ & 1.67 & 1.68 & 1.67 & 1.60 & 1.62 & 1.64 & 1.62 & 1.64 & 1.68 \\
\hline
\end{tabular}

a excluding heating time

${ }^{\mathrm{b}}$ not available

determined by difference

calculated using Reed's

ormula [23]

${ }^{\mathrm{e}}$ corrected for water

$H / C_{\text {eff }}=(H-2 \times O) / C[24,25]$

${ }^{9}$ blend 20 wt.\% in Long Residue 
cooling down, only $9 \mathrm{~mol} \%$ of the gas was $\mathrm{H}_{2}$, compared to $90 \mathrm{~mol} \%$ in the experiment at $220{ }^{\circ} \mathrm{C}$. At the same time, the ratio of produced $\mathrm{CO}_{2} / \mathrm{CH}_{4}$ strongly increased with reaction temperature $\left(220{ }^{\circ} \mathrm{C}\right.$ : $\left.0.02,270{ }^{\circ} \mathrm{C}: 0.06,310{ }^{\circ} \mathrm{C}: 0.77\right)$. These results indicate that a) the production of $\mathrm{CO}_{2}$ is favoured over that of $\mathrm{CH}_{4}$ in case of shortage of hydrogen and $b$ ) in the beginning of the experiment with an end temperature of $310{ }^{\circ} \mathrm{C}$ mainly hydrogenation occurred (low temperatures), followed by decarboxylation upon hydrogen shortage in the later phase (high temperature) of the experiment.

When OFWA was used as feed, an increasing reaction temperature led to a decrease in the oil phase product (OFWA oil $_{\text {) }}$ yield (Table 2). However, when looking at the carbon distribution (Figure 6 ), the carbon that remained in the OFWA $\mathrm{oil}_{\text {oil }}$ was approximately constant. The decrease in oil yield can be attributed to the removal of oxygen from OFWA $_{\text {oil }}$ (from 24.0 to 13.6 wt.\%, on dry basis) by water formation and to a smaller extent $\mathrm{CO}_{2}$ formation (Figure 5). Although the dry yield OFWA $\mathrm{Aq}_{\mathrm{aq}}$ was low when compared to HDO of AFWA and whole oil (factor of 3-4 lower), a remarkable trend can be observed. The highest yield of OFWA $\mathrm{Oaq}_{\mathrm{aq}}$ wastained at the intermediate reaction temperature of $270{ }^{\circ} \mathrm{C}$. At $310^{\circ} \mathrm{C}$, the OFWA aq yield decreased again by the production of gas and/or water. The $\mathrm{CO}_{2} / \mathrm{CH}_{4}$ ratio for the produced gasses favoured $\mathrm{CO}_{2}$, especially at low temperature $\left(220^{\circ} \mathrm{C}: 16.5,270{ }^{\circ} \mathrm{C}: 7.8,310^{\circ} \mathrm{C}: 1.7\right)$. In all cases the ratio was (much) higher than when AFWA was used as feed. With increasing temperature, and without hydrogen shortage, $\mathrm{CH}_{4}$ formation appears to be favoured. Furthermore, part of the components that were in the OFWA $\mathrm{A}_{\mathrm{aq}}$ at $270{ }^{\circ} \mathrm{C}$, disappeared at $310{ }^{\circ} \mathrm{C}$ forming $\mathrm{CH}_{4}$.

For the experiments using the whole oil as feedstock, the yield of oil phase product (whole-oil oil) remained approximately constant and the reduction of organics in the resulting aqueous phase product (whole-oilaq) appears to be due to the formation of gas and water (Table 2). However, similar to the case of OFWA, the carbon distribution over the product phases reveals more information (Figure 6). The increase in carbon recovery in the whole-oil ${ }_{\text {oil }}$ with the reaction temperature indicates that components with initially higher affinity for the whole-oilaq changed their polarity due to the HDO reactions and

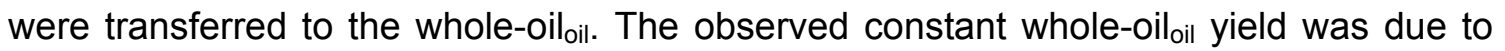
the accompanying reduction of oxygen content (from 26.7 to $15.6 \mathrm{wt} . \%$, on dry basis). These results are in line with results shown in Chapter 3. This transfer of organics is further evidenced by the results in this study that show that it is possible to produce an oil phase product from $\mathrm{HDO}$ of AFWA. The main gas produced was $\mathrm{CO}_{2}$ for all the reaction temperatures; the production of $\mathrm{C} 2-\mathrm{C} 3$ and $\mathrm{CH}_{4}$ became more significant at 310 ${ }^{\circ} \mathrm{C}$. The $\mathrm{CO}_{2} / \mathrm{CH}_{4}$ ratio $\left(220{ }^{\circ} \mathrm{C}: 7.9,270{ }^{\circ} \mathrm{C}: 7.4,310{ }^{\circ} \mathrm{C}\right.$ : 4.9$)$ was lower than for the case of OFWA, except for the highest temperature, probably due to methanation of components typically present in AFWA. Similar to OFWA, methanation appears to be favoured with increasing temperature (no hydrogen shortage occurred in these experiments). 


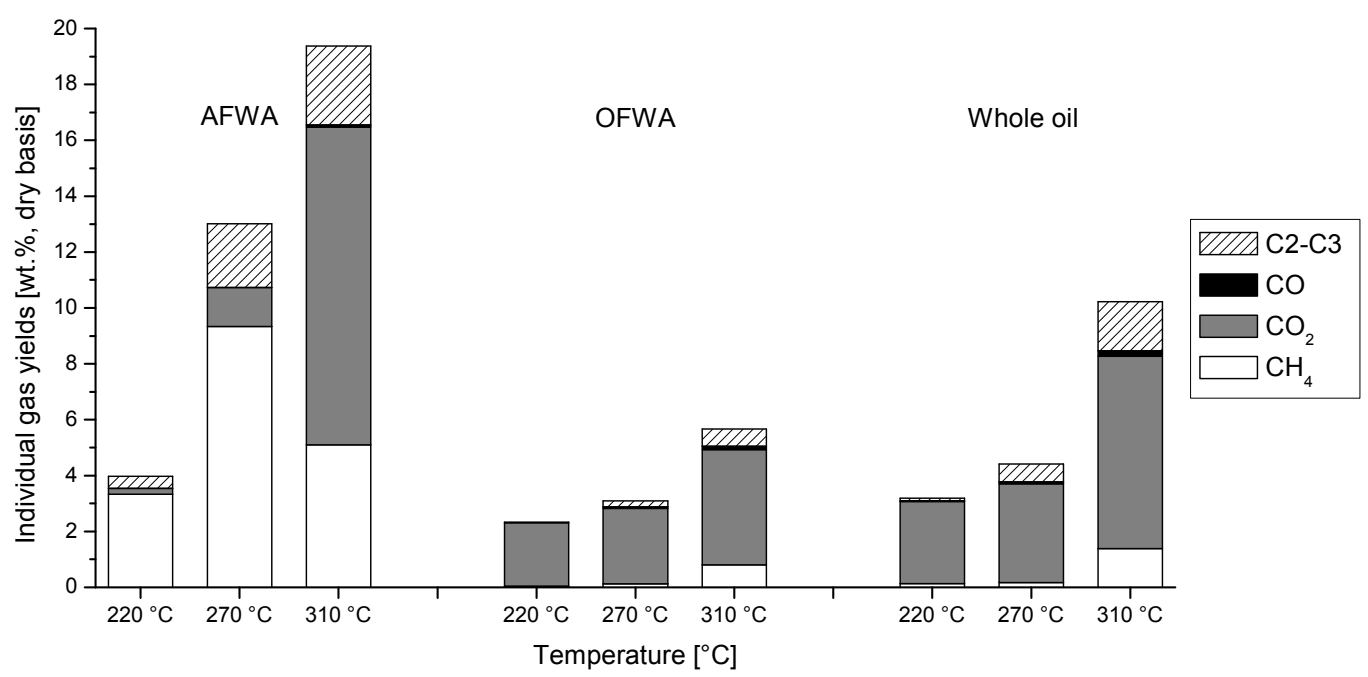

Figure 5. Individual gas yields for HDO experiments at different temperature and feedstock. C2 and C3 are mainly ethane and propane, respectively.

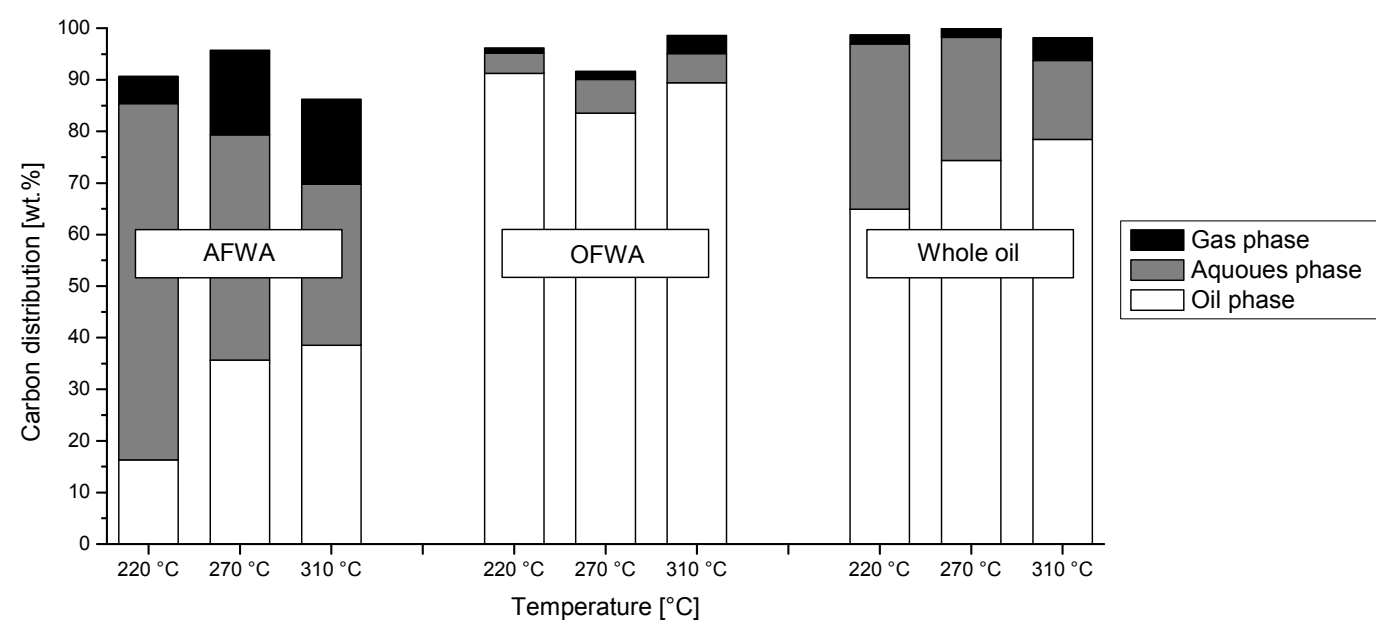

Figure 6. Carbon distribution over the product phases using different feedstocks and reaction temperature.

From the dry elemental composition of the liquid HDO products, the molar $H / C$ and $O / C$ can be calculated (calculation methods can be found in Chapter 2). The representation of these values for the three feedstocks and their HDO oil phase products can be seen in the Van Krevelen diagram in Figure 7. The results will be discussed in the following paragraphs.

The first observation in Figure 7 is the large difference in results as obtained for various feedstocks. Compared to the results obtained for whole oil, OFWA $\mathrm{oil}_{\text {il }}$ has a lower $\mathrm{O} / \mathrm{C}$, but 
also a lower $H / C$. As alredy indicated in Chapter 3 , the $H / C$ might me a better quality indicator than $\mathrm{O} / \mathrm{C}$ when considering co-processing in FCC units. On the other side of the diagram, AFWA $\mathrm{oil}_{\text {oil }}$ appears to have a higher $\mathrm{O} / \mathrm{C}$ and $H / C$ than whole-oil ${ }_{\text {oil }}$.

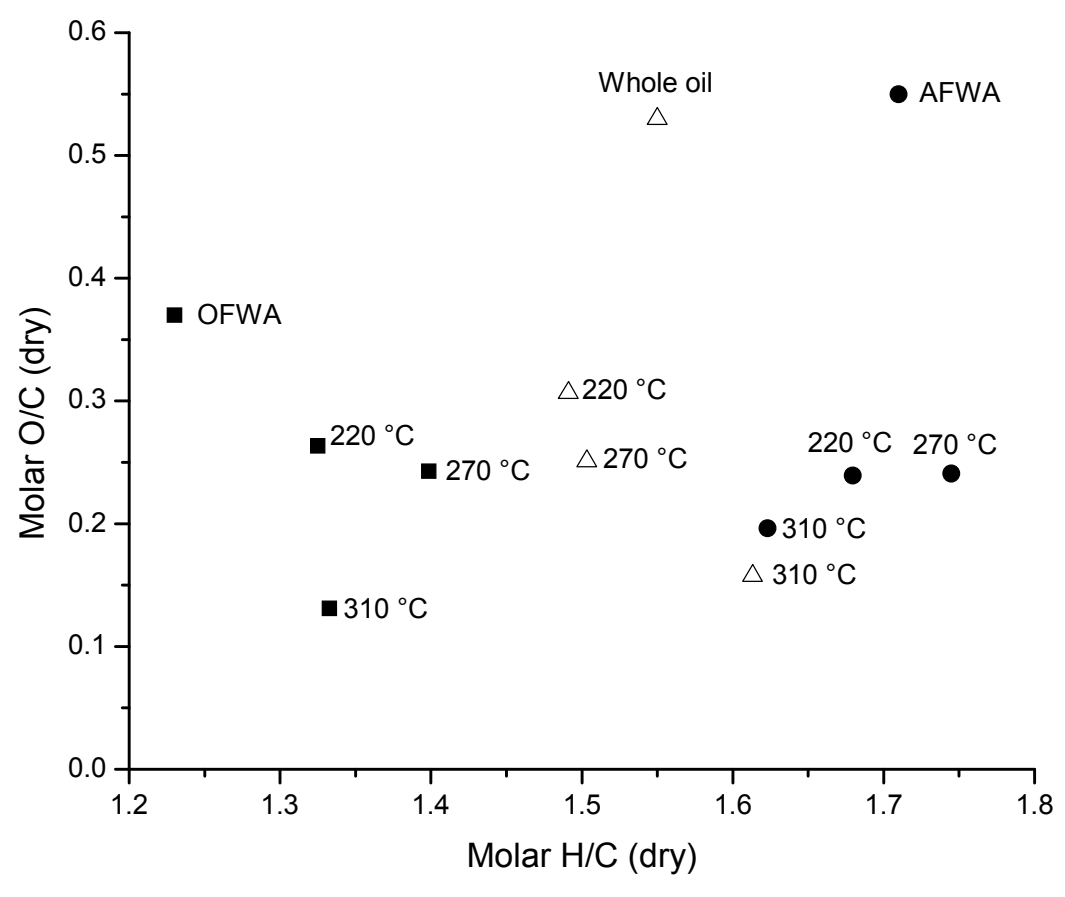

Figure 7. Van Krevelen diagram for the (dry) HDO oil phase products (from AFWA, OFWA and whole oil respectively) obtained at different temperatures. Dry analyses of the 3 feedstocks included.

For the AFWA $A_{\text {oil }}$ and compared to AFWA feed, a drastic decrease in the $O / C$ ratio is observed with only a relatively small change in $H / C$. Since the organics present in the untreated AFWA are water soluble (thus polar), this decrease in $O / C$ appears to be necessary to create a new (hydrophobic) oil phase. When comparing the AFWA $A_{\text {oil }}$ at different temperatures, an increase in $H / C$ ratio can be seen when increasing the temperature from $220^{\circ} \mathrm{C}$ to $270{ }^{\circ} \mathrm{C}$, keeping the $\mathrm{O} / \mathrm{C}$ approximately constant. At $310^{\circ} \mathrm{C}$, both the $\mathrm{H} / \mathrm{C}$ and the $\mathrm{O} / \mathrm{C}$ decreased. This can be explained by the lack of hydrogen availability and/or the fact that hydrogenation reactions are favoured at lower temperature $\left(150-250{ }^{\circ} \mathrm{C}\right)$ and deoxygenation/dehydration reactions are favoured at higher temperature $\left(>\sim 300^{\circ} \mathrm{C}\right)$ [15]. Since the $H / C$ of the AFWA $A_{\text {oil }}$ was not higher than the feed, the very high hydrogen consumption (Table 2) must overall be attributed to the high methane production, the production of water and the hydrogenation of the organics that remained in the AFWA $A_{a q}$. Analysis of these organics in the resulting AFWA $A_{a q}$ indeed yielded very high $H / C$, between 2.11 and 2.27 , and an $O / C$ decreasing with temperature from 0.44 to 0.20 (see Figure 8). The combined results at $220{ }^{\circ} \mathrm{C}$ (negligible $\mathrm{CO}_{2}$ formation, considerable oil production with lower O/C but similar $\mathrm{H} / \mathrm{C}$ as AFWA and high 
water production) further indicate that the mechanism by which $\mathrm{AFWA}_{\mathrm{oil}}$ is formed from AFWA is first hydrogenation and then dehydration of AFWA $A_{a q}$.

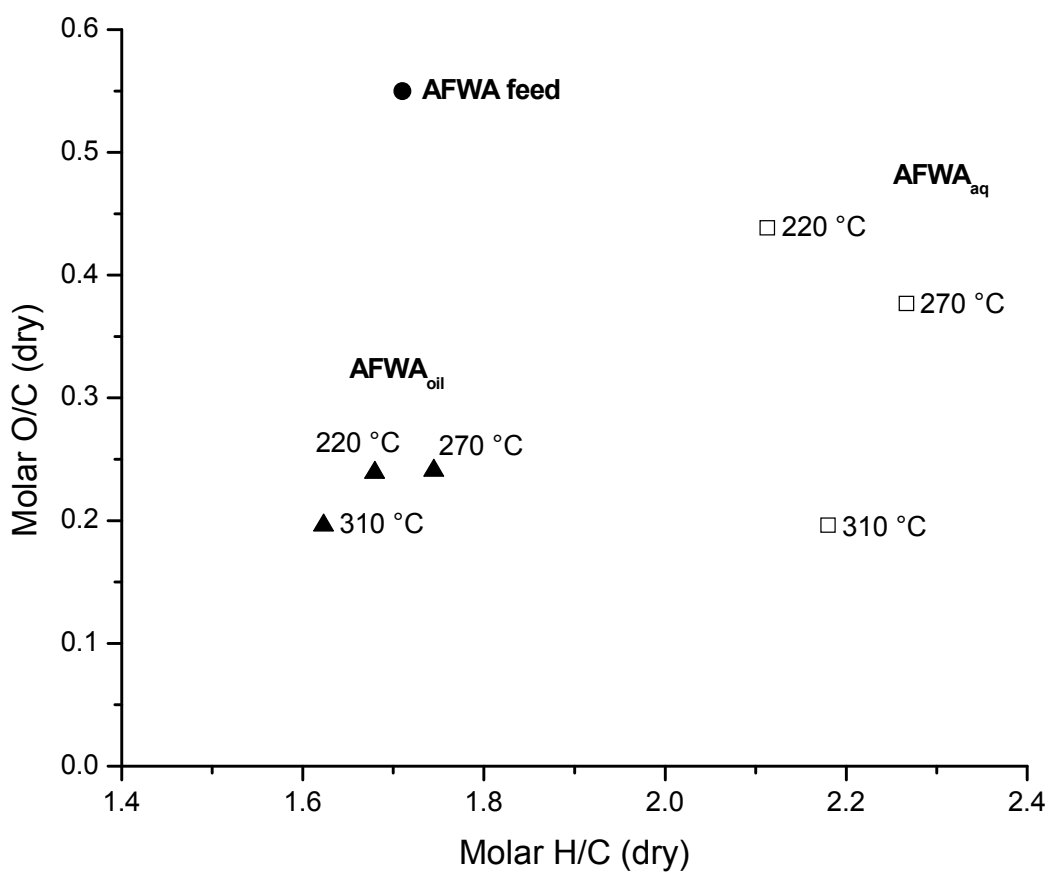

Figure 8. Van Krevelen diagram showing the dry $H / C$ and $O / C$ ratios of the AFWA feed and the $\mathrm{AFWA}_{\text {oil }}$ and $A F W A_{\text {aq }}$ products. Note that dehydration of $\mathrm{AFWA}_{\mathrm{aq}}\left(220{ }^{\circ} \mathrm{C}\right)$ gives composition $A F W A_{\text {oil }}\left(220^{\circ} \mathrm{C}\right)$.

Processing the OFWA under HDO conditions gave an oil product with lower $\mathrm{O} / \mathrm{C}$ than the feed. Although the $O / C$ of the different OFWA ${ }_{\text {oil }}$ are similar to the $A F W A_{\text {oil }}$, the $H / C$ is clearly much lower. At $220^{\circ} \mathrm{C}$, the production of water was not detected; consequently, the reduction of $\mathrm{O} / \mathrm{C}$ can only be attributed to the production of $\mathrm{CO}_{2}$ and the transfer of organics to the aqueous phase. The $O / C$ of the OFWA $A_{a q}$ was 0.67 , compared to the $O / C$ of 0.26 of the OFWA ${ }_{\text {oil. }}$ This difference in O/C was also observed for the HDO of the AFWA. At $270{ }^{\circ} \mathrm{C}$ and $310{ }^{\circ} \mathrm{C}$, the effect of the reaction temperature was similar as observed for the AFWA. For OFWA oil $_{\text {and }}$ and 220 to $270{ }^{\circ} \mathrm{C}$, there was an increase in $H / C$ ratio while $\mathrm{O} / \mathrm{C}$ remained similar. At the highest temperature $\left(310^{\circ} \mathrm{C}\right)$, a decrease of both $H / C$ and $O / C$ occurred. When looking at this low temperature hydrogenation and high temperature deoxygenation/dehydration during HDO, the same has been observed for aromatic structures such as phenol [26] and guaiacol [27], molecules that are frequently used as model compound to represent the lignin structures present in pyrolysis oil.

The $H / C$ and $O / C$ of the different whole-oil oil $_{\text {are }}$ also shown in Figure 7 . In all the experiments, the $\mathrm{O} / \mathrm{C}$ was much lower than the ones for the feed. In this case, not only 
the hydro(deoxy)genation reactions have to be taken into account, but also the transfer of organics from one phase to the other (as observed in Figure 6). The main cause for the reduction of $\mathrm{O} / \mathrm{C}$ at low temperature is the change of polarity during HDO processing that induces a phase separation. In this process, components with low affinity for the aqueous phase (typically present in the OFWA) remained as whole-oil oil, while most of the components with high water affinity (polar components typically present in the AFWA) were transferred to the whole-oil aq. However, the higher $H / C$ of the whole-oil ${ }_{\text {oil }}$ as

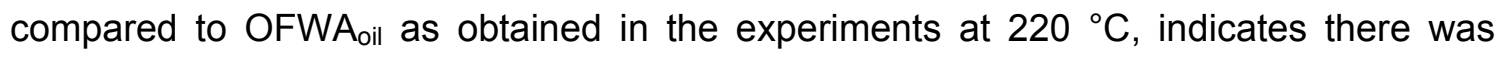
already a contribution to the whole-oil ${ }_{\text {oil }}$ from the organics originating from the AFWA. This is further confirmed by the AFWA oil $_{\text {yield }}$ of $12 \mathrm{wt} . \%$ at $220{ }^{\circ} \mathrm{C}$ (Table 2). This phase separation and transfer created a product oil with low O/C (similar to the HDO of the fractions) and an $H / C$ which is typically between the $H / C$ of the individual fractions. At $310^{\circ} \mathrm{C}$, opposite to the trend observed for HDO of AFWA and OFWA, the H/C of the

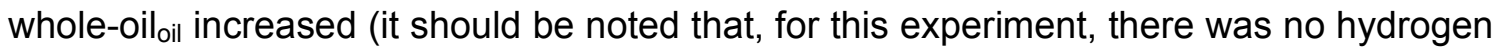
shortage as in HDO AFWA at $310^{\circ} \mathrm{C}$ ). In this case, the increase in the whole-oil ${ }_{\text {oil }}$ yield due to the HDO of AFWA components (an oil with relatively high $H / C$ ) seems to compensate for the loss of hydrogen through dehydration reactions. It should be noted that the results obtained for whole pyrolysis oil are not just the weight averaged sum of the results for the individual fractions. The result of this weight average (using fractionation and product yields) for the case of $310^{\circ} \mathrm{C}$, gives similar $\mathrm{O} / \mathrm{C}$, but lower $H / \mathrm{C}$ (1.46, compared to 1.61 for the experimental value). Comparing this results with the ones shown in Chapter 3, conducted in a bigger (5 I) autoclave, at a higher pressure of 290 bar and at similar temperatures, the produced oils had similar O/C ratios (between 0.16 and 0.28$)$, but higher $H / C(\sim 1.7$, compared to $\sim 1.5-1.6$ in the present work). This higher $H / C$ could be cause by the slower heating rate to reach reaction temperature (3040 min longer) allowing more time for hydrogenation reactions to occur (hydrogenation reactions are favoured at lower temperatures, see references above) and/or by the higher total pressure which increased the $\mathrm{H}_{2}$ partial pressure and the amount of $\mathrm{H}_{2}$ dissolved in the liquid. The hydrogen consumption of the experiments conducted at higher total pressure (at temperatures lower than $300{ }^{\circ} \mathrm{C}$ ) was approximately $20 \%$ higher.

To define the quality of the upgraded oils towards further co-processing, the oxygen content has proven not to be the only parameter that should be taken into account. The MWD (Figure 9-11), H/C (Figure 7), H/C eff (Table 2) and the MCRT (Table 2) of the HDO oils also give an indication of how well they will perform during pure or co-processing in a simulated FCC reactor.

When looking at general quality differences between the oils produced from the different feedstocks, it can be seen that OFWA ${ }_{\text {oil }}$ has a higher MWD and MCRT and lower H/C compared to AFWA oil. . Product quality of OFWA ${ }_{\text {oil }}$ is thus expected to be lower than that of AFWA oil. $_{\text {. }}$ Quality parameters for whole-oil ${ }_{\text {oil }}$ are in between these two. A general trend between the $H / C$, MCRT and MWD can be observed: the higher the $H / C$ the lower the 
MCRT and the MWD (with a few exceptions for the latter). This relationship between MWD and MCRT (or TGA residue) was already observed in Chapter 3 and literature [28].

Figure 9 shows that AFWA ${ }_{\text {oil }}$ has a similar MWD as the feed. It should be noted that the tailing (at the high molecular weight region) for the AFWA $A_{\text {oil }}$ is equal $\left(31{ }^{\circ} \mathrm{C}\right)$ or even shorter $\left(220,270{ }^{\circ} \mathrm{C}\right)$ than that of the feed. This shows that, in contrast to thermal treatment (shown in Chapter 2), in HDO processing, strong polymerisation of the sugars constituents (main components of AFWA) can be prevented. The previously mentioned shortage of hydrogen in the experiment at $310{ }^{\circ} \mathrm{C}$ is probably responsible for the somewhat longer tailing as observed for this temperature in Figure 9. This is further supported by the MCRT values shown in Table 2, where the value for the experiment at $310{ }^{\circ} \mathrm{C}$ is somewhat higher than the values for $220^{\circ} \mathrm{C}$ and $270{ }^{\circ} \mathrm{C}$. This same trend (but inverse) also appears when looking at the $H / C$ ratio. The experiment at $270{ }^{\circ} \mathrm{C}$ results in the highest $H / C$ of the oil while for the experiments at $310^{\circ} \mathrm{C}$, this value decreased again. This reduction in $\mathrm{H} / \mathrm{C}$ was also observed in Chapter 2 during HPTT of pyrolysis oil and the processing of glucose at high temperature and pressure and it was attributed to dehydration reactions [29] accompanied by polymerisation.

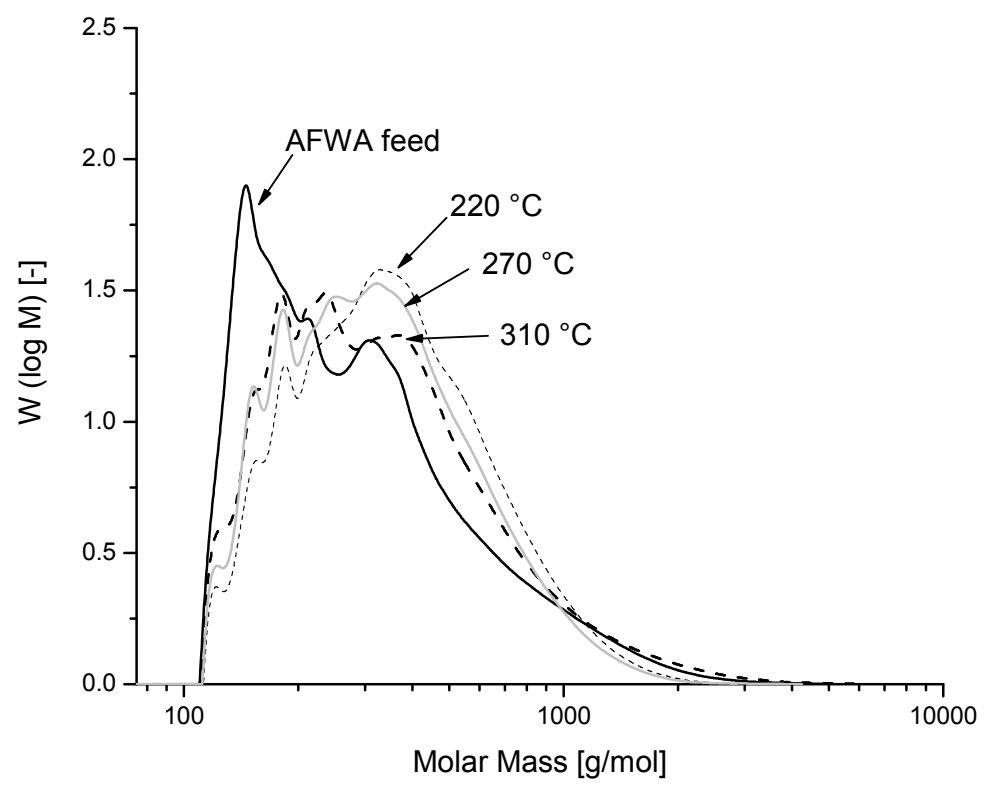

Figure 9. Molecular weight distribution obtained by GPC analysis of AFWA and its HDO oil products obtained at different temperatures.

The MWD of the OFWA feed and the HDO oil products (OFWA ${ }_{\text {oil }}$ ) show that the product obtained at $220{ }^{\circ} \mathrm{C}$ had a similar MWD to the feed, while for 270 and $310^{\circ} \mathrm{C}$ the molecular weight was lower than that of the feed oil (Figure 10). In this case, the MCRT does not follow this same trend, having the lowest value for the experiment at $270{ }^{\circ} \mathrm{C}$. 
On the other hand, the trend observed for the $\mathrm{H} / \mathrm{C}$ (from high to low $270{ }^{\circ} \mathrm{C}>310^{\circ} \mathrm{C}>$ $220^{\circ} \mathrm{C}$ ) matches the inverse of the trend of the MCRT (from low to high $270^{\circ} \mathrm{C}<310^{\circ} \mathrm{C}$ $\left.<220^{\circ} \mathrm{C}\right)$.

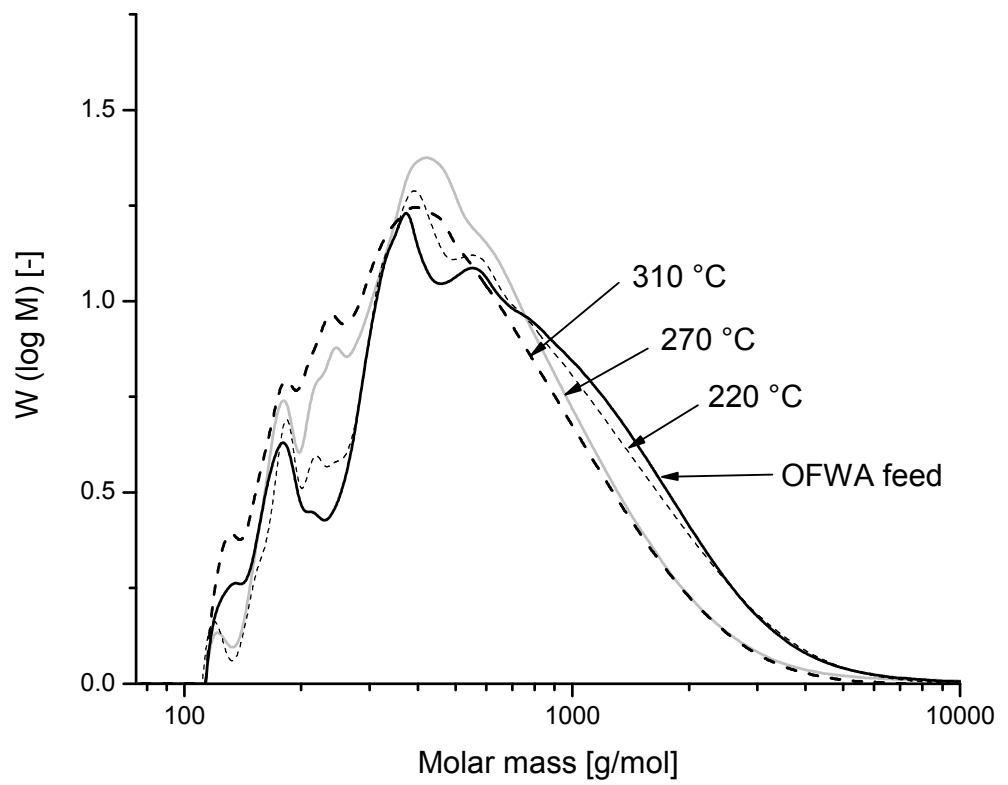

Figure 10. Molecular weight distributions obtained by GPC analysis of OFWA and its HDO oil products obtained at different temperatures

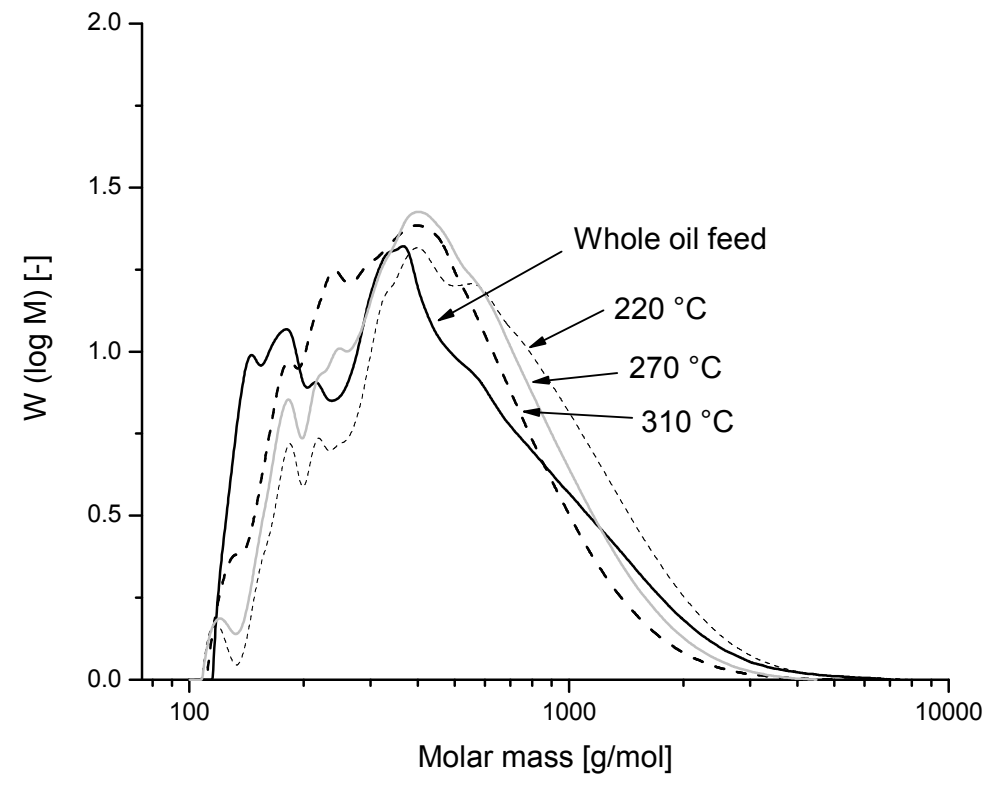

Figure 11. Molecular weight distributions obtained by GPC analysis of whole oil and its HDO oil products obtained at different temperatures 
In Figure 11 the MWD of the whole oil and its HDO oil products (whole-oil ${ }_{\text {oil }}$ ) can be seen. It shows that the whole oil feed contained both the lightest components (tall peak between 100 and $200 \mathrm{~g} / \mathrm{mol}$ ) and the heaviest (tailing). With increasing reaction temperature, the abundance of light components (originating from AFWA components) decreased, probably being converted to water soluble components and/or gas. This same effect is also seen when AFWA was used as feed. The abundance of heavy components (most of them belonging to the OFWA) also reduced as compared to the feed, this reduction being more significant with increasing reaction temperature. The same is observed when OFWA is used as feed, and it is likely caused by the depolymerisation of lignin structures [10]. Also in this case, the MCRT and the inverse of the $H / C$ follow the same trend.

\section{Upgrading routes}

In Figure 12, the carbon distribution from whole pyrolysis oil and its fractions to the HDO products is shown. At the right side of the diagram, the sum of the carbon yields of the fractions is also shown for comparison purposes. The carbon recovery in the oil phase product is higher when processing whole pyrolysis oil as compared to the recovery with intermediate fractionation. This can be attributed to the high carbon loss to the gas phase (due to the considerable gas formation when AFWA was used as feed), the larger amount of organics that remained in the aqueous phase product and the higher percentage of unrecovered carbon when fractions were used as feed.

When using whole pyrolysis oil as feed for HDO and at increasing reaction temperature, a transfer of organics is observed from the whole-oilaq to the whole-oil oil $_{\text {(as already seen }}$ in Chapter 3). This study has confirmed that it is indeed possible to create an oil phase product from the AFWA. The formation of this product appears to be important to increase the carbon recovery in the whole-oil oil (Figure 12). Although the oil obtained from HDO of AFWA (AFWA ${ }_{\text {oil }}$ ) has a high oxygen content, which caused a higher $O / C$ in the whole-oil ${ }_{\text {oil }}$ compared to OFWA ${ }_{\text {oil }}$, it also has a high $H / C($ eff) and a low MCRT, properties that appear beneficial for product quality. Therefore, upgrading of whole pyrolysis oil leads to a high carbon recovery (oil from OFWA and new oil phase from AFWA), fair quality parameters (MCRT, $H / C, H / C_{\text {eff, MWD) }}$ and also moderate hydrogen consumption.

Based upon pre-fractionation of pyrolysis oil into AFWA and OFWA, separate HDO of AFWA and OFWA is a possible process option. In this concept, the resulting oils can routed towards different refinery units trying to valorise their difference in quality. Although the quality of the AFWA ${ }_{\text {oil }}$ (in terms of $H / C, M W D$ and MCRT) is high, the high hydrogen consumption per $\mathrm{MJ}$ of product (see Table 2) and the low organic concentration of the feed increase the process costs. It should be noted that when 

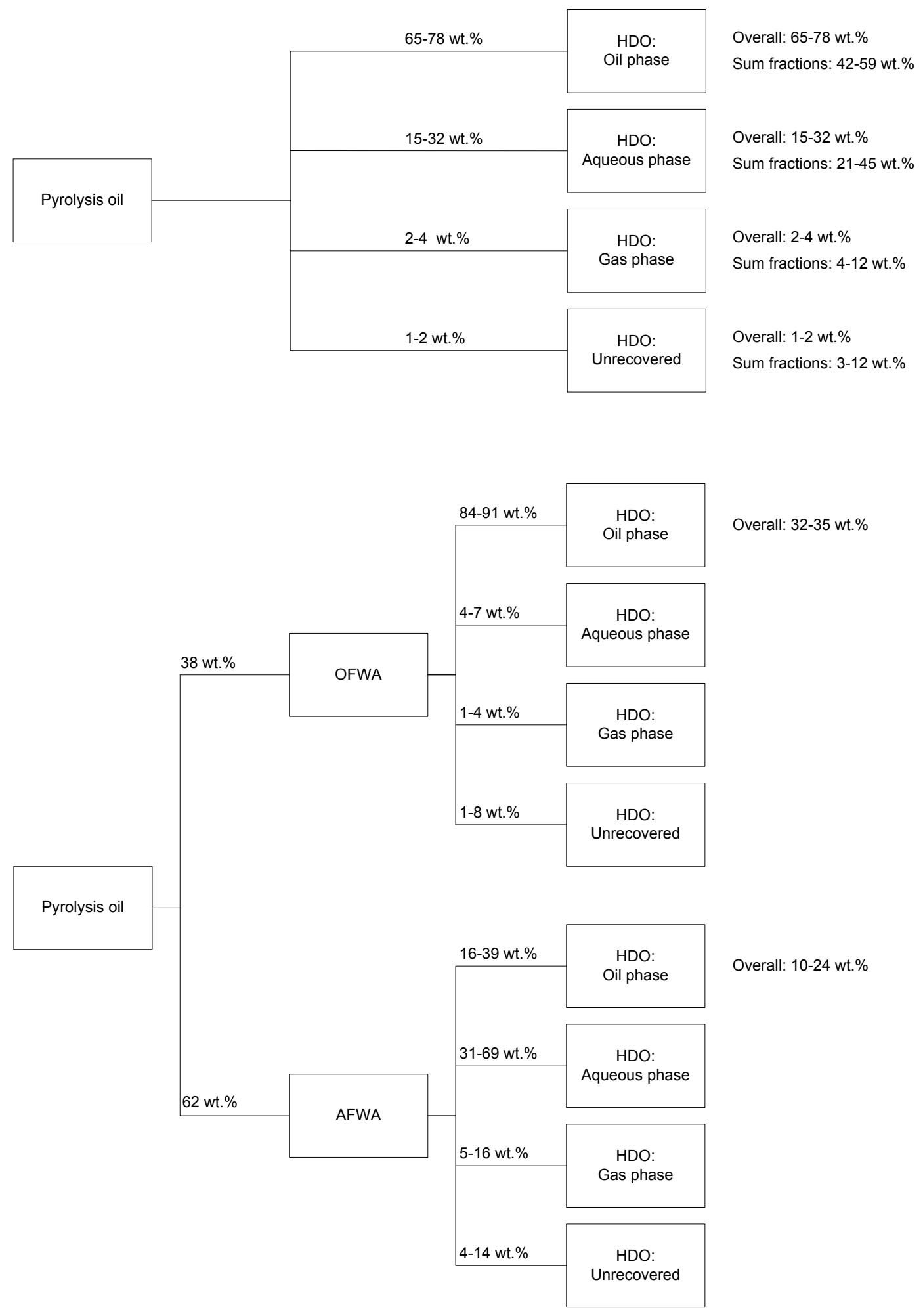

Overall: $32-35$ wt. $\%$

Overall: $10-24$ wt. $\%$

Figure 12. Carbon distribution for HDO of the pyrolysis oil and its fractions. The range corresponds to experiments at different reaction temperature. Overall values correspond to the carbon recovered from the starting pyrolysis oil in the specific product phase. 
processing AFWA, a considerable part of the hydrogen consumption was related to the production of low value gaseous products like methane. This suggest that removal of (some) light components, e.g. acids, either from whole pyrolysis oil or from the AFWA, might reduce hydrogen consumption. This would have the added benefit that at a given partial pressure of hydrogen in the HDO process, the total reactor pressure might be lowered. The light components could be recovered as value added chemicals or used for hydrogen production [30-33].

Another option that can be considered is the HDO of OFWA only, followed by coprocessing of this HDO oil [3]. As stated before, the AFWA could then be used for the recovery of chemicals and/or the production of hydrogen. In that case, the HDO of the OFWA would require less hydrogen than the HDO of the whole oil (Table 2), being beneficial for process economics. However, there are negative consequences to this approach. The total recovery of carbon in the HDO oil product would be $35 \mathrm{wt} . \%$ from the initial pyrolysis oil which is low when compared to the $78 \mathrm{wt} . \%$ when whole pyrolysis oil is processed. The reason for this is because the organics present in AFWA comprise $\sim 62$ wt.\% of the carbon in pyrolysis oil (see Figure 12). Moreover, the quality of the OFWA ${ }_{\text {oil }}$, when looking at $H / C, M W D$ and MCRT, is lower compared to the whole-oil oil. It appears that a higher HDO reaction temperature can reduce the molecular weight of the OFWA product (Figure 10), however, in this study, the $H / C$ decreased and the MCRT increased at the same time.

For the determination of the optimal route, the possibilities to use the various product streams (including remaining aqueous streams) should be assessed and an overall economic evaluation performed. In the next section, the experimental performance of various HDO oils in lab-scale refinery units (FCC, hydrotreating) is discussed.

\section{Co-processing upgraded pyrolysis oil fractions in refinery units}

The HDO oils were evaluated as feed in lab-scale refinery units. HDO oils obtained by HDO of OFWA and AFWA (both at $310^{\circ} \mathrm{C}$ ) were co-processed in lab-scale catalytic cracking (with Long Residue) and HDS (with SRGO) units. This study only indicates if the HDO oils produced from fractions can be co-processed and how this affects standard operation. An extensive study on the influence of process conditions, catalyst type and product yield speciation during co-processing is beyond the scope of this work.

\section{Catalytic Cracking}

Co-processing of HDO oils (from AFWA and OFWA) with Long Residue was carried out successfully in the MAT reactor without plugging of lines (experiments by Shell Global Solutions). Table 3 shows the true boiling point (TBP) analysis of the products obtained after catalytic cracking of pure Long Residue (used as reference) and a blend of $20 \mathrm{wt} . \%$ 
HDO oil/80 wt.\% Long Residue. In the same table, it can be seen that the cat/oil ratio needed to obtain $60 \mathrm{wt}$ \% conversion -defined as the sum of dry gas, LPG, gasoline range $\left(\mathrm{C} 5-221^{\circ} \mathrm{C}\right)$ and coke- was the same for the reference and the co-processing of OFWA $_{\text {oil, }}$ while it was slightly higher for co-processing of AFWA $_{\text {oil }}$. The product yield distributions were in all cases very similar and differences not significant. ${ }^{1}$ The differences in quality for the various HDO oils as established in the previous sections are not confirmed by the co-processing results. It should be noted that the current product yields are similar to the yields obtained in Chapter 3 using the same MAT reactor for coprocessing of $\mathrm{HDO}$ oils from pyrolysis oil (produced at temperatures ranging from $230{ }^{\circ} \mathrm{C}$ to $340{ }^{\circ} \mathrm{C}$ and total pressures of 290 bar). Also in there, apparent differences in product quality in HDO oils produced at different temperature did not result in substantial yield differences upon co-processing. A large excess of fossil feed, resulting in similar $H / C_{\text {eff }}$ of the blends, was believed to contribute to this, and might also explain the similarity of results as obtained in this study (see Table 2). Although the MCRT values of the HDO oil were different, also the coke formation during catalytic cracking was alike and similar to the reference. As in Chapter 3, this has been attributed to the hydrogen donation capacity of the fossil feed during catalytic cracking. After catalytic cracking of HDO oil from whole pyrolysis oil, phenolic components were detected in the total product, their level decreasing with HDO operation temperature (see Chapter 3).

Table 3. Product yields at constant $60 \mathrm{wt} \%$ conversion after catalytic cracking of $20 \mathrm{wt} . \%$ AFWA or OFWA $A_{\text {oil }}$ with Long Residue feed at $520^{\circ} \mathrm{C}$. Products yields (in wt.\%) normalised by amount of produced water. Between parentheses, yields including produced water (data from Shell Global Solutions).

\begin{tabular}{|c|c|c|c|c|c|}
\hline \multirow{3}{*}{$\begin{array}{l}\text { Cat/Oil ratio } \\
\text { LPG yield }\end{array}$} & \multirow{3}{*}{$\begin{array}{c}\begin{array}{c}\text { Long } \\
\text { Residue } \\
\text { (reference) }\end{array} \\
3.2 \\
8.8\end{array}$} & \multicolumn{2}{|c|}{$\begin{array}{c}20 \% \text { HDO oil from } \\
\text { OFWA }\left(310^{\circ} \mathrm{C}\right)\end{array}$} & \multicolumn{2}{|c|}{$\begin{array}{l}20 \% \text { HDO oil from } \\
\text { AFWA }\left(310^{\circ} \mathrm{C}\right)\end{array}$} \\
\hline & & \multicolumn{2}{|c|}{3.2} & \multicolumn{2}{|c|}{3.5} \\
\hline & & 9.8 & $(9.4)$ & 10.0 & $(9.6)$ \\
\hline Gasoline yield & 44.6 & 45.4 & $(43.6)$ & 44.9 & $(43.2)$ \\
\hline LCO yield & 25.5 & 25.2 & $(24.2)$ & 25.1 & $(24.1)$ \\
\hline Dry gas yield & 1.5 & 2 & $(1.9)$ & 2.1 & $(2.0)$ \\
\hline Coke yield & 5.0 & 5.3 & $(5.1)$ & 5.4 & $(5.2)$ \\
\hline $\begin{array}{l}\text { Other }(\mathrm{HCO} \text {, Slurry oil, } \\
\left.\mathrm{CO} \text { and } \mathrm{CO}_{2}\right)\end{array}$ & 14.6 & 12.3 & $(12.0)$ & 12.5 & $(12.0)$ \\
\hline Water $^{a}$ & - & - & (3.8) & - & (3.9) \\
\hline
\end{tabular}

${ }^{a}$ produced water calculated from the oxygen content in the feed, considering all the oxygen is transferred to water during catalytic cracking ( $\mathrm{CO}$ and $\mathrm{CO}_{2}$ yields were under 0.3 wt. \%).

\footnotetext{
${ }^{1}$ Note that the overall yield to gasoline is $27 \mathrm{wt.} \%$, (taking into account the OFWA ${ }_{\text {oil }}$ wet yield $(63$ wt.\%) and the gasoline yield after catalytic cracking (43.6 wt.\%)) which is similar to the gasoline yield of 30 wt. $\%$ in the UOP LCC patent [3].
} 


\section{Hydrotreating}

The limit in sulphur content (10 ppm in 2009 in EC) in gasoline or diesel is one of the most drastic parameters that must be met by the refiners. Thus, the co-processing of an HDO oil and a Straight Run Gas Oil (SRGO) can be envisaged only if the competition between HDO and HDS reactions can be easily overcome by process adjustment. Preliminary studies performed on the co-processing of a SRGO with model oxygenated compounds such as guaiacol, demonstrated that competition between HDS and HDO can occur, the severity depending on the type of components used [20,34].

In the HDS unit, the HDO oils were processed according to the sequence: SRGO (SRGO and HDO oil mixture) - SRGO, in this way, the deactivation of the catalyst after the introduction of the HDO oil could be examined (experiments by CNRS). The AFWA ${ }_{\text {oil }}$

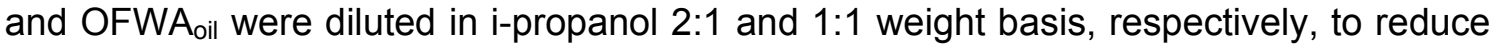
viscosity and allow pumping. These diluted oils were co-fed to the reactor with a ratio of 70:30 (in weight basis) SRGO:diluted HDO oil. Similar to the catalytic cracking experiments, both HDO oils were successfully co-processed without plugging of the reactor. However, the presence of HDO oil affected the degree of desulphurisation. For the reference experiment, upon processing only SRGO, the sulphur content of the product was on average $136 \mathrm{ppm}$ (from $13500 \mathrm{ppm}$ of the crude SRGO). When the AFWA $_{\text {oil }}\left(310{ }^{\circ} \mathrm{C}, 120 \mathrm{~min}\right)$ was co-processed, the product contained $\sim 2000 \mathrm{ppm}$ of sulphur. Just after the co-processing test, SRGO was processed pure again. Then, the desulphurisation recovered its initial value, indicating that the reduction in desulphurisation activity was due to the competition between HDO and HDS and not due to permanent catalyst deactivation. This competition was already observed during coprocessing SRGO with guaiacol as model compound [20]. When the OFWA $240 \mathrm{~min}$ ) was co-processed, the sulphur content in the product also rose compared to processing pure SRGO to a value of $376 \mathrm{ppm}$. This value is much lower than the one

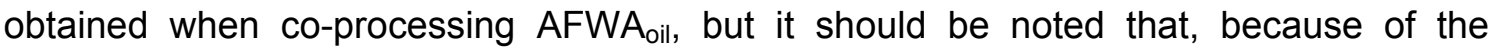
different dilution ratio in i-propanol, the concentration of HDO oil was lower in the case of

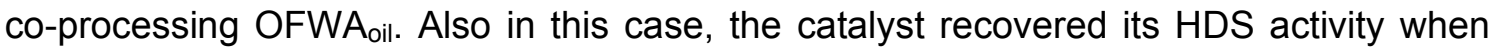
processing pure SRGO thereafter, demonstrating again the competition between HDO and HDS. After the co-processing of both $\mathrm{AFWA}_{\mathrm{oil}}$ and $\mathrm{OFWA}_{\mathrm{oil}}$, phenolic components were detected in the end product. The phenol C-O bond appears to be one of most resilient bonds in HDS/HDO conditions [20], although it should be mentioned that the catalyst used was aimed at desulphurisation and not deoxygenation. Figure 13 shows the MWD of OFWA oil $_{\text {and }}$ aFWA oil $_{\text {as }}$ as well as the MWD of the product of co-processing the OFWA $A_{\text {oil }}$ with SRGO. Because the MWD of the feed SRGO and all the products of co-processing (including also processing of pure SRGO) were very similar and overlapping, only one HDS/HDO product chromatogram is shown. In the figure, it can be seen that the MWD of OFWA ${ }_{\text {oil }}$ is higher than AFWA $_{\text {oil }}$ and they are both considerably higher than the MWD of the product oil obtained after co-processing. Therefore, during hydrotreating, not only the sulphur content was reduced but also cracking of large organic molecules originating from HDO oil occurred. This reduction of molecular weight 
during co-processing (at $380^{\circ} \mathrm{C}$ ) follows the same trend as observed in HDO of pyrolysis oil (fractions), which showed a decrease in molecular weight with increasing temperature (Figures 9-11).

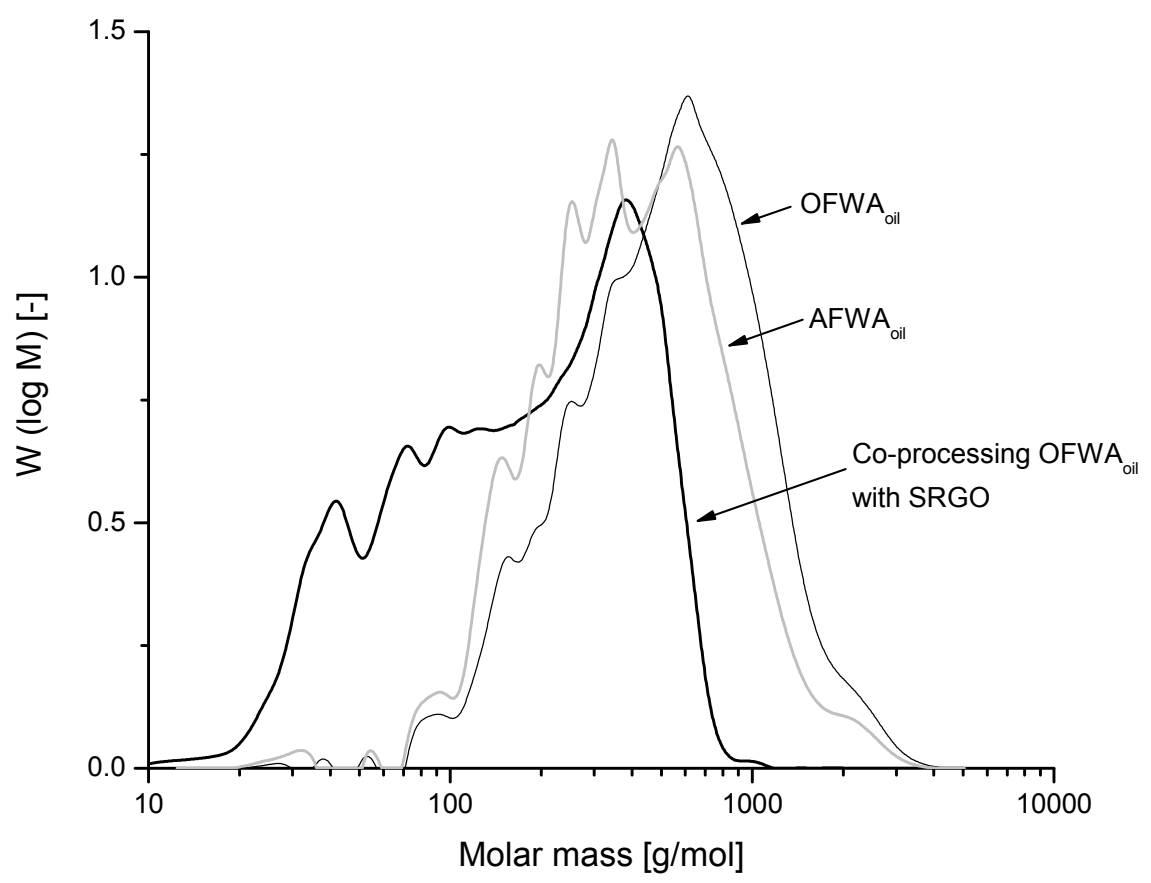

Figure 13. Molecular weight distribution of the $\mathrm{OFWA}_{\mathrm{oil}}, \mathrm{AFWA}_{\mathrm{oil}}$ and the product after coprocessing SRGO and OFWA $A_{\text {oil }}$ in the HDS unit. Feed SRGO, processed SRGO and co-processed SRGO/AFWA $A_{\text {oil }}$ gave overlapping chromatograms with the co-processed SRGO/OFWA $A_{\text {oil }}$ product and are therefore not shown (data from CNRS). 


\section{Conclusions}

By addition of water to pyrolysis oil, a phase separation is induced creating two fractions, viz. an aqueous fraction water addition (AFWA) and oil fraction water addition (OFWA). The AFWA had a higher $\mathrm{O} / \mathrm{C}$ and $H / C$ and approximately $62 \mathrm{wt} \%$ of the carbon was recovered in it. The OFWA had lower $\mathrm{O} / \mathrm{C}$ but also lower $\mathrm{H} / \mathrm{C}$ and the recovery of carbon in this fraction was approximately $38 \mathrm{wt} . \%$.

It was possible to create an oil phase (hydrophobic) product by hydrodeoxygenation (HDO) of the AFWA. The recovery of carbon in this oil phase increased substantially with the temperature, from $220{ }^{\circ} \mathrm{C}$ to $270{ }^{\circ} \mathrm{C}$ (16.3 wt.\% to $\left.35.6 \mathrm{wt} . \%\right)$, but less significant when further increasing the temperature to $310{ }^{\circ} \mathrm{C}(38.5 \mathrm{wt} . \%)$. This also explains the larger carbon recovery at increasing temperatures observed after HDO of whole pyrolysis oil. The oil phase product obtained had a similar $\mathrm{O} / \mathrm{C}$ as the product of whole oil but a higher $H / C$. This appears to be beneficial to reduce the coke formation tendency, which was confirmed by low MCRT values. On the other hand, the high $\mathrm{H}_{2}$ consumption and the noteworthy production of $\mathrm{CH}_{4}$ are downsides of this route. The $\mathrm{H}_{2}$ consumption of HDO of OFWA was lower compared the HDO of whole oil. However, the oil product obtained had lower $H / C$ and higher molecular weight and MCRT than the oil obtained from AFWA. Based on the differences in various quality parameters of the HDO oils from AFWA and OFWA, differences upon co-processing were expected.

The HDO oils produced from both AFWA and OFWA were successfully co-processed in catalytic cracking and hydrodesulphurisation (HDS) lab-scale units. Remarkably, the type of HDO feedstock did not change the product yield distribution after catalytic cracking, which is probably due to similar values of $H / C_{\text {eff }}$ of the $\mathrm{HDO}$ oils/fossil feed blends. During co-processing straight run gas oil (SRGO) and HDO oils (obtained from pyrolysis oil fractions) in a HDS unit, competition between hydrodesulphurisation and hydrodeoxygenation was observed. When the oxygenated compounds from upgraded pyrolysis oil fractions were fed to the reactor, the sulphur content of the product was higher than when only SRGO was fed. After co-processing, pure SRGO was fed again and the degree of desulphurisation recovered its initial value showing no permanent catalyst deactivation. The molecular weight distribution of all the HDS co-processed products was similar and, at the same time, similar to the distributions obtained for (un)treated SRGO. It should be noted that the catalyst used in HDS co-processing was specifically targeted towards desulphurisation and not deoxygenation.

Considering the significant differences in HDO oil quality on one side, but the similarity in co-processing results on the other, further research on product speciation of the coprocessed oils is recommended to see if initial differences in HDO oil product quality are eliminated in the co-processing procedures. 


\section{Nomenclature}

$\begin{array}{ll}\text { AFWA } & \text { Aqueous fraction water addition (untreated) } \\ \text { AFWA }_{\text {aq }} & \text { Aqueous phase product obtained by HDO of AFWA } \\ \text { AFWA }_{\text {oil }} & \text { Oil phase product obtained by HDO of AFWA } \\ \text { FCC } & \text { Fluid catalytic cracking } \\ \text { GPC } & \text { Gel permeation chromatography } \\ \text { HDO } & \text { Hydrodeoxygenation } \\ \text { HDS } & \text { Hydrodesulphurisation } \\ \text { HPTT } & \text { High pressure thermal treatment } \\ \text { H/C } & \text { Dry molar hydrogen over carbon ratio } \\ \text { H/C } & \text { H/C effective, } / / C_{\text {eff }}=\left(H-2^{*} O\right) / C \\ \text { LHSV } & \text { Liquid hourly space velocity } \\ \text { MCRT } & \text { Micro carbon residue test } \\ \text { MWD } & \text { Molecular weight distribution } \\ \text { OFWA } & \text { Oil fraction water addition (untreated) } \\ \text { OFWA } & \text { Aqueous phase product obtained by HDO of OFWA } \\ \text { OFWA } & \text { Oil phase product obtained by HDO of OFWA } \\ \text { O/C } & \text { Dry molar oxygen over carbon ratio } \\ \text { SRGO } & \text { Straight run gas oil } \\ \text { TBP } & \text { True boiling point } \\ \text { THF } & \text { Tetrahydrofuran } \\ \text { Whole-oil } & \text { Untreated/not fractionated pyrolysis oil } \\ \text { Whole-oilaq } & \text { Aqueous phase product obtained by HDO of whole-oil } \\ \text { Whole-oiloil } & \text { Oil phase product obtained by HDO of whole-oil } \\ & \end{array}$




\section{References}

[1] Baldauf W, Balfanz U, Rupp M. Upgrading of flash pyrolysis oil and utilization in refineries. Biomass Bioenerg. 1994;7:237-244.

[2] Fogassy G, Thegarid N, Toussaint G, van Veen AC, Schuurman Y, Mirodatos C. Biomass derived feedstock co-processing with vacuum gas oil for secondgeneration fuel production in FCC units. Appl. Catal. B Environ. 2010;96:476-485.

[3] Marker TL, Petri JA, Gasoline and diesel production from pyrolytic lignin produced from pyrolysis of cellulosic waste, Patent number WO 2008/027699, 2008.

[4] Elliott DC. Historical developments in hydroprocessing bio-oils. Energy Fuels 2007;21:1792-1815.

[5] Radlein D. The production of chemicals from fast pyrolysis bio-oils. In: A.V. Bridgwater editor. Fast pyrolysis of biomass. A handbook, Newbury, Berkshire: CLP Press. 1999; p. 164-185.

[6] Scholze B, Meier D. Characterization of the water-insoluble fraction from pyrolysis oil (pyrolytic lignin). Part I. PY-GC/MS, FTIR, and functional groups. J. Anal. Appl. Pyrol. 2001;60:41-54.

[7] Oasmaa A, Kuoppala E, Solantausta Y. Fast pyrolysis of forestry residue. 2. Physicochemical composition of product liquid. Energy Fuels. 2003;17:433-443.

[8] Samolada MC, Baldauf W, Vasalos IA. Production of a bio-gasoline by upgrading biomass flash pyrolysis liquids via hydrogen processing and catalytic cracking. Fuel. 1998;77:1667-1675.

[9] Piskorz J, Majerski P, Radlein D, Scott DS. Conversion of lignins to hydrocarbon fuels. Energy Fuels. 1989;3:723-726.

[10] Oasmaa A, Alén R, Meier D. Catalytic hydrotreatment of some technical lignins. Bioresource Technol. 1993;45:189-194.

[11] Meier D, Berns J, Faix O, Balfanz U, Baldauf W. Hydrocracking of organocell lignin for phenol production. Biomass Bioenerg. 1994;7:99-105. 
[12] De Wild P, Van der Laan R, Kloekhorst A, Heeres HJ. Lignin valorisation for chemicals and (transportation) fuels via (catalytic) pyrolysis and hydrodeoxygenation. Environ. Prog. Sustainable Energy. 2009;28:461-469.

[13] Elliott DC, Neuenschwander GG. Liquid fuels by low-severity hydrotreating of biocrude. In: A.V. Bridgwater and D.G.B. Boocock editors. Developments in Thermochemical Biomass Conversion, London: Blackie Academic \& Professional. 1996; p. 611-621.

[14] Gagnon J, Kaliaguine S. Catalytic hydrotreatment of vacuum pyrolysis oils from wood. Ind. Eng. Chem. Res. 1988;27:1783-1788.

[15] Laurent E, Pierret C, Grange P, Delmon B. Control of the deoxygenation of pyrolytic oils by hydrotreatment. In. Proc. of 6th conference on Biomass for energy, industry and environment, Athens, Greece. 1991; p. 665-671.

[16] Wildschut J, Arentz J, Rasrendra CB, Venderbosch RH, Heeres HJ. Catalytic hydrotreatment of fast pyrolysis oil: Model studies on reaction pathways for the carbohydrate fraction. Environ. Prog. Sustainable Energy. 2009;28:450-460.

[17] Elliott DC, Hart TR. Catalytic Hydroprocessing of Chemical Models for Bio-oil. Energy Fuels. 2008;23:631-637.

[18] Oasmaa A, Kuoppala E, Gust S, Solantausta Y. Fast pyrolysis of forestry residue. 1. Effect of extractives on phase separation of pyrolysis liquids. Energy Fuels 2003;17:1-12.

[19] Wildschut J, Mahfud FH, Venderbosch RH, Heeres HJ. Hydrotreatment of Fast Pyrolysis Oil Using Heterogeneous Noble-Metal Catalysts. Ind. Eng. Chem. Res. 2009;48:10324-10334.

[20] Bui VN, Toussaint G, Laurenti D, Mirodatos C, Geantet C. Co-processing of pyrolisis bio oils and gas oil for new generation of bio-fuels: Hydrodeoxygenation of guaïacol and SRGO mixed feed. Catal. Today. 2009;143:172-178.

[21] Oasmaa A, Kuoppala E. Solvent Fractionation Method with Brix for Rapid Characterization of Wood Fast Pyrolysis Liquids. Energy Fuels. 2008;22:42454248.

[22] Elliott DC, Sealock LJ, Baker EG. Chemical processing in high-pressure aqueous environments. 2. Development of catalysts for gasification. Ind. Eng. Chem. Res. 1993;32:1542-1548. 
[23] Domalski ES, Jobe (Jr.) TL, Milne TA, Thermodynamic data for biomass materials and waste components. The American Society of Mechanical Engineers, New York, 1987.

[24] Chen NY, Degnan Jr. TF, Koening LR. Liquid fuel from carbohydrates. Chemtech. 1986;16:506-511.

[25] Corma A, Huber GW, Sauvanaud L, O'Connor P. Processing biomass-derived oxygenates in the oil refinery: Catalytic cracking (FCC) reaction pathways and role of catalyst. J. Catal. 2007;247:307-327.

[26] Shin E-J, Keane MA. Gas-Phase Hydrogenation/Hydrogenolysis of Phenol over Supported Nickel Catalysts. Ind. Eng. Chem. Res. 2000;39:883-892.

[27] Gutierrez A, Kaila RK, Honkela ML, Slioor R, Krause AOI. Hydrodeoxygenation of guaiacol on noble metal catalysts. Catal. Today. 2009;147:239-246.

[28] Ardiyanti AR, Venderbosch RH, Heeres HJ. Process-product studies on pyrolysis oil upgrading by hydrotreatment with Ru/C catalysts. in Proceedings of the 2009 AIChE Spring National Meeting. 2009. Tampa, FL, US.

[29] Knežević D, Van Swaaij WPM, Kersten SRA. Hydrothermal conversion of biomass: I, Glucose conversion in hot compressed water. Ind. Eng. Chem. Res. 2009;48:4731-4743.

[30] Czernik S, Bridgwater AV. Overview of applications of biomass fast pyrolysis oil. Energy Fuels. 2004;18:590-598.

[31] McCall MJ, Production of Chemicals from Pyrolysis Oil, US Patent application 20080312476, 2008.

[32] Van Rossum G, Potic B, Kersten SRA, van Swaaij WPM. Catalytic gasification of dry and wet biomass. Catal. Today. 2009;145:10-18.

[33] Czernik S, French R, Feik C, Chornet E. Hydrogen by catalytic steam reforming of liquid byproducts from biomass thermoconversion processes. Ind. Eng. Chem. Res. 2002;41:4209-4215.

[34] Pinheiro A, Hudebine D, Dupassieux N, Geantet C. Impact of Oxygenated Compounds from Lignocellulosic Biomass Pyrolysis Oils on Gas Oil Hydrotreatment. Energy Fuels. 2009;23:1007-1014. 


\section{Polymerisation during pyrolysis oil upgrading}

When pyrolysis oil is subjected to high temperatures, severe polymerisation, of amongst others the sugar constituents, has been observed. This thermally induced polymerisation causes product deterioration and, therefore, its suppression or prevention is desirable to allow successful pyrolysis oil upgrading. In this study, aqueous glucose solutions were used as model system to represent the sugar fraction of pyrolysis oil. Similar to thermal treatment of pyrolysis oil, and at the typical experimental conditions $\left(300{ }^{\circ} \mathrm{C}, 5 \mathrm{~min}\right.$ ) glucose showed fast dehydration and polymerisation resulting in a water-acetone soluble product (oil), a water-acetone insoluble solid residue (WAIS) and some gas. The molecular weight of the oil decreased with increasing temperature and reaction time, however this was accompanied by increased WAIS formation. In general, the formation of WAIS increased with residence time, temperature and initial glucose concentration, while the oil yield typically decreased simultaneously. The accompanying reduction in $H / C$ ratio of the oil at more severe conditions was a negative effect with respect to product quality. Dehydration of glucose to 5-hydroxymethylfurfural appeared as an important intermediate in the polymerisation reactions.

In contrast to glucose, sorbitol (hydrogenated glucose) proofed to be very stable at the typical experimental conditions applied, showing that stabilisation of glucose by hydrogenation is possible and highlighting the role of low temperature stabilisation of sugars in the hydrodeoxygenation of pyrolysis oil. To reduce polymerisationMAIS formation at high temperatures, also the reaction of glucose with ethanol was shown to be effective. When using glucose as feed and ethanol as co-solvent, the molecular weight and the coking tendency (MCRT) of the resulting oil were reduced. When a sugar fraction derived from pyrolysis oil and whole pyrolysis oil were processed in the presence of ethanol, a decrease in polymerisationMAIS formation was observed (although less significant). 



\section{Introduction}

A way to reduce green-house gas emissions is the utilisation of biofuels. Ligno-cellulosic biomass is an attractive feedstock for the production of biofuels because these feedstocks (agricultural and industrial wastes, forest/forestry residues, etc.) do not necessarily compete with food or feed chains. Co-processing of hydrodeoxygenated pyrolysis oil in standard refineries appears to be an interesting approach for the production of these biofuels [1-3].

Early studies on pyrolysis oil hydrodeoxygenation (HDO) [4] showed that direct processing of pyrolysis oil at high temperature $\left(>300^{\circ} \mathrm{C}\right)$ leads to fast coke formation. Therefore, a low temperature pre-treatment ('stabilisation') was introduced to allow successful high temperature HDO operation [5]. Chapters 3 and 4 showed that deep deoxygenation of pyrolysis oil is not necessary to successfully co-process HDO oil (produced from whole pyrolysis oil but also its fractions) in lab-scale FCC and hydrotreating units, reducing thereby the hydrogen costs.

High pressure thermal treatment (HPTT) of pyrolysis oil was suggested in Chapter 2 as an alternative upgrading method for pyrolysis oil. In this method, pyrolysis oil was subjected to moderate temperatures $\left(200-350^{\circ} \mathrm{C}\right.$ ) and high pressures (>200 bar) during a short time ( $<5 \mathrm{~min}$ ). The obtained products consisted of an oil phase with lower oxygen (20 wt.\% on dry basis) and water content (9 wt.\%), an aqueous phase with remaining organics and some gas (mainly $\mathrm{CO}_{2}$ ). The oil phase concentrated the organics, recovering up to $81 \mathrm{wt} . \%$ of the carbon from the feed pyrolysis oil. Contrary to HDO, this method does not require hydrogen or catalyst, making it economically more attractive. However, during HPTT of pyrolysis oil, a strong increase in the molecular weight of the product oil was observed. The decrease in the sugar constituents in the aqueous phase indicated that these sugars underwent polymerisation and were transferred to the oil phase. The HPTT oil proofed to be immiscible with refinery feedstocks. Moreover, it had a very high carbon residue (MCRT of $45.1 \mathrm{wt} . \%$, on dry basis), which made it not suitable for co-processing in a lab-scale FCC unit.

This very fast polymerisation of the sugars constituents of pyrolysis oil observed during HPTT could be one reason for the coke formation during direct high temperature HDO. It is remarkable that, in Chapter 3, HDO of pyrolysis oil using slow heating rate, the increase in molecular weight was avoided. This prevention of polymerisation was also observed in Chapter 4 during HDO of an aqueous fraction (obtained by adding water to pyrolysis oil) containing most of the sugar constituents of pyrolysis oil. This suggests that sugar constituents are likely to follow a different reaction path in which they are stabilised instead of being only polymerised while still being transferred to the oil phase. Thus, the use of hydrogen would be an option to avoid excessive polymerisation, which might be sufficient to produce an oil suitable for refinery co-processing. 
In Chapter 3, a competing mechanism between the catalytic hydro(deoxy)genation reactions and polymerisation reactions has been suggested to occur during HDO processing. This competition can influence the quality of the final product. Therefore, it should be possible to steer product quality in HDO processing by the ratio of the extent of the hydro(deoxy)genation reactions to the polymerisation reactions. With this respect, the present paper evaluates the polymerisation behaviour of pyrolysis oil components under different process conditions and ways to reduce or avoid it. The data presented can be useful for processes like hydrothermal upgrading of biomass, solvolysis, etc. Nevertheless, a special focus will be given to effects of polymerisation in relation to HDO. Chapter 6 discusses the influence of hydrogen mass transfer on the ratio of hydrotreating reactions vs. polymerisation reactions, and how optimisation of mass transfer can be used to improve HDO product quality.

During pyrolysis oil upgrading, sugars (up to $35 \mathrm{wt} \%$ [6]) can contribute significantly to the increase in molecular weight. Moreover, pyrolysis oil contains a large amount of water (15-30 wt.\% [7]). Therefore, in this study, aqueous solutions of glucose have been used as model system. It should be noted that the focus of this work is the study of the overall (thermally induced) polymerisation of glucose, and not the identification of primary decay products of it, as this has been reported by many other studies [8-13]. Besides the HPTT of glucose, also the HPTT of pyrolysis oil and a sugar fraction derived from pyrolysis oil is reported.

\section{Experimental section}

\subsection{Materials and product definition}

Glucose, organosolv lignin, sorbitol and xylose used for the experiments were supplied by Sigma-Aldrich and their purity was higher than $97 \%$. Demineralised water was used to prepare the solutions. In some of the experiments, ethanol was used as co-solvent. It was obtained from Chempropack B.V. and had $99 \%$ purity.

As it will be explained in the next section, acetone (Sigma-Aldrich, $>99 \mathrm{wt} . \%$ ) was used to recover the product from the autoclave and to create lumped categories according to the solubility in this solvent. Following similar product definitions as Knežević et al. [14], the products were defined as follows:

- Water-Acetone Soluble (WAS) organics: This consists of water soluble compounds and hydrophobic compounds that are soluble in acetone. Because the autoclave was washed with an excess of acetone, these water and acetone soluble compounds formed a single phase. Due to the oily appearance of this product after the evaporation of acetone and water, the WAS product will be referred to as 'oil'. 
- Water-Acetone Insoluble (WAIS) organics: Condensed products not soluble in water and acetone (at ambient conditions). These organics formed a black solid at room temperature after filtration of the liquid product (this solid product resembles char in appearance).

Water (produced from organic feedstock) and gas are the other lumped product categories that will be taken into account to close the mass balance.

\subsection{Experimental set-up and procedure}

The experiments were carried out using an in-house made autoclave with an internal volume of $33 \mathrm{ml}$. Its lid contained two orifices, one for a thermocouple and one to connect it to a line with a pressure reader and a gate valve. The pressure and the temperature inside the autoclave could be monitored and recorded using PicoLog software. By means of a pneumatic arm, the autoclave was heated by immersion in a fluidised sand bed. This sand bed was heated by an electric oven (with pre-heated fluidisation gas). In a typical experiment, the reactor was inserted in the fluidised sand bed and after the desired reaction time, it was lifted and quenched by immersion in a water bath. This method was designed to minimise, as much as possible, the effects of heating and cooling on the final composition. Pneumatic shaking was used to mix the reactor content. For safety reasons, the set-up was placed inside a high pressure room and controlled from outside during the high temperature/pressure part of the experiment. Figure 1 shows a diagram of the set-up.

In a typical experiment, $20 \mathrm{~g}$ of an aqueous solution of glucose with a concentration ranging from 5 to $30 \mathrm{wt} . \%$ was loaded into the autoclave. It was firmly closed and connected to the pneumatic arm. The line with the pressure reader was connected to the autoclave and pressurised with 50 bar of nitrogen. At that pressure, a leak test was performed. After that, the gas was vented, removing at the same time the remaining oxygen initially present in the reactor. Then, the line connecting the autoclave to the nitrogen supply was removed and the high pressure room was closed and the remainder of the experiment was monitored from outside. Using the pneumatic arm, the autoclave was positioned on the fluidised sand bed which had a temperature of $10-15{ }^{\circ} \mathrm{C}$ higher than the desired reaction temperature. Using a piston, the autoclave was lowered to immerse it inside the bed and just before the autoclave reached the bed, vigorous shaking of the reactor was started. It normally took 3.5 to 4 minutes to reach the desired liquid temperature $\left(+/-5{ }^{\circ} \mathrm{C}\right)$. Figure 2 shows a typical temperature profile for an experiment at $300{ }^{\circ} \mathrm{C}$ and $5 \mathrm{~min}$ total time (including heating time). Because the main component present was water (mole fraction of water for $30 \mathrm{wt}$ \% glucose at beginning of experiment is $\sim 0.96$ ), the pressure inside the autoclave was approximately the vapour pressure of water at the corresponding temperature. After the desired reaction time (typically $5 \mathrm{~min}$ ) the autoclave was lifted and submerged in the water bath to quench it within few seconds ( $40 \mathrm{~s}$ to cool from 300 to $100{ }^{\circ} \mathrm{C}, 50 \mathrm{~s}$ extra to reach $50{ }^{\circ} \mathrm{C}$ ). When 
the reactor was at room temperature, it was lifted from the water bath to allow product recovery.

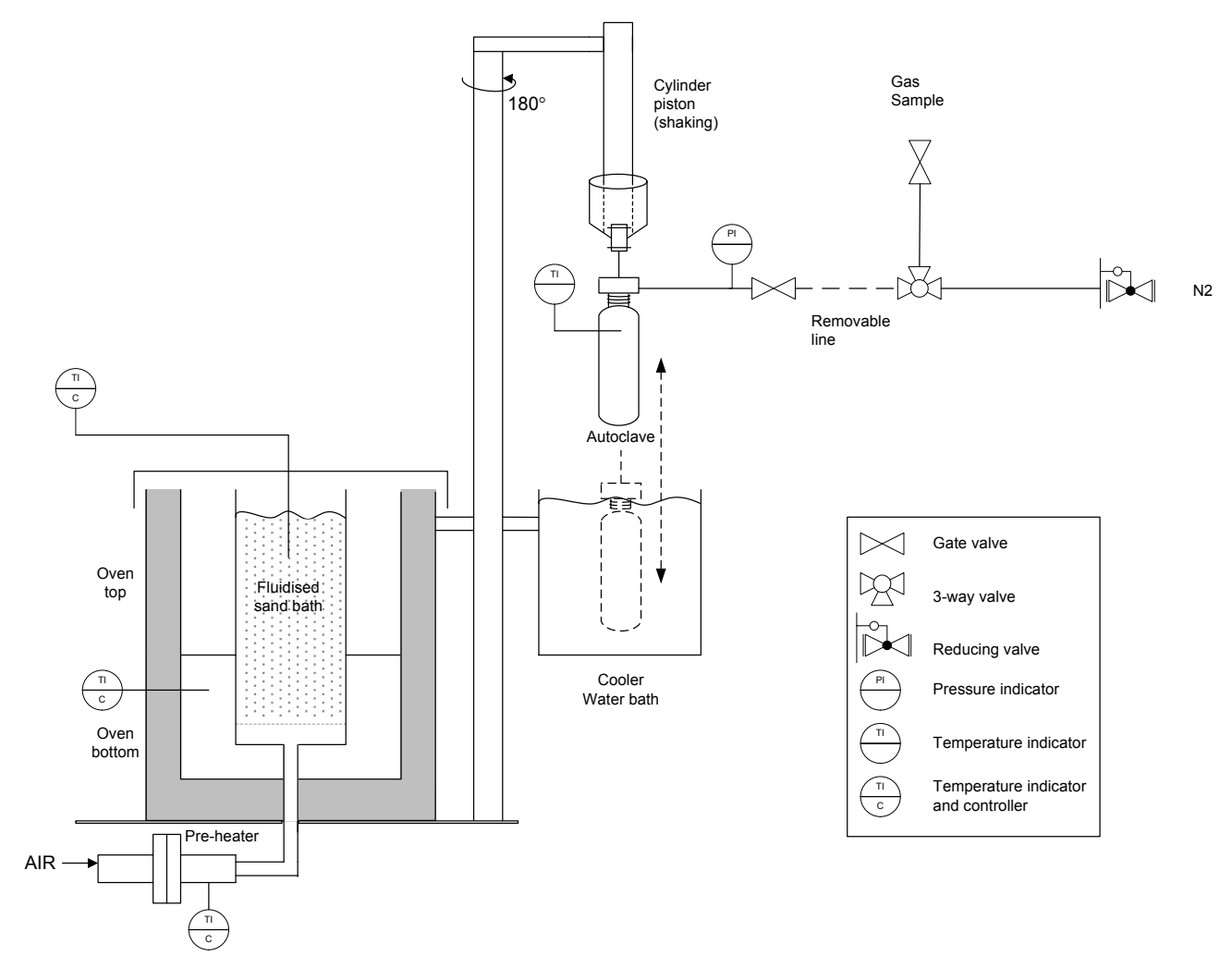

Figure 1. Schematic representation of the set-up.

From the gas produced, a sample was taken and analysed. With the gas composition and the final pressure and temperature inside the reactor, it was possible to calculate the amount of each gas produced. After complete depressurisation, the autoclave was disconnected from the arm and opened. The product (including liquid and solids in suspension) was collected in a glass jar and the autoclave was washed with an excess of acetone to recover as much product as possible. This acetone was mixed with the liquid product. If this sample mixture could not be further processed within one day, it was frozen $\left(-20^{\circ} \mathrm{C}\right)$ to prevent further reactions.

The product was then filtered to separate the WAIS. The filtration (glass microfiber filter $1.6 \mu \mathrm{m}$, Whatman GF/A) was carried out by a vacuum driven system. Under the filter, a weighed two neck round-bottom flask $(100 \mathrm{ml})$ was placed to collect the water-acetone soluble products. The filter was subsequently washed with acetone to ensure that the filter cake consisted only of WAIS. This WAIS was kept in the dessicator for 2 weeks to remove all the moisture. The acetone and the water (used as solvent and produced during reaction) in the liquid obtained after filtration were removed using a rotary evaporator. Acetone was removed by vacuum evaporation at $40{ }^{\circ} \mathrm{C}$ and ca. 350 to 450 mbar. The water was evaporated at the same temperature and at a pressure of ca. 20 to 50 mbar. The product left after the evaporation is called WAS (oil). This oil was also 
further dried in a dessicator for two weeks. After this time, both the amount of WAIS and oil were quantified and they were analysed for elemental composition. The molecular weight distribution of the oil was also determined. To check if the filtration/evaporation process could lead to further reactions, a test was conducted in which $20 \mathrm{ml}$ of a $5 \mathrm{wt} . \%$ glucose aqueous solution and $5 \mathrm{ml}$ of acetone were added into a flask and these solvents were removed following the same procedure. No increase of molecular weight was observed (results now shown). It should be noted that some loss of light components is likely to occur upon recovery of the WAS. The produced water yield was calculated from the $\mathrm{C}, \mathrm{H}$ and $\mathrm{O}$ balances following the same procedure as described by Knežević et al. [14].

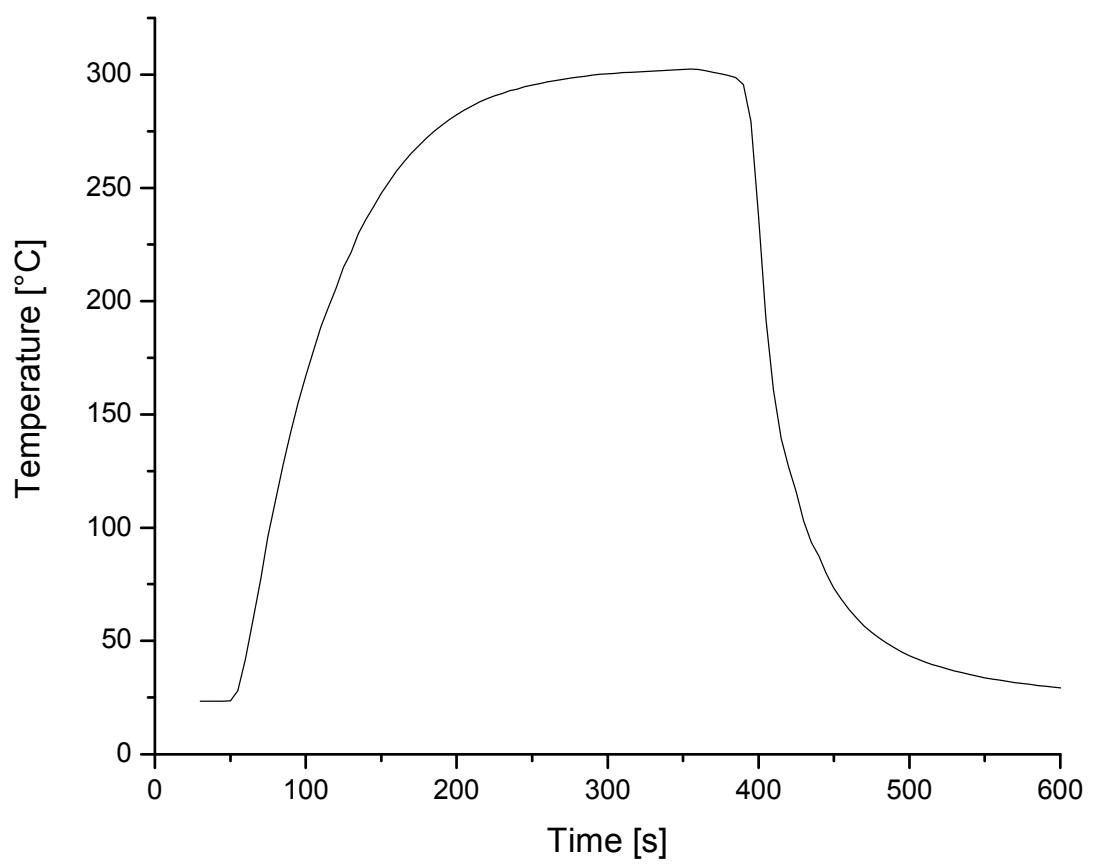

Figure 2. Temperature profile of a typical experiment at $300^{\circ} \mathrm{C}$ and 5 min total time.

\subsection{Analyses}

\section{Gas chromatograph (for permanent gasses)}

The gas sample taken at the end of each experiment was analysed using a Varian Micro GC CP-4900 with two analytical columns: $10 \mathrm{~m}$ Molsieve 5A and $10 \mathrm{~m}$ PPQ using helium as carrier gas. 


\section{Elemental analysis}

The elemental composition was determined using a Fisions Instruments 1108 EA CHNS. Oxygen was determined by difference.

\section{Molecular weight distribution}

Gel Permeation Chromatography (GPC) separates molecules by size. Using a polystyrene calibration, this separation is translated into a molecular weight distribution. Because there is no uniform relationship between molecular size and weight, GPC analysis only gives an indication of the molecular weight distribution.

Two systems, using two different solvents, were used to carry out these analyses:

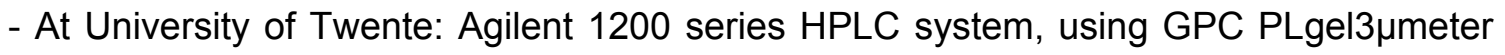
MIXED-E columns; the flow was $1 \mathrm{ml} / \mathrm{min}$ at $40{ }^{\circ} \mathrm{C}$ column temperature. The solvent used was tetrahydrofuran (THF). The diagrams shown in the experimental section were cut at low molecular weight $(\sim 100 \mathrm{~g} / \mathrm{mol})$ to remove the peak corresponding to the degradation products of THF.

-At Johann Heinrich von Thünen Institute (vTI): Agilent 1100 series HPLC system, using PolarGel-L $(300 \times 7.5 \mathrm{~mm})$ columns; the flow was $0.8 \mathrm{ml} / \mathrm{min}$ at $40{ }^{\circ} \mathrm{C}$ column temperature. In this case, the solvent used was DMSO containing $1 \% \mathrm{LiBr}$, which could also (partly) dissolve WAIS and allow its analysis.

\section{PY/GC/MS (performed by vTI)}

To characterise the constituents of the WAS, pyrolytic GC/MS was used to break the polymeric product into smaller components to be able to separate and analyse them. For this technique, the system used consisted of (1) a Frontier Lab micro furnace doubleshot Pyrolyser Py-2020iD equipped with an auto-sampler AS-1020 E and (2) an Agilent GC 6890 with a MS and FID detector. The pyrolysis temperatures and time used were 500 and $750{ }^{\circ} \mathrm{C}$ and $10 \mathrm{~s}$, respectively. The GC column used was a ZB-1701 (Phenomenex), $60 \mathrm{~m} \times 0.25 \mathrm{~mm}, 0.25 \mu \mathrm{m}$ film. Identification of the products was performed by comparing their mass spectra with the NIST and a home-made library.

\section{FTIR (performed by vTI)}

This analysis was used to determine the functional groups present in WAS, complementing the results of PY/GC/MS. The system used was a Bruker Vector 33. The position of the observed peaks was correlated to the functional groups as described in [15]. 


\section{Experimental results and discussion}

Because neither catalyst nor hydrogen was used, the type of experiments will be referred to as 'HPTT'. HPTT experiments were carried out using a variety of feedstocks (mainly glucose) and reaction conditions (temperature, reaction time and initial concentration). In this section, the reported reaction time includes the heating time of approximately $4 \mathrm{~min}$. Table 1 gives a summary of the conditions of the experiments and the corresponding carbon balance closures. Although the carbon balance closure for some experiments was rather low, the trends observed are sound and in accordance with literature [14]. The extent of polymerisation is evaluated in terms of WAIS production and molecular weight distribution of the oil.

Table 1. Overview of experiments including carbon balance closure.

\begin{tabular}{|c|c|c|c|c|c|}
\hline Feedstock & Solvent & $\begin{array}{c}\text { Temp. } \\
\left({ }^{\circ} \mathrm{C}\right)\end{array}$ & $\begin{array}{l}\text { Conc. } \\
\text { (wt.\%) }\end{array}$ & $\begin{array}{l}\text { Reac. time } \\
\text { (min) }\end{array}$ & C balance ${ }^{a}$ \\
\hline Xylose & Water & 300 & 5 & 5 & $53 \pm 7^{b}$ \\
\hline Lignin & Water & 300 & 5 & 5 & 96 \\
\hline Glucose & Water & 250 & 5 & 5 & N.A. ${ }^{c}$ \\
\hline Glucose & Water & 300 & 5 & 5 & 93 \\
\hline Glucose & Water & 350 & 5 & 5 & 97 \\
\hline Glucose & Water & 250 & 5 & 5 & N.A. ${ }^{c}$ \\
\hline Glucose & Water & 250 & 5 & 10 & 82 \\
\hline Glucose & Water & 250 & 5 & 30 & 96 \\
\hline Glucose & Water & 250 & 5 & 60 & 81 \\
\hline Glucose & Water & 300 & 5 & 5 & 93 \\
\hline Glucose & Water & 300 & 10 & 5 & 92 \\
\hline Glucose & Water & 300 & 30 & 5 & $79 \pm 2^{b}$ \\
\hline Sorbitol & Water & 300 & 5 & 5 & N.A. \\
\hline Glucose & Water/Ethanol $^{d}$ & 300 & 5 & 5 & $92 \pm 2^{\mathrm{b}, \mathrm{e}}$ \\
\hline SFPO $^{f}$ & Water & 300 & 5 & 5 & $75 \pm 2^{b}$ \\
\hline SFPO ${ }^{f}$ & Water/Ethanol $^{d}$ & 300 & 5 & 5 & $80 \pm 1^{\mathrm{b}, \mathrm{e}}$ \\
\hline Pyrolysis oil & Water & 300 & $64^{g}$ & 15 & N.A. ${ }^{c}$ \\
\hline Pyrolysis oil & Water/Ethanol & 300 & $64^{g}$ & 15 & N.A. ${ }^{c}$ \\
\hline
\end{tabular}

${ }^{\mathrm{a}}$ From carbon in glucose

${ }^{\mathrm{b}}$ Relative error (from double experiment)

${ }^{\mathrm{c}}$ Not available

${ }^{d}$ Water/Ethanol 50/50 wt.\% mixture

${ }^{\mathrm{e}}$ It should be noted that some carbon from the solvent ethanol might have reacted with the oil and increase the carbon recovery.

${ }^{\mathrm{f}}$ Sugar fraction of pyrolysis oil obtained by solid phase extraction

${ }^{9}$ Organics from pyrolysis oil in water (from pyrolysis oil or added) and/or ethanol 


\subsection{Preliminary tests on glucose, xylose and organosolv lignin}

To verify the reproducibility of the experimental set-up and procedure, triplicate experiments were carried out using $5 \mathrm{wt}$.\% glucose aqueous solution, $300{ }^{\circ} \mathrm{C}$ and $5 \mathrm{~min}$ reaction time (heating time included). Similar to Knežević et al. [14], the yield of produced water from glucose was approximately constant at $30(+/-5)$ wt.\%. This amount is related to the fast dehydration of glucose and initial decay products $(3 \mathrm{~mol}$ water per mol glucose). Literature on glucose conversion $[14,16]$ shows that under the typical experimental conditions of this study $\left(300{ }^{\circ} \mathrm{C}\right.$ and 5 min reaction time) glucose conversion is complete. Therefore, and unless otherwise stated, full conversion of the feedstock was assumed in this study. Figure 3 shows the molecular weight distribution (MWD) of untreated glucose and the oil products of these three experiments. Under the conditions mentioned, glucose (actually, its decay products, according to Knežević et al. [14]) polymerised significantly forming a much heavier (oil) product. Similar to the results of HPTT of pyrolysis oil (Chapter 2), this polymerisation appears to be very fast; in both cases polymerisation was observed within 5 min. Figure 3 also shows that the GPC chromatograms of the product oils are virtually identical. This, combined with the fact that the WAIS yields were similar $(2.5,2.8$ and 2.6 wt. $\%$, respectively), shows that good reproducibility was obtained.

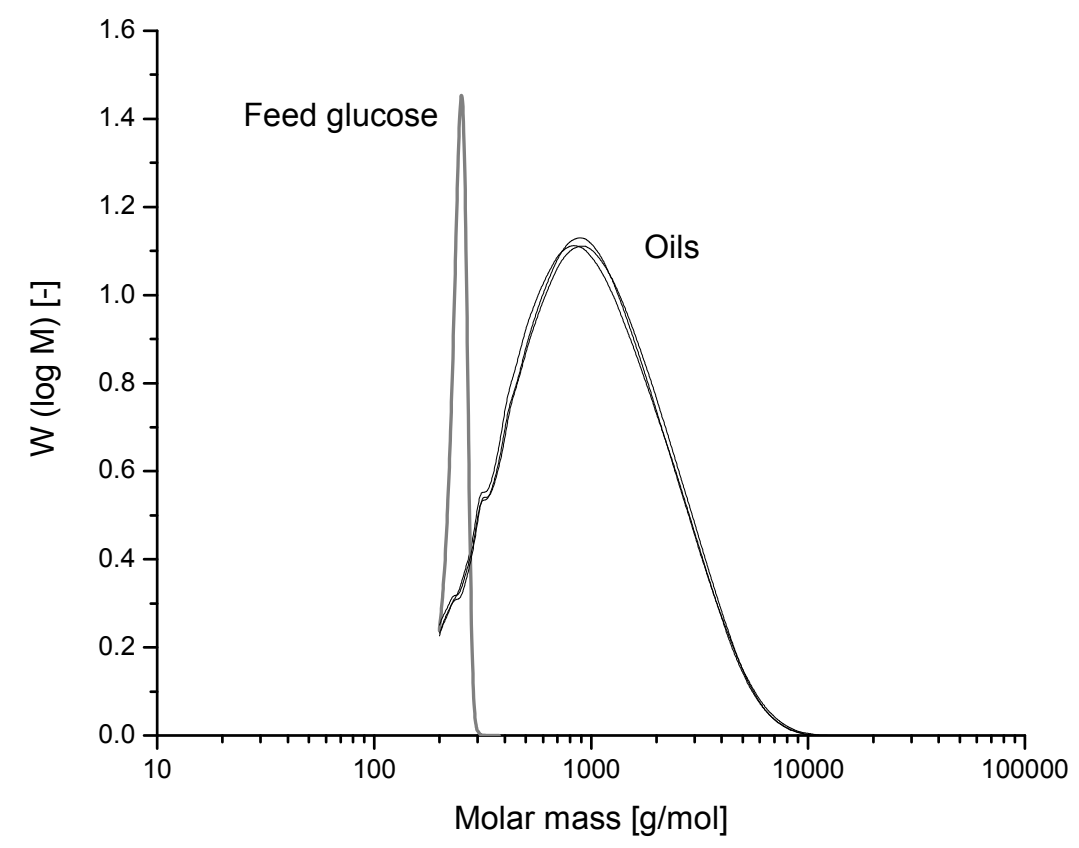

Figure 3. GPC analysis of three experiments carried out at identical operating conditions ( $5 \mathrm{wt} . \%$ glucose solution, $300{ }^{\circ} \mathrm{C}$ and $5 \mathrm{~min}$ ). The chromatogram of un-treated glucose has been reduced in size (height) 8 times for better spatial comparison. 
Pyrolysis oil from biomass contains the thermal degradation products of cellulose, hemicellulose and lignin. Figure 3 already shows the molecular weight distribution of the polymerisation products of glucose, which was used to represent the sugars in pyrolysis oil that originate from cellulose. To evaluate the possible polymerisation of components in pyrolysis oil that originate from lignin and hemi-cellulose, organosolv lignin and xylose (elementary sugar from hemi-cellulose) were used respectively as model compounds. They were also processed at $300{ }^{\circ} \mathrm{C}$ for $5 \mathrm{~min}$. Xylose was processed as $5 \mathrm{wt} . \%$ aqueous solution. Lignin could not be dissolved in water at room temperature, thus, it was dispersed $5 \mathrm{wt} \%$ in water. At the reaction conditions, lignin is expected to be, at least partially, soluble in hot compressed water (wood and pyrolysis oil, both containing considerable amounts of lignin, show this behaviour [17]). Figure 4 shows the MWD of the products of these experiments. After HPTT of lignin, no increase in the molecular weight was observed, but it was already very high before HPTT treatment. However, the WAIS yield was 6.8 wt.\%, indicating that some reactions did occur (WAIS from raw organosolv lignin is already $3.3 \mathrm{wt}$ \%). Xylose did polymerise but less than glucose. Moreover, from the GPC chromatogram it appears that not all xylose was converted, although this cannot be stated with certainty because component identification was not performed. Although the WAS fraction obtained from xylose did not show the same degree as polymerisation as glucose (compare Figure 3 and Figure 4), the WAIS production was higher than that of glucose $(5.5 \pm 2.2 \mathrm{wt} . \%)$.

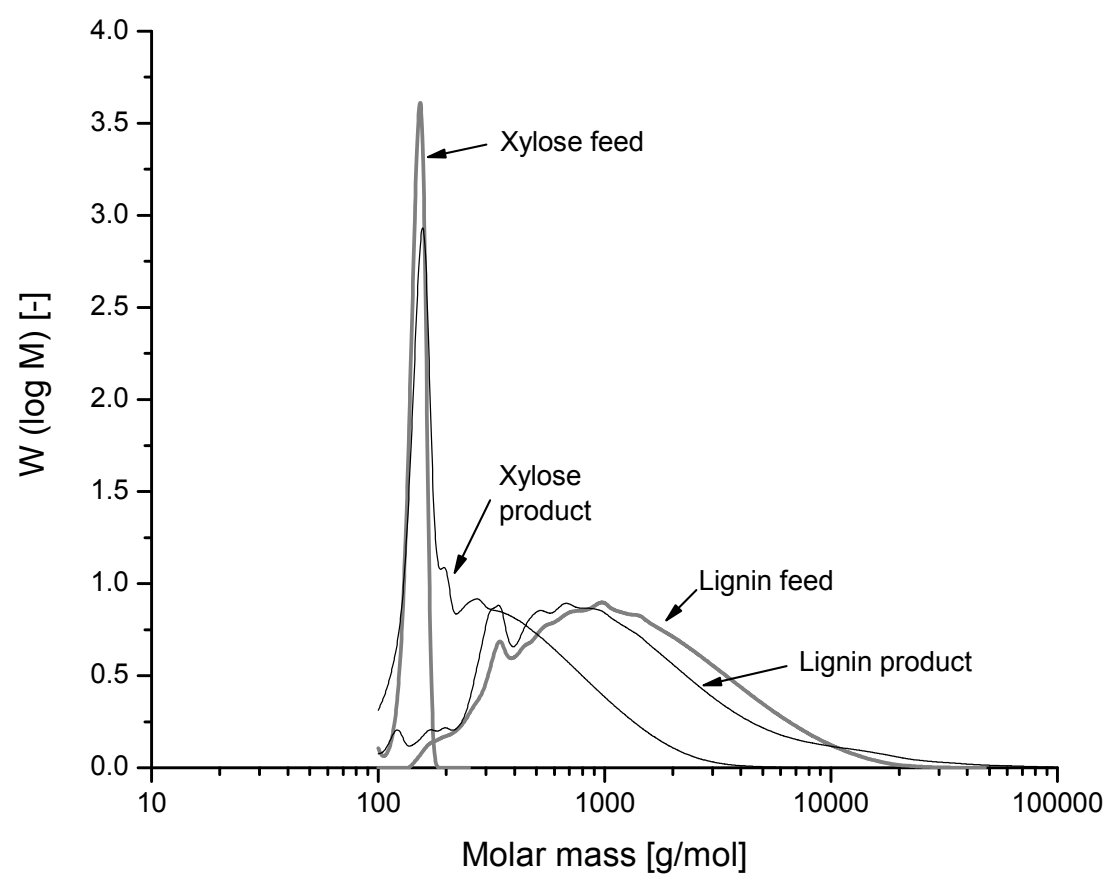

Figure 4. Molecular weight distribution of the oil obtained by processing 5 wt. $\%$ xylose and organosolv lignin in water at $300{ }^{\circ} \mathrm{C}$ during $5 \mathrm{~min}$. Un-treated organosolv lignin and xylose (the latter reduced 3 times for better spatial comparison) are also shown. 
In the HPTT of pyrolysis oil, sugars (and its decay products) are likely to contribute to the increase in molecular weight of the oil (as seen in Chapter 2). Glucose and to a lesser extent also xylose showed this fast polymerisation behaviour. Although the use of organosolv lignin did not result in a substantial increase in molecular weight, there was still a considerable amount of WAIS present after HPTT. It should be noted that the starting material already contained a considerable amount of WAIS, suggesting that only a limited extent of polymerisation can already increase the WAIS during HPTT. This indicates that not only sugars, but also lignin components are a cause of char formation during pyrolysis oil upgrading by HPTT and HDO. Nevertheless, this study will further limit itself to glucose as model component.

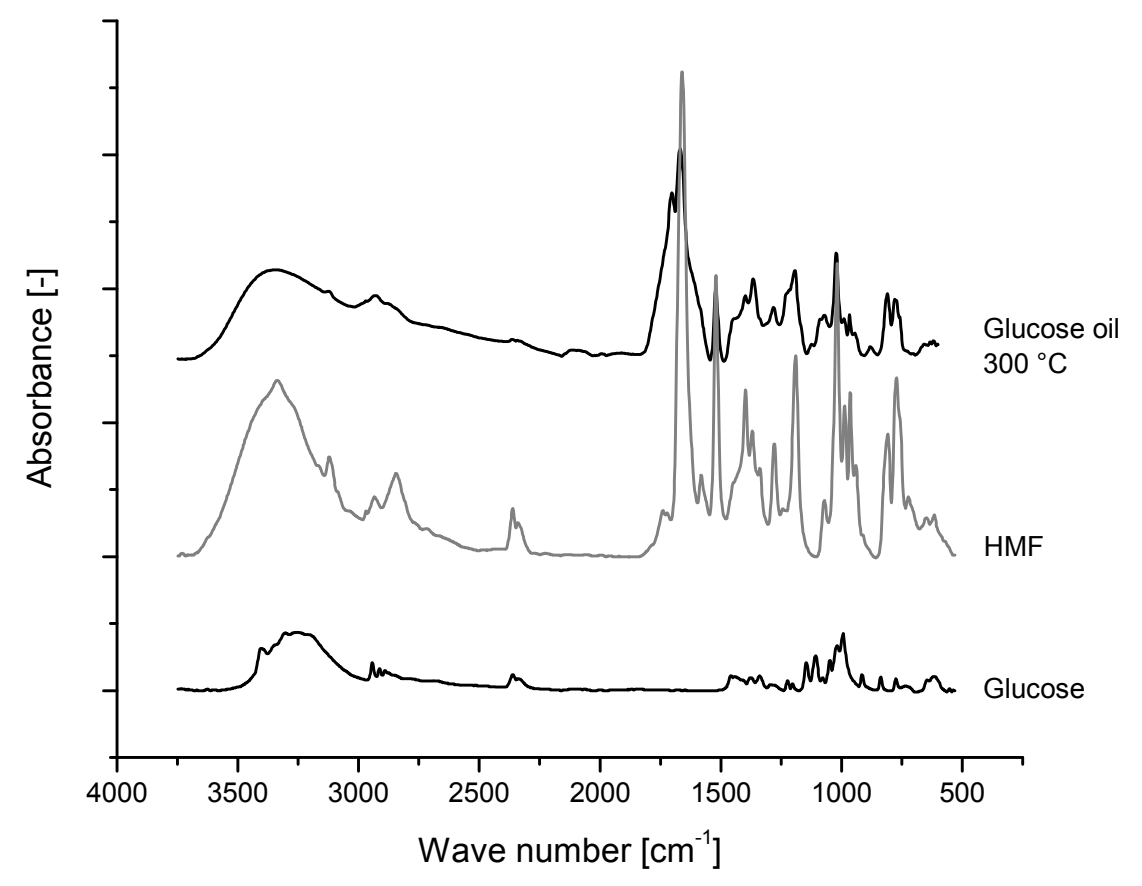

Figure 5. FTIR analyses of glucose, HMF and the oil produced from glucose at $300{ }^{\circ} \mathrm{C}, 5 \mathrm{wt} . \%$ initial concentration and 5 min reaction time.

PY/GC/MS analysis was conducted on the oil obtained from glucose $\left(300{ }^{\circ} \mathrm{C}, 5 \mathrm{wt} . \%\right.$ and $5 \mathrm{~min}$ ). With this technique, the oil polymer is broken into smaller components to make GC/MS analysis possible. The analysis with a pyrolysis temperature of $500{ }^{\circ} \mathrm{C}$ showed that $\sim 65 \%$ of the peak area in the chromatogram corresponded to 5hydroxymethylfurfural (HMF), showing that the dominant route for the formation of oil is the fast formation of furfurals from glucose followed by its polymerisation to WAS and WAIS. The fast initial dehydration of glucose observed in this work and in the literature [14] by the removal of $3 \mathrm{~mol}$ of water per mol of glucose, also indicates (at least stoichiometrically) the initial formation of HMF. The analysis carried out with a PY/GC/MS temperature of $750{ }^{\circ} \mathrm{C}$ also showed high concentrations of furanic components in the oil, but in this case also aromatic components (which can originate 
from HMF [18]) were detected. At this moment, it is not possible to know if these components originated from the breaking of the oil, or were pyrolysis reaction products. FTIR analysis of glucose, HMF and glucose oil can be seen in Figure 5. It shows that all samples contained $\mathrm{OH}$ groups (broad stretching in the region of $3400 \mathrm{~cm}^{-1}$ ). In glucose oil, peaks representative of $C=O$ bonds $\left(\sim 1670 \mathrm{~cm}^{-1}\right)$ and conjugated $C-C$ bonds (1520$1580 \mathrm{~cm}^{-1}$ ) can be observed. These peaks are also observed for HMF and can correspond to both furanic and aromatic structures. Chuntanapum and Matsumura [18] conducted 'HPTT' experiments using HMF as feed and proposed a mechanism in which HMF polymerises to char keeping its furanic structure. They also reported the formation of aromatic components from feed HMF that contributed to the polymerisation mechanism to form char. The combination of the stoichiometric and the advanced analysis results show that glucose oil is likely to consist of furanic/aromatic structures.

\subsection{Effect of process conditions on glucose polymerisation}

A series of experiments at varying process conditions (temperature, reaction time and initial glucose concentrations) was carried out to study their effect on the extent of polymerisation. The effect of reaction time on the polymerisation can be seen in Figure 6 . In these experiments, $5 \mathrm{wt} . \%$ aqueous glucose solutions were processed at $250{ }^{\circ} \mathrm{C}$ for different reactions times $(5-60 \mathrm{~min})$. Figure 6 a shows the evolution of product yields with the reaction time. The oil yield for the experiment at $5 \mathrm{~min}$ reaction time is not shown because at these conditions and in contrast to the experiments at $300{ }^{\circ} \mathrm{C}$ not all glucose was converted. Using the kinetic parameters given by Knežević et al. [14] and correcting for the experimental heating time as used in the present work, the expected conversion after $5 \mathrm{~min}$ at $250{ }^{\circ} \mathrm{C}$ is only $28 \%$. The incomplete glucose conversion at 5 minutes can also be seen in the MWD diagram (Figure 6b), where an extra peak is present at the same location of pure glucose. At 10 min reaction time, the model calculations predict a conversion of $71 \%$. The molecular weight distribution of the oil in Figure $6 \mathrm{~b}$ indeed confirms the presence of unreacted glucose, although the peak area seems to be very small. For the experiments at 30 and 60 min reaction time, full glucose conversion was achieved, which is in accordance with the model calculations. Figure 6a shows that with increasing reaction time, the oil yield continuously decreases due to the production of some extra gas but mainly due to the formation of WAIS, indicating that the oil acted (partly) as an intermediate reaction product. The trends observed in this study are similar as the ones observed by Knežević et al. [14] at 300 and $350{ }^{\circ} \mathrm{C}$, although in their case, the change in yields was faster, reaching a plateau for the WAIS yield at approximately 30 min ( $\sim 30$ wt. $\%$ at 300 and $\sim 20$ wt. $\%$ at $350{ }^{\circ} \mathrm{C}$ ). Figure $6 \mathrm{~b}$ shows the MWD of the oils produced. It can be seen that with longer reaction times, the MWD decreased. This can be explained by the mechanism proposed by Knežević et al. [14] in which, at least, two different types of oil are produced; one of the oil products might be an intermediate that would further polymerise to WAIS, the other could remain stable. They also proposed 
that the stable oil was lighter than the un-stable one. The net result of further polymerisation of the un-stable oil towards WAIS would appear in the GPC diagram as the production of a lighter oil. The hypothesis that part of the oil can further polymerise to produce WAIS was evaluated by conducting GPC analysis of the oil and WAIS in a different HPLC system. In this case, DMSO was used as solvent which was able to dissolve not only the oil, but also could partly dissolve the WAIS. Figure 7 shows the MWD of an oil produced at $300{ }^{\circ} \mathrm{C}, 5 \mathrm{~min}$ reaction time and $5 \mathrm{wt} \%$ glucose concentration and the MWD of its corresponding WAIS. This diagram clearly shows that heavier components are present in the WAIS. Furthermore, also the elemental composition of the WAIS and WAS are very comparable (the WAIS being more dehydrogenated) as can be seen in Figure 9. This further reaffirms another hypothesis of Knežević et al. [14], in which WAS and WAIS are very similar products mostly differentiated by their molecular weight and thus their solubility in acetone.
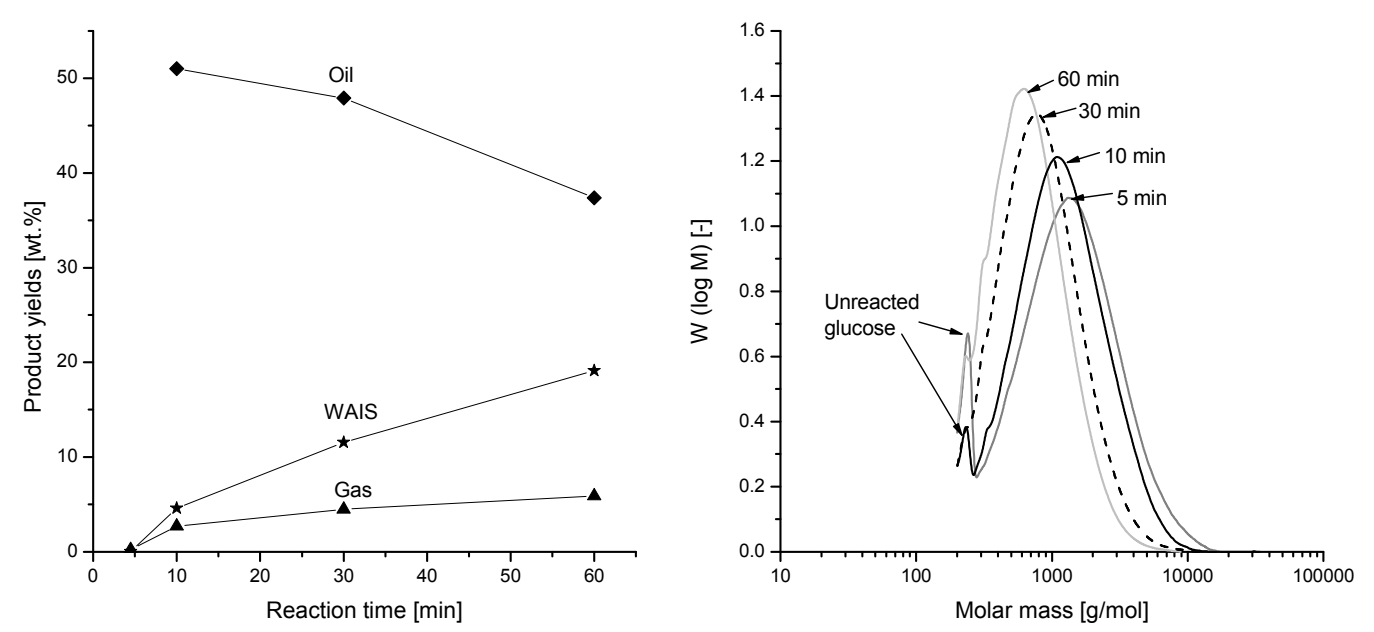

Figure 6. a) Product yields for experiments conducted at constant initial glucose concentration 5 wt. $\%$ and reaction temperature $250{ }^{\circ} \mathrm{C}$ at different reaction times. b) MWD of the oils obtained at these conditions.

Figure 8a shows the product yields (produced water yield is not shown) of $5 \mathrm{wt} \%$ aqueous glucose solution processed during $5 \mathrm{~min}$ at different temperatures. At $250{ }^{\circ} \mathrm{C}$ the oil yield is not available because not all glucose was converted. At 300 and $350{ }^{\circ} \mathrm{C}$, the oil yield was approximately constant at around $52 \mathrm{wt} \%$. With increasing temperature, the WAIS yield slightly increased, while the MWD of the oils was reduced (Figure 8b). Sasaki et al. [19] indicated that at higher temperatures (especially when reaching supercritical water conditions) bond-braking reactions can occur which could yield a lower overall molecular weight of the oil. 


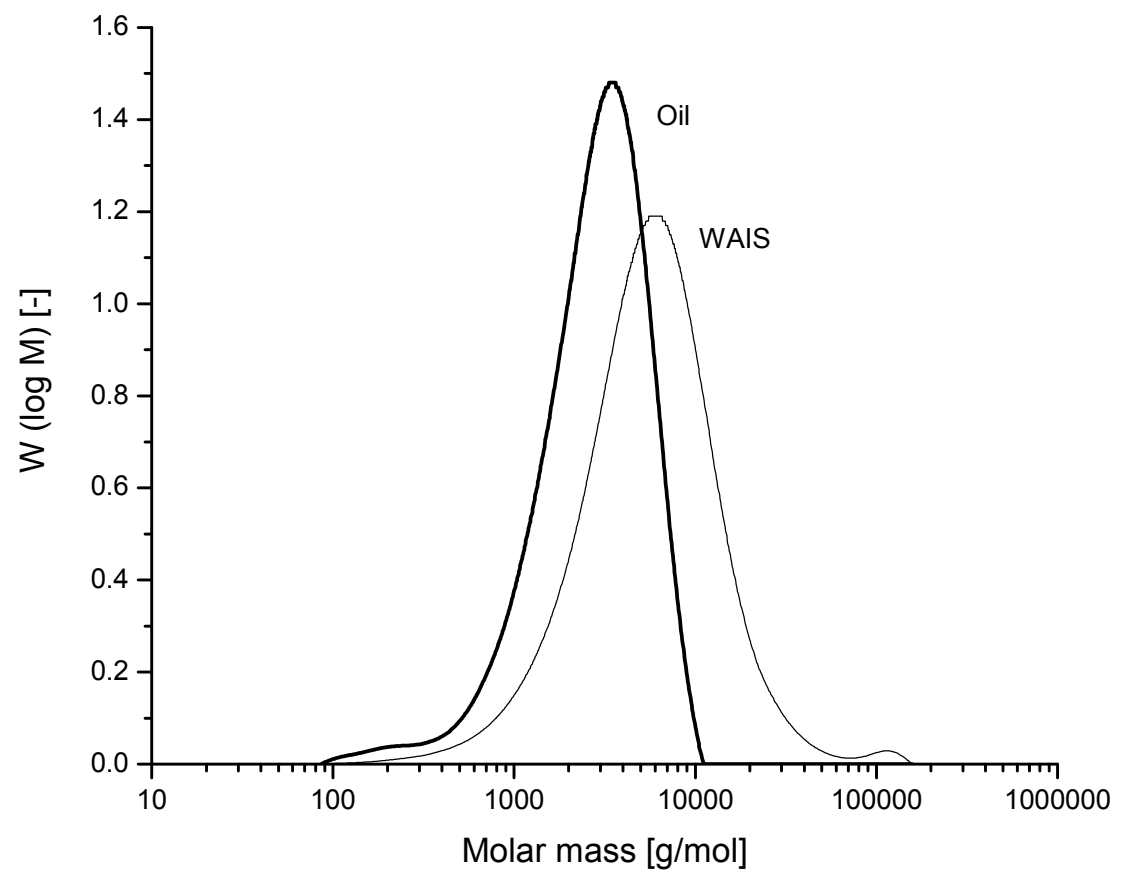

Figure 7. Molecular weight distribution of oil and WAIS produced at $300{ }^{\circ} \mathrm{C}, 5$ wt. $\%$ glucose aqueous solution and $5 \mathrm{~min}$ reaction time. DMSO was used as solvent for the GPC system.
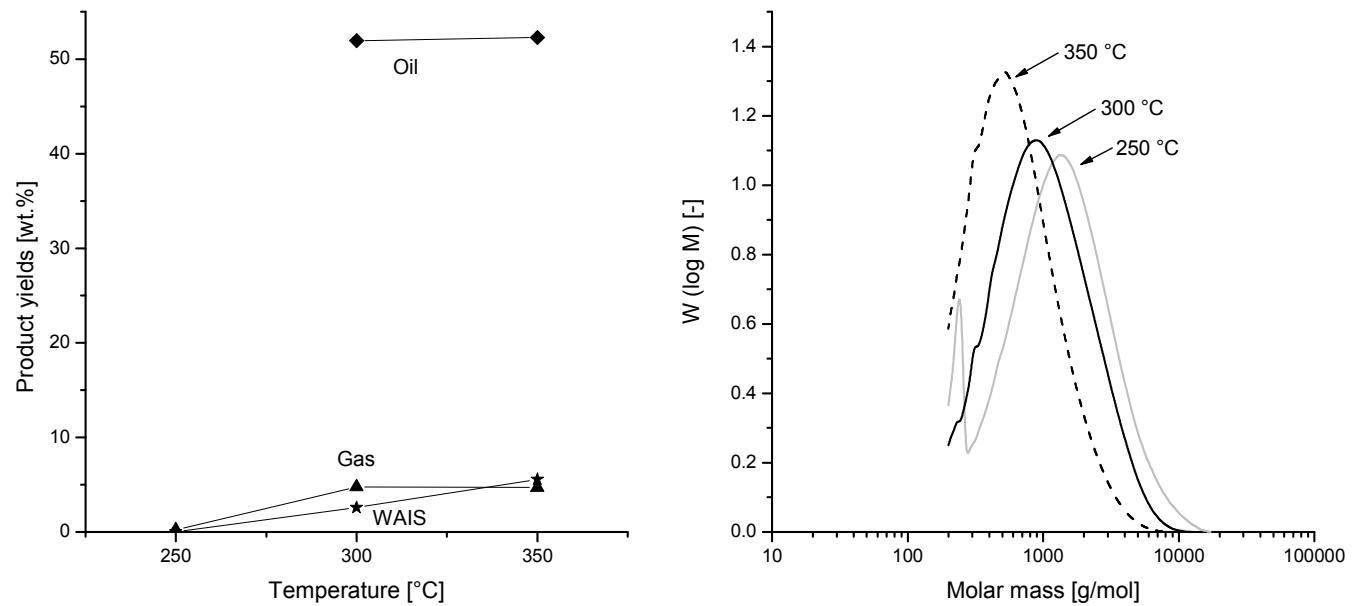

Figure 8. a) Product yields for experiments conducted at constant reaction time $5 \mathrm{~min}$ and initial glucose concentration $5 \mathrm{wt} . \%$ at different temperatures. b) MWD of the oils obtained at these conditions. 
Relating these findings to the HDO of pyrolysis oil, it appears that with increasing temperature, the polymerisation rate of sugars is increasing (producing more WAIS). Therefore, hydrotreatment of sugars should preferably be performed at a temperature in which the polymerisation rate is still slow compared to the hydrotreating/stabilisation reactions. Although an increase in molecular weight was already observed at temperatures below $250^{\circ} \mathrm{C}$, the WAIS yield was almost negligible. In contrast it is known that already at $100{ }^{\circ} \mathrm{C}$ glucose hydrogenation to sorbitol can be achieved [20]. The concept of low temperature stabilisation by hydrogenation (preventing direct polymerisation) only seems applicable if the hydrogenated product (in this case sorbitol) is less sensitive to polymerisation than the reactant (in this case glucose). This is studied in more detail in section 3.3.

With respect to co-processing upgraded pyrolysis oil by FCC, the upgraded oil should preferably have a low $\mathrm{O} / \mathrm{C}$ (demanding less hydrogen transfer from fossil feed upon coprocessing) and high $H / C$ (see Chapter 3 ). Figure 9 shows the van Krevelen diagram of glucose and its products (oil and WAIS), in which a reduction of O/C can be observed. The preferred way of oxygen removal during upgrading is the formation of only $\mathrm{CO}_{2}$, as this would increase the $H / C$ (and not require any hydrogen in case of HDO). However, from the relationship between the elemental composition of the glucose feed and the products, it can be seen that, overall, mainly dehydration occurs (as already seen by the production of $\sim 30 \mathrm{wt}$ \% water), leading to a low $\mathrm{H} / \mathrm{C}$ of the products after HPTT. The elemental composition of the WAIS appears to be very similar to the oil, but shows even more dehydrogenation. Figure 9 also shows the $H / C$ and $O / C$ ratios for pyrolysis oil and its HPTT product processed in a continuous set-up at $300{ }^{\circ} \mathrm{C}$ for $3.5 \mathrm{~min}$ (data from Chapter 2). Upon HPTT of pyrolysis oil, overall dehydration and severe polymerisation was also observed.

Figure 10 shows the product yields and the MWD of the oil for experiments conducted at a constant reaction time of $5 \mathrm{~min}$, temperature of $300{ }^{\circ} \mathrm{C}$ and varying initial glucose concentration (5-30 wt.\%). Differences in MWD can be observed but are modest and not as clear as observed for changes in temperature or residence time. With increasing concentration, a wider distribution, with slightly more heavy but at the same time light components is obtained. However, significant differences were observed in the product yields. The oil yield drastically decreased with concentration in favour of WAIS production. This suggests that the overall reaction to form WAIS from glucose has a reaction order higher than one. Chuntanapum and Matsumura [18] also found increasing WAIS (called char in their publication) production with increasing concentration of HMF, one of glucose primary decay products, via dehydration (experimental conditions: $350{ }^{\circ} \mathrm{C}$ and $\sim 400 \mathrm{~s}$ residence time). The gas yield decreased slightly but, taking into account the accuracy of the results, it could also be considered constant. Literature $[14,18]$ indicates that the gas yield is independent on the initial concentration of glucose or HMF, implying a reaction order of 1 (in terms of gas production from glucose/HMF). For the case of HPTT of pyrolysis oil, water dilution experiments shown in Chapter 2 resulted in a lower 
molecular weight of the product (WAIS production was not evaluated). Apparently, the use of low concentrations is beneficial in avoiding undesired products (properties), viz. high molecular weight or WAIS production. This can influence reactor selection in upgrading processes like HDO. A reactor with a high degree of backmixing in the initial stage of the HDO process can reduce the concentration of polymerisation precursors and therewith reduce the polymerisation rate. Also dilution of the feed might be an option to reduce the rate of polymerisation reactions.

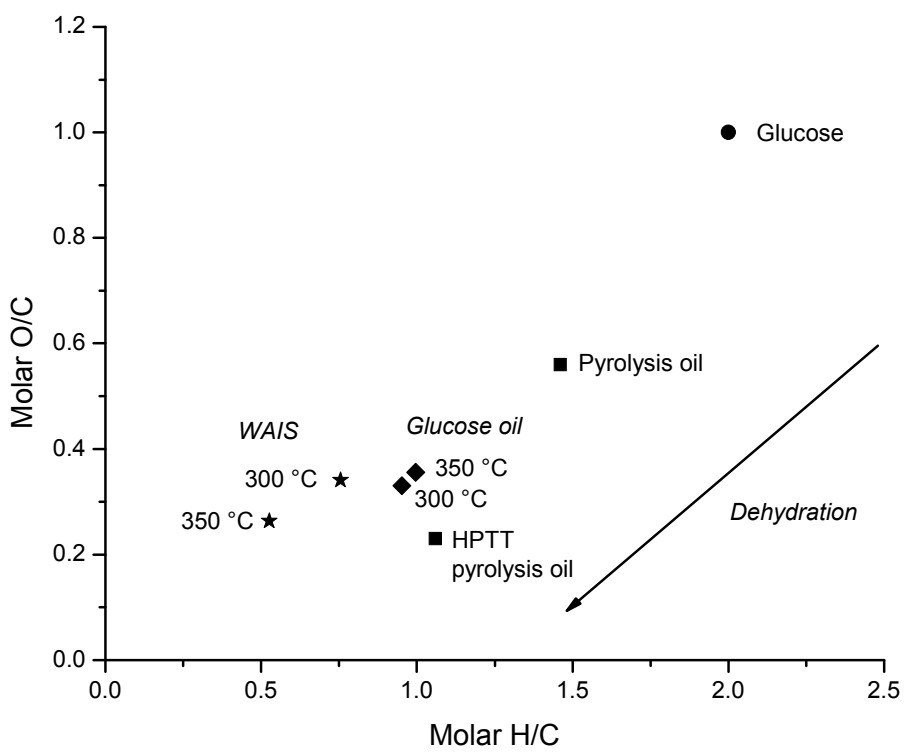

Figure 9. Van Krevelen diagram for glucose, its HPTT products (oil $\bullet$ and WAIS' ) at different temperatures and pyrolysis oil and its HPTT product, $\mathbf{\square}$ (data from Chapter 2).
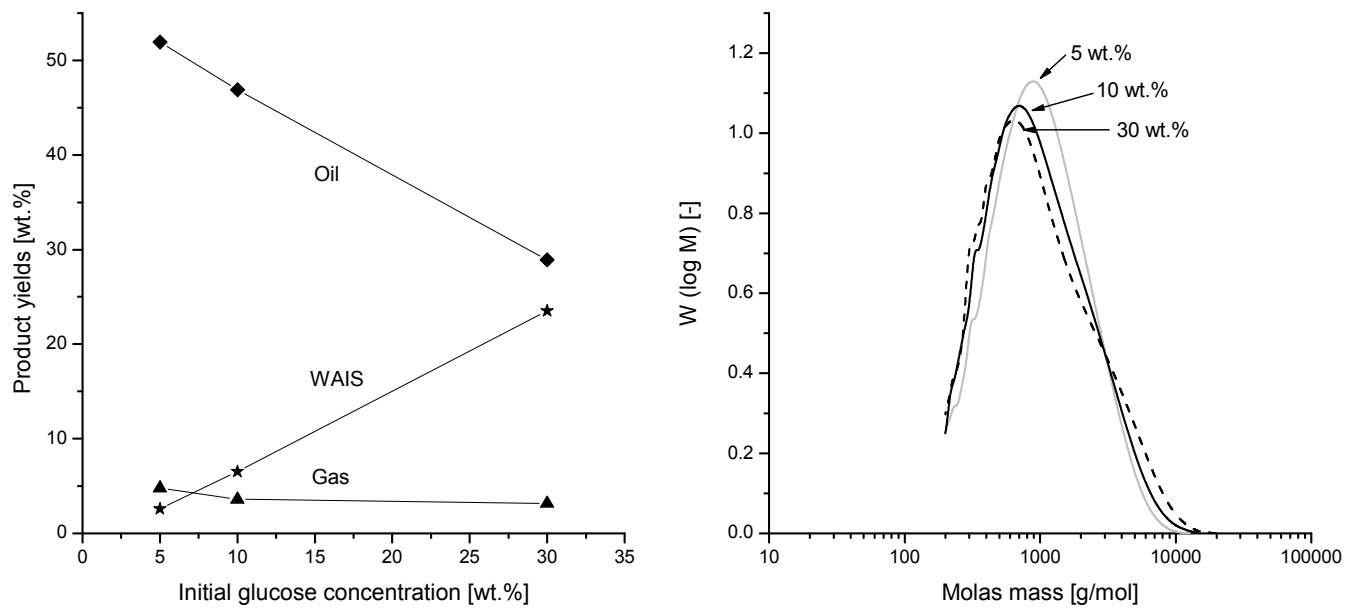

Figure 10. a) Product yields for experiments conducted at constant reaction time 5 min and temperature $300{ }^{\circ} \mathrm{C}$ at different initial glucose concentration. b) MWD of the oils obtained at these conditions. 


\subsection{Preventing polymerisation}

In previous sections, the effect of operating conditions on the polymerisation of glucose was studied. This showed that with increasing reaction time, temperature and concentration the formation of WAIS increased. In this section, two methods are considered to suppress or reduce the extent of the polymerisation by the use of chemicals, viz. hydrogenation (not hydrodeoxygenation) and ethanol as co-solvent, respectively.

Hydrotreating of pyrolysis oil has proven to be an effective way to reduce the tendency towards coke formation. Comparing the products of HPTT (Chapter 2) and HDO of pyrolysis oil (Chapter 3 and 4), the former showed and extensive increase in molecular weight and the latter did not. In both cases, water soluble sugars disappeared from the aqueous phase by-product and were transferred to the oil phase. The hydrotreating of sugars (and sugar derivates) seems to be important to stabilise pyrolysis oil. In this study, the hydrogenated product of glucose (sorbitol) was tested as model compound under HPTT conditions. After treatment of $5 \mathrm{wt} . \%$ aqueous sorbitol solution at $300{ }^{\circ} \mathrm{C}$ for $5 \mathrm{~min}$, the WAIS and gas yield were negligible. Although at lower concentration $(\sim 0.9$ wt.\%), Srokol et al. [21] also found no reactivity of sorbitol at $340{ }^{\circ} \mathrm{C}$ and 4 min reaction time. It should also be noted that the solution obtained when emptying the autoclave was transparent and clear, which was very different from the brown colour obtained when glucose was used as feedstock. The MWD of the product showed almost no difference from the feed sorbitol (results not shown). This proofs that, at least for glucose, and as already hypothesised for HDO of pyrolysis oil (in Chapters 3 and 4 and also in literature [22]), hydrogenation of sugars can prevent rapid polymerisation of these sugars.

Radlein et al. [23] patented a method to stabilise pyrolysis oil by reaction with alcohols at room temperature, adding a homogeneous inorganic acid as catalyst and using molecular sieves to remove water driving reversible reactions to completion. They observed the formation of esters and acetals (reactions that also produced water) from the reaction of pyrolysis oil with ethanol. They calculated that, after two hours, the ethanol uptake was $\sim 40 \mathrm{wt} \%$ (on dry pyrolysis oil basis). Addition of $10 \%$ methanol (at room temperature) to poplar pyrolysis oil reduced the aging rate (defined as the increase in viscosity in time) by a factor 20 [24]. Mahfud et al. [25] stabilised pyrolysis oil by reactive distillation with high boiling alcohols using solid acid catalyst and removing the water in one step. In literature, the stabilisation effect is attributed to the reaction of alcohol with among others aldehydes and ketones, reducing their concentration thereby suppressing their polymerisation. To study the stabilisation effect at high temperatures, ethanol was used as co-solvent in a HPTT of glucose. The experiments were performed in the same manner as when using the aqueous glucose solutions, however a mixture of $50 / 50 \mathrm{wt} . \%$ ethanol/water was used as solvent. In this particular case, the reaction temperature and time were $300{ }^{\circ} \mathrm{C}$ and $5 \mathrm{~min}$, respectively. Figure 11 shows the MWD of the oil resulting from this experiment and the oil produced using only water as solvent. 
Comparing the two chromatograms, it can be clearly seen that ethanol prevented the formation of heavy compounds. This is further confirmed by the fact that WAIS formation was reduced from $2.6 \pm 0.2$ to $<0.1 \mathrm{wt}$. \% when ethanol was used as co-solvent. The oil yield increased from $\sim 52.0$ to $80.0 \pm 1.5 \mathrm{wt} . \%$. This oil yield (based on glucose intake) might contain some ethanol increasing its apparent value. The gas yield decreased from $\sim 4.8$ to $0.5 \mathrm{wt}$. \%. In brief, WAIS and gas formation were reduced to a large degree, keeping the reaction products in (stable) oil form.

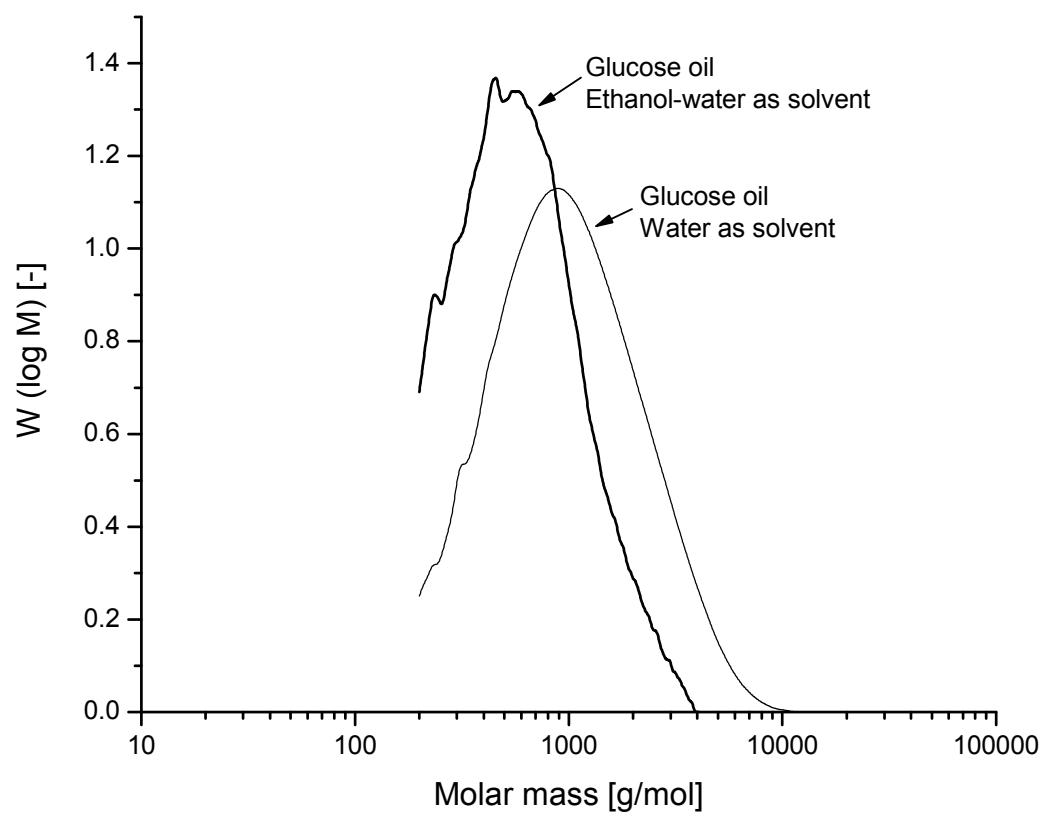

Figure 11. Molecular weight distribution of the oils produced with $5 \mathrm{wt} . \%$ glucose concentration at $300{ }^{\circ} \mathrm{C}$ and 5 min reaction time using water or water/ethanol (50/50 wt.\%) as solvent.

FTIR analysis of the oil showed similar functional groups as present in the oil obtained in the absence of alcohol (Figure 12). However, the oil produced in the presence of ethanol, shows more absorbance in the $3400 \mathrm{~cm}^{-1}$ region (corresponding to O-H bonds) which is probably due to the presence of residual ethanol in the sample. The broad peak around the $1000 \mathrm{~cm}^{-1}$ region (corresponding to $\mathrm{C}-\mathrm{O}$ bonds) can also be caused by the presence of ethanol, but the formation of ethers can also explain this peak. A peak around $1700 \mathrm{~cm}^{-1}$ shows the presence of $\mathrm{C}=\mathrm{O}$ bond, which was also observed when only water was used as solvent. A peak and two shoulders between 1500 and $1620 \mathrm{~cm}^{-1}$ (corresponding to conjugated $\mathrm{C}-\mathrm{C}$ bonds) indicate the presence of furanic or aromatic components. This seems to indicate that even when ethanol is used as co-solvent, HMF is still formed. Bicker et al. [26] showed that fructose dehydrates to HMF using methanol as solvent (and sulphuric acid as homogeneous catalyst) and then further reacts to 5-methoxymethylfurfural. In our case, it is possible that 5-ethoxymethylfurfural is thermally more stable than HMF, resulting in the reduction of WAIS formation. Van Dam 
et al. [27] conducted experiments using fructose dissolved in mixtures of water and ethylene glycol, at $88{ }^{\circ} \mathrm{C}$ for long reaction times (20-500 $\mathrm{min}$ ). They found a reduction in the formation of HMF when a co-solvent was used and they attributed this to the formation of the so called "reversion products" (less reactive fructose dimers) that acted as fructose buffer, allowing a high concentration of carbohydrates, but keeping the actual concentration of reactive fructose at low levels. If this situation also occurred in our case, this reduction in HMF concentration can also lead to the reduction in char formation (as shown in section 3.2).

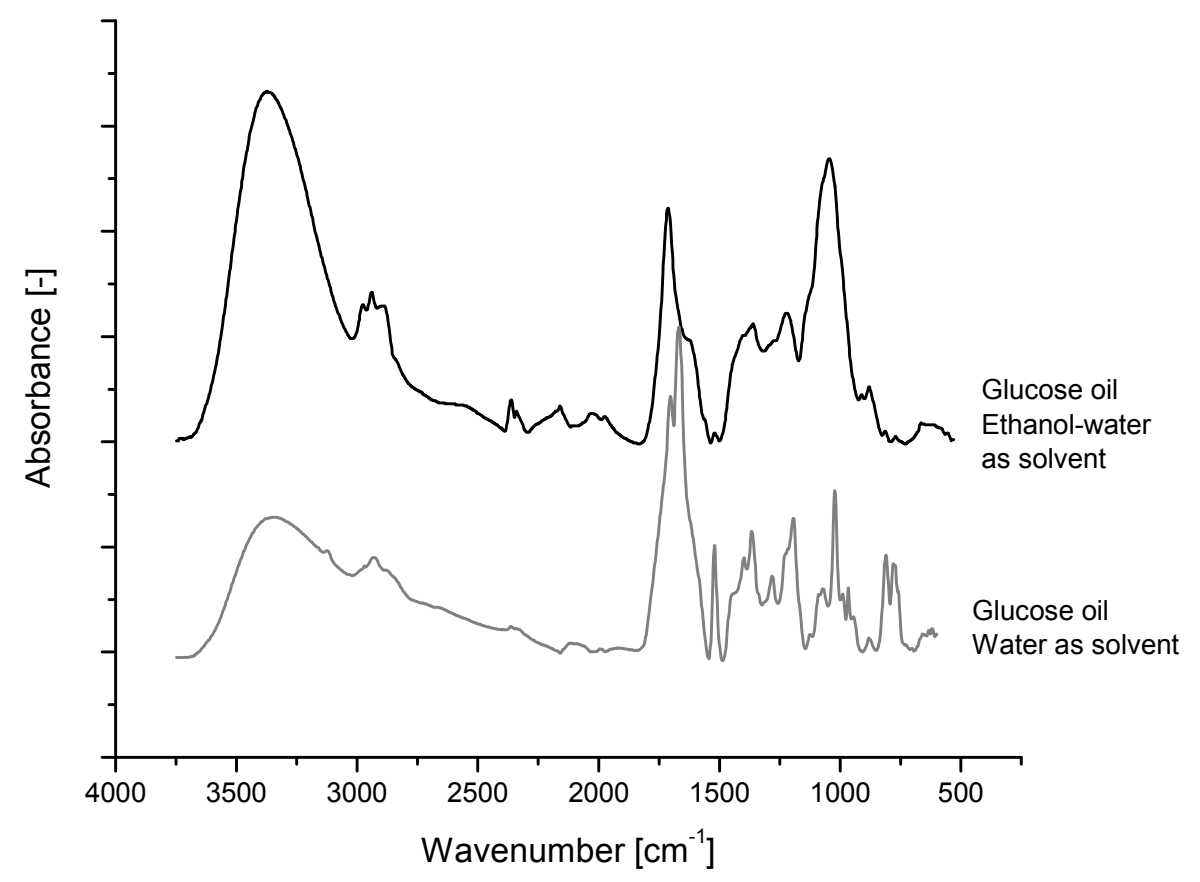

Figure 12. FTIR analysis of the oils produced at $300{ }^{\circ} \mathrm{C}, 5 \mathrm{~min}$ reaction time and $5 \mathrm{wt} . \%$ initial glucose concentration dissolved in water or water ethanol mixture $(50 / 50 \mathrm{wt})$.

MCRT analysis was conducted to evaluate the coking tendency of the oils produced using only water and water/ethanol as solvent. The values obtained were 39.3 and 27.8 wt.\% respectively. Although both values are very high, the oil produced using ethanol as co-solvent gave a clearly lower MCRT value. These results indicate that the reaction of sugar components with ethanol can help stabilising the sugars components in pyrolysis oil and facilitate further co-processing.

To validate this, HPTT experiments in the absence and presence of ethanol were carried out using a sugar fraction derived from pyrolysis oil. This sugar fraction was prepared at the von Thünen Institute (vTI, Germany) using preparative solid phase extraction of pyrolysis oil from forest residue. Figure 13 shows the MWD of the untreated fraction and its HPTT oil product using water or water/ethanol (50/50 wt.\%) as solvent. Similar to the 
experiments using glucose, the sugar concentration was $5 \mathrm{wt} \%$ and the reaction temperature and time were $300{ }^{\circ} \mathrm{C}$ and $5 \mathrm{~min}$, respectively. It can be seen that, although some increase in molecular weight was observed when ethanol was used as co-solvent, it was less severe than when only water was used. In accordance with the experiments using glucose as model compound, reduction of the yields of WAIS (from $1.7 \pm 0.5$ to 0.5 $\pm 0.1 \mathrm{wt} . \%$ ) and gas production (from $3.0 \pm 0.4$ to $1.8 \pm 0.1 \mathrm{wt} . \%$, although both very low) was observed when using ethanol as co-solvent. The oil yield also increased from $56.7 \pm$ 0.4 to $66.0 \pm 0.8$ wt. $\%$.

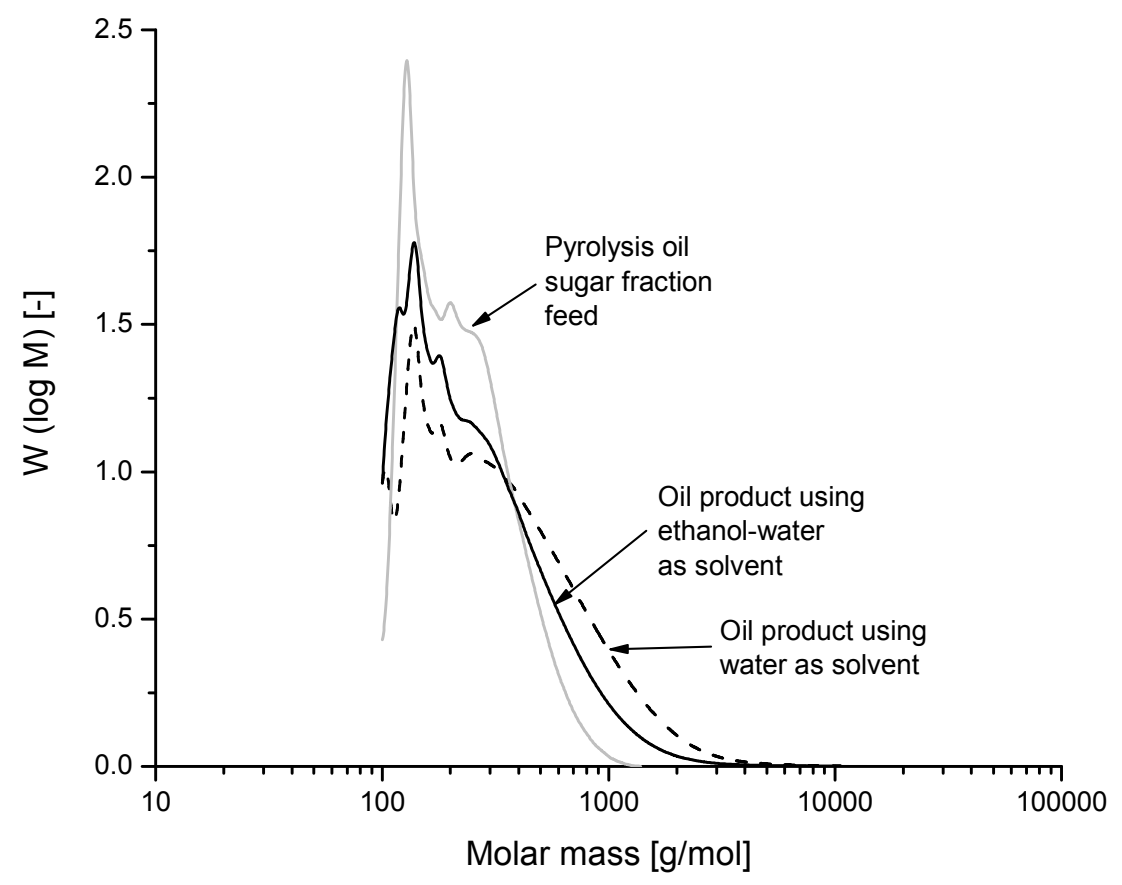

Figure 13. Molecular weight distribution of the sugar fraction of pine pyrolysis oil (obtained by solid phase extraction) and its HPTT oil product using water or water/ethanol (50/50 wt.\%) as solvent. The reaction temperature and time were $300{ }^{\circ} \mathrm{C}$ and $5 \mathrm{~min}$, respectively. The feed concentration was 5 wt. $\%$.

To further study the effect of ethanol addition prior to HPTT, an experiment at $300{ }^{\circ} \mathrm{C}$ was conducted using $85 \mathrm{wt} . \%$ pyrolysis oil with $15 \mathrm{wt} . \%$ ethanol. As reference, the same experiment was carried out using $15 \mathrm{wt} \%$ of water instead of ethanol. The pyrolysis oil used was produced by VTT, Finland, using forest residue as feed (properties of this oil can be found Chapter 3). This oil was also used to produce the aforementioned sugar fraction. Because of the expected difficulties in product recovery, a bigger $(43 \mathrm{ml})$ rector was used. The larger reactor used caused longer heating time ( $8 \mathrm{~min})$, thus, the total reaction time was set at $15 \mathrm{~min}$. After reaction, an oil and aqueous phase were produced (as already expected from Chapter 2). In both cases, severe and similar polymerisation of the oil phase was observed (see Figure 14). However, a higher amount of WAIS was found in the absence of ethanol (19.8 vs. $12.5 \mathrm{wt} \%$ from the amount of product), 
indicating further polymerisation. The appearance of these products was completely different. While for the experiment with ethanol addition the product was very viscous but still liquid, the experiment without ethanol created a solid porous material. For these experiments, and also similar to the results obtained for glucose and the sugar fraction of pyrolysis oil, the gas production was reduced (from 6.3 to 5.4 wt.\%, on organics in pyrolysis oil basis) and the $H / C$ of the oil product was higher (1.41 vs. 1.31 ; O/C equal at 0.45 ) when ethanol was added.

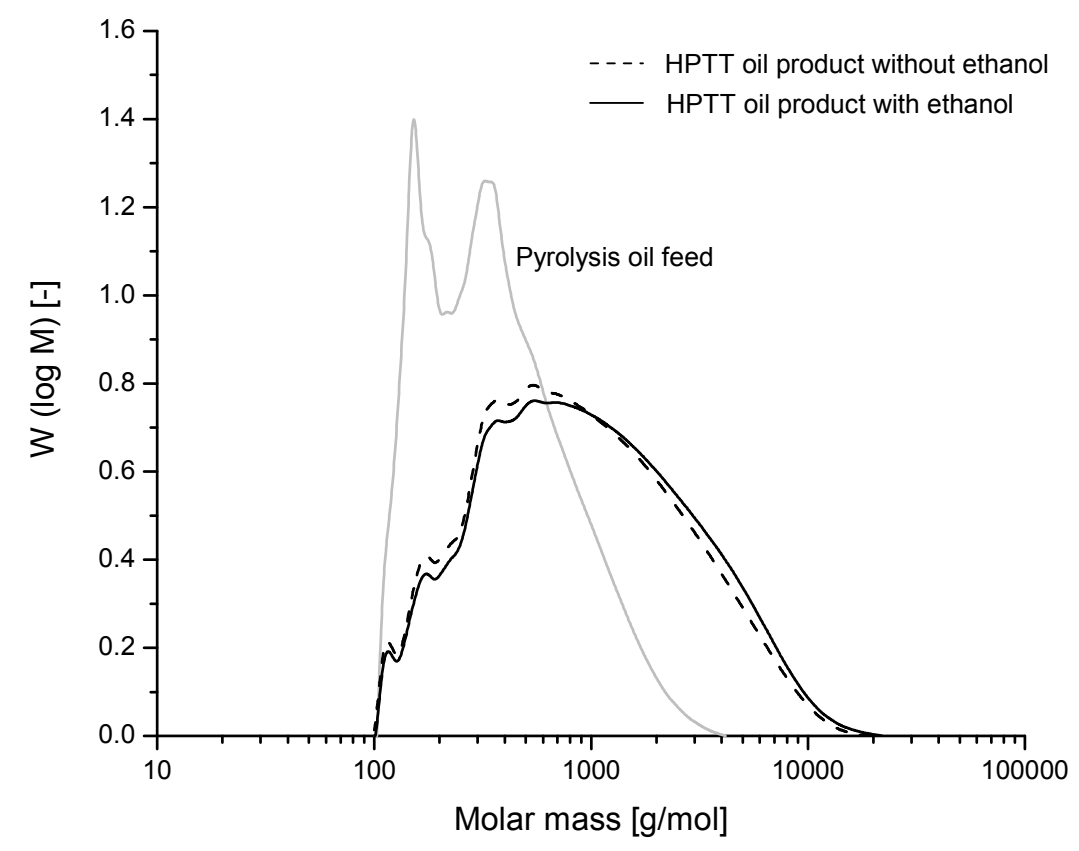

Figure 14. Molecular weight distribution of feed pyrolysis oil and the HPTT oil products for experiments with $15 \mathrm{wt} . \%$ ethanol (solid line) or $15 \mathrm{wt} . \%$ water (dashed line). Reaction temperature and time $300{ }^{\circ} \mathrm{C}$ and $15 \mathrm{~min}$, respectively.

These results show that by chemical intervention, prevention of polymerisation is possible (in molecular weight and WAIS production basis), yet, this was accompanied by a reduction in gas formation and deoxygenation. The reduction in oxygen content was either lower (O/C of glucose oil with ethanol as co-solvent: 0.78 , compared to 0.33 in its absence) or not achieved at all (sorbitol barely reacts). However, results obtained in Chapter 3 , indicate that the stability of the products towards polymerisation and the $H / C$ ratio are more important parameters with respect to upgrading pyrolysis oil for coprocessing. The experiments using ethanol as co-solvent and the experiments using sorbitol as reactant (as hydrogenated glucose model compound) show that in these cases the $H / C$ remained high $(H / C$ of glucose oil with ethanol as co-solvent: 1.70 , compared to 0.95 in its absence; sorbitol 2.33 ) and the molecular weight and the production of WAIS were reduced. Therefore, hydrotreating and/or the addition of ethanol (or in general alcohols) can successfully contribute to pyrolysis oil stabilisation. 


\section{Conclusions}

Glucose was used as model compound to represent the polymerisation behaviour of pyrolysis oil sugars during thermal processing. Similar to high pressure thermal treatment of pyrolysis oil, glucose showed fast dehydration and polymerisation. The formation of WAIS (water-acetone insoluble organics) increased with residence time, temperature and initial glucose concentration. Reduction of molecular weight of the oil product but also oil yield was observed for increasing temperature and reaction time. Further confirmation for Knežević et al. [14] hypotheses were found for:

- The formation of two types of oil: an unstable oil that further polymerised to WAIS, and the production of a stable lighter oil.

- The assumption that WAIS is similar to oil, but further polymerised, increasing its molecular weight and becoming acetone insoluble.

The results of advanced analyses (FTIR and PY/GC/MS) in combination with the observed dehydration indicate that the oil produced from glucose consisted of furanic and aromatic structures (with 5-hydroxymethylfurfural possibly being an important intermediate).

In contrast to glucose, sorbitol (hydrogenated glucose) proofed to be very stable under the HPTT conditions applied. This example showed that stabilisation of glucose by hydrogenation is possible, and highlights the role of (low temperature) stabilisation of sugars in the hydrodeoxygenation of pyrolysis oil. To reduce polymerisation/WAIS formation at high temperatures, also the reaction of glucose (derivates) with ethanol was shown to be effective. Glucose (or its decay products) polymerised to produce oils in both the presence and the absence of ethanol. However, when ethanol was present as co-solvent, the molecular weight and the coking tendency (MCRT) of the oil and the amount of WAIS were reduced when compared to the results using aqueous solutions of glucose only. When a sugar fraction derived from pyrolysis oil and whole pyrolysis oil were processed in the presence of ethanol, a decrease in WAIS formation was also observed. 


\section{References}

[1] Baldauf W, Balfanz U, Rupp M. Upgrading of flash pyrolysis oil and utilization in refineries. Biomass Bioenerg. 1994;7:237-244.

[2] Marker TL, Petri JA, Gasoline and diesel production from pyrolytic lignin produced from pyrolysis of cellulosic waste, Patent: WO 2008/027699, 2008.

[3] Fogassy G, Thegarid N, Toussaint G, van Veen AC, Schuurman Y, Mirodatos C. Biomass derived feedstock co-processing with vacuum gas oil for secondgeneration fuel production in FCC units. Appl. Catal. B Environ. 2010;96:476-485.

[4] Elliott DC, Baker EG, Process for upgrading biomass pyrolyzates, US patent: $4795841,1989$.

[5] Elliott DC, Neuenschwander GG. Liquid fuels by low-severity hydrotreating of biocrude. In: A.V. Bridgwater and D.G.B. Boocock editors. Developments in Thermochemical Biomass Conversion, London: Blackie Academic \& Professional. 1996; p. 611-621.

[6] Oasmaa A, Solantausta Y, Arpiainen V, Kuoppala E, Sipila K. Fast Pyrolysis BioOils from Wood and Agricultural Residues. Energy Fuels. 2009;24:1380-1388.

[7] Oasmaa A, Czernik S. Fuel oil quality of biomass pyrolysis oils-State of the art for the end users. Energy Fuels. 1999;13:914-921.

[8] Watanabe M, Aizawa Y, lida T, Levy C, Aida TM, Inomata H. Glucose reactions within the heating period and the effect of heating rate on the reactions in hot compressed water. Carbohyd. Res. 2005;340:1931-1939.

[9] Kabyemela BM, Adschiri T, Malaluan RM, Arai K. Kinetics of Glucose Epimerization and Decomposition in Subcritical and Supercritical Water. Ind. Eng. Chem. Res. 1997;36:1552-1558.

[10] Kabyemela BM, Adschiri T, Malaluan R, Arai K. Degradation Kinetics of Dihydroxyacetone and Glyceraldehyde in Subcritical and Supercritical Water. Ind. Eng. Chem. Res. 1997;36:2025-2030. 
[11] Kabyemela BM, Adschiri T, Malaluan RM, Arai K, Ohzeki H. Rapid and Selective Conversion of Glucose to Erythrose in Supercritical Water. Ind. Eng. Chem. Res. 1997;36:5063-5067.

[12] Kabyemela BM, Takigawa M, Adschiri T, Malaluan RM, Arai K. Mechanism and Kinetics of Cellobiose Decomposition in Sub- and Supercritical Water. Ind. Eng. Chem. Res. 1998;37:357-361.

[13] Kabyemela BM, Adschiri T, Malaluan RM, Arai K. Glucose and Fructose Decomposition in Subcritical and Supercritical Water: Detailed Reaction Pathway, Mechanisms, and Kinetics. Ind. Eng. Chem. Res. 1999;38:2888-2895.

[14] Knežević D, Van Swaaij WPM, Kersten SRA. Hydrothermal conversion of biomass: I, Glucose conversion in hot compressed water. Ind. Eng. Chem. Res. 2009;48:4731-4743.

[15] Yurkanis Bruice P, Organic Chemistry, Second ed., Prentince Hall Pearson Education Upper Saddle River, NJ, 1999.

[16] Matsumura Y, Yanachi S, Yoshida T. Glucose Decomposition Kinetics in Water at $25 \mathrm{MPa}$ in the Temperature Range of 448-673 K. Ind. Eng. Chem. Res. 2006;45:1875-1879.

[17] Knežević D, Van Swaaij WPM, Kersten SRA. Hydrothermal conversion of biomass: II, Conversion of wood, pyrolysis oil, and glucose in hot compressed water. Ind. Eng. Chem. Res. 2010;49:104-112.

[18] Chuntanapum A, Matsumura Y. Formation of Tarry Material from 5-HMF in Subcritical and Supercritical Water. Ind. Eng. Chem. Res. 2009;48:9837-9846.

[19] Sasaki M, Goto K, Tajima K, Adschiri T, Arai K. Rapid and selective retro-aldol condensation of glucose to glycolaldehyde in supercritical water. Green Chem. 2002;4:285-287.

[20] Gallezot P, Nicolaus N, Flèche G, Fuertes P, Perrard A. Glucose Hydrogenation on Ruthenium Catalysts in a Trickle-Bed Reactor. J. Catal. 1998;180:51-55.

[21] Srokol Z, Bouche A-G, van Estrik A, Strik RCJ, Maschmeyer T, Peters JA. Hydrothermal upgrading of biomass to biofuel; studies on some monosaccharide model compounds. Carbohyd. Res. 2004;339:1717-1726.

[22] Gagnon J, Kaliaguine S. Catalytic hydrotreatment of vacuum pyrolysis oils from wood. Ind. Eng. Chem. Res. 1988;27:1783-1788. 
[23] Radlein D, Piskorz J, Majerski P, Method of upgrading biomass pyrolysis liquids for use as fuels and as source of chemicals by reactions with alcohols, European Patent 0718392 A1, 1999.

[24] Diebold JP, Czernik S. Additives To Lower and Stabilize the Viscosity of Pyrolysis Oils during Storage. Energy Fuels 1997;11:1081-1091.

[25] Mahfud FH, Melin-Cabrera I, Manurung R, Heeres HJ. Biomass to Fuels: Upgrading of Flash Pyrolysis Oil by Reactive Distillation Using a High Boiling Alcohol and Acid Catalysts. Process Saf. Environ. 2007;85:466-472.

[26] Bicker M, Kaiser D, Ott L, Vogel H. Dehydration of d-fructose to hydroxymethylfurfural in sub- and supercritical fluids. J. Supercrit. Fluid. 2005;36:118-126.

[27] van Dam HE, Kieboom APG, van Bekkum $\mathrm{H}$. The Conversion of Fructose and Glucose in Acidic Media: Formation of Hydroxymethylfurfural. Starch - Stärke 1986;38:95-101. 


\section{Competition between hydrotreating and polymerisation reactions during pyrolysis oil hydrodeoxygenation. Indications on mass transfer limitations}

Hydrodeoxygenation (HDO) of pyrolysis oil is an upgrading step that allows further coprocessing of the oil product in (lab-scale) standard refinery units to produce advanced bio-fuels. During HDO, desired hydrotreating reactions are in competition with polymerisation reactions that can lead to unwanted product properties. To suppress this polymerisation, a low temperature HDO step, referred to as stabilisation, is typically used. In the present work, small batch autoclaves have been used to study at near isothermal conditions the competition between hydrotreating and polymerisation reactions. While fast polymerisation reactions take place above $200{ }^{\circ} \mathrm{C}$, hydrogen consumption was already observed for temperatures as low as $80{ }^{\circ} \mathrm{C}$. Hydrogen consumption increased with temperature and reaction time, however, when the end temperature exceeded $250{ }^{\circ} \mathrm{C}$, hydrogen consumption achieved a plateau. This was thought to be caused by the occurrence of fast polymerisation reactions, and the refractivity of the products to further hydrotreating reactions. The effect of the gas-liquid mass transfer was evaluated by using different stirring speeds. The results of these experiments (carried out at $300{ }^{\circ} \mathrm{C}$ ) showed that in first 5 min of HDO, gas-liquid mass transfer appears to be limiting the overall rate of hydrotreating reactions, leading to undesired polymerisation reactions and product deterioration. Afterwards, intra-particle mass transfer/kinetics seems to be governing the hydrogen consumption rate. Estimations on the degree of utilisation (effectiveness factor) for industrially sized catalysts show that this is expected to be much lower than 1, at least, in the early stage of HDO (first $30 \mathrm{~min}$ ). Catalyst particle size should thus be carefully considered when designing industrial processes not only to minimise reactor volume but also to improve the ratio of hydrotreating to polymerisation reactions. 



\section{Introduction}

Hydrodeoxygenation (HDO) of pyrolysis oil is an upgrading step that allows coprocessing of biomass products with fossil feed in (lab-scale) standard refinery units (as seen in Chapters 3 and 4 and in literature [1, 2]). During HDO, pyrolysis oil is treated at temperatures between 150 and $450{ }^{\circ} \mathrm{C}$, high hydrogen pressures (50-250 bar) and in the presence of an active catalyst. An overview of the more recent developments in HDO of pyrolysis oil has been written by Elliott in 2007 [3].

Early studies on HDO of pyrolysis oil report that directly processing pyrolysis oil at high temperatures $\left(>300^{\circ} \mathrm{C}\right)$ was troublesome, showing coking and plugging of lines [4]. For that reason, a low temperature HDO step (referred to as stabilisation) was introduced, probably reducing the reactivity (towards polymerisation/polycondensation reactions) of functional groups such as aldehydes, ketones and double $\mathrm{C}=\mathrm{C}$ bonds [5]. In this way, successful HDO operation at high temperature was feasible, achieving higher deoxygenation levels (typically $>95 \%$ ) $[6,7]$.

In Chapter 3, HDO experiments were carried out in a batch autoclave at 290 bar total pressure (200 bar $\mathrm{H}_{2}$ initial), $230-340{ }^{\circ} \mathrm{C}$ end temperature and $5 \mathrm{wt} \% \mathrm{Ru} / \mathrm{C}$ catalyst. Heating rates in the autoclave were very low; it typically took $1.5-2 \mathrm{~h}$ to reach the desired end temperature. The total reaction time (after heating to the desired temperature) was 4 hours, after which the reactor was cooled. For all the experiments, more than $50 \%$ of the hydrogen consumption took place during the heating time. Therefore, the low temperature stabilisation reactions were an integrated part of the experiments. Compared to the feed, the resulting HDO oil had a lower oxygen content and coking tendency (measured as MCRT), while the molecular weight was reduced with increasing temperature. Although the oxygen content of the resulting HDO oils was still relatively high (up to $28 \mathrm{wt}$. $\%$ on dry basis), these oils could be co-processed in lab-scale refinery units without any operational problems. Moreover, yields were comparable to the ones obtained when processing fossil feed only.

High pressure thermal treatment (HPTT) is a process in which pyrolysis oil is subjected to temperatures between $200-350^{\circ} \mathrm{C}$, pressures higher than 200 bar and short residence times (< $5 \mathrm{~min}$ ) in the absence of catalyst and hydrogen (see Chapter 2). Experiments conducted in a continuous HPTT set-up showed that, similar to HDO, the oxygen and water content of the oil product are reduced, increasing its energy density. However, during HPTT and opposite to HDO, pyrolysis oil underwent polymerisation shown by a severe increase in molecular weight and viscosity of the oil product. An aqueous phase with the remainder of the organics and some gas (mainly $\mathrm{CO}_{2}$ ) were also produced. While HDO oils could be co-processed in a lab-scale refinery unit, the high molecular 
weight HPTT oils could not be processed due to their high coking tendency (measured by MCRT), molecular weight and its immiscibility with fossil feed.

Although both HPTT and HDO can produce an oil with lower and similar oxygen content, other properties are completely different. Moreover, the processes are carried out on completely different timescales. HPTT can lead to a deoxygenated though heavily polymerised product within 2 minutes, while HDO requires much longer reaction times, but produces an oil with a molecular weight distribution similar or even lower than the feed (see Chapter 3). As already seen by the coking of lines during direct high temperature HDO processing, the polymerisation reactions (typical during HPTT) can also be present during HDO. The 'stabilisation step' at reduced temperature level is therefore aimed to favour the rate of the hydrogenation/hydrodeoxygenation reactions with respect to that of the competing polymerisation reactions [4] (see Figure 1 for schematic representation of this competition).

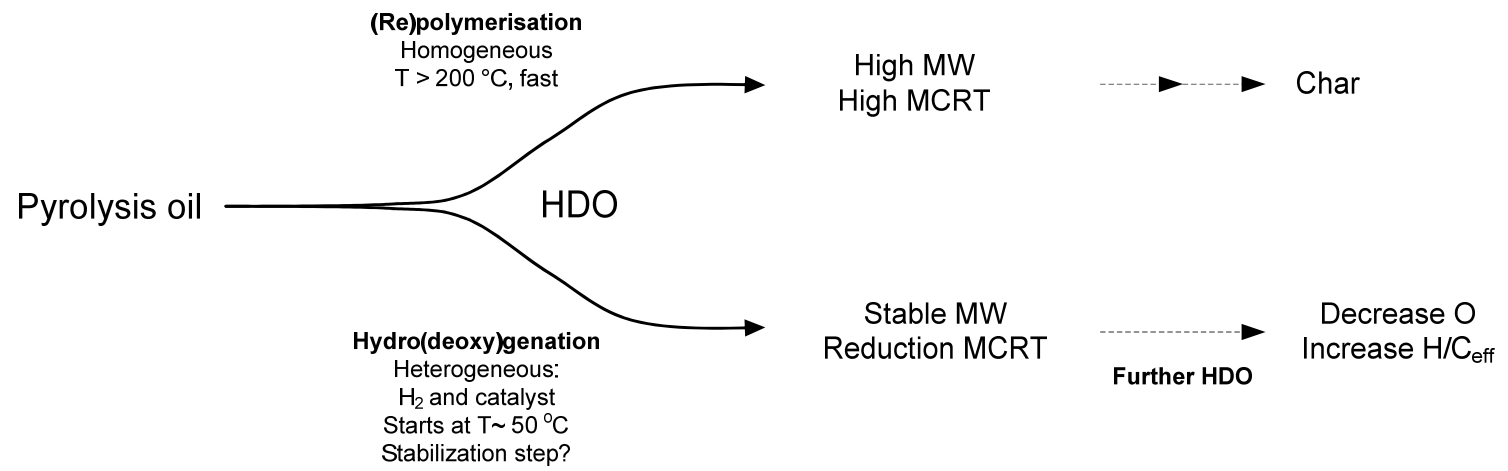

Figure 1. Schematic representation of the competition between polymerisation and hydrodeoxygenation reactions.

In this chapter, experimental and theoretical results of the HDO of pyrolysis oil are reported and discussed, specifically addressing the competition between the polymerisation and hydrotreating/hydrodeoxygenation reactions in the early stage of the HDO process (first $30 \mathrm{~min}$ ). Different process conditions (such as stirring intensity, heating time, reaction temperature, etc.) were used to study their effect on the competing reactions and on final product properties.

\section{Model development HDO and polymerisation}

For the numerical evaluation of experiments in terms of competition between hydro(deoxy)genation and polymerisation, several assumptions have to be made. It should be noted that some of these assumptions are rather rough. However, considering that these are just the first steps in modelling the HDO process [8-10] and the fact that 
this study aims to validate the scheme in Figure 1 (identifying the parameters/rate controlling steps that can influence the balance between HDO and polymerisation), this is not considered a major drawback.

For the hydrogen consuming, heterogeneous, reactions it is assumed that:

- The hydrotreating reactions can only take place at or inside the catalyst.

- Both hydrogen and pyrolysis oil components are assumed to be able to enter the pores of the porous catalyst particles to react at the internal surface area.

- Although pyrolysis oil is a mixture of many different components, with each of them having its own hydro(deoxy)genation reaction mechanism and corresponding kinetic expression, in this work a uniform (lumped) kinetic expression for the hydrotreating reactions is used.

- For hydrogen, the reaction order is assumed to be 1 (this has been observed for hydrogenation of benzene [11] and glucose [12]).

- The concentration of reactive pyrolysis oil components is constant. The contribution of pyrolysis oil (components) in the kinetic expression is thus lumped into a pseudo first order rate constant.

- Reactions are assumed to be irreversible.

- For hydrogen, Fickian diffusion is assumed inside the catalyst pores.

In the present three phase system, several (serial) resistances can influence the overall hydrogen uptake rate. Considering that in the current experiments the fraction of hydrogen in the gas is high as compared to other non-condensable gases, the $\mathrm{H}_{2}$ mass transfer resistance from the gas phase to the gas-liquid interface will be neglected. Moreover, a possible mass transfer resistance of pyrolysis oil components towards or inside the catalyst will also be neglected. Based on these and the previously mentioned assumptions, the resulting flux equation as used in this study is defined as:

$$
N_{H_{2}}=\frac{C_{H_{2}, G}}{\frac{1}{m \cdot k_{L} \cdot a_{G L}}+\frac{1}{m \cdot k_{S} \cdot a_{S}}+\frac{1}{m \cdot \eta \cdot k_{1} \cdot \varepsilon_{s}}}\left[\mathrm{~mol} \cdot \mathrm{m}_{\text {liquid }}^{-3} \cdot \mathrm{s}^{-1}\right]
$$

From this equation, it can be seen that, for the experimental conditions applied in this study, three resistances for hydrogen consumption have to be taken into account: gasliquid mass transfer, mass transfer from the bulk of the liquid to the catalyst surface and apparent kinetics (determined by intrinsic reaction kinetics and simultaneous diffusion inside the catalyst). The relative importance of each resistance can be estimated by (approximate) calculations as will be shown in the following sections.

To prevent product deterioration, the hydrogen uptake rate related to HDO as in Eq. 1 should be at least of the same order of magnitude as the rate of the thermal polymerisation reactions. Chapter 2 showed that these un-catalysed polymerisation 
reactions are very fast during HPTT of pyrolysis oil, creating a polymerised product within $5 \mathrm{~min}$ at temperatures above $250{ }^{\circ} \mathrm{C}$. In Chapter 5 , HPTT experiments using glucose as model compound showed that conversion of glucose to a polymerised product at $300{ }^{\circ} \mathrm{C}$ also occurred within $5 \mathrm{~min}$, while experiments conducted at $250{ }^{\circ} \mathrm{C}$ and $5 \mathrm{~min}$ had a (calculated) conversion of only $28 \mathrm{wt} . \%$. This illustrates why a HDO pretreatment of pyrolysis oil at temperatures of $150-250{ }^{\circ} \mathrm{C}$ (stabilisation) is typically applied before performing HDO at higher temperatures.

\section{Experimental section}

\subsection{Materials}

Pyrolysis oil as used in this study was supplied by VTT, Finland, and produced from forest residue. Table 1 shows some properties of this oil. The oil was stored at $-10{ }^{\circ} \mathrm{C}$ to avoid aging. The amount needed for one experiment was brought to room temperature the day before usage.

Table 1. Properties of the forest residue pyrolysis oil.

\begin{tabular}{lc}
\hline & Pyrolysis oil \\
\cline { 2 - 2 } $\begin{array}{l}\text { Elemental composition } \\
\text { and water content }\end{array}$ & \\
C dry (wt.\%) & 54.3 \\
H dry (wt.\%) & 7.0 \\
O dry (wt.\%) & 38.7 \\
Water (wt.\%) & 25.0 \\
& \\
Carbon residue & \\
MCRT (wt.\%) & \\
MCRT dry ${ }^{\mathrm{b}}$ (wt.\%) & 19.7 \\
\hline a by difference & 26.2 \\
${ }^{b}$ corrected for water content
\end{tabular}

$\mathrm{H}_{2}$ and $\mathrm{N}_{2}$ (both $99.9 \%$ purity) were obtained from the high pressure network in the laboratory, fed by cylinders from Linde gas. $\mathrm{CO}_{2}$ used to study the gas-liquid mass transfer characteristics was available at $99.99 \%$ purity from Linde Gas.

The catalyst used was 5 wt.\% Ruthenium on activated carbon $(\mathrm{Ru} / \mathrm{C})$, delivered by Sigma-Aldrich. The average particle size was $14 \mu \mathrm{m}$. The use of such small catalyst size is expected to decrease both external and internal mass transfer resistances. Surface area, pore size distribution and pore volume of the catalyst were determined using BET analysis (Table 2). The ruthenium distribution on the surface of the catalyst particles is assumed to be homogeneous, but was not further investigated. 
Table 2. BET analysis of the Ru/C catalyst.

\begin{tabular}{ll}
\hline & Ruthenium on Carbon catalyst \\
\cline { 2 - 2 } BET surface area & $810 \pm 11 \mathrm{~m}^{2} / \mathrm{g}$ (total) \\
& $579 \mathrm{~m}^{2} / \mathrm{g}$ (micropores only) \\
Langmuir surface area & $1094 \pm 10 \mathrm{~m}^{2} / \mathrm{g}$ \\
Pore volume (porosity), $\varepsilon$ & $0.27 \mathrm{~cm}^{3} / \mathrm{g} \mathrm{STP}$ \\
Pore size & Most pores between 60 and $120 \AA$ \\
\hline
\end{tabular}

\subsection{Experimental set-ups and procedure}

Small in-house made autoclaves, with volumes of 9,40 and $45 \mathrm{ml}$ were used in this study. During the experiments, the mixing of the contents of the 9 and $40 \mathrm{ml}$ reactor was done by fast shaking of the whole autoclave; the $45 \mathrm{ml}$ reactor used a hollow shaft stirrer $(0-48 \mathrm{~Hz})$. The hollow shaft stirrer is expected to improve mass transfer as compared to the shaken autoclaves. These reactors were fixed to a pneumatic arm. The pneumatic arm had an internal piston that allowed the reactors to be immersed in a fluidised sand bed and a cooling bath to obtain fast heating and cooling, respectively (see Figure 2). The fluidised sand bed was heated by two electric ovens with independent temperature controllers. The fluidisation gas was pre-heated by a separate heating element.

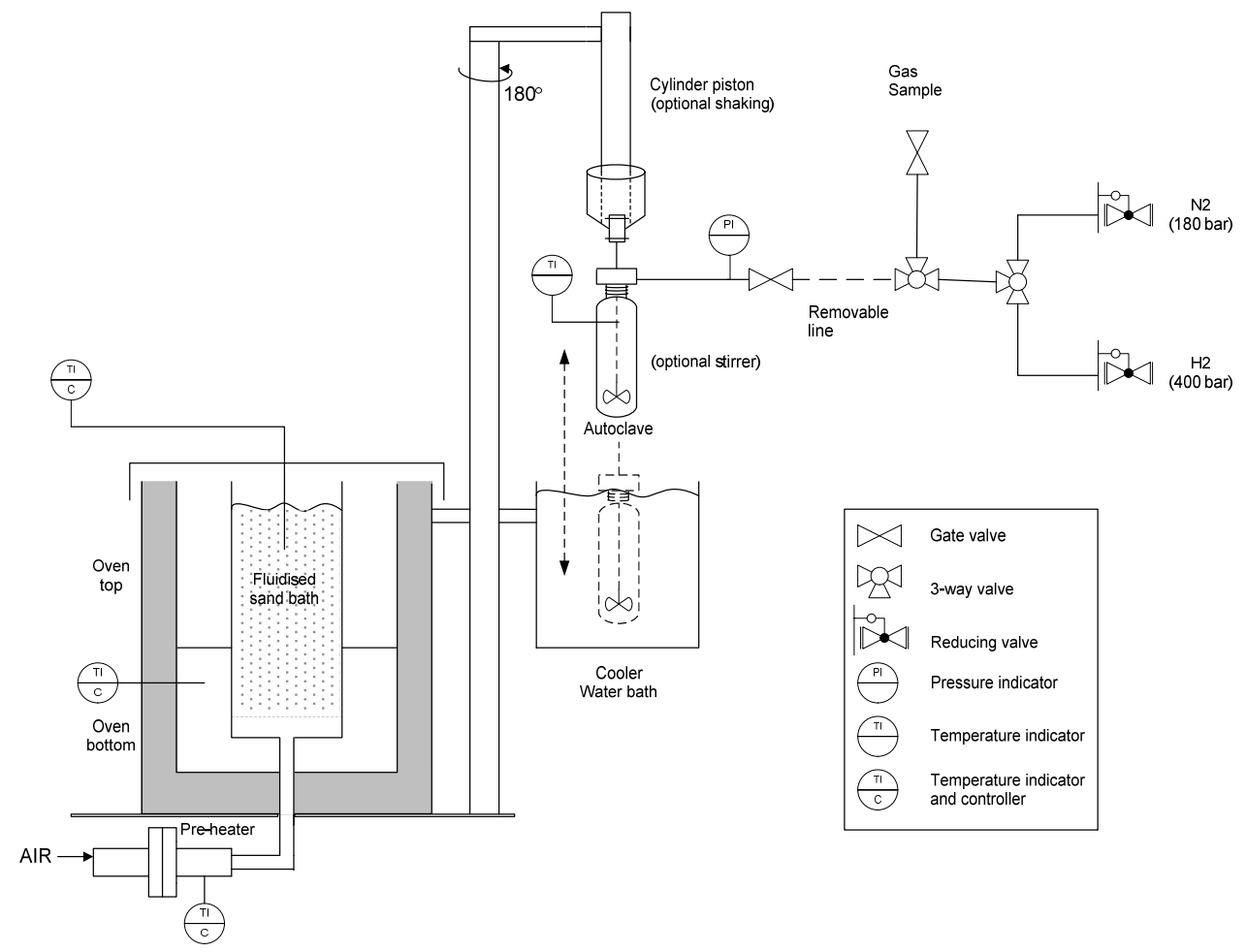

Figure 2. HDO set-up diagram. 
In each of the reactors a thermocouple inside the reactor recorded the inner temperature. Figure 3 shows that the heating rate decreased with reactor volume, but was very quick in all cases compared to the heating rate of the $5 \mathrm{I}$ autoclave used in Chapter 3.

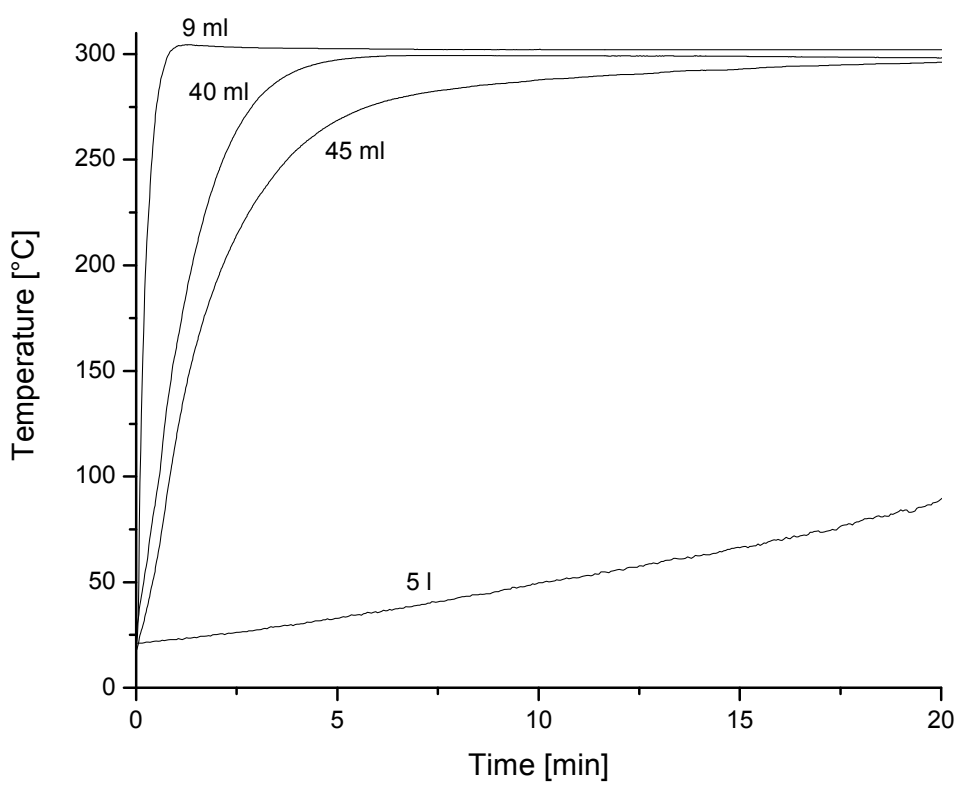

Figure 3. Temperature profile during experiments using different autoclave size. Data for the $5 \mathrm{I}$ reactor corresponds to experiment conducted at $300^{\circ} \mathrm{C}$ shown in Chapter 3 .

In a typical experiment, the reactor was filled with the desired amount of pyrolysis oil (reactor filling about $50 \%$ ) and 5 wt.\% catalyst. The reactor was then closed tightly and attached to the moving arm. After leak testing with nitrogen, the reactor was purged and filled with 120 bar of hydrogen. If the reactor was again leak free, the gas line was detached.

At the start of an experiment, the pneumatic arm was moved to the position over the sand bed and then immersed in the bed (which was at constant temperature between 80 and $300{ }^{\circ} \mathrm{C}$ ). For the stirred experiments, stirring was started prior to heating to presaturate the liquid. For the shaken reactors, shaking was started directly while lowering the reactor into the bed, for the same purpose. After the desired reaction time (from 10 to $60 \mathrm{~min}$ ), the reactor (both stirred and shaken) was lifted from the hot sand bed, moved over the water bath and lowered into the cooling water.

After the reactor was cooled to room temperature, pressure was noted and a gas sample was taken for analysis. Then, the reactor was depressurised completely. The liquid sample including the catalyst was collected in a syringe. The reactor walls were scraped with a metal bar to ensure, as much as possible, the recovery of the contents. For the shaken reactors, samples from experiments at higher temperatures (above $200{ }^{\circ} \mathrm{C}$ ) 
generally were more difficult to collect due to the high viscosity of the resulting liquid product, making liquid analysis impossible.

The collected liquid sample was filtered by attaching a filtration unit with Whatman Grade 3 filter paper (retention from $6 \mu \mathrm{m}$ ) to the syringe and pressing the liquid sample trough the filter (manually or by nitrogen pressure).

Separate gas-liquid mass transfer experiments were carried out to obtain an indication of $k_{L} \cdot a_{G L}$ in the stirred autoclave. These were performed at $20{ }^{\circ} \mathrm{C}$ using degassed water and $\mathrm{CO}_{2}$. The reasons for choosing this system are clarified in section 4.3.

\subsection{Monitored parameters and analysis methods}

Total hydrogen consumption was monitored as key parameter for hydrotreating reactions. To evaluate the extent of polymerisation reactions, molecular weight measurements were carried out with an Agilent Technologies HPLC 1200 series using gel permeation chromatography (GPC) columns (more details about this equipment can be found in Chapter 2). The coking tendency of the upgraded oils was measured by micro carbon residue tests (MCRT) according to ASTM standard D4530-07 with an ACRM3 Micro Carbon Residue Tester from Tanaka Scientific. This parameter has been found to correlate well with the molecular weigh distribution (MWD) of upgraded pyrolysis oil (see Chapters 3 and 4), and thus, was also used to evaluate polymerisation.

Besides that, various other techniques were used to analyse samples. The water content of samples (used to calculate dry MCRT) was determined by Karl Fischer titration with a Metrohm $787 \mathrm{KF}$ Titrino. Titrations were carried out with Hydranal in a 3:1 mixture of methanol and dichloromethane. The composition of the gas samples obtained after the experiments was determined with a Varian CP-4900 micro gas chromatograph (for further details see Chapter 2).

\section{Experimental results and discussion}

\subsection{Experiments}

Experiments were carried out in both shaken and stirred reactors. The shaken reactors were especially used to study the influence of end temperature, reaction time and heating rate (by using differently sized reactors, the external surface area to internal volumes changed, obtaining different heating rates). The stirred reactor was specifically 
used to study the influence of stirring rate and catalyst hold-up. Various other experiments in the stirred reactor were performed to obtain $k_{L} \cdot a_{G L}$ values as needed in the numerical interpretation. In Table 3 , an overview of the experiments carried out is shown.

Table 3. Overview of experimental series, their goal and process conditions.

\begin{tabular}{|c|c|c|}
\hline Series & Reactor / Goal & Conditions \\
\hline 1 & $\begin{array}{l}\text { Shaken } \\
\text { Effect of reaction time } \\
\text { and end temperature }\end{array}$ & $\begin{array}{l}9 \mathrm{ml} \text { reactor, } 5 \mathrm{~g} \text { liquid } \\
10-30-60 \mathrm{~min} \\
80-120-165-200-250-300{ }^{\circ} \mathrm{C} \\
120 \text { bar } \mathrm{H}_{2}, 5 \text { wt. } \% \text { catalyst }\end{array}$ \\
\hline 2 & $\begin{array}{l}\text { Shaken } \\
\text { Effect of heating time }\end{array}$ & $\begin{array}{l}9-40 \mathrm{ml} \text { reactor, } 5-20 \mathrm{~g} \text { liquid } \\
30 \mathrm{~min} \\
300^{\circ} \mathrm{C} \\
120 \text { bar } \mathrm{H}_{2}, 5 \text { wt. \% catalyst }\end{array}$ \\
\hline 3 & $\begin{array}{l}\text { Stirred } \\
\text { Effect of catalyst hold-up }\end{array}$ & $\begin{array}{l}45 \mathrm{ml} \text { reactor, } 20 \mathrm{~g} \text { liquid } \\
30 \mathrm{~min} \\
300^{\circ} \mathrm{C} \\
48 \mathrm{~Hz} \text { stirring } \\
120 \text { bar } \mathrm{H}_{2}, 2.5-5-7.5 \text { wt. } \% \text { catalyst }\end{array}$ \\
\hline 4 & $\begin{array}{l}\text { Stirred } \\
k_{L} \cdot a_{G L} \text { estimation }\end{array}$ & $\begin{array}{l}45 \mathrm{ml} \text { reactor, } 20 \mathrm{~g} \text { liquid } \\
\mathrm{CO}_{2} \text { absorption in } \mathrm{H}_{2} \mathrm{O}, 20{ }^{\circ} \mathrm{C} \\
8.6-48,1 \mathrm{~Hz} \text { stirring }\end{array}$ \\
\hline 5 & $\begin{array}{l}\text { Stirred } \\
\text { Effect of stirring speed }\end{array}$ & $\begin{array}{l}45 \mathrm{ml} \text { stirred, } 20 \mathrm{~g} \text { liquid } \\
30 \mathrm{~min} \\
300^{\circ} \mathrm{C} \\
0-7-15-48 \mathrm{~Hz} \text { stirring } \\
120 \text { bar } \mathrm{H}_{2}, 5 \text { wt. } \% \text { catalyst }\end{array}$ \\
\hline
\end{tabular}

\subsection{Qualitative assessment of results}

\subsubsection{Temperature level}

In Figure 4, the total hydrogen consumption is shown for the experiments of series 1. The hydrogen consumption was calculated from the difference in initial and final reactor pressure, corrected for produced gases (mainly $\mathrm{CO}_{2}$ and $\mathrm{CH}_{4}$ ). These results show that there was already hydrogen consumption at $80^{\circ} \mathrm{C}$, which is in line with the results shown in Chapters 3 and 4 . Up to a temperature of $200{ }^{\circ} \mathrm{C}$, the hydrogen consumption increased with both temperature and reaction time. However, the experiments at 250 and $300{ }^{\circ} \mathrm{C}$ showed no further increase in hydrogen consumption compared to the experiment at $200{ }^{\circ} \mathrm{C}$. This stop in the increase of hydrogen consumption can not be 


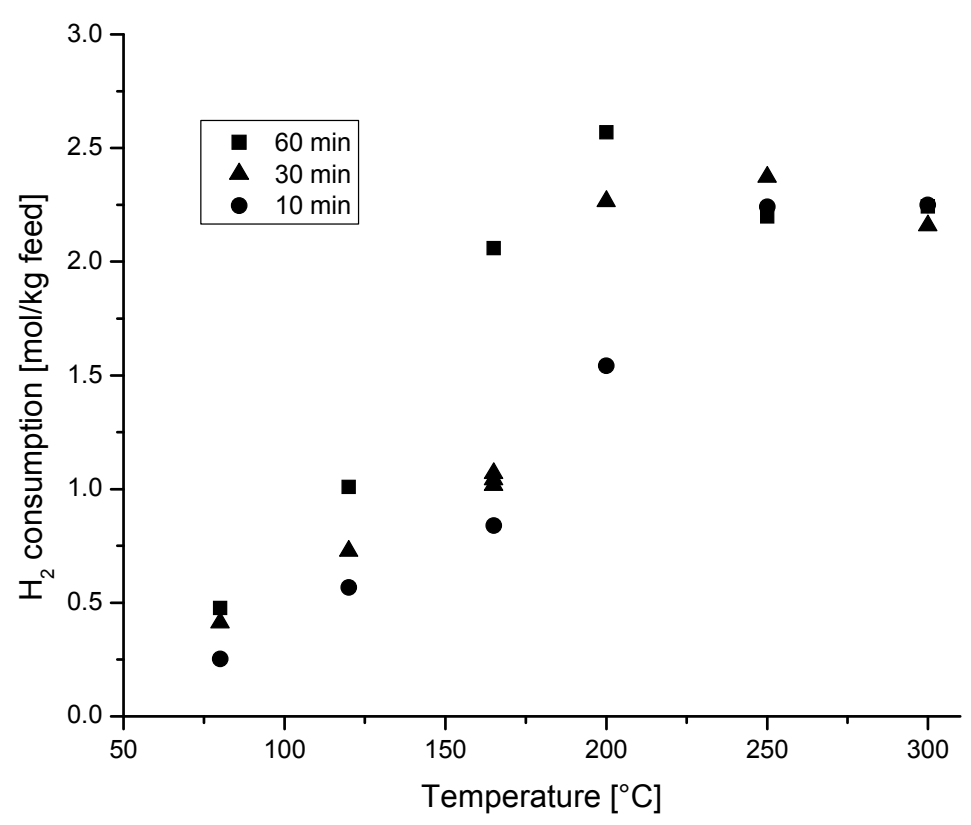

Figure 4. Total hydrogen consumption as a function of temperature and reaction time in the shaken $9 \mathrm{ml}$ autoclave.

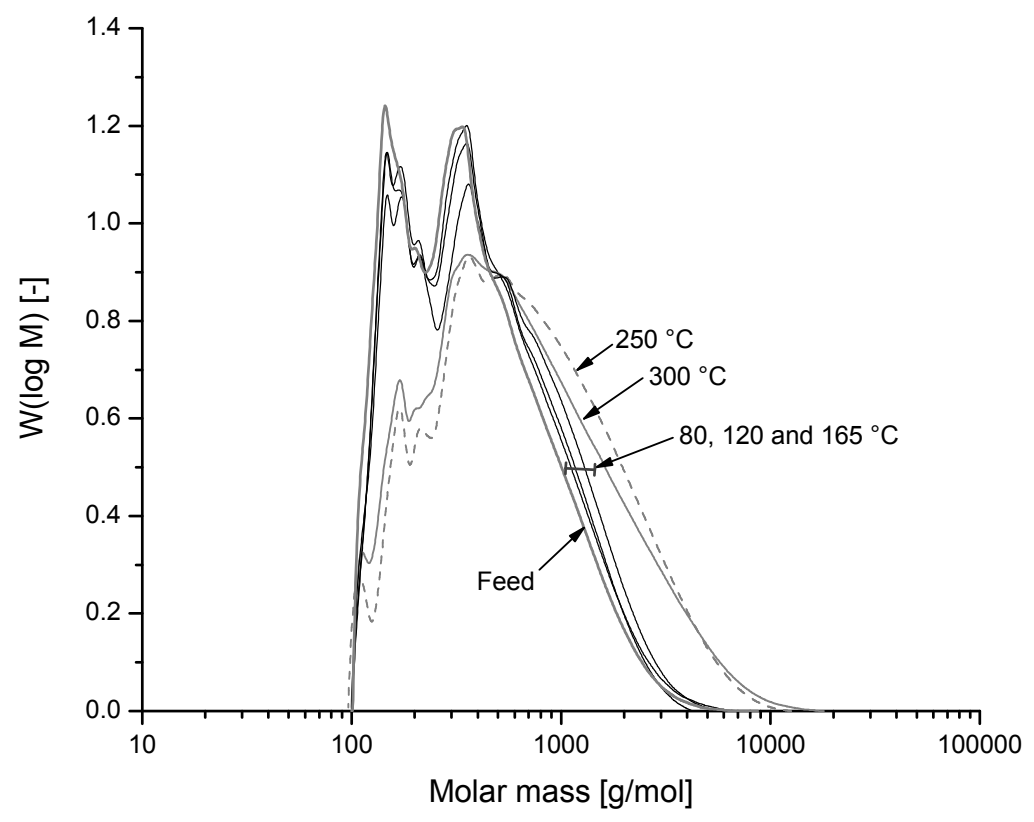

Figure 5. Molecular weight distribution of the oil products after HDO in the $9 \mathrm{ml}$ shaken autoclave using different temperatures. The reaction time and the initial $\mathrm{H}_{2}$ pressure were 30 min and 120 bar, respectively. 
explained by a possible shortage of hydrogen as only half of the initially present quantity was consumed. Moreover, the maximum hydrogen consumption $\left(\sim 2.5 \mathrm{~mol} / \mathrm{kg}_{\mathrm{feed}}\right)$ is low as compared to the hydrogen consumption shown in Chapter 3 for the $5 \mathrm{I}$ autoclave (9.3$13.2 \mathrm{~mol} / \mathrm{kg}_{\text {feed, }}$, for end temperatures of 230 to $340{ }^{\circ} \mathrm{C}$ ), indicating that HDO reactions can still further consume $\mathrm{H}_{2}$ when enough time is given to allow the low temperature stabilisation reactions to occur (using, for example, low heating rates). Total catalyst deactivation also can not explain these results, as an experiment with a re-used catalyst still showed considerable activity, although somewhat lower than a fresh catalyst (results not presented). The results at high temperatures might be explained by the expected fast polymerisation at and above $250{ }^{\circ} \mathrm{C}$ leading to a polymerised product that is refractive to further consumption of hydrogen. The occurrence of polymerisation also can be deduced from Figure 5, which shows that the oil products produced at 250 and $300{ }^{\circ} \mathrm{C}$ have higher molecular weight than the products obtained at lower temperature (which have a molecular weight similar to or slightly higher than that of the feed oil).

\subsubsection{Heating rate}

The effect of heating rate on the competition between polymerisation and hydrotreating was evaluated by using two differently sized reactors ( 9 and $40 \mathrm{ml}$ ), a total reaction time of 30 minutes and a temperature of $300{ }^{\circ} \mathrm{C}$ (series 2, Table 3). The increase in reactor size changed the external heat exchange area to the internal volume, resulting in longer heating times to reach $300{ }^{\circ} \mathrm{C}$. This is illustrated in Figure 3 and also quantitatively expressed in Table 4. It should be noted that in all cases the heating rate was very fast, especially when compared to the heating rate in the 5 I autoclave used in Chapter 3 . The use of differently sized reactors can also influence the mass transfer characteristics, this effect was however not explicitly quantified and neglected in the analysis. Although the heating time in both cases was short compared to the reaction time of 30 min (see Figure 3), a shift in the ratio between hydrotreating reactions and polymerisation reactions (and thus product properties) was still observed: hydrogen consumption decreased with increasing heating rate (Table 4). As already indicated in the previous sections, these results also suggest that giving less time for low temperature hydrotreating reactions to occur (by increasing the heating rate from ambient temperature to $300{ }^{\circ} \mathrm{C}$ ), polymerisation reactions are increasingly favoured and can inhibit hydrotreating reactions.

The MWD of the resulting oils (Figure 6) confirm this: with increasing heating rate, the average molecular weight increased. For comparison, the result obtained in Chapter 3 for an experiment in the $5 \mathrm{I}$ autoclave at $300{ }^{\circ} \mathrm{C}$ (end temperature) is also given, which had a typical heating time of 90 minutes. This curve shows a distinct shift to the left when compared to feed oil, which indicates that, overall, cracking and not polymerisation occurred in that case. 
Table 4. Comparison of hydrogen consumption per $\mathrm{kg}$ feed for different reactor sizes in the shaken setup. The reactions conditions were: $300{ }^{\circ} \mathrm{C}, 5 \mathrm{wt} . \%$ catalyst and $30 \mathrm{~min}$ reaction time.

\begin{tabular}{ccc}
\hline $\begin{array}{c}\text { Reactor volume } \\
(\mathbf{m l})\end{array}$ & $\begin{array}{c}\text { Heating rate } \\
\left({ }^{\circ} \mathbf{C} / \mathbf{s}\right)^{\mathbf{a}}\end{array}$ & $\begin{array}{c}\mathbf{H}_{2} \text { consumption } \\
(\mathbf{m o l} / \mathbf{k g} \text { feed })\end{array}$ \\
\hline 9 & 7.6 & 2.16 \\
40 & 1.3 & 3.43 \\
\hline${ }^{a}$ Average to reach $285^{\circ} \mathrm{C}$ & &
\end{tabular}

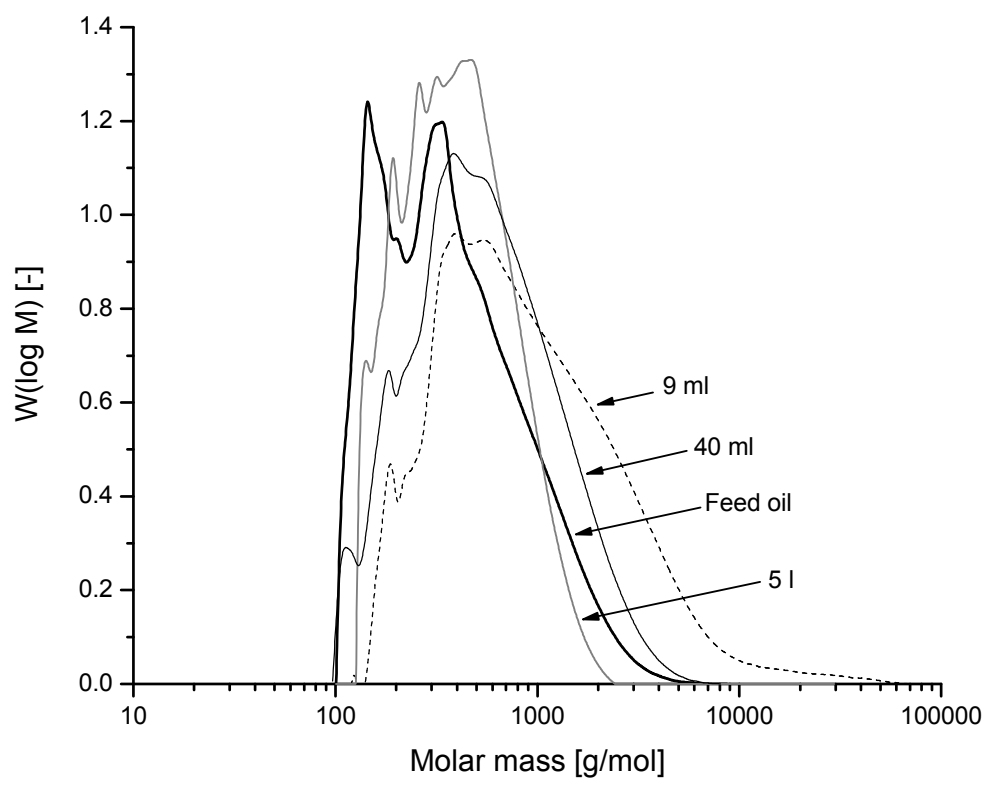

Figure 6. Molecular weight distribution curves of oil products obtained in experiments carried out using the shaken set-ups with different reactor volumes $(9$ and $40 \mathrm{ml})$. Reaction temperature: 300 ${ }^{\circ} \mathrm{C}$. Reaction time: 30 minutes. The data for the $5 \mathrm{I}$ experiment (from Chapter 3 ) correspond to $4 \mathrm{~h}$ reaction time (plus $\sim 90 \mathrm{~min}$ heating time) at $300{ }^{\circ} \mathrm{C}$ end temperature.

\subsubsection{Catalyst hold-up}

If the mass transfer resistance to the catalyst particles $\left(N_{H_{2}}=m \cdot k_{s} \cdot a_{s} \cdot C_{H_{2}, G}=m \cdot k_{s} \cdot\left(6 \cdot \varepsilon_{s} / d_{p}\right) \cdot C_{H_{2}, G}, E q .2\right)$ or the apparent kinetics inside the catalysts $\left(N_{\mathrm{H}_{2}}=m \cdot \eta \cdot k_{1} \cdot \varepsilon_{s} \cdot C_{H_{2}, G}\right.$, Eq.3) would be the overall rate controlling step, a proportional relationship between catalyst hold-up and hydrogen conversion rate should be observed (if $\mathrm{H}_{2}$ pressure is constant). Because the experiments were carried out batch wise, a non-stationary gas mass balance should be used to derive the theoretical relationship between average flux (or total hydrogen consumption over a certain time interval) and catalyst hold-up. If either of the aforementioned resistances is limiting, the following proportionality can be derived from such balance: 
$\ln \left(n_{\mathrm{H}_{2}, G}(t \min ) / n_{\mathrm{H}_{2}, \mathrm{G}}(0)\right)=-C_{1} \cdot \varepsilon_{s} \cdot t$. In the $45 \mathrm{ml}$ autoclave $(48 \mathrm{~Hz}, 30 \mathrm{~min})$, three different catalyst hold-ups $(2.5,5$ and $7.5 \mathrm{wt} . \%)$ were used to study whether this dependency was observed (see series 3 in Table 3). The results of these experiments (Table 5) show an increase of $-\operatorname{In}\left(n_{\mathrm{H}_{2}, \mathrm{G}}(30 \mathrm{~min}) / n_{\mathrm{H}_{2}, \mathrm{G}}(0)\right)$ with catalyst concentration. This dependence is more important at lower catalyst concentrations (from 2.5 to $5 \mathrm{wt} . \%$ ) than at higher (from 5 to 7.5 wt.\%). Nevertheless, the proportional dependence between $-\ln \left(n_{H_{2}, G}(30 \mathrm{~min}) / n_{H_{2}, G}(0)\right)$ and $\varepsilon_{S}$ as expected in a regime governed by mass transfer to the catalyst or apparent kinetics (also for the case that the effectiveness factor $\eta<1$ ) did not occur. This indicates that, in these HDO experiments, the results must have been affected by the gas-liquid mass transfer resistance $\left(N_{H_{2}}=m \cdot k_{L} \cdot a_{G L} \cdot C_{H_{2}, G}\right.$, Eq. 4). Table 5 additionally shows that the coking tendency of the oil products increased when a lower catalyst hold-up was used. This indicates that by reducing the overall rate of the hydrotreating reactions, the overall occurrence of polymerisation is favoured.

Table 5. Correlation between the catalyst amount, the hydrogen consumption, the logarithm of the final/initial hydrogen mol ratio in the gas phase and the coking tendency. Experiments were carried out in the $45 \mathrm{ml}$ stirred autoclave at $300{ }^{\circ} \mathrm{C}$ and 30 minutes reaction time and $48 \mathrm{~Hz}$ stirring speed.

\begin{tabular}{cccc}
\hline $\begin{array}{c}\text { Catalyst amount } \\
\text { (wt. \%) }\end{array}$ & $-\ln \left(n_{\mathrm{H}_{2}, \mathrm{G}}(30 \mathrm{~min}) / n_{\mathrm{H}_{2}, \mathrm{G}}(0)\right)$ & $\begin{array}{c}\text { Hydrogen } \\
\text { consumption } \\
\text { (mol/kg }\end{array}$ & $\begin{array}{c}\text { Coking tendency } \\
\text { (dry MCRT, wt.\%) }\end{array}$ \\
\hline 2.5 & 1.17 & 4.53 & 21.4 \\
5 & 1.82 & 5.15 & 18.1 \\
7.5 & 1.94 & 5.64 & 17.2 \\
\hline
\end{tabular}

\subsection{Mass transfer limitations during HDO}

\subsection{1 $k_{L} \cdot a_{G L}$ estimation}

To be able to explain the results obtained at various stirring speed, an estimation of the dependence of $k_{L} \cdot a_{G L}$ on stirring speed in the reactor is needed. Data on $k_{L} \cdot a_{G L}$ was obtained using absorption of $\mathrm{CO}_{2}$ in water as non-reactive model system (series 4 in Table 3). The choice of $\mathrm{CO}_{2} /$ water as model system was preferred over $\mathrm{H}_{2} /$ water or $\mathrm{H}_{2}$ /pyrolysis oil because the low solubility of $\mathrm{H}_{2}$ in water and the lack of accurate physical solubility data of $\mathrm{H}_{2}$ in pyrolysis oil, respectively. Moreover, a low temperature was used to obtain a low water vapour pressure, making an accurate monitoring of the relatively small pressure decrease because of physical absorption possible. It should be noted that temperature typically increases $k_{L} \cdot a_{G L}$ because it reduces the viscosity and surface tension of the liquid (example by Zieverink et al. [13]). 
The gas-liquid mass transfer experiments were interpreted using well known theories for gas absorption [14]. The experimentally derived $k_{L} \cdot a_{G L}$ values are given in Figure 7. Although these $k_{L} \cdot a_{G L}$ data are only indicative for actual experimental HDO conditions (pyrolysis oil, high temperature and pressure), they strongly indicate that, in this set-up, variation of the stirring rate from 7 to $48 \mathrm{~Hz}$ causes a substantial (order of magnitude) change in $k_{L} \cdot a_{G L}$.

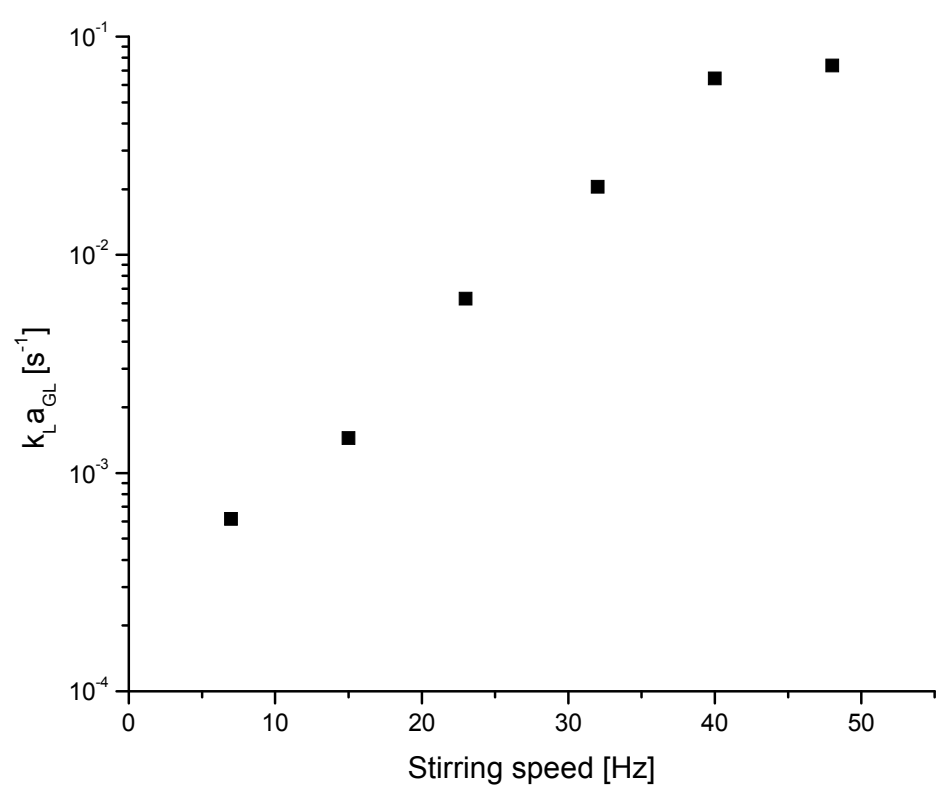

Figure 7. $k_{L} \cdot a_{G L}$ values for stirring speeds from 7 to $48 \mathrm{~Hz}$ at $20{ }^{\circ} \mathrm{C}$ in the stirred $45 \mathrm{ml}$ autoclave, determined by $\mathrm{CO}_{2}$ physical absorption in water.

\subsubsection{Influence of the stirring speed on the competing reactions}

Experiments were carried out in the $45 \mathrm{ml}$ stirred autoclave using various stirring rates at $300{ }^{\circ} \mathrm{C}$, a reaction time of 30 minutes, a catalyst concentration of $5 \mathrm{wt} \%$ and an initial hydrogen pressure of 120 bar (series 5, Table 3). Figure 8a gives the MWD of the oil products, showing that heavier products were obtained when decreasing the stirring intensity. At the same time, $\mathrm{H}_{2}$ consumption increased with stirring speed (Figure $8 \mathrm{~b}$ ). This shows that with decreasing stirring speed, and thus $k_{L} \cdot a_{G L}$, polymerisation reactions were increasingly favoured over hydrotreating reactions. Thus, the gas-liquid mass transfer resistance (Eq. 4) appears to be important in the competition between polymerisation and hydrotreating reactions in the early stage of the HDO process. The maximum hydrogen consumption observed (at $48 \mathrm{~Hz}$ ) in 30 minutes at $300{ }^{\circ} \mathrm{C}$ was 5.2 $\mathrm{mol} / \mathrm{kg}_{\text {feed. }}$ This hydrogen consumption in only 30 minutes (early stage of HDO) is substantial when compared to the consumption in the $5 \mathrm{I}$ autoclave and 5.5 hours of reaction time $\left(11.7 \mathrm{~mol} / \mathrm{kg}_{\text {feed }}\right)$. This also indicates that in the early stage of the HDO 
process, hydrogen consuming reactions can be (very) fast. In the next section, this is also quantitatively verified.
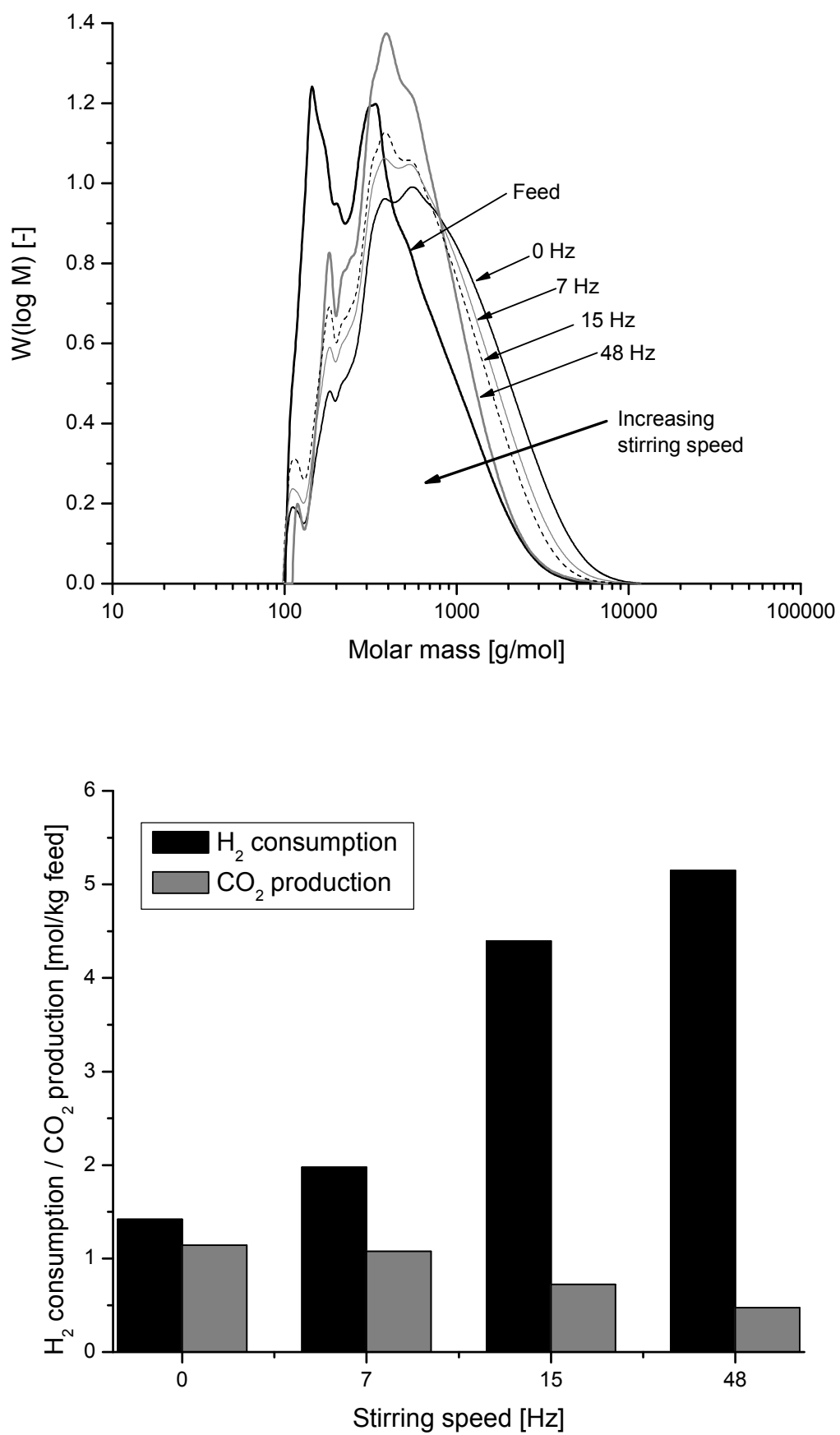

Figure 8. a) Molecular weight distribution of the oil products obtained at different stirring speed. Experiments were carried out in the $45 \mathrm{ml}$ stirred autoclave at $300{ }^{\circ} \mathrm{C}$ for 30 minutes using $5 \mathrm{wt} . \%$ catalyst. b) $\mathrm{H}_{2}$ consumption and $\mathrm{CO}_{2}$ production for the same experiments. 
It is also interesting to observe how the $\mathrm{CO}_{2}$ production (typically observed during high pressure thermal treatment of pyrolysis oil in Chapter 2) increased with a decrease in stirring speed (Figure 8b). In Chapter 4, during HDO of an aqueous fraction obtained by adding water to pyrolysis oil, $\mathrm{CO}_{2}$ production also increased upon a shortage of hydrogen. These findings suggest that not only in HPTT but also in HDO, the extent of $\mathrm{CO}_{2}$ production is related to the extent of polymerisation reactions.

When comparing the $k_{L} \cdot a_{G L}$ and the $-\ln \left(n_{H_{2}, G}(30 \mathrm{~min}) / n_{H_{2}, G}(0)\right)$, a proportional dependence should be observed if the gas-liquid mass transfer would control the hydrogen uptake (rate). Table 6 shows that at low stirring speeds (under $15 \mathrm{~Hz}$ ), this dependence is significant and more than proportional. It should be taken into account that part from the hydrogen consumption might originate from pre-saturation of the liquid and, moreover, the $k_{L} \cdot a_{G L}$ values used are only indicative. However, at the $48 \mathrm{~Hz}$, the linearity is not present anymore, indicating that other mass transfer or kinetic resistances are also taking place. These results are consistent with those obtained using different catalyst hold-up, in which the change of catalyst hold-up at low values had stronger effect on the hydrogen consumption than when changed within high values.

Table 6. Correlation between the $k_{L} \cdot a_{G L}$ and the final/initial hydrogen mol ratio in the gas phase. Experiments conducted in the $45 \mathrm{ml}$ autoclave at $300{ }^{\circ} \mathrm{C}, 30 \mathrm{~min}$ and $5 \mathrm{wt} . \%$ catalyst.

\begin{tabular}{ccc}
\hline Stirring speed $[\mathrm{Hz}]$ & $\boldsymbol{k}_{\mathrm{L} \cdot \mathrm{a}_{\mathrm{GL}}}$ & $-\ln \left(\boldsymbol{n}_{\mathrm{H}_{2}, \mathrm{G}}(30 \mathrm{~min}) / n_{\mathrm{H}_{2}, \mathrm{G}}(0)\right)$ \\
\hline 0 & 0 & 0.24 \\
7 & $6.1710^{-4}$ & 0.36 \\
15 & $1.4410^{-3}$ & 1.09 \\
48 & $7.3510^{-2}$ & 1.82 \\
\hline
\end{tabular}

\subsubsection{Rate controlling step}

In the previous sections, it has been shown that neither the mass transfer (Eq. 2 and 4) nor the apparent kinetics (Eq. 3) is the only controlling step in the hydrotreating reactions, at least for the whole reaction time of 30 minutes. In this section, the hydrogen consumption rate in subsequent time intervals is analysed to evaluate the importance of each resistance in these time intervals. First, the two mass transfer terms in Eq. 1 are compared, assuming that the apparent kinetics is very fast and not limiting. This would reduce Eq. 1 to:

$$
N_{H_{2}}=\frac{C_{H_{2}, G}}{\frac{1}{m \cdot k_{L} \cdot a_{G L}}+\frac{1}{m \cdot k_{S} \cdot a_{S}}} \quad\left[\mathrm{~mol} \cdot m_{\text {liquid }}^{-3} \cdot s^{-1}\right]
$$


As the distribution coefficient $m$ is present in both resistances, it is only necessary to compare $k_{L} \cdot a_{G L}$ to $k_{S}$. $a_{S}$ to indicate which of these mass transfer resistances is more important. Based on the conservative assumption of a Sherwood number of 2 and a diffusivity of $\mathrm{H}_{2}$ in water at room temperature of $4.6 \cdot 10^{-9} \mathrm{~m}^{2} / \mathrm{s}$ [15] (which would be higher at higher temperature), $k_{s}$ is estimated to be at least $6.5 \cdot 10^{-4} \mathrm{~m} / \mathrm{s}$. To calculate $a_{s}$, the catalyst hold-up $\left(\varepsilon_{s}\right)$ is needed, which is approximately $0.046 \mathrm{~m}^{3}$ catalys $/ \mathrm{m}^{3}$ liquid. ${ }^{1}$ This gives an $a_{s}$ of $1.98 \cdot 10^{4} \mathrm{~m}_{\text {catalyst }}^{2} / \mathrm{m}^{3}$ liquid, resulting in a $k_{s} \cdot a_{s}$ of $12.95 \mathrm{~s}^{-1}$. This value is more than two orders of magnitude higher than the $k_{L} \cdot a_{G L}$ values as reported in this study (Figure 8). Therefore, in this study Eq. 5 can be further simplified to:

$N_{\mathrm{H}_{2}}=m \cdot k_{L} \cdot a_{G L} \cdot C_{H_{2}, G}$

(Eq. 6)

It should be noted that, in the derivation of Eq. 6, it has been assumed that apparent kinetics was not limiting, while for the actual experiments shown in the previous section some influence of the catalyst hold-up and was observed for 30 minutes reaction time. Because $k_{S}$. $a_{S}$ has proven not to be limiting, it can be concluded that the influence of catalyst hold-up in the previous section was due to the apparent kinetic term (Eq. 3). This also means that actual $k_{L}$. $a_{G L}$ values will be at least equal to or higher than the ones derived using experimental fluxes and Eq. 6. In Table 7, the experimental hydrogen consumption rate for two time intervals is shown. These intervals are from 3 to 5 min (excluding, in this way, large part of the heating time) and from 5 to $30 \mathrm{~min}$ (the rest of the experiment). The rate was determined from the change in reactor pressure in time (subtracting the water vapour pressure at the corresponding temperature). The $\mathrm{H}_{2}$ consumption rate decreased strongly with the reaction time. The last column in Table 7 shows the calculated $\mathrm{H}_{2}$ consumption rate as if the liquid side mass transfer was the rate controlling step using Eq. 6. Considering the uncertainty in the estimates used in the calculations (among others $k_{L} \cdot a_{G L}, m$, pyrolysis oil density), the theoretically predicted gas-liquid mass transfer rate agrees well with the experimentally observed hydrogen consumption rate for the period of 3-5 min. However, the measured average hydrogen consumption rate for the period of $5-30 \mathrm{~min}$ is much lower than the maximum mass transfer flux predicted using Eq. 6. These findings indicate that in the first period of reaction process (3-5 $\mathrm{min}$ ), gas-liquid mass transfer is to a large extent limiting the overall hydrogen consumption rate, but its importance decreases with time/conversion. The hydrogen consumption rate at/inside the catalyst (governed by apparent kinetics, see Eq. 3) is expected to become more important in this second period (5-30 min). A reason for this behaviour might be that because of the fast heating to high temperatures many pyrolysis oil components become reactive towards hydrotreating at the same time [5]. This requires a large flux of hydrogen, resulting in depletion of hydrogen in the liquid and thus gas-liquid mass transfer limitations in the early stage of HDO. Slower and

\footnotetext{
1 In the experiment $20 \mathrm{~g}$ of liquid $\left(16.7 \mathrm{~cm}^{3}\right)$ and $1 \mathrm{~g}$ of catalyst $\left(\sim 0.77 \mathrm{~cm}^{3}\right.$, by using a skeletal density of $2 \mathrm{~g} / \mathrm{cm}^{3}$ $[16,17]$ and porosity of $0.27 \mathrm{~cm}^{3} / \mathrm{g}$ ) were used.
} 
gradual heating, like used in the $5 \mathrm{I}$ autoclave experiments in Chapter 3 , would probably avoid this.

Table 7. Estimated average $\mathrm{H}_{2}$ consumption rates and temperatures at different time intervals for the experiment in the stirred $45 \mathrm{ml}$ autoclave $\left(5 \mathrm{wt} . \%\right.$ catalyst, $300{ }^{\circ} \mathrm{C}$ end temperature, 30 minutes total, $\mathrm{H}_{2}$ initial pressure of 120 bar).

\begin{tabular}{|c|c|c|c|c|c|c|}
\hline $\begin{array}{l}\text { Time } \\
\text { interval }\end{array}$ & \multicolumn{2}{|c|}{$\begin{array}{l}\text { Measured average } \mathrm{H}_{2} \\
\text { consumption rate }\end{array}$} & $\begin{array}{c}\text { Average } \\
\text { temperature } \\
\text { in time } \\
\text { interval } \\
\text { (range) }\end{array}$ & $\begin{array}{c}\text { Distribution } \\
\text { coefficient }^{\mathrm{b}} \\
(m)\end{array}$ & $\begin{array}{c}\text { Average } \mathrm{H}_{2} \\
\text { concentration in } \\
\text { the gas in the } \\
\text { time interval } \\
\left(C_{H 2, G}\right)\end{array}$ & $\begin{array}{c}\text { Predicted } \mathrm{H}_{2} \\
\text { consumption } \\
\text { rate } \\
\text { assuming } \\
\text { overall G-L } \\
\text { limitation }^{\mathrm{d}}\end{array}$ \\
\hline$(\min )$ & $\begin{array}{c}(\mathrm{mol} / \mathrm{min} \\
\left.\mathrm{kg}_{\mathrm{feed}}\right)\end{array}$ & $\begin{array}{l}(\mathrm{mol} / \mathrm{s} . \\
\left.\mathrm{m}_{\text {feed }}^{3}\right)^{\text {a }}\end{array}$ & $\left({ }^{\circ} \mathrm{C}\right)$ & - & $\left(\mathrm{mol} / \mathrm{m}^{3}\right)$ & $\left(\mathrm{mol} / \mathrm{s} . \mathrm{m}_{\text {feed }}^{3}\right)$ \\
\hline $3-5$ & 0.61 & 12.1 & 265 (248-276) & 0.087 & 2058 & 13.2 \\
\hline $5-30$ & 0.06 & 1.2 & $289(277-290)$ & 0.122 & 908 & 8.2 \\
\hline \multicolumn{7}{|c|}{$\begin{array}{l}\text { B Because the changes in density of pyrolysis oil are not known, the density at room temperature }\left(1200 \mathrm{~kg} / \mathrm{m}^{3}\right) \text { was used } \\
\text { b Estimated by interpolation data from distribution coefficients for } \mathrm{H}_{2} \text { in water at different temperatures [18] } \\
{ }^{c} \text { From estimated } \mathrm{H}_{2} \text { partial pressure in reactor }\end{array}$} \\
\hline \multicolumn{7}{|c|}{$\begin{array}{l}\text { d Using Eq. 6; } m_{\mathrm{H} 2 \text {-water }} \text { from [18], } \mathrm{C}_{\mathrm{H} 2, \mathrm{G}} \text { from the average } \mathrm{H}_{2} \text { partial pressure (in the interval) and Soave-Redlich-Kwong equation of } \\
\text { state, and the } k_{L} \cdot a_{G L} \text { (measured in the } \mathrm{CO}_{2} / \text { water model system) at } 48 \mathrm{~Hz} \text { from Figure } 8 \text {. }\end{array}$} \\
\hline
\end{tabular}

\subsection{Estimation for industrial reactors}

Previous sections showed that gas-liquid mass transfer resistances are likely to be important during the initial period of the HDO process (3-5 $\mathrm{min})$, especially for experiments carried out above $200{ }^{\circ} \mathrm{C}$. The model reactors as used in this study typically have high specific energy input and thus good mass transfer characteristics when compared to industrial reactors. It is therefore likely that gas-liquid mass transfer resistances also play an important role in industrial application, especially during the early stage of the HDO process. Other resistances can become of much more importance in industrial reactors due to the use of larger particles: these include not only extra-particle but also intra-particle mass transfer resistances (in this study the catalyst particle size was very small). It should be kept in mind that even when mass transfer characteristics are (very) good, the intrinsic kinetics, the catalyst hold-up and degree of utilisation (or effectiveness factor) of the catalyst should also be such that overall the hydrotreating reactions are favoured over the polymerisation reactions. An estimate on the degree of utilisation for larger particles sizes than used in this study will be given based on current experimental data.

The previous section has shown that in an initial period ( $<5$ minutes) at a temperature of $300{ }^{\circ} \mathrm{C}$ liquid side mass transfer is likely to be controlling the overall hydrogen consumption rate. The following equation can thus be postulated: 
$N_{H_{2}, 3-5 \min , \text { experimental }}<m \cdot \eta \cdot k_{1,3-5 \min } \cdot \varepsilon_{s} \cdot C_{H_{2}, G}$

Using Eq. 7 will thus yield a lower boundary for $k_{1,3-5 \mathrm{~min}}$. Because only one particle size was used in this study $(14 \mu \mathrm{m})$, the actual degree of utilisation $(\eta)$ could not be determined. To estimate $\eta$ for larger particle sizes than the one used it this study, it was additionally assumed that $\eta(14 \mu \mathrm{m})=1$. This enables the calculation of a 'lower-lower' boundary for $k_{1}$ (using Eq. 7) and thus estimation of $\eta_{\max }$ for larger particles. Using the measured $\mathrm{H}_{2}$ consumption rate in the period of 3-5 min, the estimated $\mathrm{H}_{2}$ distribution coefficient and average $\mathrm{H}_{2}$ concentration in the same interval (see Table 7), the kinetic rate constant in this period is estimated to be $k_{1,3-5 \mathrm{~min}}>=1.46 \mathrm{~s}^{-1}$. Again, this only gives a lower boundary for the kinetic constant in this time period as it has been shown that gasliquid mass transfer limitations were present and $\eta(14 \mu \mathrm{m})$ was assumed to be unity.

With $k_{1,3-5 \min }$ known and using the Thiele modulus $\left(\phi=\left(d_{p} / 6\right) \cdot \sqrt{k_{1} / D_{\text {eff }}}\right)$, the degree of utilisation $(\eta=\tanh \phi / \phi)$ can be calculated for different particle sizes. $D_{\text {eff }}$ was estimated by using the diffusivity of $\mathrm{H}_{2}$ in water corrected by the porosity of the catalyst particle $(\varepsilon)$ and a tortuosity factor $(\tau),\left(D_{\text {eff }}=\varepsilon . D_{H_{2}} / \tau\right)$. For the catalyst used, the porosity was 0.27 $\mathrm{cm}^{3} / \mathrm{g}$, but the tortuosity was not known. Typically, $\tau$ has a value between 2 and 5 [19]. Therefore, an intermediate value of 0.1 for the $\varepsilon / \tau$ was taken. Figure 9 shows the influence of the particle size (industrial hydrogenation reactors use catalyst particles with a size up to $1 / 4$ inch [20]) on the degree of utilisation. Because the degree of utilisation is affected by diffusivity, and the diffusivity of $\mathrm{H}_{2}$ in water at high temperature is not known, it was estimated using the Einstein-Stokes correlation. The figure shows that even with the estimated higher diffusivity, increasing the particle size would reduce the (maximum) degree of utilisation significantly below 1 . When the same calculation procedure is repeated for the interval of $5-30 \mathrm{~min}, k_{1}, 5-30 \mathrm{~min}$ is calculated to be $0.24 \mathrm{~s}^{-1}$. In Figure 9, the estimated degree of utilisation for this reaction rate constant is also shown. Although higher than for the initial period of the experiment, also in this case it is significantly below 1 . This can again affect the ratio of the hydrogenation to the polymerisation reactions in the early stage of the HDO process and therewith influence product quality if not properly accounted for. 


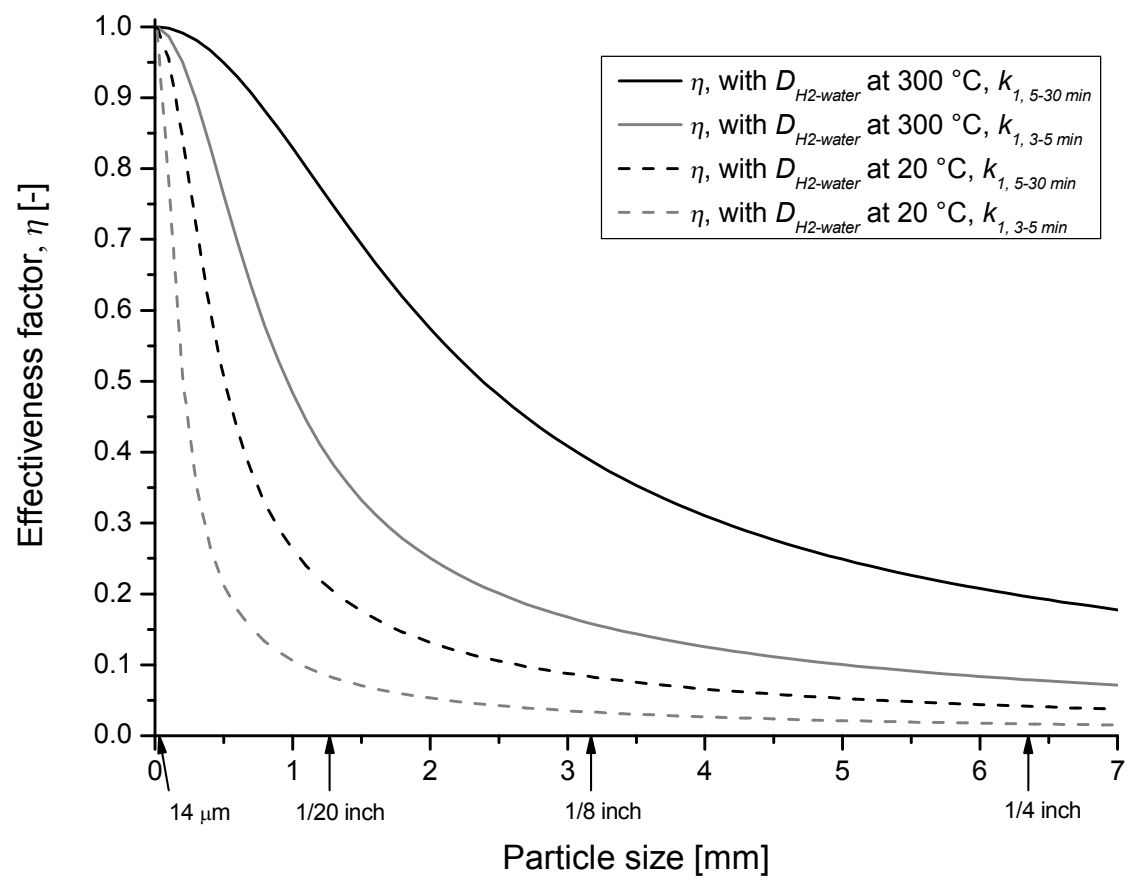

Figure 9. Estimate of (maximum) effectiveness factor (or degree of utilisation) of a Ru/C catalyst particle of HDO process $\left(300{ }^{\circ} \mathrm{C}\right)$ as a function of catalyst particle size. The dotted lines corresponds to values calculated using the diffusivity of $\mathrm{H}_{2}$ in water at $20^{\circ} \mathrm{C}$. The solid lines uses an approximation of the diffusivity by correcting the diffusivity at $20{ }^{\circ} \mathrm{C}$ by temperature and viscosity (using the Einstein-Stokes correlation, $D_{\mathrm{H} 2,20{ }^{\circ} \mathrm{C}}=5.11 \cdot 10^{-9} \mathrm{~m}^{2} / \mathrm{s}, D_{\mathrm{H} 2}, 300{ }^{\circ} \mathrm{C}=1.02 \cdot 10^{-7} \mathrm{~m}^{2} / \mathrm{s}=$ $\left.=(\mu / \mathrm{T})_{20}{ }^{\circ} \mathrm{C} /(\mu / \mathrm{T})_{300}{ }^{\circ} \mathrm{C} \cdot D_{\mathrm{H} 2}, 20{ }^{\circ} \mathrm{C}\right)$. The grey lines correspond to the effectiveness factor at the initial period of reaction (3-5 $\mathrm{min}$ ) and the black lines to the later period (5-30 $\mathrm{min})$. 


\section{Conclusions}

The competition between polymerisation and hydrotreating reactions occurring during the early stage of pyrolysis oil hydrodeoxygenation (HDO) has been studied using (near) isothermal, intensively mixed reactors. The aim was to identify process conditions that are of influence on this competition in order to be able to minimise polymerisation reactions that typically lead to undesirable product properties.

Low temperatures favoured hydrotreating reactions. However, if the heating rate to temperatures above $200-250{ }^{\circ} \mathrm{C}$ was fast, not giving enough time to the hydrotreating reactions below these temperatures to occur, polymerisation quickly took place creating a product refractive towards hydrotreating.

Experiments carried out at $300{ }^{\circ} \mathrm{C}$ using different stirring speeds showed that total hydrogen consumption increased with stirring speed, while the extent of polymerisation decreased (measured by the molecular weight distribution of the oil product and $\mathrm{CO}_{2}$ production). This indicates that gas-liquid mass transfer limitations were occurring. An increase in the catalyst hold-up reduced the extent of polymerisation and increased the hydrogen uptake (although less than proportional), indicating that intraparticle/kinetic resistances also played a role in the experiments.

Calculations on the hydrogen consumption rates for various time intervals in a 30 min experiment at $300{ }^{\circ} \mathrm{C}$ (high intensity stirring) showed high consumption rates in the initial period (under $5 \mathrm{~min}$ ) and lower rates afterwards. Using estimations on the mass transfer coefficients, the gas-liquid mass transfer appeared to be the controlling step during the initial period. Afterwards, the intraparticle/kinetic resistances gained importance.

Indicative calculations on the effect of catalyst size showed that, in the early stage of HDO process, the expected degree of utilisation for particle sizes typically used in industrial fixed bed reactors is below unity.

This work has shown that hydrotreating reactions can be favoured over polymerisation reactions by selecting adequate reactor (good mixing), catalyst (small particles) and process conditions (enough time at low temperature). Insights obtained in this study can help in the design of industrial HDO reactors. 


\section{List of abbreviations and symbols}

\begin{tabular}{|c|c|}
\hline$a_{G L}$ & Gas-liquid interface area $\left[\mathrm{m}^{2}{ }_{\text {interface }} \cdot \mathrm{m}^{-3}{ }_{\text {liquid }}\right]$ \\
\hline$C_{1}$ & $\left.\left(1 /\left(\left(d_{p}\right)\left(6 \cdot m \cdot k_{s}\right)\right)+\left(1 / m \cdot \eta \cdot k_{1}\right)\right)\right) \cdot\left(1 / N_{G}\right)$ \\
\hline$a_{s}$ & Catalyst area per unit of liquid volume: $6 . \varepsilon_{s} / d_{p}\left[\mathrm{~m}_{\text {catalyst }}^{2} \cdot \mathrm{m}^{-3}\right.$ liquid $]$ \\
\hline$C_{H 2, G}$ & Concentration of hydrogen in the gas phase $\left[\mathrm{mol} . \mathrm{m}_{\mathrm{gas}}^{-3}\right]$ \\
\hline$C_{H 2, L}$ & Concentration of hydrogen in the liquid phase $\left[\mathrm{mol}^{-\mathrm{m}^{-3}}{ }_{\text {liquid }}\right]$ \\
\hline$D_{\text {eff }}$ & Effective diffusivity $\left[\mathrm{m}^{2} \cdot \mathrm{s}^{-1}\right]$ \\
\hline$D_{H 2, L}$ & Diffusivity of hydrogen in a liquid $\left[\mathrm{m}^{2} \cdot \mathrm{s}^{-1}\right]$ \\
\hline$d_{p}$ & Particle size/diameter $[\mathrm{m}]$ \\
\hline$E_{a}$ & Activation energy $\left[\mathrm{kJ} . \mathrm{mol}^{-1}\right]$ \\
\hline GPC & Gel permeation chromatography \\
\hline HDO & Hydrodeoxygenation \\
\hline HPTT & High pressure thermal treatment \\
\hline$k_{0}$ & Arrhenius constant $\left[\mathrm{s}^{-1}\right]$ \\
\hline$k_{1}$ & Reaction rate constant for hydrogen consuming reactions $\left[\mathrm{s}^{-1}\right]$ \\
\hline$k_{H P T T}$ & Reaction rate constant for HPTT gas formation $\left[\mathrm{s}^{-1}\right]$ \\
\hline$k_{L}$ & Gas-liquid mass transfer coefficient $\left[\mathrm{m}^{3}\right.$ liquid. $\left.\mathrm{m}_{\text {interface }} \mathrm{s}^{-1}\right]$ \\
\hline$k_{s}$ & Liquid-solid mass transfer coefficient $\left[\mathrm{m}^{3}\right.$ liquid. $\left.\mathrm{m}_{\text {catalyst }}^{2} \mathrm{~s}^{-1}\right]$ \\
\hline$m$ & Distribution coefficient (from Henry's law): $\left(C_{H 2, L} / C_{H 2, G}\right)_{\text {at equilibrium }[-]}$ \\
\hline MCRT & Micro carbon residue test \\
\hline MW & Molecular weight \\
\hline MWD & Molecular weight distribution \\
\hline$n_{H 2}$ & Hydrogen moles \\
\hline$N_{H 2}$ & Hydrogen molar flux $\left[\right.$ mol. $\mathrm{m}^{-3}$ liquid. $\left.\mathrm{S}^{-1}\right]$ \\
\hline$R$ & Gas constant: $8.314\left[\mathrm{~J} \cdot \mathrm{mol}^{-1} \cdot \mathrm{K}^{-1}\right]$ \\
\hline $\operatorname{Re}$ & Reynolds number: $d_{p} \cdot v \cdot \rho \cdot \mu^{-1}[-]$, from reference [21] \\
\hline Sc & Schmidt number: $\mu . \rho . D^{-1}[-]$, from reference $[21]$ \\
\hline Sh & Sherwood number: $2+R e^{n}+S c^{m}=k_{S} \cdot d_{p} \cdot D^{-1}[-]$, from reference [21] \\
\hline$t$ & Time $[\mathrm{s}]$ \\
\hline$T$ & Temperature $[\mathrm{K}]$ \\
\hline$v$ & Velocity $\left[\mathrm{m} \cdot \mathrm{s}^{-1}\right]$ \\
\hline$V_{G}$ & Gas volume $\left[\mathrm{m}_{\mathrm{gas}}^{3}\right]$ \\
\hline \multicolumn{2}{|c|}{ Greek symbols } \\
\hline$\varepsilon$ & Porosity $\left[\mathrm{m}_{\text {pore }}^{3} \cdot \mathrm{g}^{-1}\right.$ catalyst $]$ \\
\hline$\varepsilon_{s}$ & Catalyst hold-up $\left[\mathrm{m}^{3}\right.$ catalyst. $\mathrm{m}^{-3}$ liquid] \\
\hline$\phi$ & Thiele modulus: $\left(d_{p} / 6\right) \cdot k_{1}^{1 / 2} \cdot D_{\text {eff }}^{-1 / 2}[-]$ \\
\hline$\eta$ & Effectiveness factor or degree of utilisation of a porous catalyst: $(\tanh \phi) \cdot \phi^{-1}[-]$ \\
\hline$\mu$ & Viscosity $[\mathrm{Pa} . \mathrm{s}]$ \\
\hline$\rho$ & Density $\left[\mathrm{kg} / \mathrm{m}^{3}\right]$ \\
\hline$\tau$ & Tortuosity factor [-] \\
\hline
\end{tabular}




\section{References}

[1] French RJ, Hrdlicka J, Baldwin R. Mild hydrotreating of biomass pyrolysis oils to produce a suitable refinery feedstock. Environ. Prog. Sustain. Energy. 2010;29:142150.

[2] Fogassy G, Thegarid N, Toussaint G, van Veen AC, Schuurman Y, Mirodatos C. Biomass derived feedstock co-processing with vacuum gas oil for secondgeneration fuel production in FCC units. Appl. Catal. B Environ. 2010;96:476-485.

[3] Elliott DC. Historical developments in hydroprocessing bio-oils. Energy Fuels 2007;21:1792-1815.

[4] Elliott DC, Baker EG, Process for upgrading biomass pyrolyzates, US patent: 4795841 (1989).

[5] Laurent E, Pierret C, Grange P, Delmon B. Control of the deoxygenation of pyrolytic oils by hydrotreatment. In: Proc. of 6th conference on Biomass for energy, industry and environment, Athens, Greece. 1991; p. 665-671.

[6] Elliott DC, Neuenschwander GG. Liquid fuels by low-severity hydrotreating of biocrude. In: A.V. Bridgwater and D.G.B. Boocock editors. Developments in Thermochemical Biomass Conversion, London: Blackie Academic \& Professional. 1996; p. 611-621.

[7] Venderbosch RH, Ardiyanti AR, Wildschut J, Oasmaa A, Heeres HJ. Stabilization of biomass-derived pyrolysis oils. J. Chem. Technol. Biot. 2010;85:674-686.

[8] Zhang S, Yong-Jie Y, Li T, Ren Z. Study of Hydrodeoxygenation of Bio-oil from the fast pyrolysis of biomass. Energy Source. 2003;25:57-65.

[9] Sheu Y-HE, Anthony RG, Soltes EJ. Kinetic studies of upgrading pine pyrolytic oil by hydrotreatment. Fuel Process. Technol. 1988;19:31-50.

[10] Zhang S, Yan Y, Li T, Ren Z. Lumping Kinetic Model for Hydrotreating of Bio-oil from the Fast Pyrolysis of Biomass. Energy Source. Part A. 2009;31:639 - 645.

[11] Voorhoeve RJH, Stuiver JCM. Kinetics of hydrogenation on supported and bulk nickel-tungsten sulfide catalysts. J. Catal. 1971;23:228-235.

[12] Guo H, Li H, Xu Y, Wang M. Liquid phase glucose hydrogenation over Cr-promoted Ru-B amorphous alloy catalysts. Mater. Lett. 2002;57:392-398.

[13] Zieverink MMP, Kreutzer MT, Kapteijn F, Moulijn JA. Gas-Liquid Mass Transfer in Benchscale Stirred Tanks Fluid Properties and Critical Impeller Speed for Gas Induction. Ind. Eng. Chem. Res. 2006;45:4574-4581.

[14] Cents AHG, Brilman DWF, Versteeg GF. Mass-Transfer Effects in the Biphasic Hydroformylation of Propylene. Ind. Eng. Chem. Res. 2004;43:7465-7475. 
[15] Handbook of Chemistry and Physics, 84th ed, ed. D.R. Lide. CRC Press, Boca Raton, 2003.

[16] Agarwal RK, Noh JS, Schwarz JA, Davini P. Effect of surface acidity of activated carbon on hydrogen storage. Carbon. 1987;25:219-226.

[17] Agarwal RK, Schwarz JA. Analysis of high pressure adsorption of gases on activated carbon by potential theory. Carbon. 1988;26:873-887.

[18] Baranenko VI, Kirov VS. Solubility of hydrogen in water in a broad temperature and pressure range. Atom. Energy+. 1989;66:30-34.

[19] Van Santen RA, van Leeuwen PWNM, Moulijn JA, Averill BA, Catalysis: An integrated approach, 2nd ed., Elsevier Science BV, Amsterdam, 2000.

[20] Sanfilippo, D. and Rylander, P. N. 2009. Hydrogenation and Dehydrogenation. Ullmann's Encyclopedia of Industrial Chemistry.

[21] Harriott P. Chemical reactor design. Marcel Dekker, Inc., New York, 2003. 


\section{Abstract}

Via pyrolysis, dry solid biomass can be converted into an easier to handle liquid (pyrolysis oil), with higher volumetric energy density. However, currently pyrolysis oil has limited end-user applications due to its low energy density (compared to fossil fuels) and instability.

The route considered in this thesis comprises the upgrading of pyrolysis oil and its further co-processing in standard refineries to produce transportation fuels. In the present concept, pyrolysis oil is produced where biomass is available and then transported to a central upgrading unit. This unit is located next or inside a standard petroleum refinery, enabling the use of existing facilities. The obtained product can be further distributed using existing distribution networks.

The present thesis describes and discusses pyrolysis oil upgrading by high pressure thermal treatment (HPTT) and hydrodeoxygenation (HDO), and its subsequent coprocessing in lab-scale refinery units. After HPTT, pyrolysis oil underwent phase separation, yielding a gas phase, an aqueous phase and an oil phase. The energy density of the resulting oil phase was higher than that of the starting pyrolysis oil due to its lower oxygen and water content. Conversion and transfer of water soluble organics to the oil phase was observed, increasing the energy recovery in the final product. However, severe and very fast polymerisation was also observed, especially at temperatures above $250{ }^{\circ} \mathrm{C}$. This polymerisation created a product with high coking tendency that could not be co-processed in lab-scale refinery units. After HDO of pyrolysis oil (and fractions obtained by adding water to it), phase separation was also observed, again creating an oil with lower oxygen and water content. Similar to HPTT, transfer of organics from the aqueous to oil phase was detected, increasing the energy recovery in the oil phase with process severity. However, during HDO, polymerisation was avoided and the oil produced had a molecular weight that could be even lower than that of pyrolysis oil. HDO oils (with high remaining oxygen content) produced at different conditions and from various pyrolysis oil fractions, could be co-processed with Long Residue in a lab-scale catalytic cracking unit. The resulting yields to gasoline and light cycle oil (diesel precursor) were near the same as obtained using the pure fossil reference feed. The presence of such fossil co-feed enabled hydrogen transfer reactions from the fossil feed to the HDO oils components and appeared to be crucial to obtain a good product distribution. Co-processing HDO oils with straight run gas oil in a lab-scale hydrodesulphurisation unit was performed without operational problems, but competition between oxygen and sulphur removal reactions was detected. Dedicated HDO experiments showed that mass transfer resistances can limit the extent of the hydrotreating reactions (favouring in this way the extent of undesired polymerisation reactions, thus deteriorating product quality) and need careful consideration when designing demo units and industrial HDO reactors. 


\section{Samenvatting}

Vaste biomassa kan via pyrolyse worden omgezet in een makkelijker hanteerbare vloeistof (pyrolyse-olie), die tevens een hogere volumetrische energiedichtheid heeft. Op dit moment kent pyrolyse-olie echter nog maar een beperkt aantal eindtoepassingen als gevolg van de, in vergelijking met fossiele brandstoffen, lage energiedichtheid en instabiliteit.

De route die in dit proefschrift beschreven wordt, bestaat uit het veredelen ('upgraden') van pyrolyse-olie tot een product dat vervolgens gelijktijdig met fossiele olie in bestaande raffinaderijen tot transportbrandstoffen kan worden verwerkt ('co-processing'). In het onderliggende concept voor biomassa valorisatie wordt pyrolyse-olie geproduceerd daar waar biomassa beschikbaar is, en vervolgens getransporteerd naar- en verwerkt in een upgrading proces, vlakbij of zelfs binnen een bestaande raffinaderij. Hierdoor kan gebruik gemaakt worden van de daar aanwezige faciliteiten en bovendien kunnen de uiteindelijke producten via bestaande distributie netwerken verspreid worden.

Dit proefschrift beschrijt de upgrading van pyrolyse-olie door middel van HPTT (een thermische behandeling onder hoge druk) en HDO (Hydrodeoxygenatie), en de daaropvolgende verwerking van de resulterende olie in labschaal raffinaderij processen. $\mathrm{Na}$ HPTT van pyrolyse-olie werd een olie-, een gas- en een waterige fase verkregen. De energiedichtheid van de geproduceerde HPTT olie was hoger dan die van de oorspronkelijke pyrolyse-olie als gevolg van een reductie in het zuurstof- en watergehalte. Een hevige en snelle polymerisatie bij temperaturen van $250{ }^{\circ} \mathrm{C}$ en hoger had tot gevolg dat de HPTT olie ongeschikt werd bevonden voor verdere verwerking. Bij HDO van pyrolyse-olie werd wederom een olie-, een gas- en een waterige fase verkregen. Bij $\mathrm{HDO}$ trad geen (sterke) polymerisatie op; het gemiddelde molecuulgewicht was soms zelfs lager dan dat van de voeding. HDO oliën bereid vanuit verschillende pyrolyse-olie fracties en geproduceerd bij verschillende procescondities konden allen zonder operationele problemen, ondanks het soms hoge resterende zuurstof gehalte van de HDO oliën, gelijktijdig met een 'Long Residu' worden verwerkt in een lab-schaal katalytische kraakproces. De opbrengsten aan benzine en Light Cycle Oil (waaruit diesel wordt bereid) waren nagenoeg gelijk aan deze verkregen met alleen een fossiele voeding. Waterstofoverdracht vanuit deze fossiele co-voeding naar de HDO olie bleek noodzakelijk om een goede productverdeling te verkrijgen. Ook het co-processen van HDO olie met 'Straight Run Gas Oil' in een labschaal ontzwavelingsproces kon zonder operationele problemen worden uitgevoerd. Er werd echter wel een competitie tussen ontzwaveling en deoxygenatie waargenomen. Gerichte HDO experimenten hebben aangetoond dat waterstof stofoverdrachtsweerstanden de mate van hydrotreating (hydrogenering en de-oxygenering) vermindert en dat gelijktijdig de mate van polymerisatie toeneemt, hetgeen uiteindelijk resulteert in kwaliteitsverlies van de olie. Bij de verdere ontwikkeling van deze technologie en met name het ontwerp van demo units en industriële HDO reactoren dient hier terdege rekening mee te worden gehouden. 


\section{Resum}

La biomassa sòlida pot ser processada via piròlisi i convertida en un líquid amb més densitat energètica i que és més fàcil de manipular, anomenat oli de piròlisi. Tanmateix, actualment, l'oli de piròlisi té poques aplicacions finals a causa de la seva baixa densitat energètica (comparant-lo amb combustibles fòssils) i és tèrmicament inestable.

La ruta considerada en aquesta tesi comprèn el procés des de la biomassa fins a la producció de combustibles per al transport. En aquest concepte, l'oli de piròlisi és tractat per millorar les seves propietats i després processat conjuntament amb petroli a la refineria. D'aquesta manera, l'oli de piròlisi és produït prop d'on la biomassa és disponible $\mathrm{i}$ després és transportat a una unitat central. Aquesta unitat millora les propietats de l'oli fent-lo processable en la refineria. La unitat de millora és dins de la refineria, cosa que facilita l'ús de les instal-lacions i les xarxes de distribució existents.

Aquesta tesi descriu i analitza la millora de propietats de l'oli de piròlisi mitjançant dos processos: tractament tèrmic a alta pressió (HPTT, en les seves sigles en anglès) i hidrodesoxigenació (HDO). Després de processar l'oli de piròlisi mitjançant HPTT, aquest es separa en diferents fases (aquosa, oli i gas). La densitat energètica de la fase oli resultant és més alta que la de l'oli de piròlisi inicial a causa de la reducció del seu contingut d'aigua i oxigen. Durant el procés, components solubles en aigua polimeritzen ràpidament i són transferits a la fase oli. A causa d'aquesta polimerització, el producte final té una alta tendència a la formació de carbó de coc i no es pot processar en instal-lacions de refinatge (mida de laboratori). En processar oli de piròlisi (i fraccions obtingudes mitjançant l'addició d'aigua a aquest) via HDO, també s'observa la separació en diferents fases. Igual que durant HPTT, el producte en fase oli conté menys aigua i oxigen, cosa que incrementa la densitat energètica. Tanmateix, en aquest cas, la polimerització no es produeix, i l'oli creat pot tenir fins i tot un pes molecular més baix que el de l'oli de piròlisi. Olis produïts mitjançant HDO, amb alts continguts d'oxigen, poden ser co-processats amb Long Residue (fracció de petroli) en unitats de laboratori de craquejat catalític, produint gasolina i precursors de dièsel amb quantitats similars que processant Long Residue pur. La presència del Long Residue durant el craquejat és clau per tal que es produeixin reaccions de transferència d'hidrogen (del Long Residue al olis produïts via HDO) i s'obtingui la distribució desitjada dels productes.

Durant l'HDO, existeix una competició entre les reaccions de polimerització i d'hidrogenació. Diferents factors poden afectar la direcció cap a la qual es decanta la balança. Aquests factors (temperatura de reacció, transferència de matèria, mida de les partícules de catalitzador...) són molt importants i s'han de tenir en compte a l'hora de dissenyar reactors industrials d'HDO. 


\section{Publications list}

The chapters in this thesis are based on the following publications:

De Miguel Mercader $\mathrm{F}^{\mathrm{a}}$, Groeneveld $\mathrm{MJ}^{\mathrm{a}}$, Kersten SRA ${ }^{\mathrm{a}}$, Venderbosch $\mathrm{RH}^{\mathrm{b}}$, Hogendoorn $\mathrm{JA}^{\text {a }}$. Pyrolysis oil upgrading by high pressure thermal treatment. Fuel. 2010;89:

2829-2837.

De Miguel Mercader $\mathrm{F}^{\mathrm{a}}$, Groeneveld $\mathrm{MJ}^{\mathrm{a}}$, Kersten $\mathrm{SRA}^{\mathrm{a}}$, Way $\mathrm{NWJ}^{\mathrm{c}}$, Schaverien $\mathrm{CJ}^{\mathrm{c}}$, Hogendoorn $\mathrm{JA}^{\mathrm{a}}$. Production of advanced biofuels: Co-processing of upgraded pyrolysis oil in standard refinery units. Appl. Catal. B Environ. 2010;96:57-66.

De Miguel Mercader $F^{a}$, Groeneveld $\mathrm{MJ}^{\mathrm{a}}$, Kersten $S R A^{\mathrm{a}}$, Geantet $\mathrm{C}^{\mathrm{d}}$, Toussaint $\mathrm{G}^{\mathrm{d}}$, Way $\mathrm{NWJ}^{\mathrm{c}}$, Schaverien $\mathrm{CJ}^{\mathrm{c}}$, Hogendoorn $\mathrm{JA}^{\mathrm{a}}$. Hydrodeoxygenation of pyrolysis oil fractions. Process understanding and quality assessment through co-processing in refinery units. Submitted for publication. 2010.

De Miguel Mercader $\mathrm{F}^{\mathrm{a}}$, Garcia Alba $\mathrm{L}^{\mathrm{a}}$, Windt $\mathrm{M}^{\mathrm{e}}$, Meier $\mathrm{D}^{\mathrm{e}}$, Kersten SRA ${ }^{\mathrm{a}}$, Hogendoorn $\mathrm{JA}^{\mathrm{a}}$. Polymerisation during pyrolysis oil upgrading. Submitted for publication. 2010.

De Miguel Mercader $F^{a}$, Koehorst PJJ', Heeres $\mathrm{HJ}^{\mathrm{f}}$, Kersten SRA ${ }^{\mathrm{a}}$, Hogendoorn $\mathrm{JA}^{\mathrm{a}}$. Competition between hydrotreating and polymerisation reactions during pyrolysis oil hydrodeoxygenation. Indications on mass transfer limitations. Submitted for publication. 2010.

\footnotetext{
${ }^{a}$ Thermo-Chemical Conversion of Biomass Group, Research Institute IMPACT, Faculty of Science and Technology, University of Twente, P.O. Box 217, 7500AE Enschede, The Netherlands.

${ }^{\mathrm{b}}$ BTG - Biomass Technology Group, P.O.Box 835, 7500AV Enschede, The Netherlands.

${ }^{\mathrm{c}}$ Shell Global Solutions International B.V., Grasweg 31, 1031HW Amsterdam, The Netherlands.

d Institut de Recherches sur la Catalyse et l'Environnement (IRCELYON), UMR5256 CNRS Université Lyon 1, 2 Av. A. Einstein, F-69626 Villeurbanne, France.

e vTI-Institute of Wood Technology and Wood Biology, Leuschnerstr. 91, 21031 Hamburg, Germany.

${ }^{f}$ Department of Chemical Engineering, Institute of Technology and Management, University of Groningen, Nijenborgh 4, 9747AG, Groningen, The Netherlands.
} 


\section{Acknowledgements}

I am very happy to be writing these final words. During these last four years, I have lived very different experiences and I have felt very different emotions. In general, I leave with the feeling that I have grown as a person and also as a professional. This thesis would not have been finished without the support of a lot of people, who helped me with advice and guidance or with support and distraction (also needed every now and then not to become crazy). Here, I will try to thank all these people.

First of all, I would like to thank my promoter Wim van Swaaij for giving me the opportunity to carry out the $\mathrm{PhD}$ within a great project and great research group. Secondly, to my assistant promoter Kees Hogendoorn and supervisor Sascha Kersten, even though initially it took some time to get used to each other and to our own ways of working, I think in the end we made a great team. You taught me how to be independent and responsible for my work and you treated me as an important part of the team, encouraging me to grow from the student I was to the free thinking researcher I am. I would especially like to thank you for your patience and help during these last few months, even helping me during your holiday time. I also want to thank you for giving me the opportunity to work in the development of new technologies for renewable energies, contribute to a (hopefully) better world and to be part of a fantastic research group with a great working and social atmosphere.

I want to give a few special words to Michiel Groeneveld, who was my professor during part of my $\mathrm{PhD}$ and unfortunately passed away. Although we did not spend much time together, he showed me that he enjoyed his work, doing it with amazing knowledge and a passion and willingness to share it with everyone else. I learnt a lot from you and I will always remember you.

I also would like to thank all the BIOCOUP project partners for their collaboration on work that has made this thesis possible. I was lucky to be part of such a large European project, I still remember the first meeting in Amsterdam when I was introduced to all these people that I had read so many publications. I would like to thank you all for including me in the project. Especially, I would like to thank the partners with direct input in this thesis, resulting in some co-authored publications: BTG, CNRS, Shell, University of Groningen, VTI and VTT.

I want to mention the other PhD students participating in the BIOCOUP sub-project with whom I had frequent contact: Agnes, Andrea, Jelle (indirectly) and Michael. I made it! and soon it will be your time... Maybe we were not the biggest wigs in the project, but we did a lot of work, without fighting and always having a good time after the meetings. Good luck finishing your PhDs! 
Now I want to mention the people from the TCCB group that helped me during this time. I want to thank Erna and Yvonne for their help during the moments I was the busiest. I could always count on you. Huge thanks to the technicians Benno, Henk, Karst and Robert. It has been very exciting designing new set-ups with you and testing all this high pressure equipment. Without you I really could not have done anything! For my colleagues (Anand, Dragan, Elly, Guus, Judith, Kumar, Laura, Magdalena, Mariken, Nick, Prasad, Pavlina, Roel, Wim, Wei and the MSc and BSc students): it has been great sharing all this time with you. You were always available to help me with any workrelated problem and borrel-related solution. To my students (Alex, Antal, Felix, Iris, Laura, Marion, Peter and Relus): thanks for your help with this thesis. I hope I taught you something, in any case, I learnt a lot from you.

From all the TCCB people I would like to specially thank three of them. First of all, Guus. He was my supervisor during my MSc assignment (already at TCCB) and since then, he has been the person I could rely on most. He has become one of my best friends. He is not only an amazing scientist but an even better person. Thank you for all your help!! The other two people are, of course, my paranymphs: Pavlina and Laura. Pavlina was my first Mediterranean link when I arrived to The Netherlands and we quickly realised that we had a lot in common (specially our feelings towards the Dutch weather). Laura (Miss Tarragona 2003) was my student and later became a PhD at the TCCB too. Being from Catalunya made our relationship very easy and I always had someone to talk to in my mother tongue (or at least we tried, because nowadays we talk some sort of strange catalenglish language...). Thanks to the two of you for soooooo many complicities and laughing times.

When I left Catalunya to come to The Netherlands, instead of losing one family, I gained two more! My second family came from all the friends I made in Macandra and the ones that joined later: Pablo, Flavia, Lucas, Raily, Michael, Maral, Berta, Marius, Azita, Sander, Rebeca, Guus, Judith, Pavlina, Dimitris, Laura, Can and Simon. Since we were (and still are) all away from home, we all created a big "Dutch family", which still continues nowadays. Thank you all for making me feel at home even being far away.

Also thanks to the music-side friends: Niels, Christina, Lorena, Jordi, Simon, Harmke and Lukas. It has been great to slowly get inside a world, I would have never imagined myself in (I am hopeless in music), learn about it and make very good friends along the way. Even at the busy times, going to concerts has always helped set engineering aside for some time and enjoy some new experiences.

Very special thanks to my best friends Imma and Vane. Our daily emails made me feel as if I was in Catalunya. It has been a great comfort having you there. Also thanks to Imma (my famous Spanish designer) for the cover and inner design of the thesis. 
Bé, ara escriuré una mica en català perquè també ho entengueu. Vull donar les gràcies a l'Imma i la Vane pels nostres correus electrònics diaris. Saber què feu cada dia i poder-vos explicar el que em passa per aquí, m'ha fet sentir com si no hagués marxat mai.

Of course, I would like to thank all my family for their unconditional support and love. Even when explaining certain life choices that they might not understand, they were always there for me, accepting me and loving me. I would like to thank my father, who also passed away while I was in The Netherlands. You always believed in me, supported, helped and accepted me. I know that you would have been very proud and happy for this accomplishment. I always think of you and I miss you, but you are always with me.

Vull donar les gràcies a la tota la meva família (mama, papa, Òscar, Sandra, Jana, Nuri, Carlos, Carles i Biel) pel seu suport i amor incondicional. Fins i tot quan us vaig explicar la opció que havia triat, i sabent que seria difícil d'entendre, sempre heu estat al meu costat, acceptant-me, ajudant-me i estimant-me. Vull donar les gràcies al meu pare, que va morir durant el transcurs d'aquest doctorat. Tu sempre vas creure en mi, vas ajudarme i acceptar-me. Sé que hauries estat molt orgullós de mi i feliç de veure on he arribat. Et trobo a faltar, però sempre estàs al meu costat.

To finalise, I would like to thank Michael (and my extended kiwi family) for your love and support. Without you, I could have never done it. Whenever I had a bad day, you were always there to cheer me up. You expanded my views and enriched me as a person. I love you. 


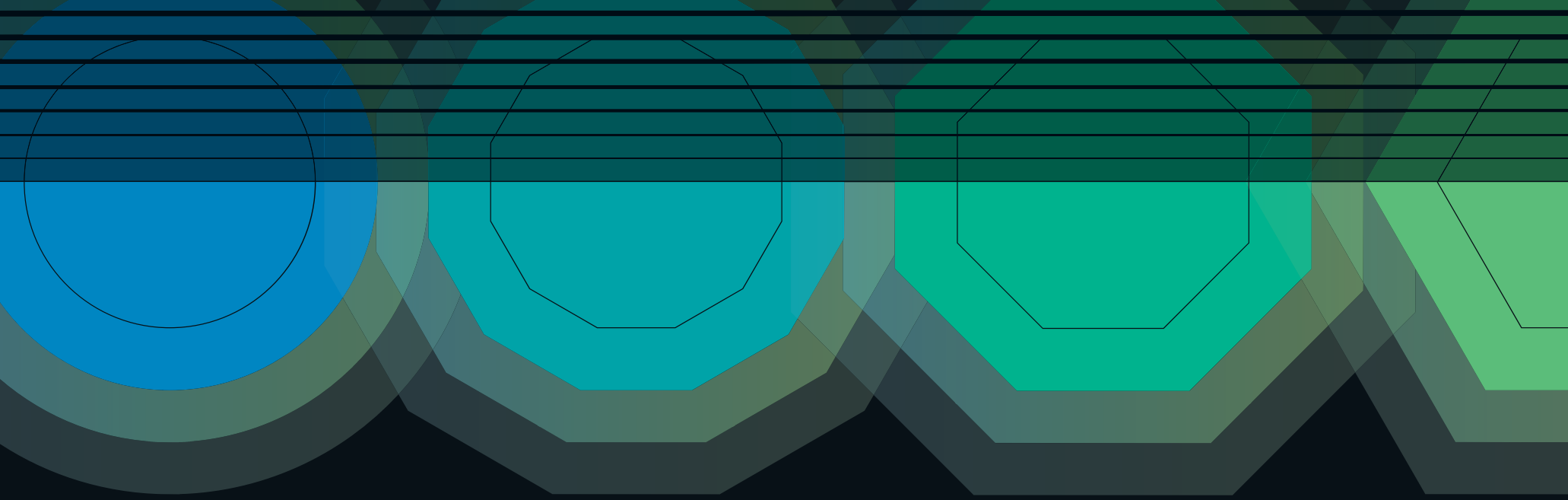

